\title{
Concrete Decontamination by Electro-Hydraulic Scabbling (EHS)
}

\author{
RECEIVED
}

Topical Report

March 30, 1996
MAR 261997

OSTI

Work Performed Under Contract No.: DE-AC21-93MC30164

\author{
For \\ U.S. Department of Energy \\ Office of Fossil Energy \\ Morgantown Energy Technology Center \\ P.O. Box 880 \\ Morgantown, West Virginia 26507-0880 \\ By \\ Trexton Defense System \\ 201 Lowell Street \\ Wilmington, Massachusetts 01887-2941
}




\section{Disclaimer}

This report was prepared as an account of work sponsored by an agency of the United States Government. Neither the United States Government nor any agency thereof, nor any of their employees, makes any warranty, express or implied, or assumes any legal liability or responsibility for the accuracy, completeness, or usefulness of any information, apparatus, product, or process disclosed, or represents that its use would not infringe privately owned rights. Reference herein to any specific commercial product, process, or service by trade name, trademark, manufacturer, or otherwise does not necessarily constitute or imply its endorsement, recommendation, or favoring by the United States Government or any agency thereof. The views and opinions of authors expressed herein do not necessarily state or reflect those of the United States Government or any agency thereof. 


\section{TABLE OF CONTENTS}

Section

Page

List of Illustrations

$\mathrm{v}$

List of Tables

Acknowledgments

ix

$\mathrm{x}$

1.0 EXECUTIVE SUMMARY 1

$\begin{array}{lll}2.0 & 10\end{array}$

2.1 Electro-Hydraulic Scabbling Concept 10

2.2 Program Objectives 10

2.2.1 General Objectives 10

2.2.2 Phase II Objectives 12

2.3 Background 14

$\begin{array}{lll}3.0 & \text { PROTOTYPE EHS SYSTEM DESIGN } & 18\end{array}$

A. Scabbling Subsystem

3.1 Electric Power Supply 18

3.1.1 Chargers and Storage Capacitors 18

3.1.2 Pulse Forming Network 18

3.2 Scabbling Module 25

3.2.1 Electrodes 25

3.2.2 Supporting Frame 35

3.2.3 High-Voltage Cables and Connectors 35

3.3 Scabbling Chamber 38

$\begin{array}{lll}\text { 3.3.1 Enclosure } & 38\end{array}$

3.3.2 Positioner 44

3.4 Process Controls 47

4.0 PROTOTYPE EHS SYSTEM DESIGN 52

B. Water and Waste Flow Subsystem and EHS Carriage

4.1 General Considerations 52

4.2 Designs of the Water Flow System 52

4.3 Removal of EHS-Generated Concrete Rubble 54

4.4 Water/Waste Flow Subsystem Suggested by Pentek 57

4.5 EHS System Carriage - Forklift Truck and System Integration 58 Issues 

SYSTEM

5.1 Electromechanical System (EMS) Developed and Tested at the SPB TU Site

5.2 Design and Assembly of the Mobile EMS

66

6.0 SCABBLING TRIALS AT TSD EVERETT SITE

$\begin{array}{lll}6.1 & \text { Introduction } & 82\end{array}$

6.2 Qualitative Description and Evaluation of Scabbling Operation 82 Features and Problem Areas

6.2.1 Electric Features: Factors Affecting Scabbling Efficiency 82 of the EH Discharge

6.2.2 Mechanical and Flow Features 85

6.3 Quantitative Characterization of TSD Scabbling Trials 86

6.4 Operation of EM SHV System at TSD Site 94

6.5 Demonstration of EH Scabbling Technique at TSD 94

7.0 FIELD TEST/DEMONSTRATION AT DOE FERNALD SITE

7.1 Objectives of Fernald Field Test/Demo 97

7.2 Site Background 98

7.3 Test/Demonstration Area 98

7.4 Regulatory Issues/Documentation 100

7.5 Test/Demo Preparation and Implementation 100

$\begin{array}{ll}7.6 \text { Scabbling Operation } & 103\end{array}$

7.6.1 Scabbling Equipment Used 103

7.6.2 Test Conditions and Preliminary Evaluation of 107 Performance

8.0 RESULTS OF FERNALD CONCRETE DECONTAMINATION 111 TRIALS

8.1 Scabbling Performance 111

8.2 Decontamination Performance 119

$\begin{array}{ll}\text { 8.2.1 Introduction } & 119\end{array}$

8.2.2 Radioactivity Meter Survey 120

8.2.3 XRF Spectrometer Survey 120

8.2.4 Scabbling of Concrete Floor Areas with Defects 124

8.2.5 Core Samples Analysis 124

8.2.6 Radioactivity and XRF Data Comparison and 128 General Conclusions 
8.3 Characterization of EHS-Generated Waste 130

8.3.1 Introduction 130

8.3.2 Process Water and Concrete Rubble (Sludge) Analysis 132

8.3.3 Other Sampling and Analysis Data 137

8.3.4 Summary and Recommendations 141

9.0 CONCEPTUAL DESIGN, PERFORMANCE PROJECTIONS, 144 AND ANTICIPATED ECONOMICS OF THE FULL-SCALE EHS SYSTEM

9.1 Conceptual.EHS-III System Design 144

9.2 Projected EHS-III System Performance 148

9.3 Economics of Small-Scale Industrial EHS System 149

9.4 Commercialization of EHS Technology 155

$\begin{array}{lll}10.0 & \text { REFERENCES } & 157\end{array}$ 


\section{LIST OF ILLUSTRATIONS}

Figure

Page

1-1 Prototype EHS-01 Unit in Operation at Fernald 3

1-2 Artist's Rendering of Electro-Hydraulic Scabbling Commercial 3 Prototype Unit

1-3 Concrete Scabbling Depth Profile $\quad 7$

2-1 Concept of Electro-Hydraulic Scabbling 11

2-2 Projected EHS Advantages and Benefits 13

3-1 Conceptual Schematic of HV Power Supply 19

3-2 Oscillograms of EH Discharge Current and Voltage for Different Circuit 20 Inductivity and Resistivity Values

3-3 Open Spark Gap Switch 22

3-4 Pulse Sequence Typical for an Open Spark Gap Operating in 23 Overvoltage Mode

3-5 GP-41B Spark Gap Switch by EG\&G 24

3-6 HV Spark Gap Switch with Hydrodynamic Trigger 24

3-7 Electric Schematic and Specification of EHS-01 Power Supply 26

3-8 Electric Schematic and Specification of EHS-02 Power Supply 27

3-9 EHS-01 Power Supply Assembly 28

3-10 EHS-02 Power Supply Assembly 29

3-11 Electrode Module Development $\quad 30$

3-12 Electrode Module Development (continued) 31

3-1.3 Electrode Configuration Development (continued) 32

3-14 Electrode Configuration Development (continued) 33

3-15 Single-electrode (a) and multielectrode (b) discharge chambers 36

3-16 Scabbling Module Frame for Double Pair (a) and Single Pair (b) Strip 37 Electrodes

3-17 Designs and Specification of HV Coaxial Cables 39

3-18 Schematics of HV Cable and Power Supply Cooling 39 
3-19 Solid Copper Cable-to-Electrode Connectors 40

3-20 Schematic of Scabbling in Cycle Mode 41

3-21 First ("small") Water Enclosure/Scabbling Chamber Made for a Cycling 42 Processing

3-22 . Second ("large") Enclosure/Scabbling Chamber Shown Supported by a 45 Forklift

3-23 Large Enclosure 45

3-24 Two-Raw Polyurethane Foam Gaskets of Different Density (black and 46 white) Installed in Metal Channels Along Bottom Perimeter of the Enclosure

3-25 Mechanical Arrangement of a Scabbling Module and XZ Positioner Inside 48 the Enclosure

3-26 XZ Positioner with Motorized Coupled Unislide X-drive (by Velmex) and 49 Pneumatic Z-drive

3-27 Interior of a Process Control Cabinet 50

3-28 Electric Schematic of a Process (scabbling and positioning) Control System 50

3-29 Electric Circuit used to Protect Motor Controller and Process Computer 51 from the EH Discharge Interference

4-1 Schematic of Water/Debris Flow System for a Large Scabbling Chamber 53

4-2 Single-Container Water/Debris Flow System 55

4-3 Single-Container Flow System Mounted on a Forklift 56

4-4 Pentek Water Flow Subsystem Components Assembled for Preliminary 59 Testing at Everett Site (May 1995)

4.5 Components of Modified Pentek Water Flow Subsystem Prepared for Testing/Demonstration at Everett site (July 1995)

46 EHS System Concept Version 60

4-7 EHS System Concept Version using a Single Pallet Truck for all 61

4-8 EHS System Concept Version using a Straddle Forklift Truck 62

4-9 Arrangement of the Scabbling Module and Positioner (with water enclosure 64 removed and close-up shown above) on a Pallet Truck used in the Initial Floor Scabbling Trials at Everett Site 
4-10 Integrated Scabbling Unit at Everett (a) and Fernald (b) Sites 65

5-1 Scabbling System Installed in Open Water Pool over Concrete Floor 67 at SPB TU Site

5-2 Electric Schematic of SPB TU High-Voltage Generator (HVG) 68

5-3 HVG Assembly Drawing 68

5-4 Drawing of a Multielectrode Module (MEM) Built by SPB TU 69

5-5 Side (a) and Bottom (b) Views of the MEM 70

5-6 MEM Positioner Installed in the Water Pool at the SPB TU Site 71

5-7 Electromechanical System (EMS) in Operation 72

5-8 Schematic of an Alternative Electrode System with a Single Pair of Strip 74 Electrodes

5-9 Electric Schematic of EHS-03R High Voltage Generator/Pulser 75

5-10 Electric Schematic of EHS-04R High Voltage Generator/Pulser 76

5-11 EHS-03R Unit Assembled at Everett Site 77

5-12 EHS-04R Unit (with DC charger on the top) Assembled at Everett Site 77

5-13 Assembly Drawing of EHS-03R Cabinet Interior 79

5-14 Assembly Drawing of EHS-04R Cabinet Interior 80

5-15 Sample Oscillograms of EHS-03R Current Pulses 81

6-1 Scabbling Chamber/Flow System Configurations used in the April 88 and May Everett Site Trials

6-2 EHS Configuration in the April/May Everett Site Trials 89

6-3 Scabbled Concrete Floor Areas at Everett Site 90

6-4 Surface of Scabbled Concrete Areas at Everett Site 91

6-5 EHS-01 Unit at Everett Site in July Preliminary Demonstration 95

7-1 Fernald Environmental Management Project 99

$\begin{array}{lll}7-2 & \text { Fernald Building 6 Plan } & 101\end{array}$

$\begin{array}{lll}7-3 & \text { Building } 6 \text { Work (Scabbling) Area } & 104\end{array}$ 
7-4 Scabbling Equipment in Building 6 Unloading/Storing Area 105

7-5 Preparation of EHS-01M Power Supply for Scabbling Operation 105

7-6 Arrangement of Scabbling Equipment for Fernald Trials 106

7-7 Flow System used in Fernald Trials 106

$\begin{array}{lll}7-8 & \text { EHS-01 Unit in Scabbling Operation at Fernald } & 108\end{array}$

8-1 Scabbling Depth Distribution for Floor Segment A Cross Section 113

8-2 Elevation Maps for Floor Segments A and C 114

8-3 Elevation Relief for Floor Segments A and C 117

8-4 Depth Distribution Function for Two Floor Segment A Cross Section 118

8-5 Results of Pre- and Post-Scabbling Radioactivity Measurements 121 over Floor Segments B, C, F, and G (TSD Data)

8-6 Radioactivity $\beta \gamma$ (in CPM) and XRF (in ppm) Signals vs.

8-7 Locations of Scabbled Floor Segments, XRF Measurements Points $(\cdot)$ and Concrete Core Sampling (o) in Building 6

8-8 In Reference to the Discussion on the Evaluation of Uranium Contaminant Distribution

8-9 Comparison of Radioactivity and XRF Data for Floor Segment D 131

8-10 Schematic of Process Water and Solid Wastes Sampling 133

8-11 In Reference to the Measurement of Concrete Surface Contamination 136 by Residual Fines

8-12 Half-Thickness vs. Photon Energy for Concrete 138

8-13 Maximum Range of Beta Particles vs. Energy 138

8-14 Occurrence Frequency for Concrete Decontamination 142

9-1 Conceptual Drawing of EHS-III Unit 145

9-2 Artist's Rendering of Electro-Hydraulic Scabbling Commercial 146 Prototype Unit

9-3 Alternative Elevated Runway EHS-IV Configuration for Decontamination of Larger Open Areas 


\section{LIST OF TABLES}

Table

Page

1-1 Main Design and Operating Parameters for Small-Scale Industrial EHS System

1-2 Projections of Operating Costs for Small-Scale Industrial EHS System

1-3 Reduction of Concrete Floor Radioactivity by EHS

1-4 Reduction of Concrete Floor Uranium Content by EHS

2-1 Energy Partition (\%) for Explosions in Water

6-1 Range of Conditions and Operating Parameters for Scabbling Trials at TSD Everett Site

6-2 Operating and Performance Parameters for EH Scabbling Trials at TSD Everett Site

7-1 Description of Fernald Scabbling Trials

8-1 Operating and Performance Data for Fernald Scabbling Trials

8-2 Pre- and Post-Scabbling Radioactivity Readings Averaged over Floor

Segments, taken by (a) FERMCO, and (b) TSD Teams

8-3 Pre- and Post-Scabbling XRF ("Total Uranium") Readings for Floor Segments $F$ and $G$

8-4 Pre- and Post-Scabbling XRF Data Averaged Over Floor Segments

8-5 Averaged Total Uranium Content in Water, Sludge Solids, and Dry Dust Samples

8-6 Weight of Concrete Rubble

8-7 Amount of Dry Dust Collected After Scabbling 139

8-8 Concrete Penetration Parameters for Uranium Radiation 139

8-9 Total Uranium XRF Readings (PPM) for Scabbled Concrete Floor 140 Segments

9-1 Design/Operating Parameters and Performance Projections for EHS-III Unit 150

9-2 Design/Operating Parameters and Performance Projections for Small-Scale 151 Industrial Unit EHS-IV

9-3 Design and Operating Parameters for Commercial Prototype EHS Unit 
9-4 Estimate of Capital (Equipment) Cost for EHS-IV Unit

9-5 Estimate of Total Decontamination Cost for Operating EHS-IV Unit 


\section{ACKNOWLEDGMENTS}

Textron Systems Division (TSD) wishes to acknowledge the technical and administrative collaboration and support of the FERMCO staff at the DOE Fernald facility. The cooperative interaction that began with the initial arrangements for the tests, the performance of the test program, and the prompt provision of test analysis were eminently important to the success of the program. In particular, TSD wishes to acknowledge the efforts of Dick Martineit, Ken Geiger, and Kathy Adams in making the tests a success as well as a satisfying experience

TSD also wishes to acknowledge the managerial and technical contributions of METC COR's Mary Beth Ashbaugh, Kelly Pearce, and James Longanbach. Their direction and suggestions have been most valuable. 


\subsection{EXECUTIVE SUMMARY}

Electro-Hydraulic Scabbling (EHS) technology and equipment for decontaminating concrete structures from radionuclides, organic substances, and hazardous metals is being developed by Textron Systems Division (TSD). This wet scabbling technique involves the generation of powerful shock waves and intense cavitation by a strong pulsed electric discharge in a water layer at the concrete surface. The high pressure impulse results in stresses which crack and peel off a concrete layer of a controllable thickness. Scabbling produces contaminated debris of relatively small volume which can be easily removed, leaving clean bulk concrete.

This new technology is being developed under Contract No. DE-AC21-93MC30164. The project objective is to develop and demonstrate a cost-efficient, rapid, controllable process to remove the surface layer of contaminated concrete while generating minimal secondary waste. The primary target of this program is uranium-contaminated concrete floors which constitute a substantial part of the contaminated area at DOE weapon facilities.

Development of the Concrete EHS System is planned in three phases. Phase I, the feasibility of the electro-hydraulic technology for concrete scabbling, was completed in 1994. Phase II, the design, building and testing of an integrated subscale, unit was performed at TSD with the concluding tasks of test and analysis being performed at a DOE site (Fernald). Phase II results are delineated in the following list and described in detail in the text of this Topical Report.

- Designed and assembled a prototype EHS system.

- Conducted scabbling experiments with a noncontaminated concrete floor at the TSD Everett facility.

- Made multiple changes in hardware and in the operating parameters to improve scabbling performance and to prolong the lifetimes of the components - mainly pulseforming network and scabbling module/electrodes.

- Explored the feasibility of an alternate super-high voltage (>100 kV) scabbling system; assembled associated power supplies and multielectrode scabbling module.

- Designed and tested versions* of a water recirculating/concrete debris separating subsystem; assembled and implemented simple flow subsystem design.

- Conducted preliminary demonstration of EHS system operation at TSD Everett site (August 1995).

- Prepared equipment for field experiments/limited demonstration of the prototype EHS system at DOE Fernald site. Completed logistic and Health/Safety arrangements and test plans for these experiments.

- Conducted field experiments/demonstrations at Fernald (September 1995); collected data on EHS performance and decontamination efficiency. In Figure 1-1, the EHS unit is shown during operation in Building \#6 at Fernald.

- Evaluated results of Fernald trials.

\footnotetext{
*Including a version designed by Pentek, Inc.
} 
- Based on the results at TSD Everett and DOE Fernald trials, made projections of the performance (Table 1-1) and decontamination costs (Table 1-2) for an industrial EHS system, shown as artist's rendering in Figure 1-2.

- Submitted Phase III work program to DOE.

The progress achieved by the Phase $I$ efforts, which culminated in the preliminary tests at the Fernald Site, is illustrated by a summary of the results of these tests.

- Approximately 30 square feet of concrete floors were processed/decontaminated using a subscale EHS unit.

- In these trials, the equipment operated reliably, without malfunction in either mechanical, electrical, or flow subsystems. The EHS unit was operated in a semiautomatic mode, with two functions (scabbling proper and debris removal) involving some manual controls and operations.

Tasks performed in Phase II led to the following conclusions:

- It was shown that EHS provides removal of $1 / 4$ " to 1 " of concrete layer in a single pass. Depth of removal can be controlled by varying the pulse energy, pulse frequency, and scabbling module travel velocity.

- A width of the scabbled path can be preselected in a broad range by changing the length of the scabbling electrodes. A 26 "-wide path width was achieved.

- An electric power supply of relatively unsophisticated design satisfies EHS requirements and can be assembled using commercially-available components.

- A scabbling module of a simple and rugged configuration, with a single pair of linear electrodes, has been designed. It is reliable, has a long lifetime, and needs minimum maintenance.

- By using wide electrodes, uniform scabbling can be achieved without involving lateral positioning of the scabbling module; a two-coordinate ( $\mathrm{X}$ and $\mathrm{Z}$ ) device with either electric power or pneumatic drive is adequate for the module positioning.

- The use of a scabbling chamber (water enclosure) kept under sufficiently negative air pressure by a vacuum blower isolates the scabbling area and prevents leakage of the process water and concrete debris over the surrounding floor areas.

- The scabbling rate depends on the electric power input setup, scabbling depth, and type/quality of concrete. At $3 / 8$ " scabbling depth and $8 \mathrm{~kW}$ nominal AC power (4 $\mathrm{kW}$ actually used), the rate of scabbling process proper (or "net rate" which does not account for positioning, system transfer, and debris removal) was $16 \mathrm{ft}^{2} / \mathrm{hr}$ at the TSD site and $10 \mathrm{ft}^{2} / \mathrm{hr}$ at the Fernald site, where the floor was made of tougher concrete with finer gravel. With positioning/transfer taken into account, the total scabbling time would be about $50 \%$ longer.

- Energy consumption scabbling of the "tough" concrete (as encountered at the Fernald site) is about $0.5 \mathrm{kWh}$ per one sq. $\mathrm{ft}$. of concrete floor area, or about $16 \mathrm{kWh}$ per one cu. ft. of concrete removal. With auxiliaries (motors, blowers, compressors, etc.) taken into account, the electric consumption would be about 1.5 times higher. 


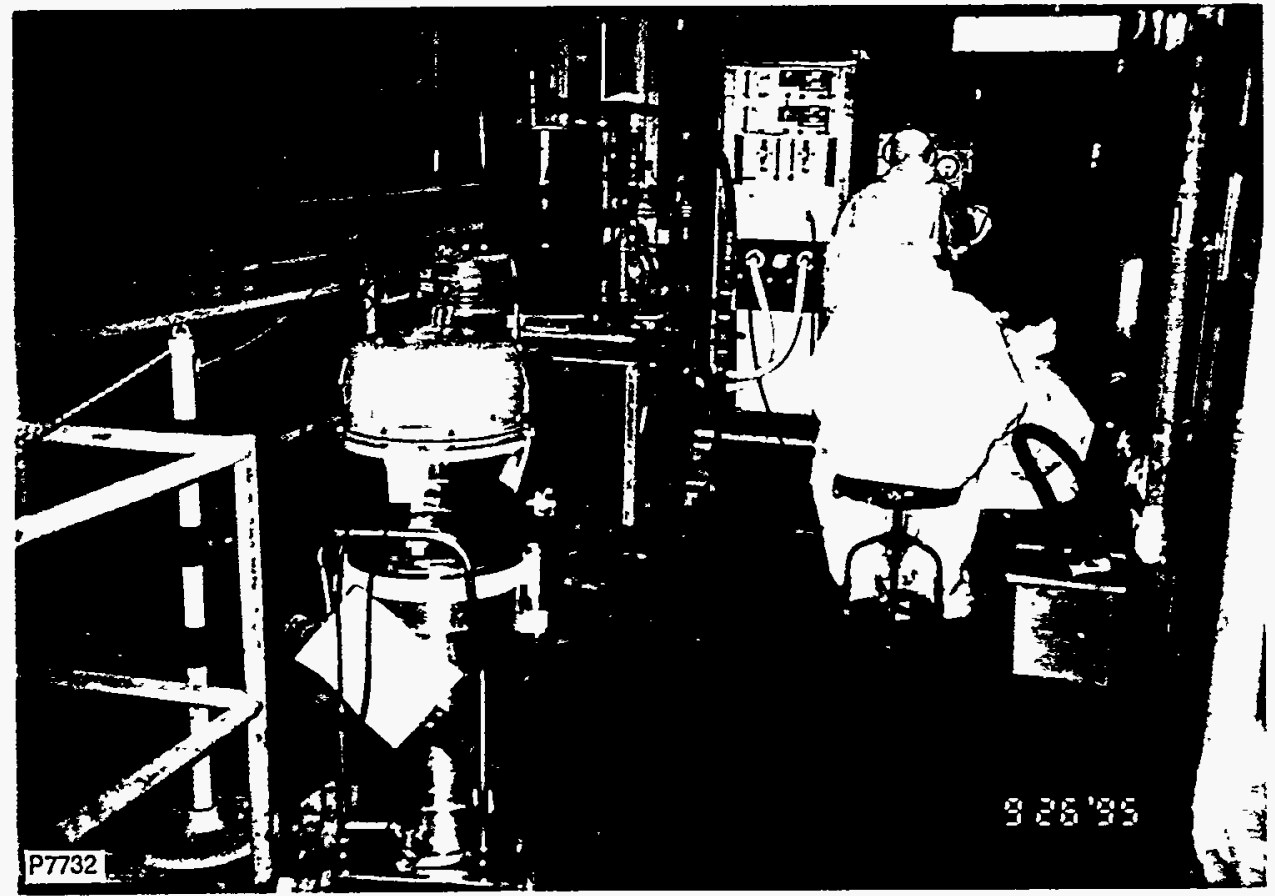

Figure 1-1 Prototype EHS-01 Unit in Operation at Fernald

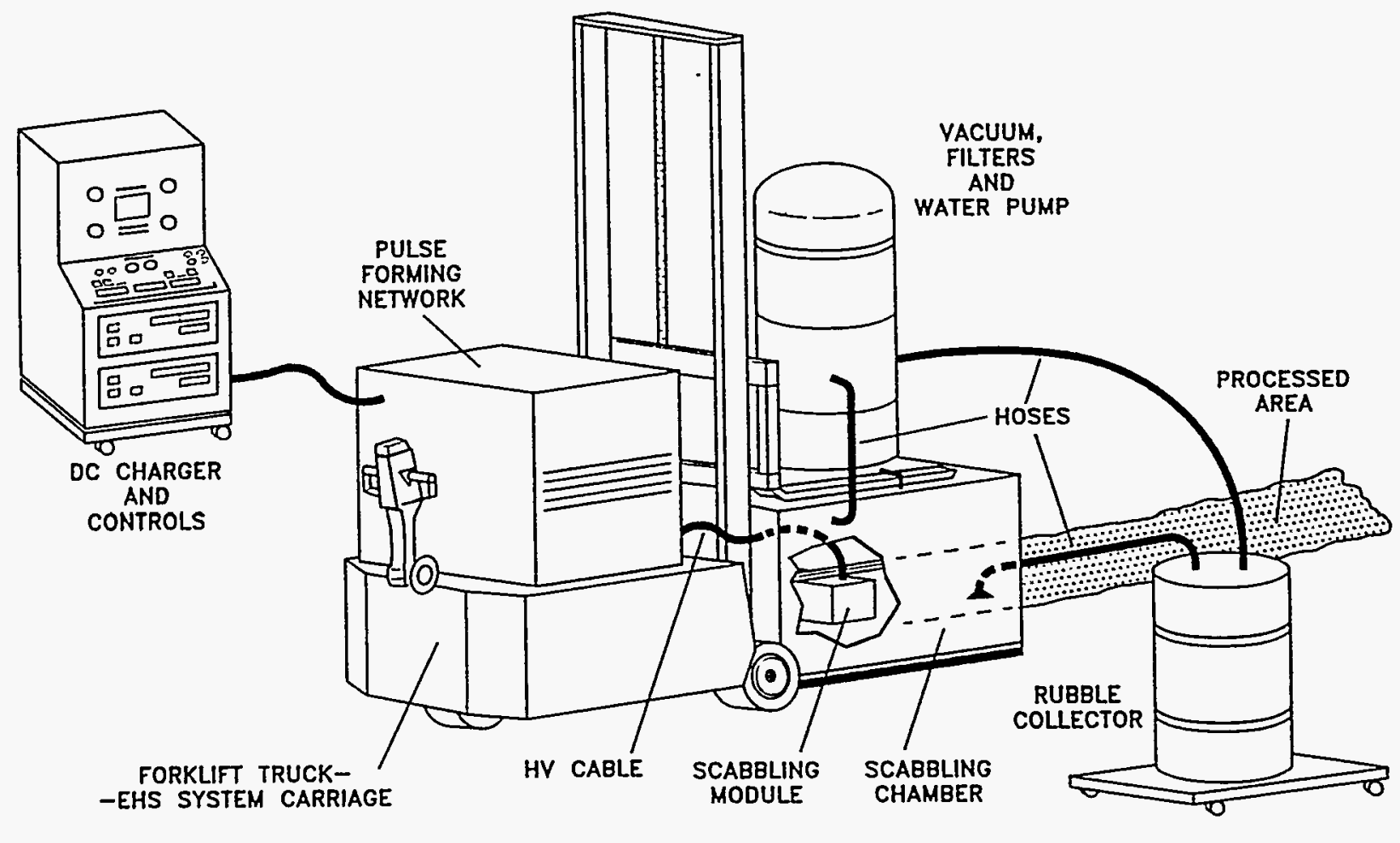

Figure 1-2 Artist's Rendering of Electro-Hydraulic Scabbling EHS-III Unit 
TABLE 1-1

MAIN DESIGN AND OPERATING PARAMETERS FOR SMALL-SCALE INDUSTRIAL EHS SYSTEM

\begin{tabular}{|l|c|}
\hline Main Unit Dimensions LxWxH - in. & $80-100 \times 36-44 \times 50-70$ \\
\hline Unit Weight (total) - lbs. & $1000-1200$ \\
\hline Nominal AC Power (scabbling) & $32 \mathrm{~kW}(16 \times 2)$ \\
\hline Nominal AC Power (ancillaries) & $6 \mathrm{~kW}$ \\
\hline Operating (max) Voltage & $30 \mathrm{kV}$ \\
\hline Single Pulse Energy & $4 \mathrm{~kJ}$ \\
\hline Pulse Frequency & $6 \mathrm{~Hz}$ \\
\hline Electrode Width - in. & 30 \\
\hline Number of Pulses per Cycle & 3000 \\
\hline Scabbled Area per Cycle - sq. ft. & 7.5 \\
\hline Scabbling (pulsing+positioning) Duration per Cycle - min. & $10-6.5$ \\
\hline Total Cycle Duration - min. & $16-12.5$ \\
\hline Scabbling Depth (average) - in. & $1 / 4$ \\
\hline Scabbling Rate (net) - sq. ft./hr. & $50-80$ \\
\hline Scabbling Rate (effective) - sq. ft./hr. & 30 \\
\hline Volume of Concrete Removed per Cycle - cu. ft. & 1.5 \\
\hline Water Consumption (makeup) - gal./sq. ft. & $0.5-1.0$ \\
\hline Electric Energy Total Consumption - kWh/sq. ft. & 0.85 \\
\hline
\end{tabular}


TABLE 1-2

PROJECTIONS OF OPERATING COSTS FOR SMALL-SCALE INDUSTRIAL EHS SYSTEM

\begin{tabular}{|c|c|}
\hline Item & Cost, $\$ / \mathrm{ft}^{2}$ \\
\hline Scabbling Depth & $1 / 4^{\prime \prime}$ \\
\hline $\begin{array}{l}\text { Scabbling Rate: } \\
\mathrm{ft}^{2} \text { per hour } \\
\mathrm{ft}^{2} \text { per year }\end{array}$ & $\begin{array}{l}31 \\
41,000\end{array}$ \\
\hline $\begin{array}{l}\text { Consumables: } \\
\text { Electricity(1) } \\
\text { Water } \\
\text { Other }\end{array}$ & $\begin{array}{l}0.85 \\
0.04 \\
0.11\end{array}$ \\
\hline Subtotal & 1.00 \\
\hline Capital(2) & 0.89 \\
\hline Labor ${ }^{(3)}$ & 6.47 \\
\hline Waste Disposal & 0.24 \\
\hline Total, $\$ / \mathrm{ft}^{2}$ & 8.60 \\
\hline
\end{tabular}

Main Assumptions:

(1) At $0.1 \$ / \mathrm{kWh}$ rate.

(2) For 140,000 equipment cost, 1320 net scabbling hours per year, five years service life, yearly spare parts cost equal $22 \%$ of amortization cost ( $\$ 28,000$ and $\$ 6000$, respectively).

(3) At 6 hours per day, 1320 hours per year net operating time. Two operators (technicians) also performing setup and maintenance; $\$ 75 / \mathrm{hr}$ technician's labor cost, including overhead expenses, but not including H\&S services, sampling/analytical services, waste post-treatment, and removal from the work area.

(4) Waste (concrete rubble + process water + miscellaneous) disposal at \$8/cubic foot. 
- Water consumption has been controlled by recirculating the process water after separation of concrete debris by filtration. Preliminary estimates based on the Fernald trials show water makeup volume about 1.5 gal. per sq. ft.. of the floor processed. In these trials, a significant amount of water was lost during debris removal from the processed floor. By using a better debris removal technique, it should be possible to reduce the water loss to one-half or one-third of that observed in Fernald trials.

- EH scabbling results in an uneven decontaminated surface (see Figure 1-3). The "peaks" correspond to harder stones (gravel) not crushed by EH treatment, and the "valleys" to softer components of the heterogeneous concrete "matrix" which are removed and partially crushed by the EH action. Concrete composition and strength affect the surface structure/appearance and may also have influence on the efficiency of the decontamination process.

Contamination of the concrete floor surface at the Fernald site was characterized by measuring the level of radioactivity with $\beta$ and $\gamma$ Geiger counter and, independently, by measuring the "total uranium" content with $x$-ray fluorescence (XRF) technique.

Comparison of pre- and post-scabbling values provided an evaluation of EHS effectiveness.

- Both indicators, counts per minute and uranium content, demonstrate a reduction of more than 10 times of local and average radioactivity (see data in Tables 1-3 and 14).

- Relatively high (but still several times lower than initial) levels of contamination observed at some isolated floor areas are likely due to an inadequate removal of a few concrete (dried) debris particulates.

To address this important issue, future development will use two approaches: a) mechanized removal of most of the wet debris within each scabbling cycle; and b) adding a "finishing" stage to remove dry fines in cases where these provide a significant part of the total residual radioactivity.

- Uranium is removed not only from the flat floor areas but also from the floor defects (cracks, grooves, indentations) where initial uranium concentration is much higher than the average.

- Samples of the process water and concrete debris were taken. They will be analyzed to supplement surface data by the uranium balance and partition (between waste streams) information. Additional useful information is expected to come from analysis of the concrete core samples.

- Samples of process water and concrete debris were taken and analyzed to supplement surface data by information on uranium partitions between various waste streams. An average uranium concentration is 400 to $800 \mathrm{ppm}$ in sludges (wet concrete debris) and in unfiltered water (comparable to that in the surface concrete layer), and very low $(<10 \mathrm{ppm})$ in filtered water.

- Water analysis data indicates that uranium contaminant present in concrete is not soluble. Therefore, recontamination due to (filtered) water recirculation does not occur. 

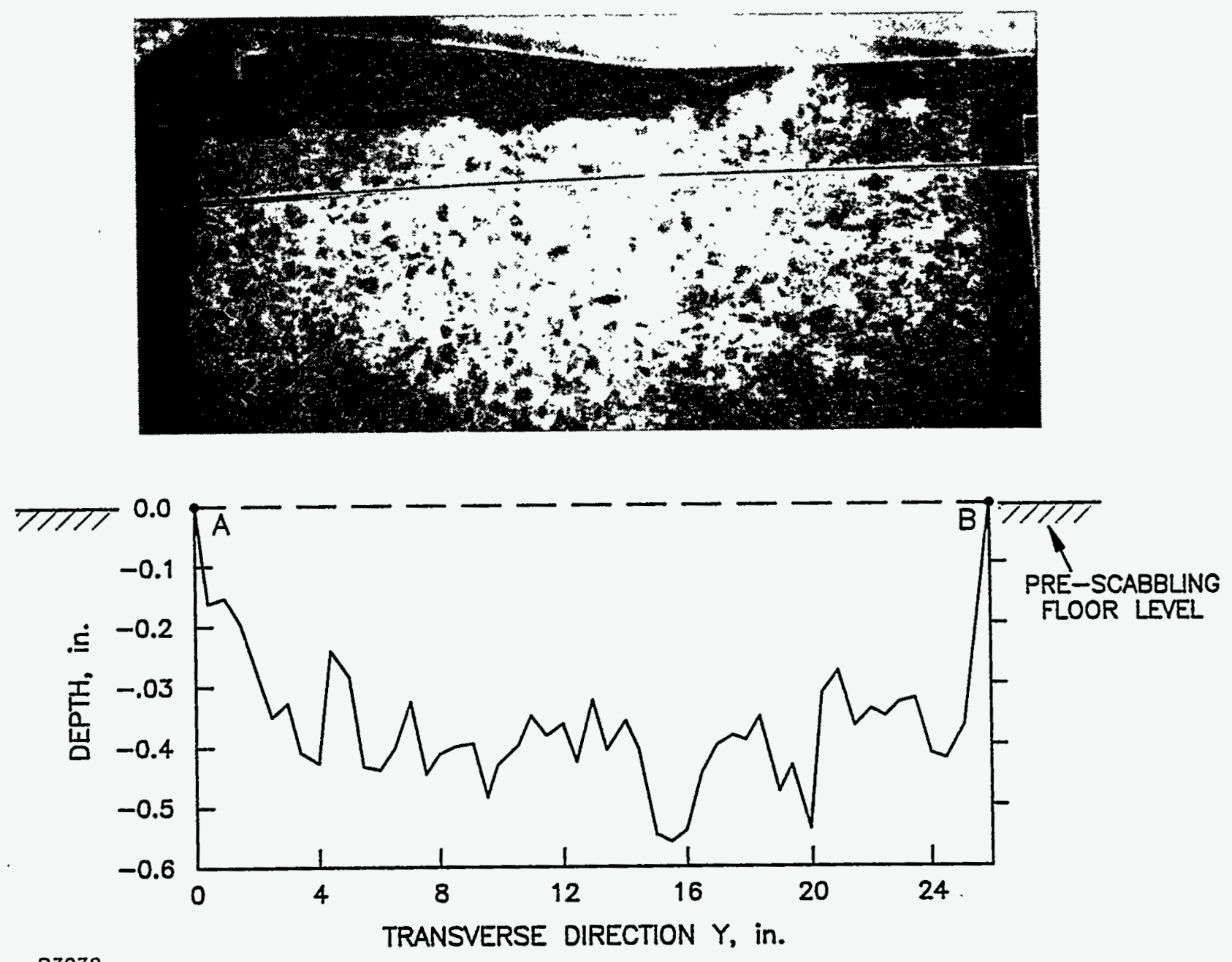

P3032

Figure 1-3 Concrete Scabbling Depth Profile 
TABLE 1-3

REDUCTION OF CONCRETE FLOOR RADIOACTIVITY BY EHS

\begin{tabular}{|c|c|c|c|}
\hline \multirow{2}{*}{ Floor Segment Designation } & \multicolumn{2}{|c|}{ Average Radioactivity, CPM } & CPM Ratio \\
& Pre-Scabbling & Post-Scabbling & \\
\hline & 370 & 26 & 14.2 \\
\hline B & 1130 & 19 & 59.0 \\
\hline C & 3060 & 210 & 15.5 \\
\hline D & 1280 & 280 & 4.6 \\
\hline F & 450 & 122 & 3.7 \\
\hline G & 860 & 78 & 11.0 \\
\hline I & 1240 & 25 & 49.0 \\
\hline Average & 1200 & 109 & 11.0 \\
\hline
\end{tabular}

TABLE 1-4

REDUCTION OF CONCRETE FLOOR URANIUM CONTENT BY EHS

\begin{tabular}{|c|c|c|c|}
\hline \multirow{2}{*}{ Floor Segment Designation } & \multicolumn{2}{|c|}{ Average Radioactivity, CPM } & \multirow{2}{*}{ CPM Ratio } \\
\hline & Pre-Scabbling & Post-Scabbling & \\
\hline A & 720 & 233 & 3.1 \\
\hline B & 2500 & 570 & 4.4 \\
\hline C & 1640 & 202 & 8.1 \\
\hline D & 1180 & 275 & 4.3 \\
\hline F & 1120 & 212 & 5.3 \\
\hline G,H & 3100 & 560 & 5.5 \\
\hline Average & 1710 & 340 & 5.1 \\
\hline
\end{tabular}




\section{General Conclusions}

By developing the EHS technology, we are addressing the following PRDA items:

- Technologies that remove part of the concrete-surface and, for insoluble uranium and recycle systems, produce no secondary liquid waste.

- Technologies that decontaminate concrete to levels that satisfy Nuclear Regulatory Commission (NRC) Regulatory Guide 1.86 (DOE Order 5400.5) for the cleaned concrete surface.

- Technologies that decontaminate concrete to levels that satisfy proposed IAES limits for unrestricted release of previously bulk contaminated materials.

- Technologies with lower costs to remove, decontaminate, and convert cleaned concrete to a reusable form and the contaminated concrete debris into disposable form compared to state-of-the-art technologies.

Phases I and II of the project demonstrated that decontamination of concrete by EH scabbling is feasible, and that equipment for performing this task can be built and perform reliably and safely. The rate of decontamination with a very moderate scale (about $30 \mathrm{~kW}$ ) EHS unit is expected to be about $30 \mathrm{sq}$. ft. per hour for $1 / 4$ "-deep single path scabbling. This should be sufficient for many applications. Electric energy consumption of about $1 \mathrm{kWh}$ per sq. $\mathrm{ft}$.and the total operating cost of around $\$ 10$ per square foot are projected for $1 / 4^{\prime \prime}$ to $1 / 2^{\prime \prime}$ deep scabbling. The expense is dominated by the cost of labor. Substantial scale-up and further automation should be straightforward. The larger unit would provide a higher scabbling rate and lower operating costs and would make the projected EHS decontamination costs significantly lower.

Prospects for the commercialization of EHS are being explored. During Phase II, it was concluded that the EHS unit can best be constructed as a device comprised of three integrated subsystems: power and control, scabbling head, and recycle modules. The unique requirements of the EHS approach made the combination of the EHS core system with existing surface decontamination hardware (e.g., Pentek's dry scabbling device) impractical. Thus, TSD will design and construct the fully integrated EHS unit and make it available, along with a trained operator, to decontamination and decommissioning service companies. A video has been made describing the EHS approach and showing it in operation at Fernald. The video is now being distributed to $\mathrm{D}$ and $\mathrm{D}$ service companies with suggestions for them to participate as advisors in the Phase III program.

TSD strongly recommends to continue further development and full-scale demonstration of the EHS technology through Phase III of the project. The Phase III program has been recently updated and submitted to DOE for approval. 


\subsection{INTRODUCTION}

\subsection{ELECTRO-HYDRAULIC SCABBLING CONCEPT}

Contamination of concrete structures by radionuclides, hazardous metals, and organic substances (including PCB's) occurs at many DOE sites. Removal of the concrete surface layer is considered as the most effective decontamination technology, especially where the contaminants penetrate to a significant (up to 1 inch) depth. By scabbling, the whole mass of concrete structure is subdivided into contaminated debris (rubble) of relatively small volume and clean bulk concrete structure.

Textron Systems Division (TSD) is developing Electro-Hydraulic Scabbling (EHS), characterized conceptually in Figure 2-1. This controllable concrete scabbling technique is based on the Electro-Hydraulic effect. This term summarizes several physical and chemical phenomena which accompany high voltage spark discharges in water.

A strong, short spark-like electric discharge in liquid is accompanied by:

- Generation and propagation of an intense shock wave.

- Generation and pulsation of gaseous/vapor discharge cavity (cavitation).

- Radiation of electromagnetic waves by the discharge channel.

Accordingly, the EH effect has found previous technical applications for crushing and grinding of minerals, drilling of rocks, forming of metals, cleaning of surfaces, and demolition of foundations (see Phase I Topical Report). ${ }^{(1)}$

Specifically, when the discharge takes place close to the concrete surface, cracks are formed and spalling of the material takes place. By varying the parameters of the electric discharge, e.g., energy, duration, and repetition rate, the depth of scabbling can be controlled.

\subsection{PROGRAM OBJECTIVES}

\subsubsection{General Objectives}

Because the contamination of concrete structures (walls, floors, ceilings, etc.) varies in type, concentration, and especially depth of penetration into the concrete, many techniques do not guarantee complete decontamination, or multiple processing passes are required to achieve acceptable contaminant removal.

If the remaining surface and structure are decontaminated to a satisfactory level, the building may be reused or disposed of as nonhazardous, nonradioactive waste. Just as important, the amount of secondary waste - hazardous, radioactive concrete rubble - would be much lower than in the case of demolition of the whole structure. According to estimates provided in the D\&D ID document, up to one inch penetration of contaminants can be expected. 


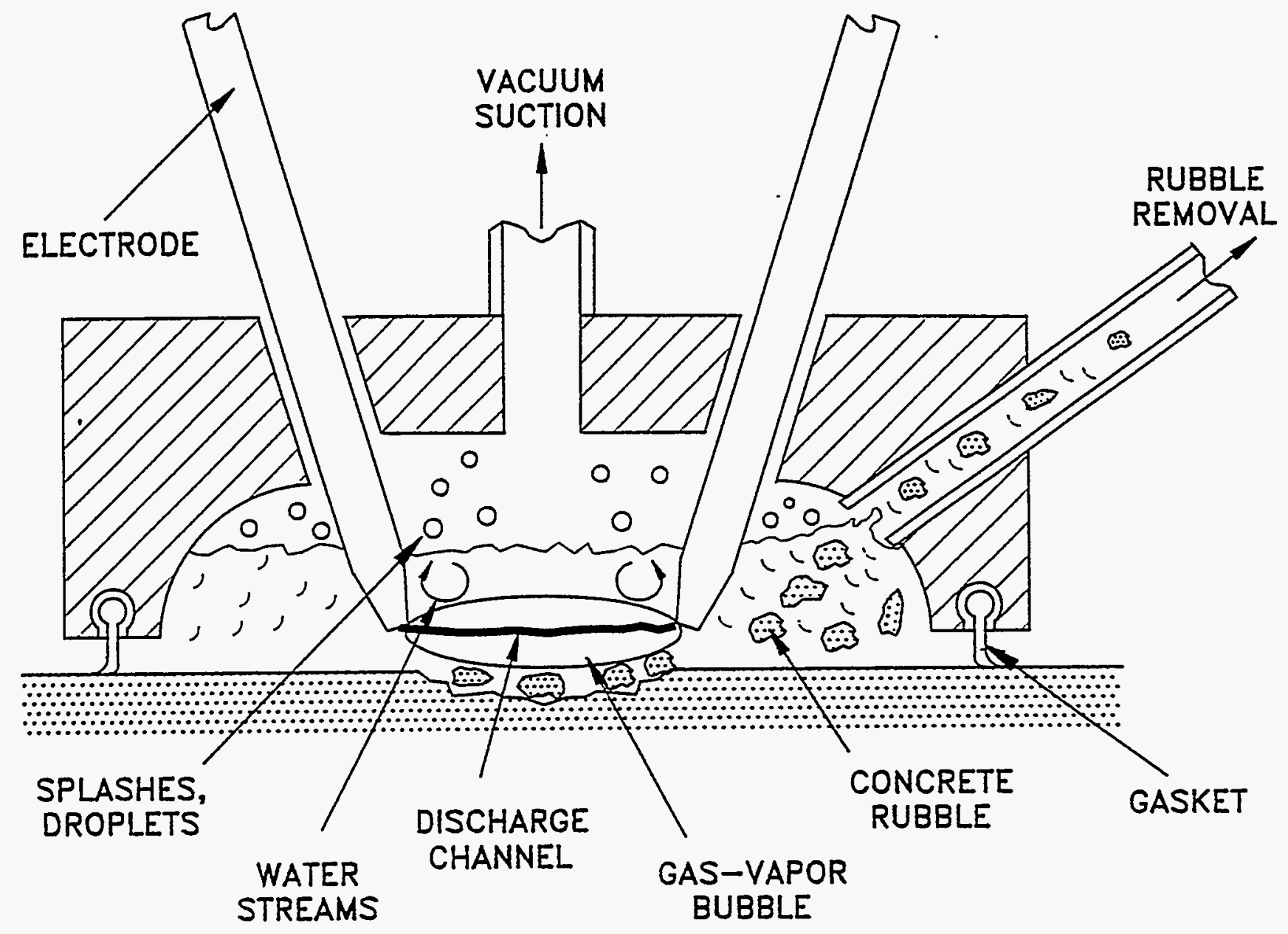

P3000

Figure 2-1 Concept of Electro-Hydraulic Scabbling 
A successful concrete scabbling technique should provide:

- High productivity (high scabbling rate).

- Cost effectiveness (including cost of equipment, consumables, and labor).

- Scabbling depth control.

- Low volume of secondary waste.

- Ability to remove, transport, separate, and store the secondary waste.

- Environmental protection and health safety for operating personnel (e.g., remote control of the scabbling unit).

Availability of a mobile unit, providing flexibility in application at a variety of sites, convenience and time saving in operation and equipment preparation, would be a considerable advantage.

It is projected that EHS technology will provide a sizable improvement over other available concrete decontamination techniques. Reduced energy and water consumption, and dust generation, plus rapid processing of the concrete surface should result in a faster, less expensive and safer cleaning procedure. The main advantages from the development of EHS technology are listed in Figure 2-2.

\subsubsection{Phase II Objectives}

The primary objective of the first phase of the three-phase project was to prove the technical feasibility of EH technology for scabbling of concrete This objective has been achieved as described in the Phase I Topical Report. ${ }^{(1)}$

Phase II of the project had the following main objectives:

- To design, assemble, and test Electromechanical, Flow, and Carriage/Control EHS subsystems.

- To provide super-high voltage option of the Electromechanical subsystem.

- To integrate subsystems in a prototype EHS unit.

- To test the unit in clean concrete scabbling operations.

- To conduct demonstrations of the unit at the TSD/Everett site.

- To plan and prepare EHS field experiments/demonstrations at the DOE Fernald site.

- To conduct contaminated concrete scabbling at Fernald and to prove the feasibility of uranium removal by the EHS technique. 
- HIGH POWER INPUT (energy per unit volume)

$\longrightarrow$ HIGH DECONTAMINATION RATE

- BETTER PROCESS CONTROLLABILITY, BROAD RANGE OF SINGLE-PASS SCABBLING DEPTH

$\longrightarrow$ APPLICABLE FOR LARGE CONCRETE SURFACES AND DEEP LOCAL DECONTAMINATION

- LOWER (THAN MANY OTHERS) ENERGY CONSUMPTION

- LOW WATER CONSUMPTION

$\longrightarrow$ LESS SECONDARY WASTE

- NO DUST FORMATION, NO CROSS-CONTAMINATION

$\longrightarrow$ LOWER HEALTH/SAFETY RISK TO WORKERS AT ENVIRONMENTAL REMEDIATION SITES

- REASONABLE EQUIPMENT AND OPERATING COSTS

Figure 2-2 Projected EHS Advantages and Benefits 
- To analyze and report all design and performance data, including results of Fernald trials.

Each of these objectives has been achieved as described in the following sections of this report.

\subsection{BACKGROUND}

Among the techniques for decontamination of concrete, chemical methods remove only surface deposits of contaminants, a thin layer of paint, or a very thin layer of concrete itself. Other demolition methods, such as mechanical grinding, air hammers, or high pressure water guns, involve the generation of large volumes of contaminated dust or water, destruction of the whole concrete body, or at least removal of a substantial part of its thickness. Electro-hydraulic scabbling, which is the subject of this program, occupies an intermediate position, being capable of removing surface layer in about a $1 / 4$ " to 1 " thickness range in one pass over the concrete object, while not generating large volumes of contaminated dust or water.

Features of the Electro-Hydraulic effect, ${ }^{(2-0)}$ which is the basis of EHS technology, are mentioned briefly in this section. A strong and short (pulsed) electric discharge in liquid is accompanied by the propagation of shock waves and cavitation. The EH effect has common features, with phenomena associated with conventional (chemical) underwater explosions. However, the multiparameter nature of the "electric explosion" provides more possibilities for process control than are available for ordinary explosions. By varying these parameters of the electric discharge (energy, duration, repetition rate), conditions most favorable for certain applications can be generated.

Shock waves are most effective for crushing brittle materials. It has been shown that breaking of materials by shock wave impingement is due to formation of radial cracks generated by a compression wave and by tensile stresses which are developed after reflection of compression waves from free surfaces of solids. The low tensile strength of brittle, especially inhomogeneous, materials is responsible for this feature. For comminution of materials, e.g., fine grinding, and for scabbling of thin surface layers, after-discharge phenomena (cavitation and explosive boiling) are of major importance.

On the basis of electric discharge physics, approximate theories describing expansion of discharge channel in liquid have been developed. The theories estimate transfer of electric energy into mechanical energy, total and partial hydrodynamic efficiencies vs. discharge geometry and electrical parameters, and pressure at the shock wave front vs. distance. Some quantitative data characterizing the $\mathrm{EH}$ effect and destruction of solids are provided below.

Plasma of the discharge channel in water has temperatures in the $15,000-35,000 \mathrm{~K}$ range, and shock waves generated by the channel expansion propagate with 2 to $3.5 \mathrm{~m} / \mathrm{s}$ velocity, with 5,000 to $20,000 \mathrm{~atm}$ pressure at the shock front.

A much slower than the shock wave phenomenon is a process of growing and subsequent oscillation of the discharge cavity with a characteristic time of about one millisecond. Partition of energy input between three modes for underwater explosion of TNT, electric explosion of thin wire, and electric spark is given in Table 2-1. 
TABLE 2-1

ENERGY PARTITION (\%) FOR EXPLOSIONS IN WATER

\begin{tabular}{|c|c|c|c|}
\hline & \multicolumn{3}{|c|}{ TYPE OF EXPLOSION } \\
\hline Mode & Chemical (TNT) & Wire & EH \\
\hline Acoustic (Shock Wave) & 63 & 58 & 30 \\
\hline Cavitation (Bubble Formation) & 31 & 27 & 22 \\
\hline Radiative and Conductive Losses & 6 & 15 & 48 \\
\hline
\end{tabular}


Two material destruction mechanisms are usually considered: a) fracture by propagation of direct compression wave; and b) peeling, resulting from tension stresses accompanying propagation of the reflected wave. For minerals and building materials, tension strength usually is 5 to 20 times lower than compression strength (for concrete, this ratio is in the 6 to 10 range); therefore, the second mechanism is more important. The effect of the explosion changes with distance. In the near zone, compression and comminution of material by gases/vapors from chemical/electric explosion takes place; at larger distances (loosening zone), cracks are formed by compressive or tensile stresses.

The destruction mode is correlated with acoustical toughness of materials. Materials with pa $>2 \times 10^{6} \mathrm{~g} / \mathrm{cm}^{2} \mathrm{~s}$ are destroyed by stress waves, and with $\rho \mathrm{a}<5 \times 10^{5}$ mostly by the direct action of gases generated by explosion, for concrete $p a$ is rather low. Therefore, an EH explosion of relatively long duration and low voltage is expected to be more efficient.

Efficiency of energy transfer to a solid body and specific energy consumption (q) depend strongly on the location of the explosion source: it is usually rather low $(\sim 2 \%)$ for an unrestricted "surface" source, and 10-20 times higher for a source located in a blast-hole.

Both theoretical estimates and experiments indicate that for surface and blast-hole explosion, respectively, specific energy is

$$
\begin{gathered}
\mathrm{q}_{\text {surf }}=\frac{C U^{2} / 2}{2 / 3 \pi \mathrm{R}^{3}}=11 \theta \\
\text { and } \\
\mathrm{q}_{\text {hole }}=0.6 \theta
\end{gathered}
$$

(here $C$ is energy storage capacitance, $U$ is operating voltage, $R$-indentation radius, and $\theta-$ "toughness" which is proportional to compressive strength). For concrete with $\theta=1$, $\mathrm{q}_{\text {surf }}=110$ $\mathrm{J} / \mathrm{cm}^{3}$ and $q_{\text {hole }}=6 \mathrm{~J} / \mathrm{g}$. Evidently, for higher energy efficiency, the configuration of the EHS device (electrode geometry, their distance from the surface, etc.) should be chosen to provide some directed action of the electric explosion.

By using these and other relevant estimates, EHS energy requirements can be projected. Consideration of the energy transformation path results in the conclusion that only $2 \%$ to $40 \%$ of energy delivered to water (or 1\% to $20 \%$ of a AC "wall-plug" energy is effectively transformed into energy for concrete disintegration. The actual value depends as much on intelligent selection of the discharge parameters and electrode/discharge geometry as on conditions for propagation of shock waves and explosion products. As already mentioned, EH explosions in a restricted volume provide an efficiency close to the upper limit, while unrestricted explosions, e.g., in the case of scabbling, result in efficiencies not exceeding a few percent. For preliminary estimates, 0.5 to $1.5 \%$ of "wall-plug to rubble" efficiency may be assumed.

Using concrete strength data, we obtain a specific energy required to crush various makes of concrete from infinite size (bulk) to 100 microns in the 50 to $150 \mathrm{~J} / \mathrm{cm}^{3}$ range. To calculate the specific energy required to crush concrete to other characteristic dimensions (D), the scaling $E \sim 1 / D^{1 / 2}$ can be used. Assuming $D=3 \mathrm{~mm}$, we arrive at specific energy requirements of 9 to 27 $\mathrm{J} / \mathrm{cm}^{3}$ range. At $1 \%$ of concrete destruction efficiency, this corresponds to the energy 
consumption of 900 to $2700 \mathrm{~J} / \mathrm{cm}^{3}, 400$ to $1200 \mathrm{~J} / \mathrm{g}$, or 110 to $330 \mathrm{kWh} / \mathrm{t}$. Summarizing available data, we arrive at the conclusion that a specific destruction energy at about $200 \mathrm{kWh} / \mathrm{t}$ can be used as a conservative basis for a priori estimations. By a $1 \mathrm{~cm}$ deep scabbling, $25 \mathrm{~kg}$ of concrete is removed per $1 \mathrm{~m}^{2}$; therefore, $5 \mathrm{kWh} / \mathrm{m}^{2}$ energy consumption can be expected for EHS. 


\subsection{PROTOTYPE EHS SYSTEM DESIGN \\ A. Scabbling Subsystem}

The scabbling subsystem consists of electric power supply scabbling module mounted on a positioner inside a scabbling chamber (water enclosure), and scabbling process controls. These components are interdependent, and their development, modifications, and testing proceeded partially in sequential and partially in parallel steps. In the following sections we describe the development history only briefly, devoting more attention to a "final" product.

\subsection{ELECTRIC POWER SUPPLY}

The power supply (see simplified electric schematics Figure 3-1) includes two main components: High Voltage DC source charging energy storing capacitors, and Pulse Forming Network (PFN) assembled in a single cabinet. Two power supplies, designated EHS-01 and EHS-02, were assembled.

\subsubsection{Chargers and Storage Capacitors}

High voltage power supplies made by two manufacturers were used as chargers: ALE402 and ALE-802 units operating at $30 \mathrm{kV}(\max )$, rated $4 \mathrm{~kW}$ and $8 \mathrm{~kW} \mathrm{AC}$, respectively, and made by Electronic Measurements Co. (Neptune, NJ), and CCDS unit operating at $35 \mathrm{kV}$ (max),

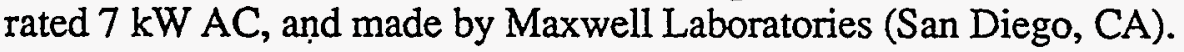

In the EHS-01 power supply, two ALE-402 units were installed to operate in a masterslave (parallel) configuration. They could also be substituted with one ALE-802 unit. In the future, all three units can be used in a master-slave configuration providing $16 \mathrm{~kW}$ power. These DC sources charged two paralleled $35 \mathrm{kV}$ (max) capacitors of a total $12.6 \mu \mathrm{F}$ through resistors. In the EHS-02 power supply, a single Maxwell unit charged $35 \mathrm{kV}(\max ), 10 \mu \mathrm{F}$ capacitors through $500 \mathrm{ohm}$ resistor.

\subsubsection{Pulse Forming Network}

Short, high-voltage, high current pulses were formed by discharging the capacitors via a low inductance spark gap switch, low ballast resistor, cable, and main water submerged scabbling electrode gap. Oscillograms in Figure 3-2 show a typical current pulse period of 15-30 $\mu$ corresponding to $0.5-2.5 \mu \mathrm{H}$ inductance and total $0.3-1.0 \mathrm{ohm}$ discharge circuit resistance. Most of the resistance is attributed to the working (water) spark gap itself; increase of the gap width results in resistance increase and stronger discharge damping.

A spark gap switch is the most important as well as the most vulnerable component of the PFN. Various switches were tried, none of them being entirely satisfactory for EHS applications where at least tens of thousands (and preferably more) of current pulses reaching $50 \mathrm{kA}$ (peak) value should be generated at a few $\mathrm{Hz}$ frequency. This corresponds to a charge transfer of a few coulombs $(\mathrm{C})$ and a total charge transfer of the order of 5,000 C per hour of scabbling.

We encountered two main problems: a short spark gap lifetime and unreliable functioning of a pulse triggering/timing device. Two types of switches are in use currently. In EHS-01, an open spark gap operating in a free-running (overvoltage) mode is installed. This 


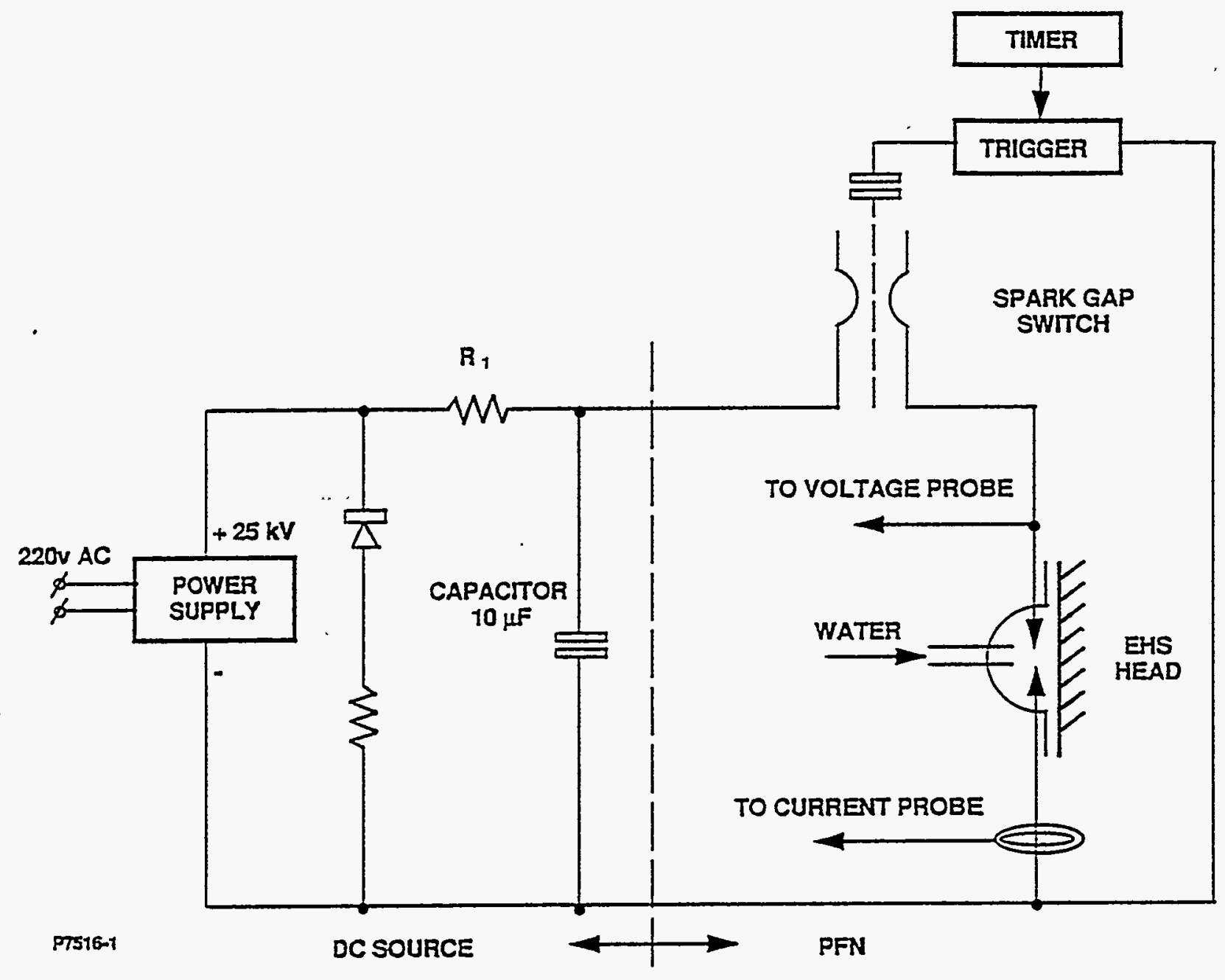

Figure 3-1 Conceptual Schematic of HV Power Supply 

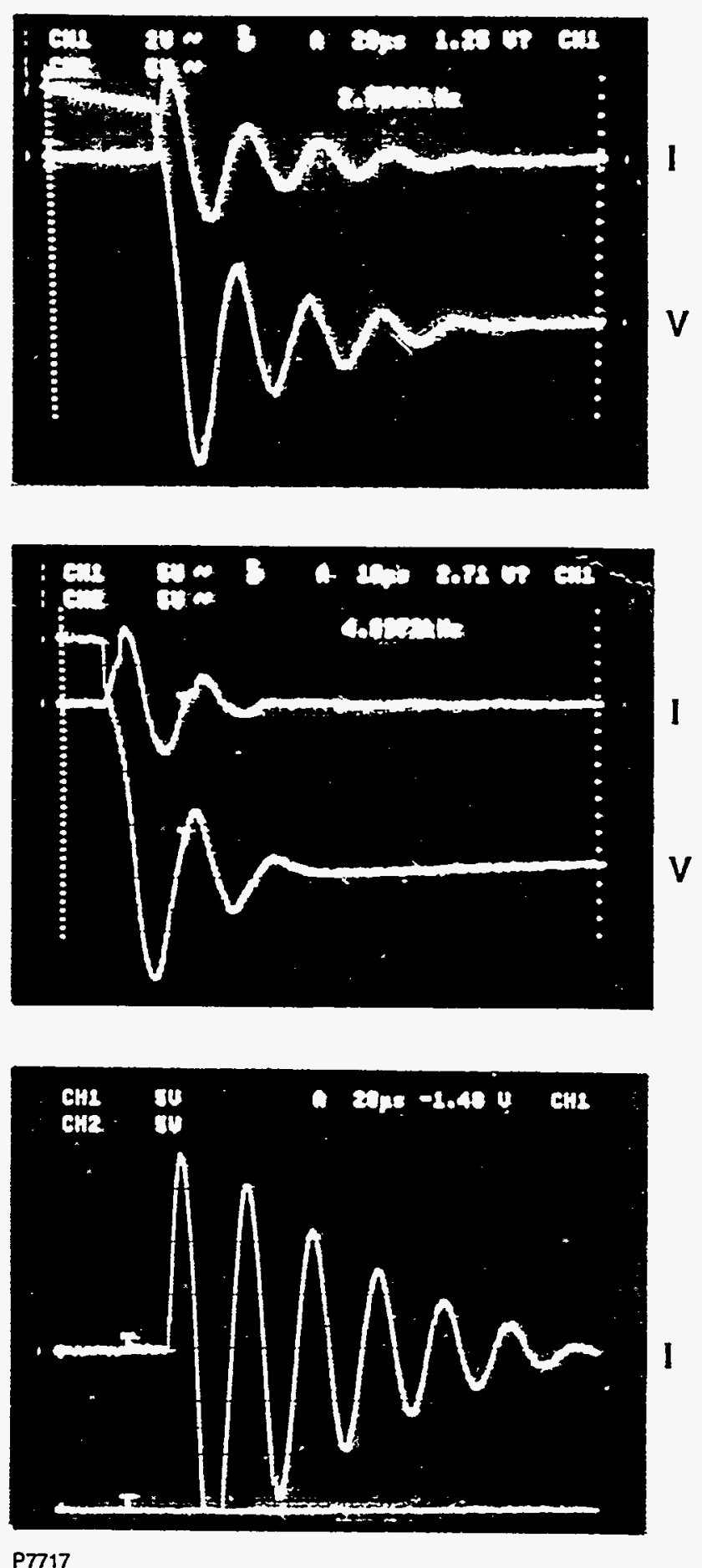

Figure 3-2 Oscillograms of EH Discharge Current and Voltage for Different Circuit Inductivity and Resistivity Values 
switch (Figure 3-3) has copper/tungsten alloy electrodes and plexiglass disks as mounting elements. It does not have any triggering device, frequency of pulses being defined by the interelectrode distance and charging voltage (i.e., rate of charging). The advantages of this switch are its low cost and long lifetime. There are, though, certain shortcomings: a) high operating noise, and b) irregularity of pulsing (variation of interpulse timing) and a related difference in pulse voltage and, consequently, in pulse energy.

Figure 3-4 illustrates typical pulse sequences obtained with this spark gap in operation. Periodic variations of the discharge voltage are shown. These variations may increase scabbling efficiency and reduce scabbling rate if, for instance, the concrete fracture has a certain minimum energy threshold.

In the EHS-02 unit, a closed, pressurized spark gap, Model GP-41 B by EG\&G, shown in Figure 3-5a, is used. A standard module (TM-11A, also made by EG\&G) controlled by -a simple, battery-driven low power pulser is used for triggering at 0.5 to $5 \mathrm{~Hz}$ frequency. At $0.5 \mathrm{C}$ charge transfer, this spark gap has, according to specification, a lifetime of about 10,000 pulses. The actual lifetime observed in our experiments using several units was between 4,000 and 15,000 at about (total) $2000 \mathrm{C}$, which is insufficient for scabbling applications. The spark gap's failure mode was from an isolator crack (see Figure 3-5b) developing due to conductive deposits, resulting in electric breakdown over the inside surface of the insulator. At our request, EG\&G manufactured several spark gaps with a proprietary compound in the discharge chamber which is supposed to reduce formation of the metallic deposits and to lengthen the lifetime. These spark gaps have yet to be tested in the long-duration operation.

Three other types of spark gaps are under consideration for use in a full-scale EHS unit: 1) A semi-closed (flow-through) spark gap with graphite electrodes. This high-action switch, Model ST-300A developed by Physics International Co., operates at voltages up to $55 \mathrm{kV}$, peak currents reaching $600 \mathrm{kA}$, and has an electrode lifetime (total) of 160,000 C. The switch should be equipped with a (custom) series injection trigger; 2) A vacuum switch, Model TVS-40 manufactured by Maxwell Labs., Inc., is analogous to a spark gap developed by the Electrotechnical Institute (Moscow, Russia). According to specifications, the unit tolerates a total of $100 \mathrm{C}$ charge transfers at $50 \mathrm{kA}$ and has 20,000 pulses lifetime, which is acceptable for scabbling. Two switches can be operated in parallel, if necessary. On the negative side, this spark gap requires a rather high-powered triggering unit; 3) An open spark gap similar to the one used in the EHS-01 unit, but improved by using a "hydrodynamic" trigger developed recently by TSD specifically for scabbling PFN. The new triggering method is based on the injection of small amounts of aerosol in the interelectrode space (see Figure 3-6). This addition provides a better control of pulse frequency and energy while preserving the long lifetime of the initial simple design. Long-duration tests of this switch are due.

In addition to chargers, storage capacitors, and PFN, the power supply units have the following elements:

- AC cable connectors (220 V for our units).

- AC insulating line filter or STACO insulating power supply (optional; insulation may be useful to reduce $A C$ voltage fluctuation due to EM noise generated by pulsing. 


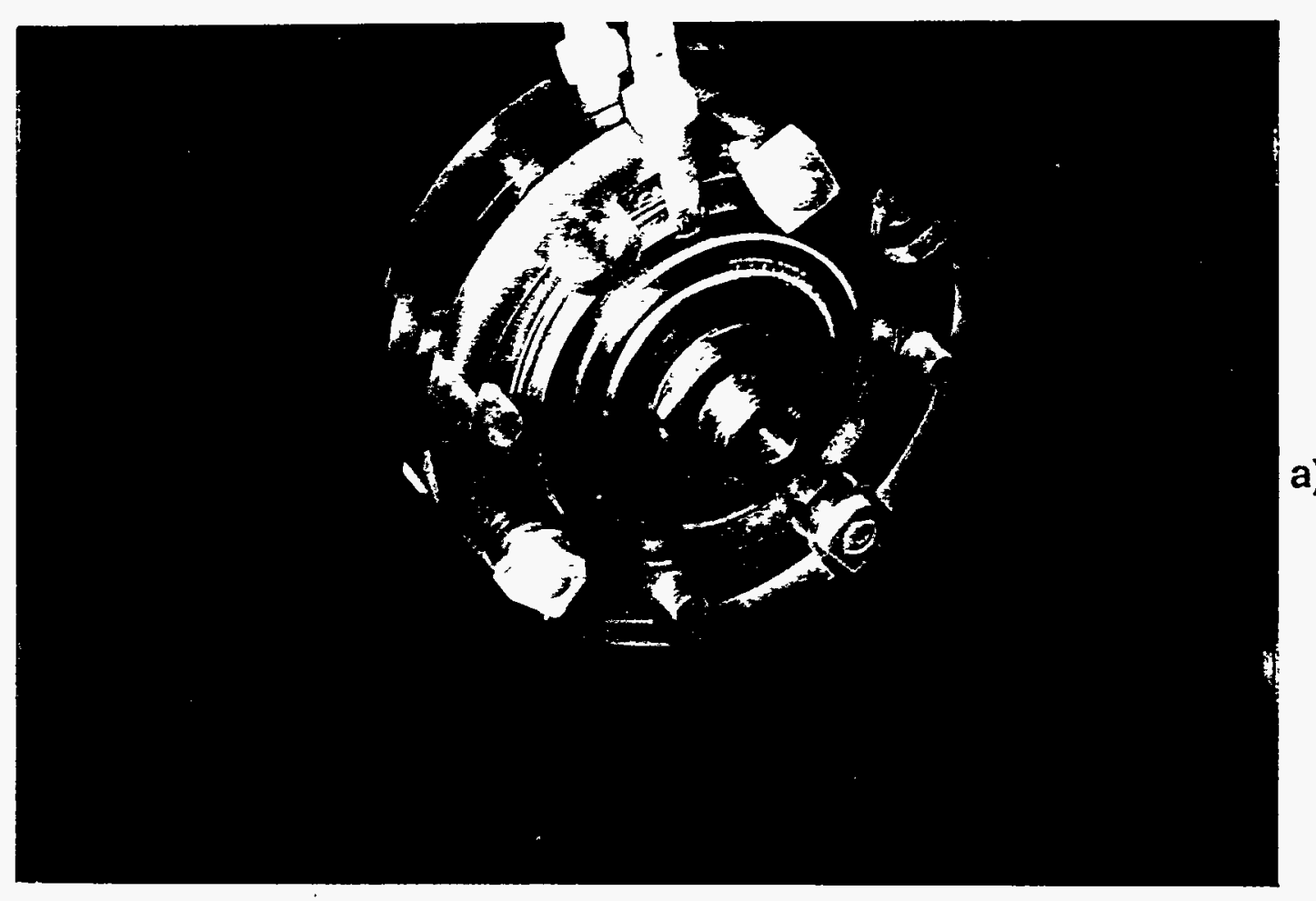

a)

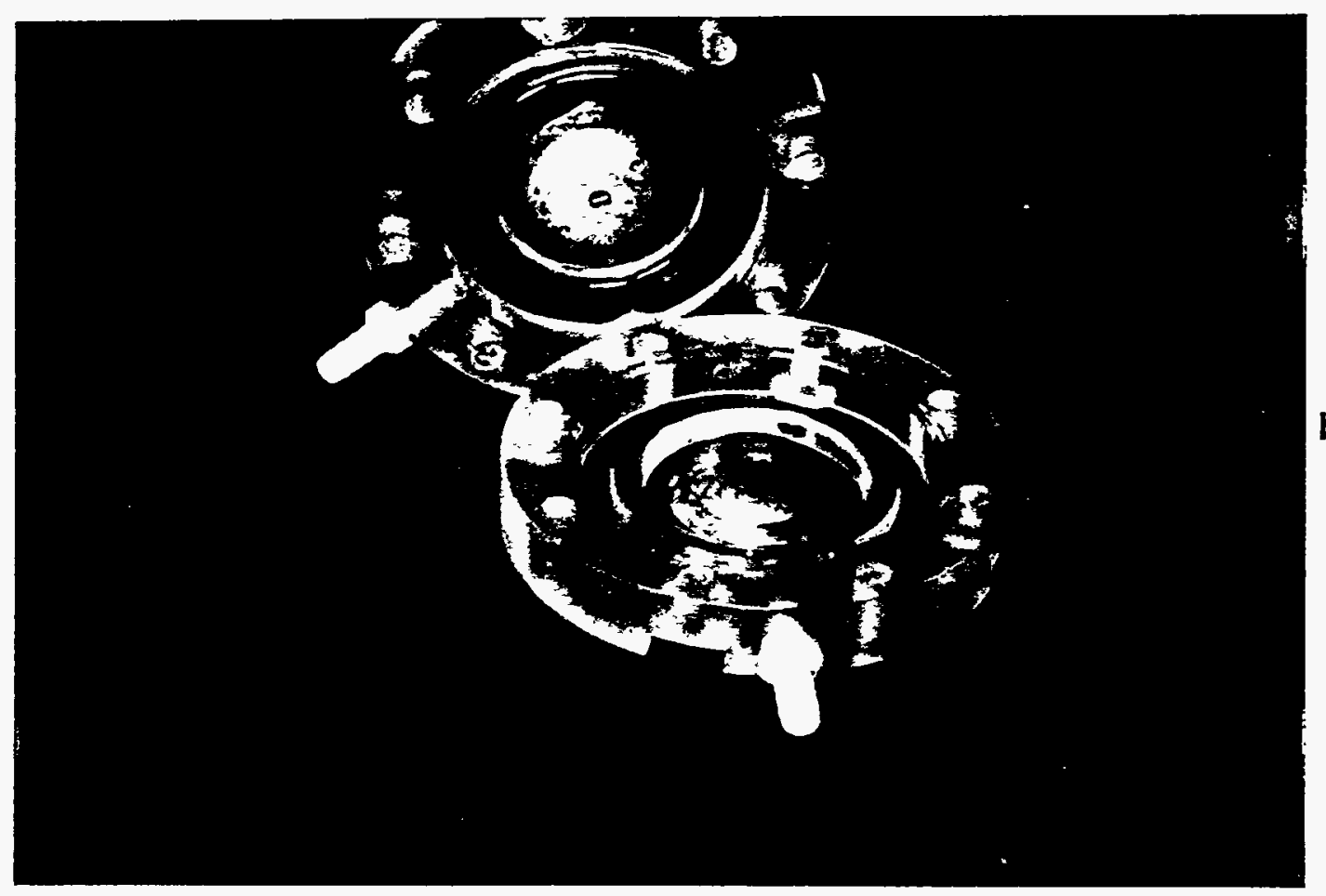

b)

P7718

Figure 3-3 Open Spark Gap Switch

a) switch assembled, b) switch interior after 50,000 pulses 


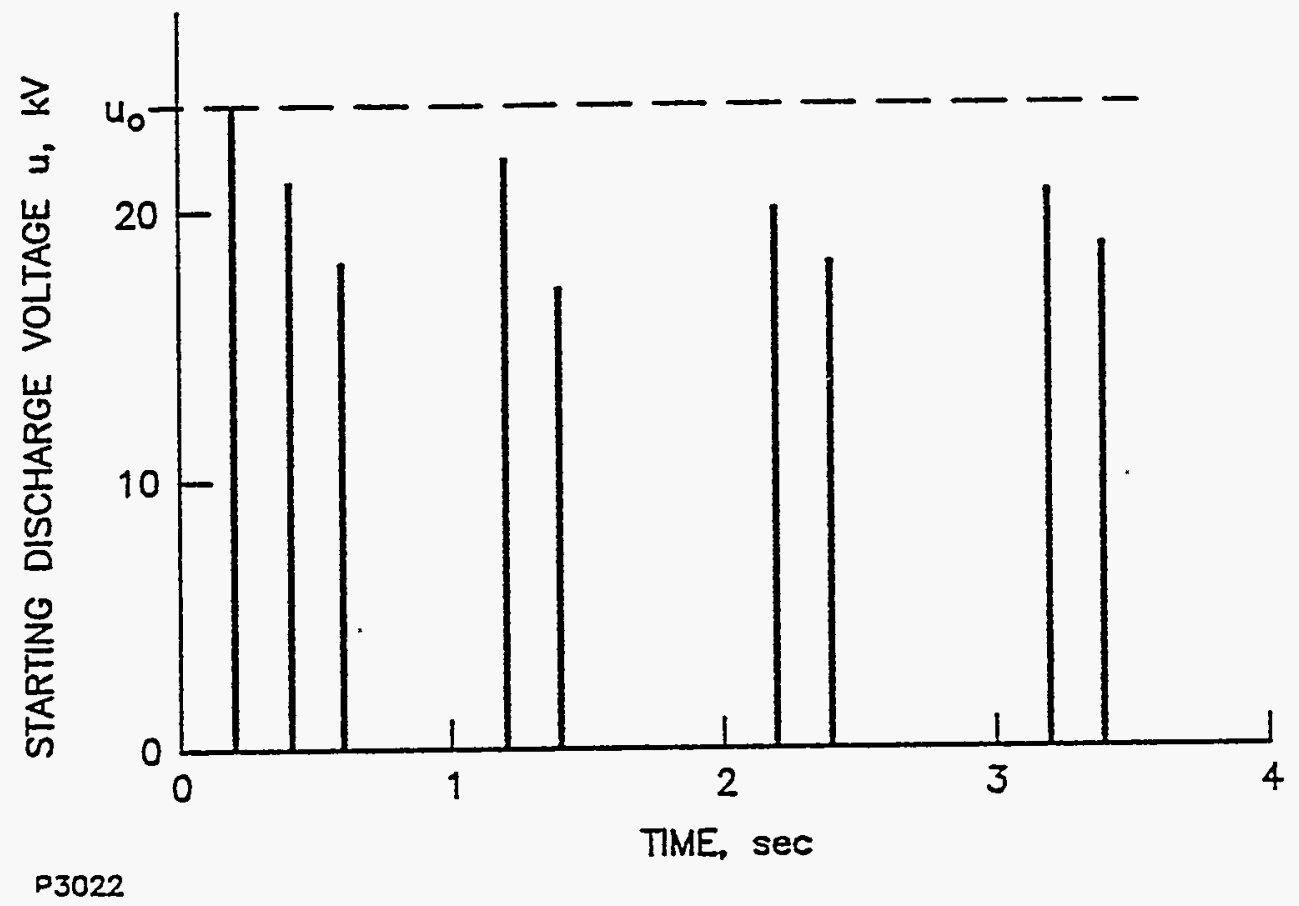

Figure 3-4 Pulse Sequence Typical for an Open Spark Gap Operating in Overvoltage Mode 


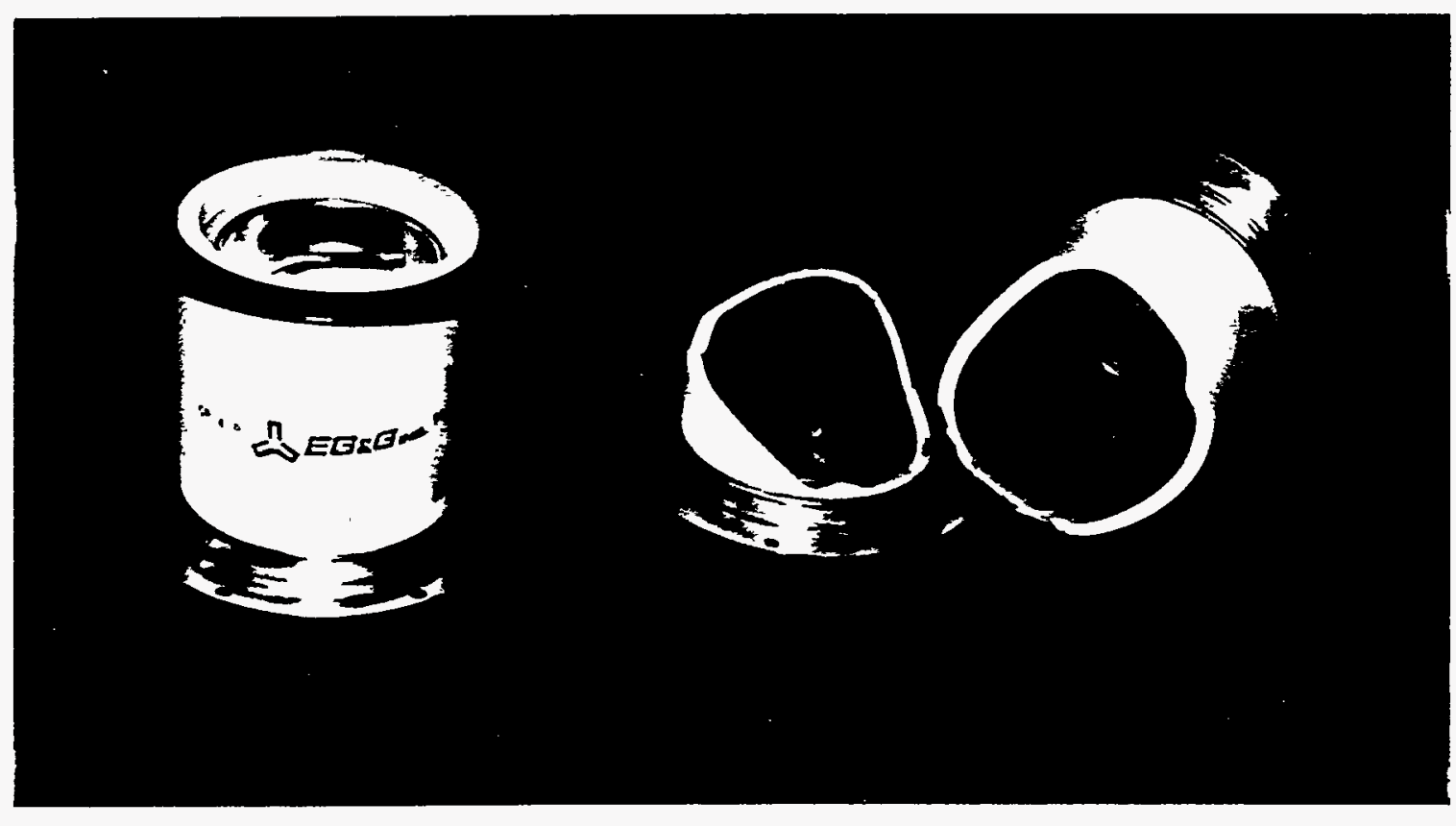

Figure 3-5 GP-41B Spark Gap Switch by EG\&G

a) original, b) damaged by internal breakdown

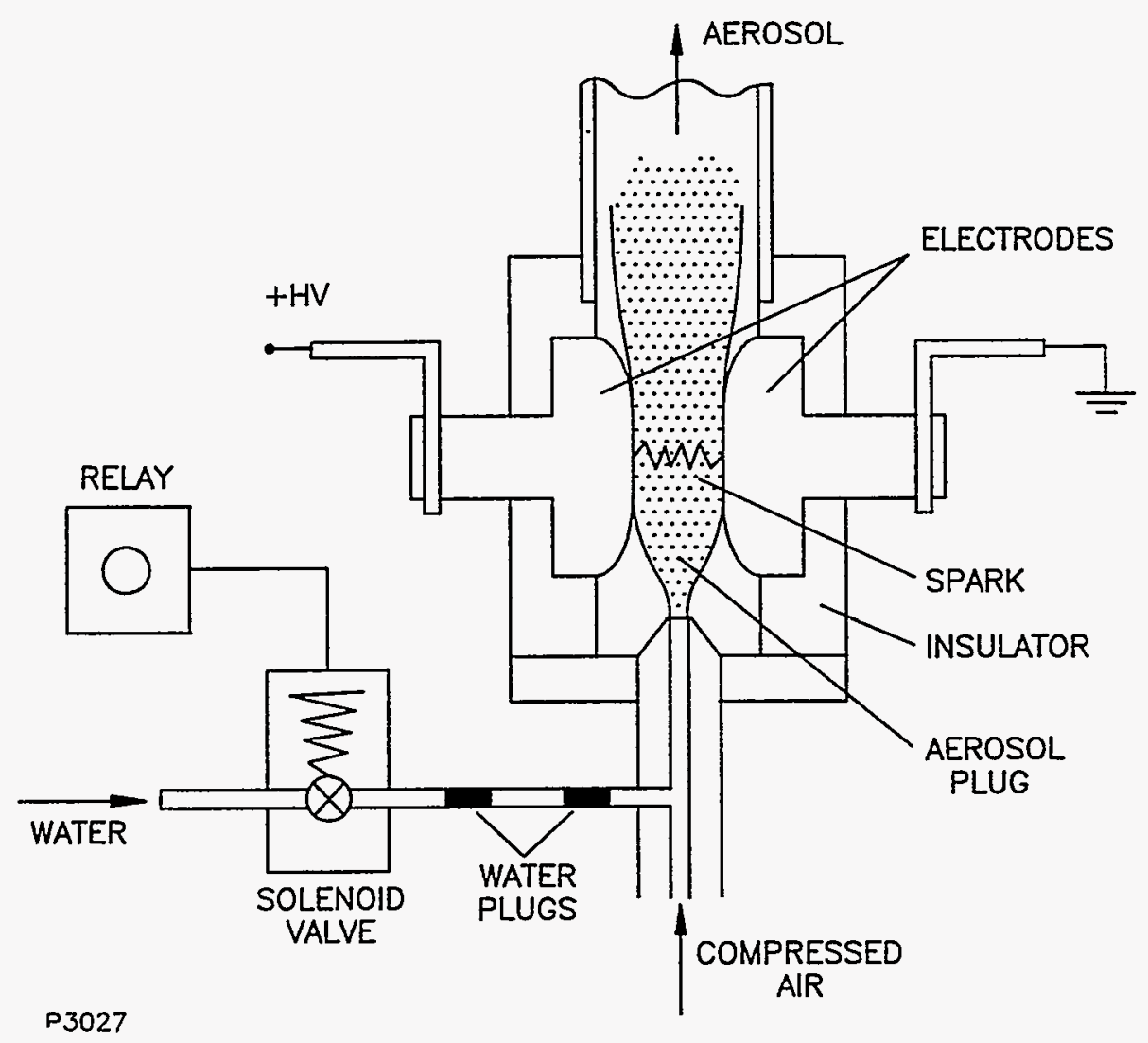

Figure 3-6 HV Spark Gap Switch with Hydrodynamic Trigger (recent TSD design) 
- Resistor (100 ohms) to separate "grounds" of the charging and "pulsing" parts of circuitry.

- Diode array to reduce effect of a pulse current oscillation on the charger and capacitor.

- Air fans, external blowers or compressed air supply to cool cabinet interior and, specifically, resistors and spark gaps.

- Compressed air supply to provide flow through open gap switch and to cool HV cable (see below).

- Current transformer (or loop) and voltage divider to measure pulse current and voltage (digital oscilloscope, Tektronix Model 2430, is used for these measurements).

- Safety components:

- $\quad$ "Drop switch" to discharge capacitors (to a ground cable).

- Interlock at the cabinet door.

Detailed electrical schematics and specifications of the EHS-012 and EHS-02 units are shown in Figures 3-7 and 3-8. Figures 3-9 and 3-10 show exterior and interior views of the power supply cabinets.

\subsection{SCABBLING MODULE}

A scabbling module is a concrete processing tool, i.e., the central component of the EHS system. It is comprised of a pair (or more) of electrodes, an electrode support frame, and HV cables connecting electrodes to the power supply.

\subsubsection{Electrodes}

There was a long path of development between the single pair of rod electrodes used in most of the Phase I experiments to scabble a rather narrow, 1"-2", strip of concrete to the electrode system capable of making a two foot or wider scabbled trail. A history of the electrode configuration development is illustrated by Figures 3-11 to 3-14. The following alternatives were considered initially:

a) Use a single pair of rod electrodes processing a wide floor area by sequential running of many adjacent parallel strips. In this case, the electrode pair had to be repositioned rather frequently in a lateral direction $Y$ (perpendicular to the scabbling direction $\mathrm{X}$ ). Another mechanical adjustment would be necessary. Because rod electrodes have a rather small tip area subject to electric erosion, it would be necessary to adjust the interelectrode gap periodically. 


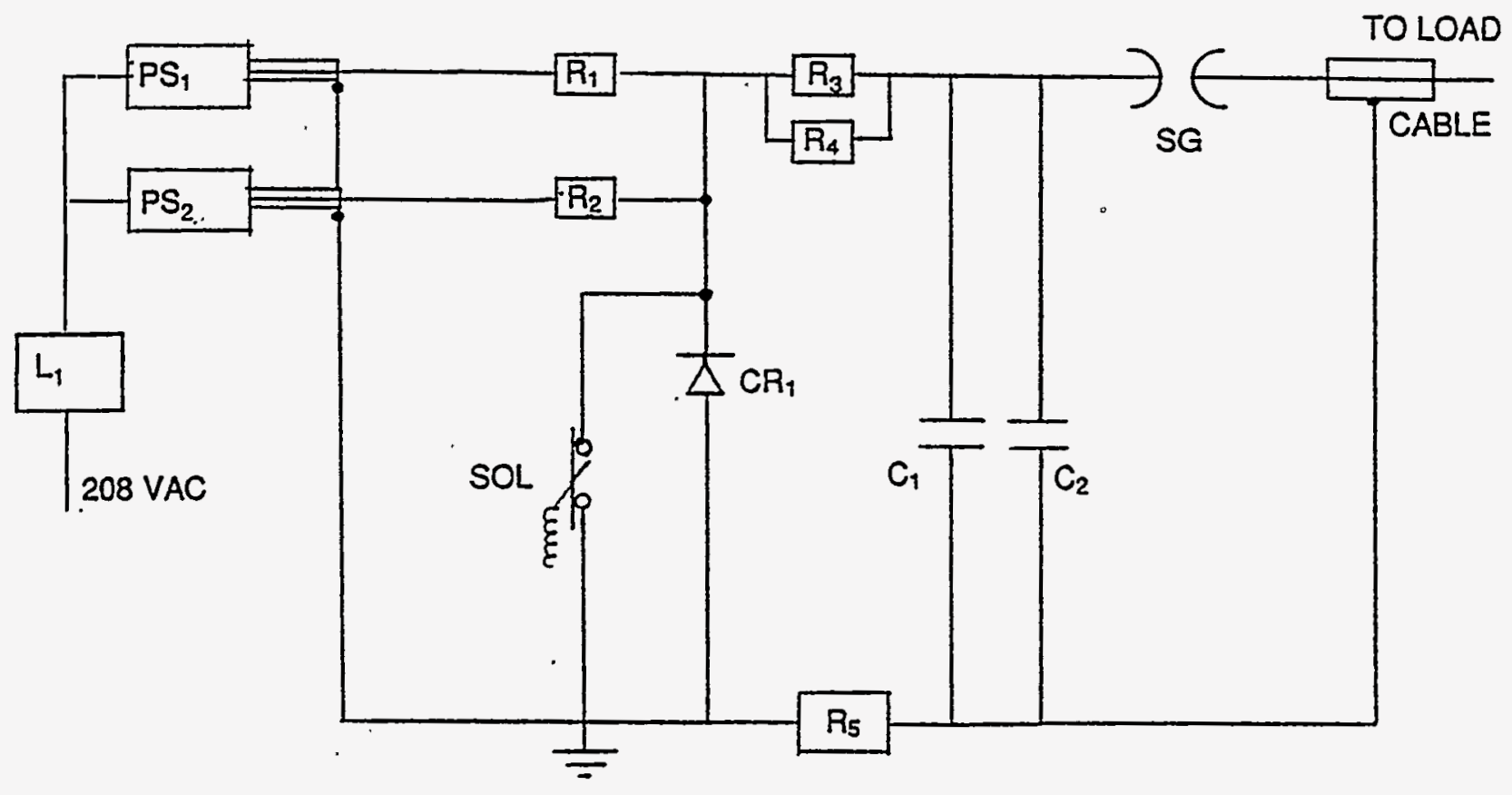

P7754

\begin{tabular}{|l|l|}
\hline$P S_{1}, P S_{2}$ & $\begin{array}{l}\text { Power Supply } \\
\text { ALE-402.25 kV 4kW }\end{array}$ \\
\hline$L_{i}$ & Line (AC) Fiter \\
\hline$R_{1}, R_{2}$ & 50 ohm. 25 watt \\
\hline$R_{2}, R_{d}$ & $1 \mathrm{~K}$.225 watt \\
\hline$C_{1}$ & $50 \mathrm{kV}$. Diode \\
\hline$R_{5}$ & 100 ohm. 100 watt \\
\hline$C_{i}, C_{2}$ & $6.3 \mu \mathrm{F}, 50 \mathrm{kV}$ \\
\hline SOL & Switch \\
\hline Spark Gad & TSD Ooen \\
\hline
\end{tabular}

Figure 3-7 Electric Schematic and Specification of EHS-01 Power Supply 


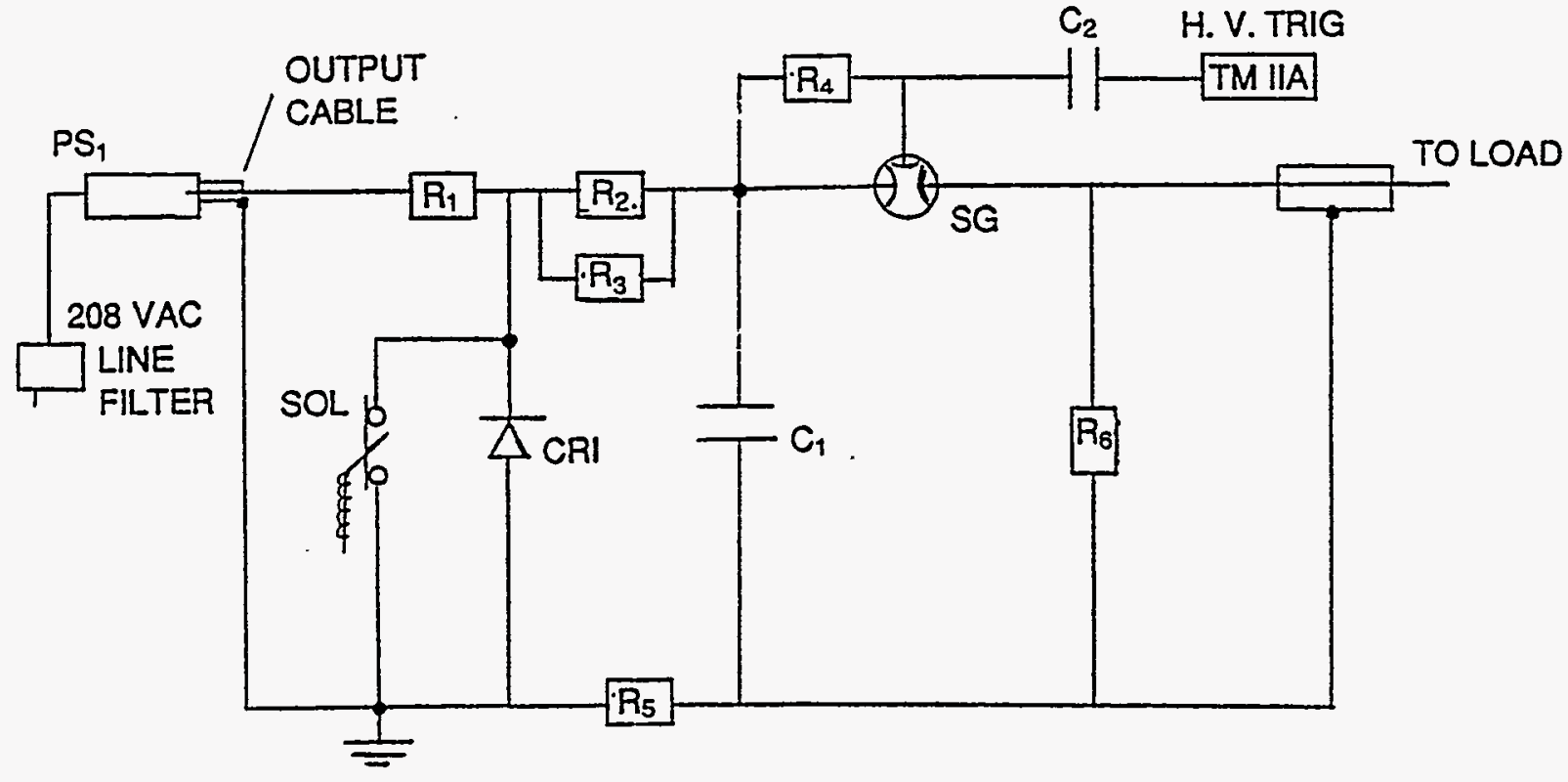

\begin{tabular}{|l|l|l|}
\hline $\mathrm{PS}_{1}$ & $\begin{array}{l}\text { Power Supply } \\
\text { Maxwell. CCDC }\end{array}$ & $\begin{array}{l}35 \mathrm{kV} \\
7 \mathrm{~kW}\end{array}$ \\
\hline$R_{1}$ & 50 ohm & 25 watt \\
\hline$R_{2}, R_{3}$ & 1000 ohm & 225 watt \\
\hline$R_{4}$ & $20 \mathrm{Mohm}$ & 15 watt \\
$R_{6}$ & $20 \mathrm{Mohm}$. & 225 watt \\
\hline $\mathrm{C}_{1}$ & $50 \mathrm{kV}$ & Diode Stack \\
\hline$C_{1}$ & $10 \mathrm{uF}, 35 \mathrm{kV}$ & \\
\hline$S O L$ & $.30 \mathrm{kV}$ Solenoid & Switch \\
\hline$S G$ & Spark Gap & GP-41P EG\&G \\
\hline$C_{2}$ & $500 \mathrm{oF}, 25 \mathrm{kV}$ & \\
\hline$R_{5}$ & $100 \mathrm{ohm}$ & 100 watt \\
\hline
\end{tabular}

P7753

Figure 3-8 Electric Schematic and Specification of EHS-02 Power Supply 


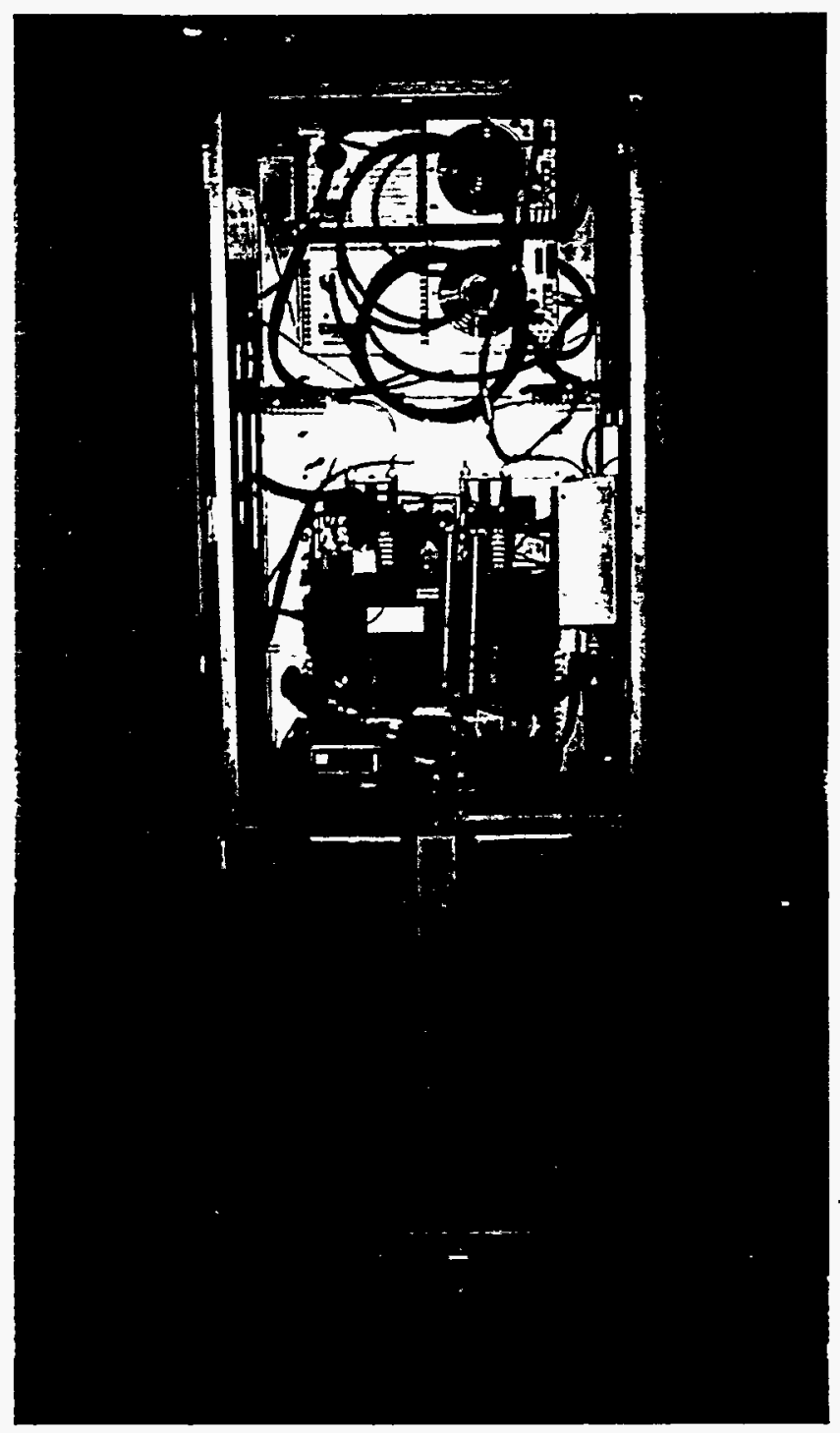

P7720

a)

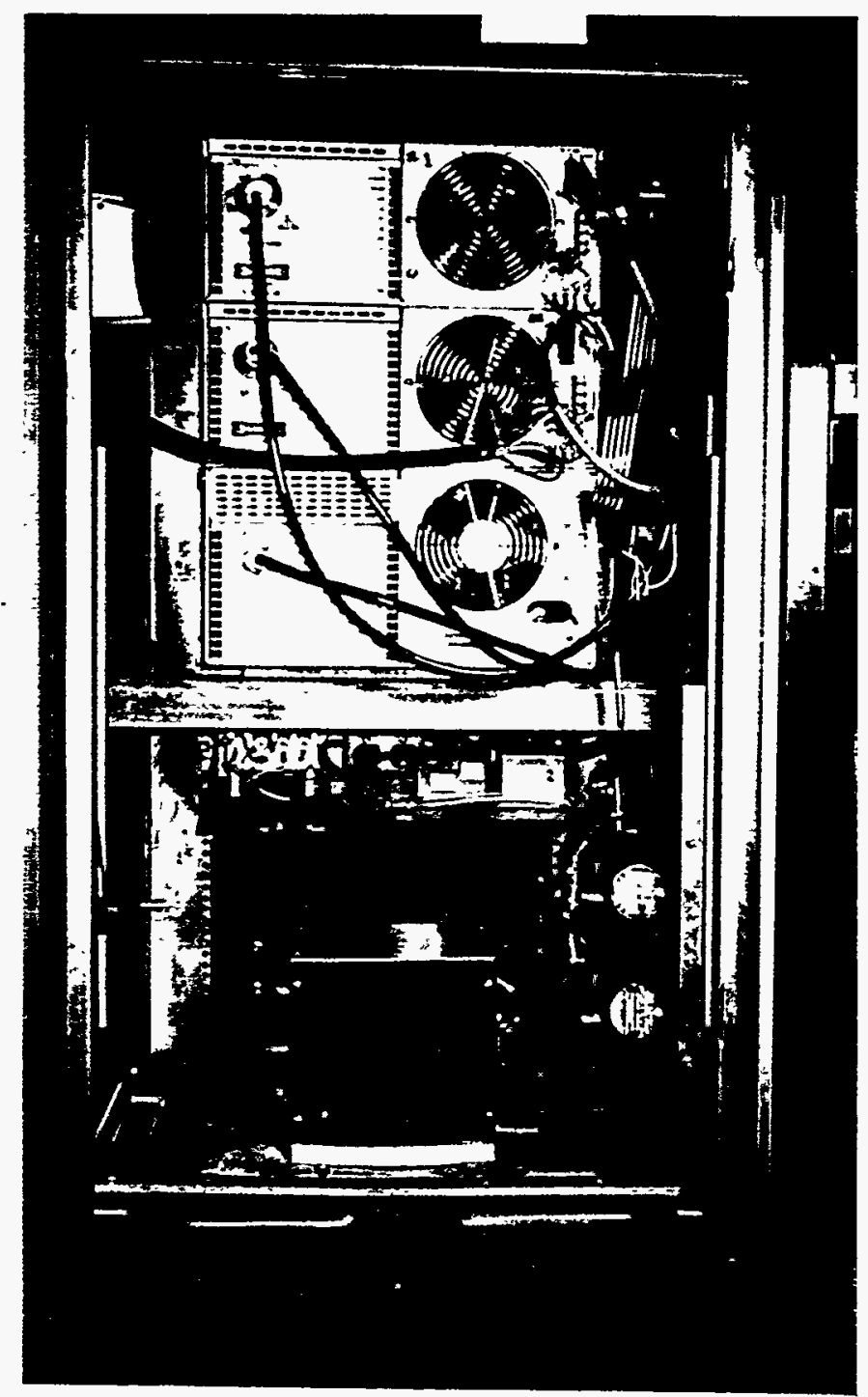

Figure 3-9 EHS-01 Power Supply Assembly

a) original with two ALE charges

b) last version with three ALE chargers 


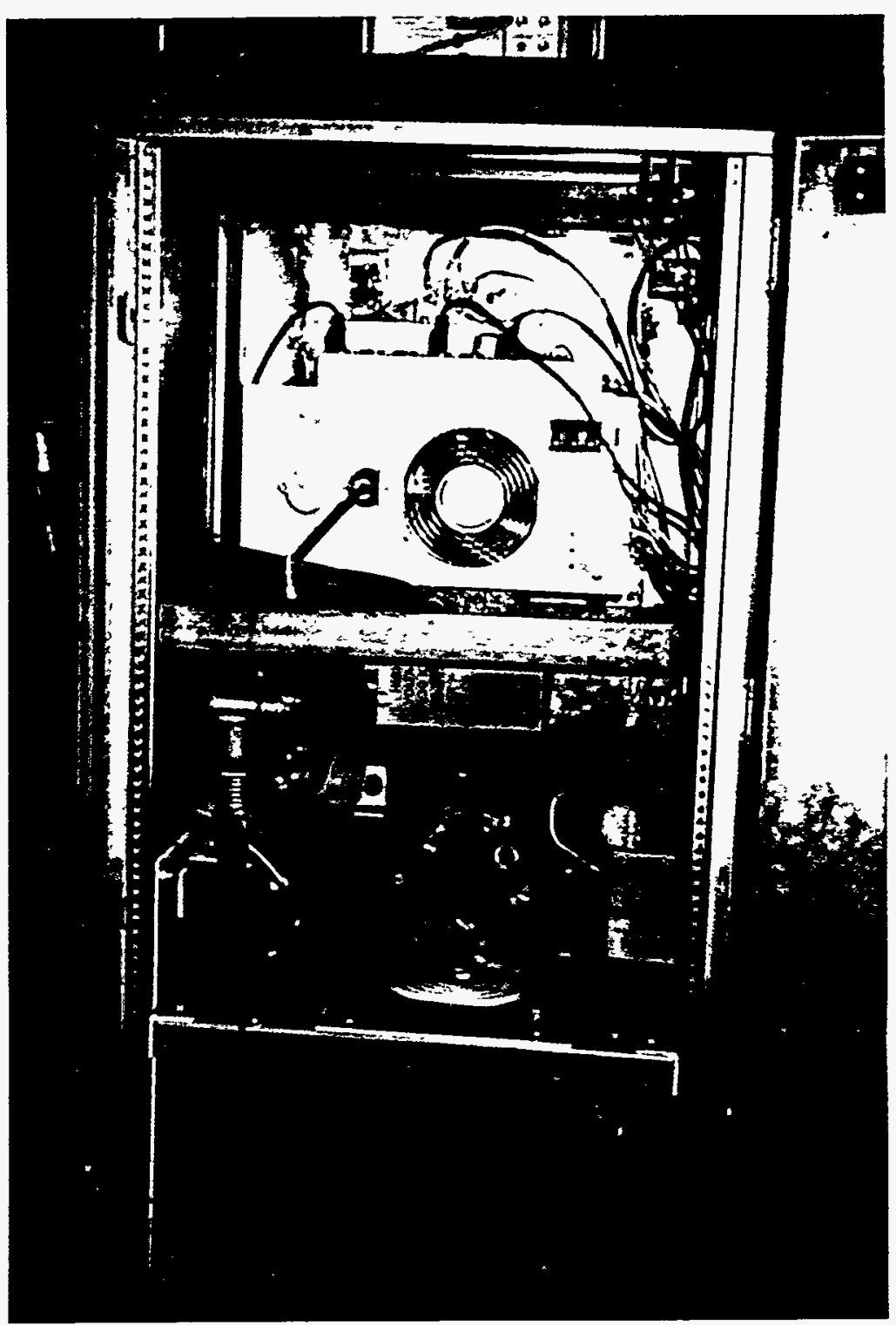

P7721

Figure 3-10 EHS-02 Power Supply Assembly 


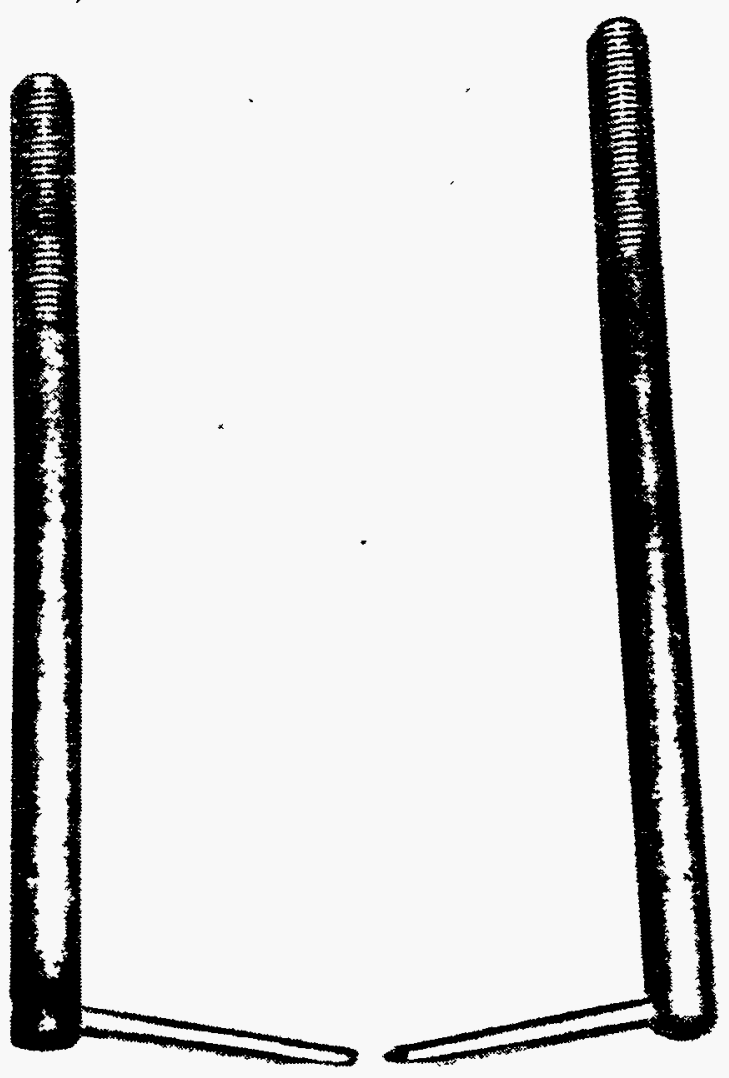

a)

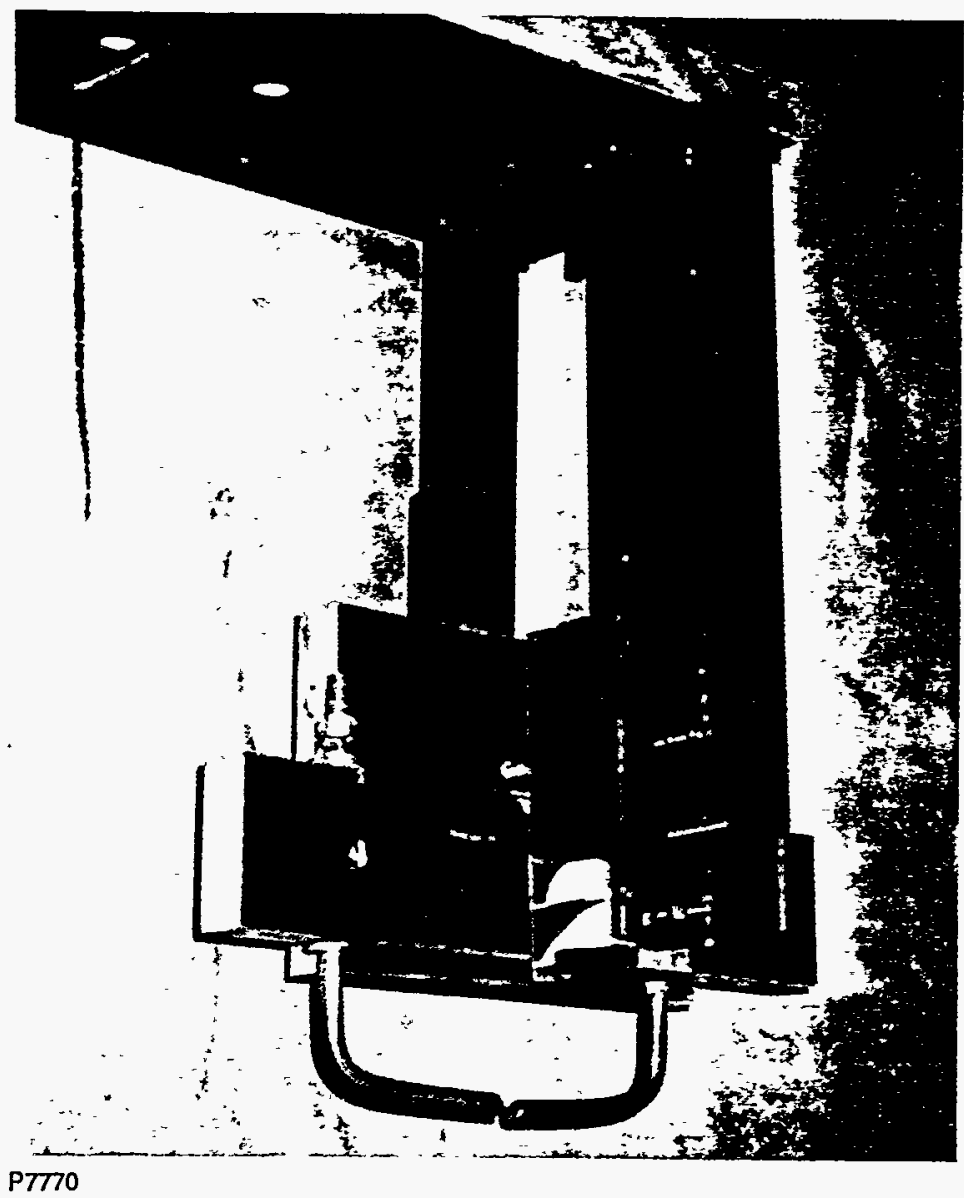

b)

Figure 3-11 Electrode Module Development: configurations with single rod electrode pairs 

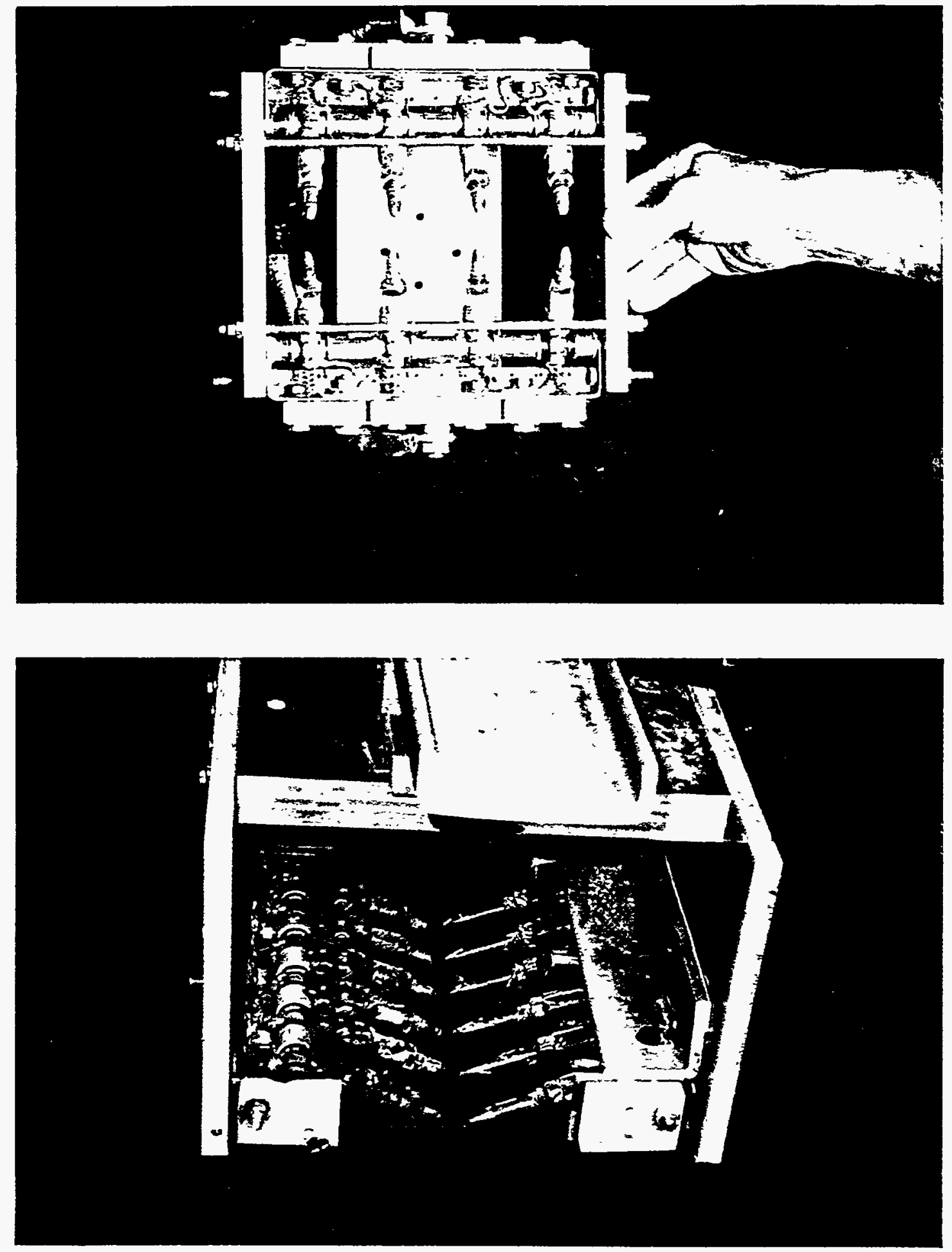

P7722

Figure 3-12 Electrode Module Development (continued): multielectrode modules with individual electrode supports 


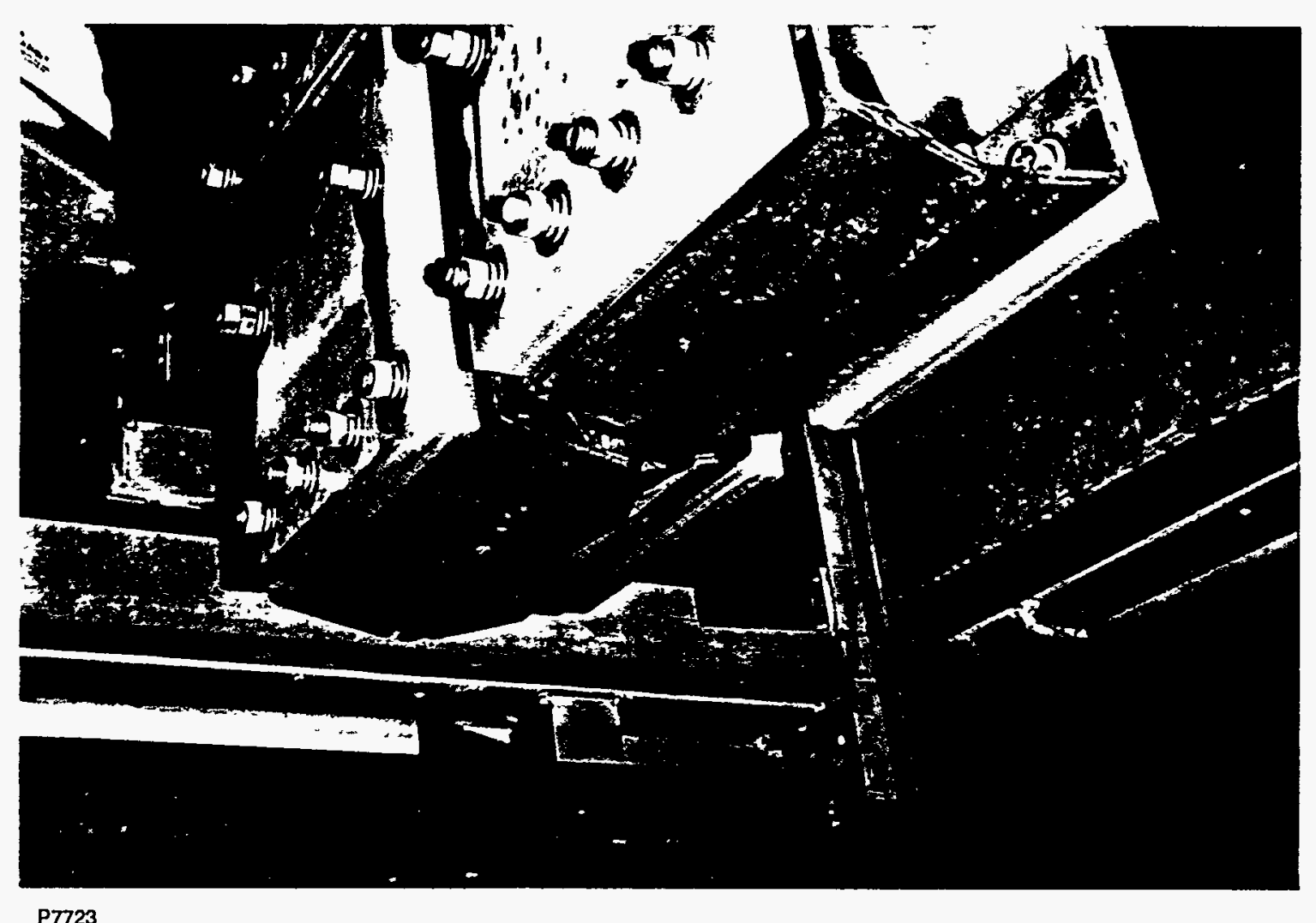

Figure 3-13 Electrode Configuration Development (continued): module with two pairs of short (8") strip electrodes 

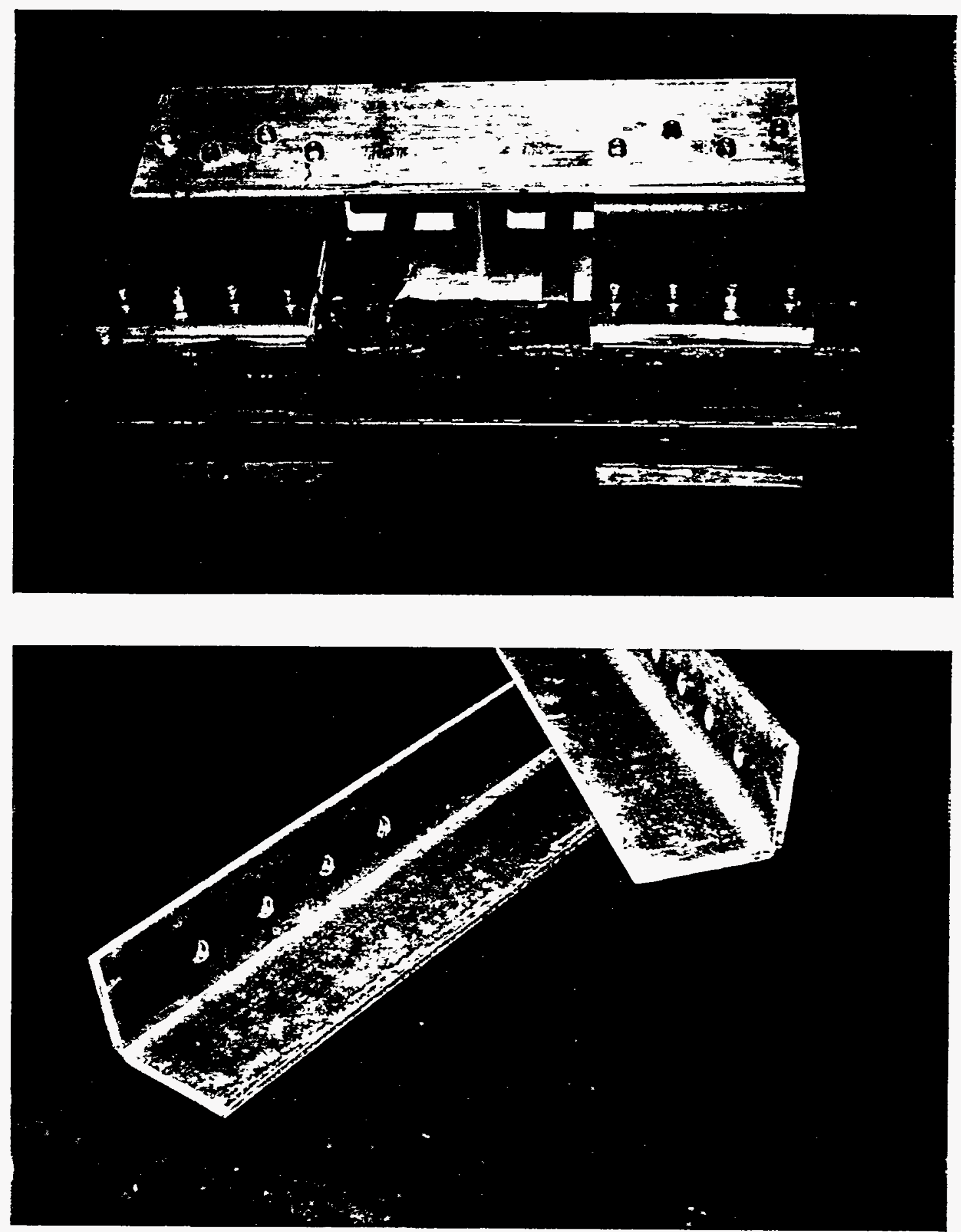

P7724

Figure 3-14 Electrode Configuration Development (continued): module with a single pair of strip electrodes (a), and construction of 26 "-inch long strip electrodes (b) 
b) Use a row of several rod electrode pairs to increase the scabbling width and either avoid Y-traverses altogether or make them less frequent. The electrode pairs can be either connected to separate (individual) or to a single pulser.

There are several issues involved:

- a more complicated mechanical arrangement (see also below);

- interaction between discharge channels and pulsers when several pulsers are employed;

- uniform distribution of discharges between the electrode pairs (equal frequency of pulses and uniform scabbling) when single power supply is used;

- $\quad$ electrode erosion is still of concern.

c) Use of a single pair of long strip-like parallel electrodes over the whole desired scabbling width (or, as a compromise, only two or three shorter electrode strips).

The main issue in this arrangement is related to the uniformity of discharge occurrence along the gap. There is no assurance that discharges will occur randomly along the gap (instead of being concentrated over certain gap regions) and scabbling intensity/depth, as well as electrode erosion, will be sufficiently uniform in the Y-direction. It could be expected that, due to a larger electrode tip area acting as discharge base, electrode erosion (per unit length) will be smaller, and electrode gap adjustment could be less frequent if necessary at all.

An important issue related to the design of an electrode/electrode support frame/electrode positioner is the mode of electrode positioning. We are considering here continuous vs. stepwise electrode movement along the concrete surface. In the Phase I experiments, the electrode pair was moved continuously, and pulsing/scabbling took place simultaneously with the electrode transfer. Even in the event that a single electrode pair is used, this simplest and most natural approach could be troublesome: to assure effective pulsing and scabbling, electrode tips should be in contact with concrete surface. This means that both, or at least one, of the electrode tips are brushing against the surface, and may be caught in surface ruggedness created by scabbling. The brushing results in electrode displacement and in changes in the gap length. These effects were actually observed with a single electrode pair, and various measures, like use of spring or pneumatic electrode holders, were tried to solve the problem but were only partially successful. In the case of multielectrode modules, the individual flexible supports of each electrode were becoming even more complicated and unreliable in operation.

It was decided, after trying various design modifications, to abandon continuous electrode movement and turn to more complicated traverse modes where electrode movement and pulsing are separated in time. Specifically, pulsing/scabbling takes time at some fixed electrode positions $\left(Z_{0}\right)$ in contact with concrete, then the electrodes (electrode frame) are lifted 1"-2" over the concrete surface, moved in direction $(X)$ to the other scabbling position, and lowered again to $\mathrm{Z}_{\mathrm{o}}$ (contact with concrete) level where scabbling continues. This traverse pattern requires vertical $(Z)$ positioning (electric or pneumatic), which complicates the module design. Also, it adds to processing time. This additional time is, though, relatively small when many scabbling pulses are used at each location (as is the case with long electrodes). 
Eventually, the $\mathrm{XZ}$ positioning mode was accepted as a standard one for both single strip electrodes and multielectrode modules. In the final strip electrode design, the electrodes were made of either carbon or stainless steel. Flat steel stock $3 / 16^{\prime \prime}$ or $1 / 4^{\prime \prime}$ thick was bent to form a $105^{\circ}$ angle (see Figure 3-14b), with its vertical part to be attached to G-10 holders and also used as an electrical contact plate.

\subsubsection{Supporting Frame}

The frame supporting single or multiple electrodes should be:

- mechanically solid to prevent electrode disalignment due to brushing of the concrete surface or due to vertical pressure provided to secure electrode/concrete contact;

- tough enough to withstand impulse loading by shock waves propagating in water,

- electrically insulated to prevent HV breakdowns above the water surface;

- hard enough to prevent erosion by water streams, concrete debris impact, and cavitation

- convenient for supporting and strong bolting of electrodes and cables.

The only material which meets these requirements is G-10 fiberglass. This material, in the form of $1 / 2$ to 2 " thick plates and in combination with steel or aluminum reinforcing/holding profiles (angles, rods, U-shaped), was used in all designs of all EHS modules, starting with small, single-electrode discharge chambers as in Figure 3-15a,b and continuing with discharge chambers containing several electrode pairs (Figure 3-15c) and to frames holding "strip" electrode pairs of various lengths as in Figures 3-13 and 3-16.

In the most recent design (i.e., the one used in the field test/demo), a strip electrode module (frame and electrodes proper) is attached to Z-shaped steel brackets, which are, in turn, mounted on a XZ positioner (see 3.3.2).

\subsubsection{High-Voltage Cables and Connectors}

Selection or design of high voltage cables carrying very high current "scabbling" pulse is not trivial. The cables should meet the following requirements:

- high electric breakdown resistance of the core/shield insulation (for coaxial cable) and high resistance of the outer insulation layer;

- high thermal capacity, i.e., not to be overheated by repetitive current pulses;

- low inductance, not to increase pulse length over a few tens of ms;

- mechanical flexibility - low (minimum) curvature radius to fit inside the scabbling chamber and to follow the traverse of the scabbling module;

- water tightness. 


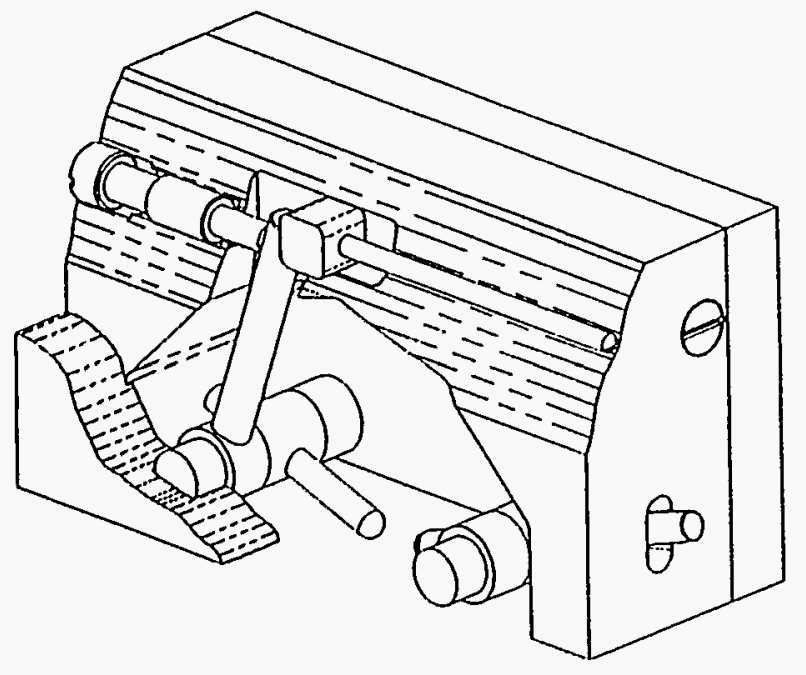

a)
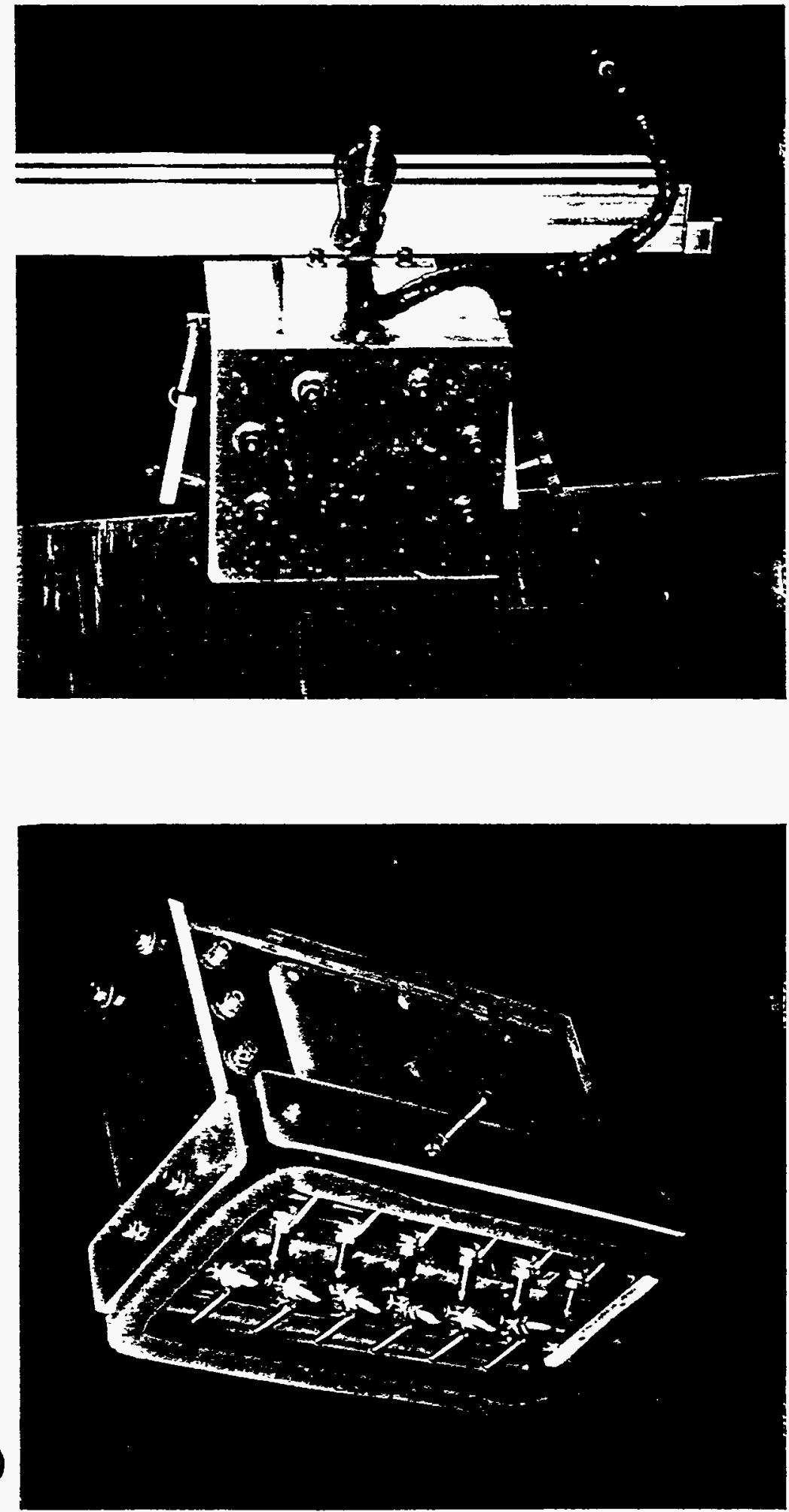

Figure 3-15 Single-electrode (a) and multielectrode (b) discharge chambers 


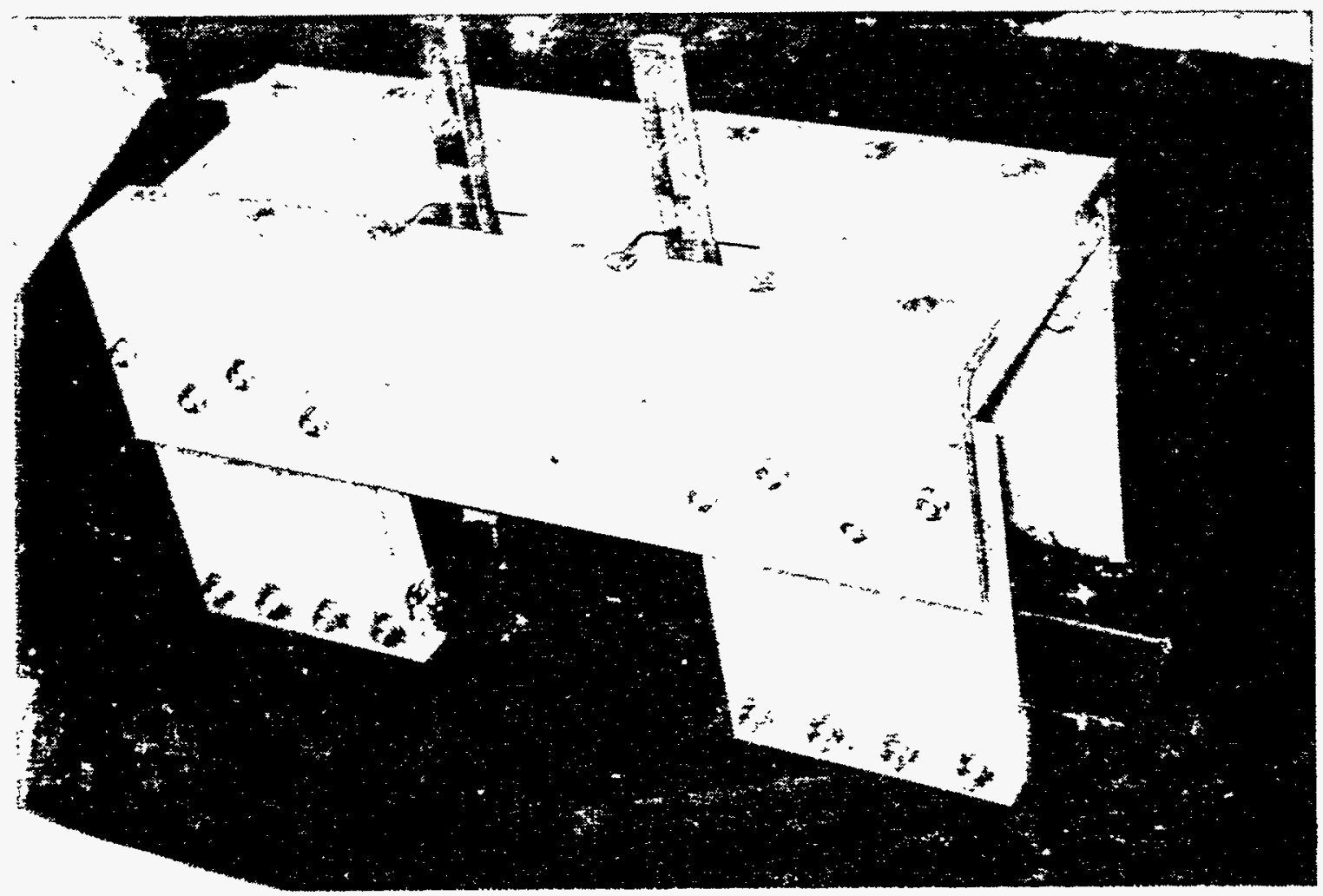

a)

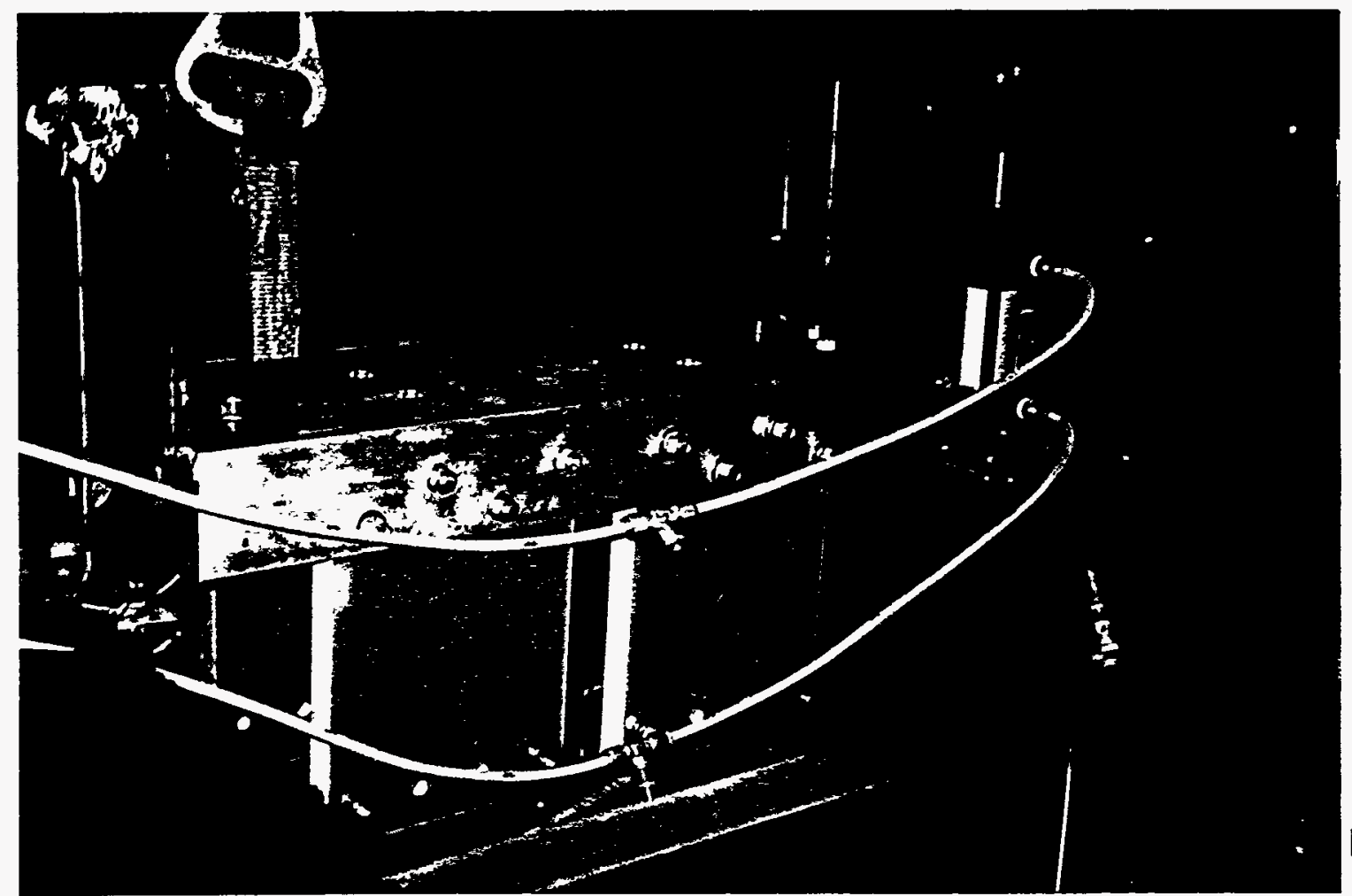

b)

P7769

Figure 3-16 Scabbling Module Frame for Double Pair (a) and Single Pair (b) Strip Electrodes 
Two types of coaxial HV cable, both supplied by Dielectric Sciences, Inc. (Chelmsford, MA) were used. Characteristics of these cables are given in Figure 3-17. Thermal capacity of these cables was not sufficient for operation at more than $1 \mathrm{~Hz}$ pulse frequency. To resolve this problem: a) two cables were used for each scabbling module, and b) cables were encased in plastic hoses and cooled by a strong flow of compressed air introduced through a "tee "connector. Only part of the cables ( 8 '-10' long) located outside the scabbling chamber had to be cooled; cable lengths inside the chamber remained at reasonably low temperature due to cooling by splashed process water. Air leaving the cooling hoses was directed inside the power supply cabinet serving as part of their cooling system. Schematics of cable and cabinet cooling are shown in Figure 3-18.

Connectors between HV cables and electrodes are very vulnerable parts, subject to strong water pulses. After some troublesome experiences, an acceptable solution to this problem has been found. Massive copper rods of rectangular cross section (see Figure 3-19), bolted to electrodes, insulated by polyethylene tubing, and passing through windows cut in the G-10 frame are performing properly. Another important design requirement is to have all metal surfaces (electrodes, cable terminals, fasteners) completely submerged in water; otherwise electric breakdown takes place above the water surface. Due to low breakdown voltage characteristics for droplet/aerosol-filled air, this type of parasitic breakdown may occur over rather long air gaps.

\subsection{SCABBLING CHAMBER}

The scabbling chamber ("enclosure" is another term sometimes used) isolates space where concrete processing takes place. The chamber prevents process water covering concrete and contaminated debris from spreading over adjacent surfaces. The chamber contains a positioner to move the scabbling module. In the current design, the scabbling chamber is supported by a forklift.

\subsubsection{Enclosure}

There were several efforts to run the EH discharge within small, from $10^{\prime \prime} \times 10^{\prime \prime}$ (footprint) single electrode pair to 12" x 20", multielectrode enclosures. Figure 3-15 provides examples of some designs tried. To contain the process water, the perimeter of the enclosure may be equipped with a flexible gasket. The main problem with this design was rapid gasket erosion by water pulses. When the enclosure has to be dragged over a concrete surface, the erosion becomes intolerable.

To overcome these difficulties, another concept has been introduced, namely, separation of two tasks: 1) module positioning along $\mathrm{XYZ}$ or $\mathrm{XZ}$ only directions within the enclosure (or within the same scabbling cycle); and 2) a whole scabbling chamber (enclosure) relocation to the next scabbling segment (area) where the following cycle begins. In this mode, the scabbling chamber is large and water-holding gaskets are far enough from the electrodes. Also, each cycle takes substantial time, therefore intercycle time intervals (required for scabble chamber transfer and water recirculation) are of relatively short duration. Figure 3-20 shows the processing cycle.

The first enclosure made to operate in this mode is shown in Figure 3-21. This enclosure has a 24" x 35 " footprint and is 36 " high. A scabbling module with a 12" wide strip electrode is 


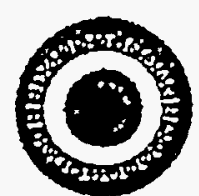

$2153 R 1$

\begin{tabular}{|c|c|c|c|c|c|c|c|c|c|c|c|}
\hline Voltage & Main & Sondue & Size & Dielectric In & acion & Shield & & & & & \\
\hline$\overline{D C X Y}$ & $\overline{\text { Awg }}$ & $\begin{array}{l}\mathrm{Sq} \\
\mathrm{mm}\end{array}$ & $\begin{array}{l}\text { Dia } \\
\mathrm{cm}\end{array}$ & Material & $\begin{array}{l}\text { Dia } \\
\mathrm{cm}\end{array}$ & Construction & $\begin{array}{l}\text { Awg. } \\
\text { Equiv }\end{array}$ & $\begin{array}{l}\text { Jacket } \\
\text { Mar1 }\end{array}$ & $\begin{array}{l}\text { Ouf } \\
D_{\text {in }} \\
\mathrm{cm}^{2}\end{array}$ & $\begin{array}{l}\text { Impedance } \\
\text { Ohms }\end{array}$ & $\begin{array}{c}\text { Capacitance } \\
\text { pFifi. }\end{array}$ \\
\hline 50 & $\not 2$ & 33.62 & 0.66 & LDHMWPE & 134 & $23 x \neq 1419 / 27$ & \#1 & PVC & 1.99 & 24 & 77 \\
\hline
\end{tabular}

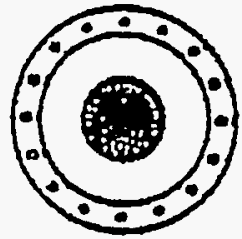

2107

\begin{tabular}{|c|c|c|c|c|c|c|c|c|c|c|c|}
\hline Voltage & Main & onduer & Size & Dielecric & irion & Shield & & & & & \\
\hline$\overline{D C k V}$ & Awg & Sq & $\begin{array}{l}\text { Dia } \\
\text { on }\end{array}$ & Material & $\begin{array}{l}\text { Dia } \\
\text { orn }\end{array}$ & Construcion & $\begin{array}{l}\text { Awg } \\
\text { Equiry }\end{array}$ & $\begin{array}{l}\text { Jacker } \\
\text { Marl }\end{array}$ & $\begin{array}{l}\text { Our } \\
D_{\text {in }} \\
\text { on }\end{array}$ & $\begin{array}{l}\text { Irspedance } \\
\text { Ohms }\end{array}$ & $\begin{array}{c}\text { Capacience } \\
\text { pFifi. }\end{array}$ \\
\hline 50 & $\# 1$ & 44.21 & 0.83 & E-R & 1.91 & $16+22$ TC & $\# 10$ & PYC & 254 & 28 & 75 \\
\hline
\end{tabular}

Figure 3-17 Designs and Specification of HV Coaxial Cables

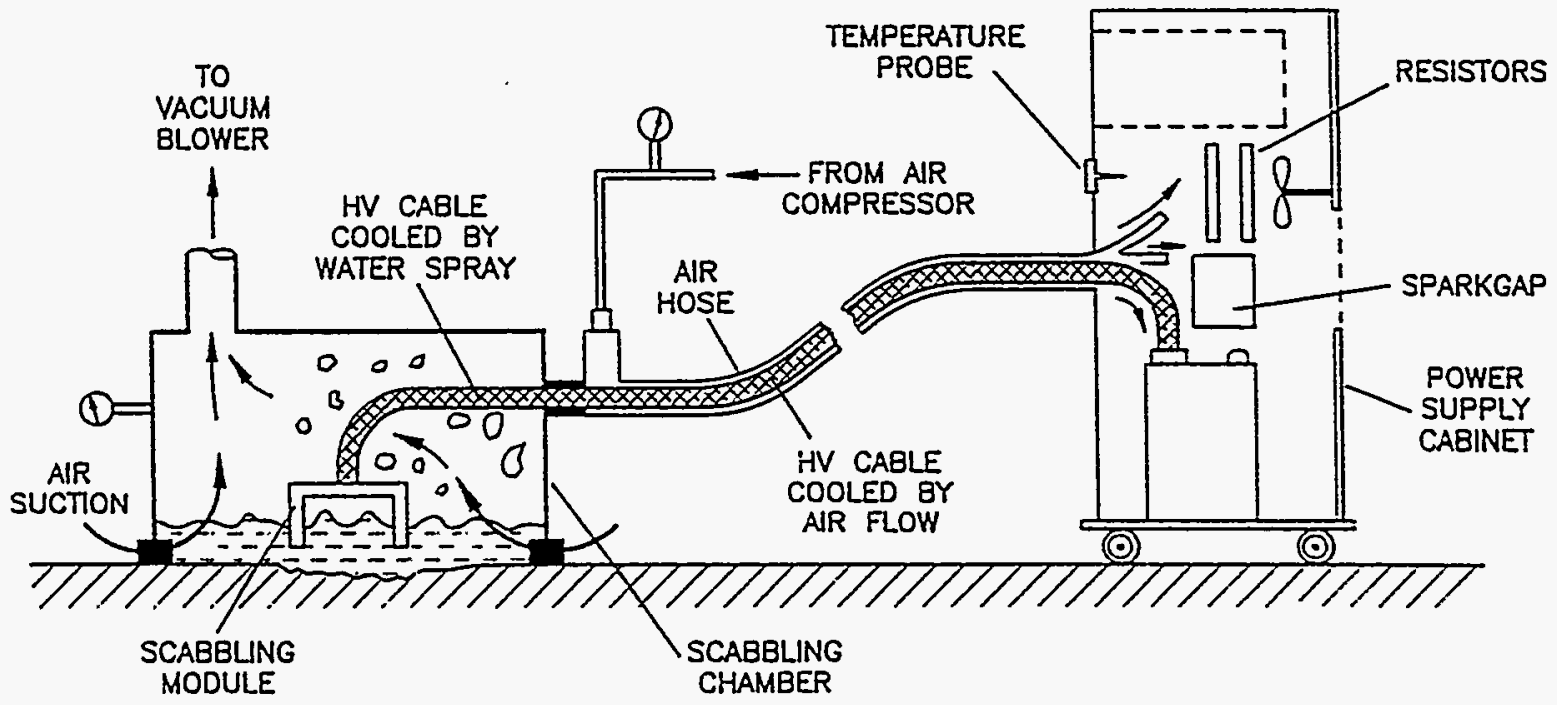

P3024

Figure 3-18 Schematics of HV Cable and Power Supply Cooling 


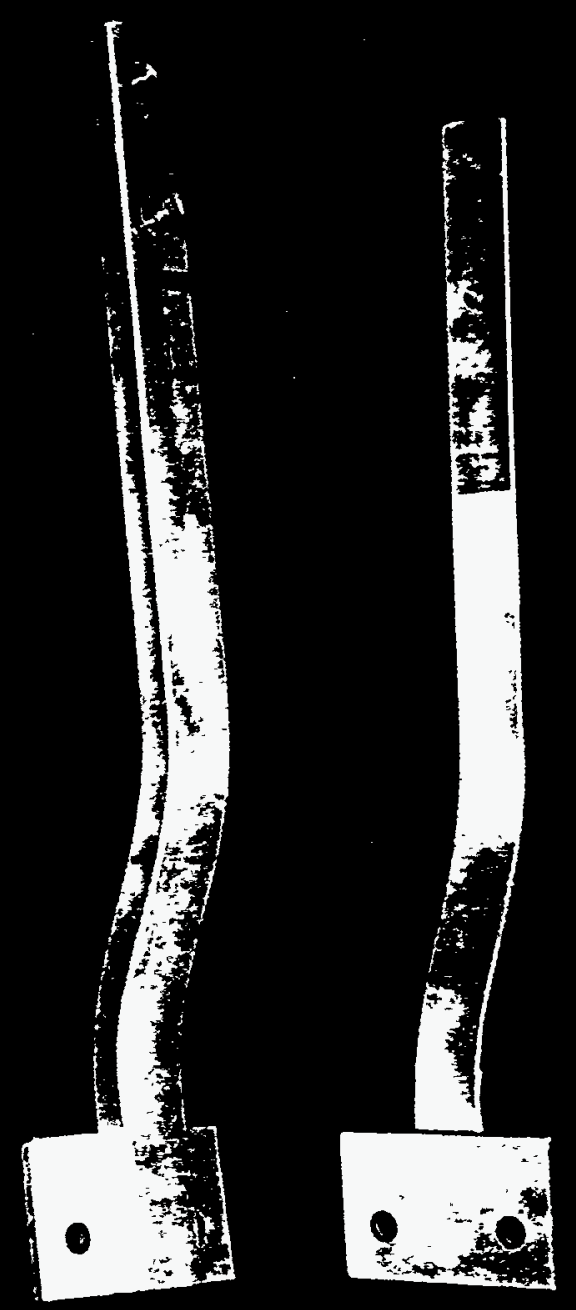

P7727

Figure 3-19 Solid Copper Cable-to-Electrode.Connectors 

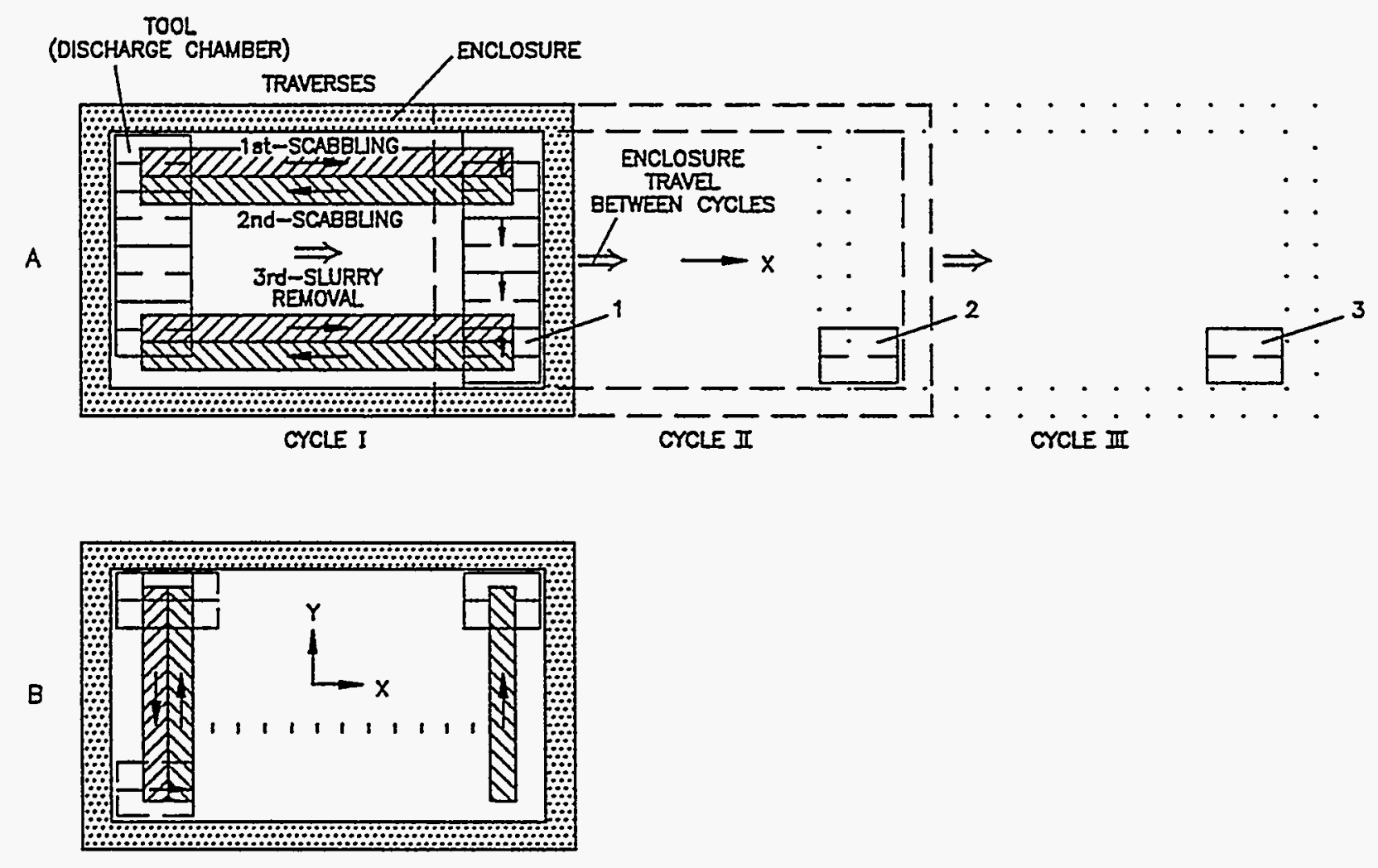

P2922

Figure 3-20 Schematic of Scabbling in Cycle Mode (with periodically moving enclosure) Option A - scabbling with multielectrode (or strip) module moving along $X$ axis; module positions shown at the end of Cycles I, II, III Option B - scabbling with single-electrode module moving along either $\mathrm{X}$ or $\mathrm{Y}$ axis ( $\mathrm{Y}$-axis scabbling shown) 


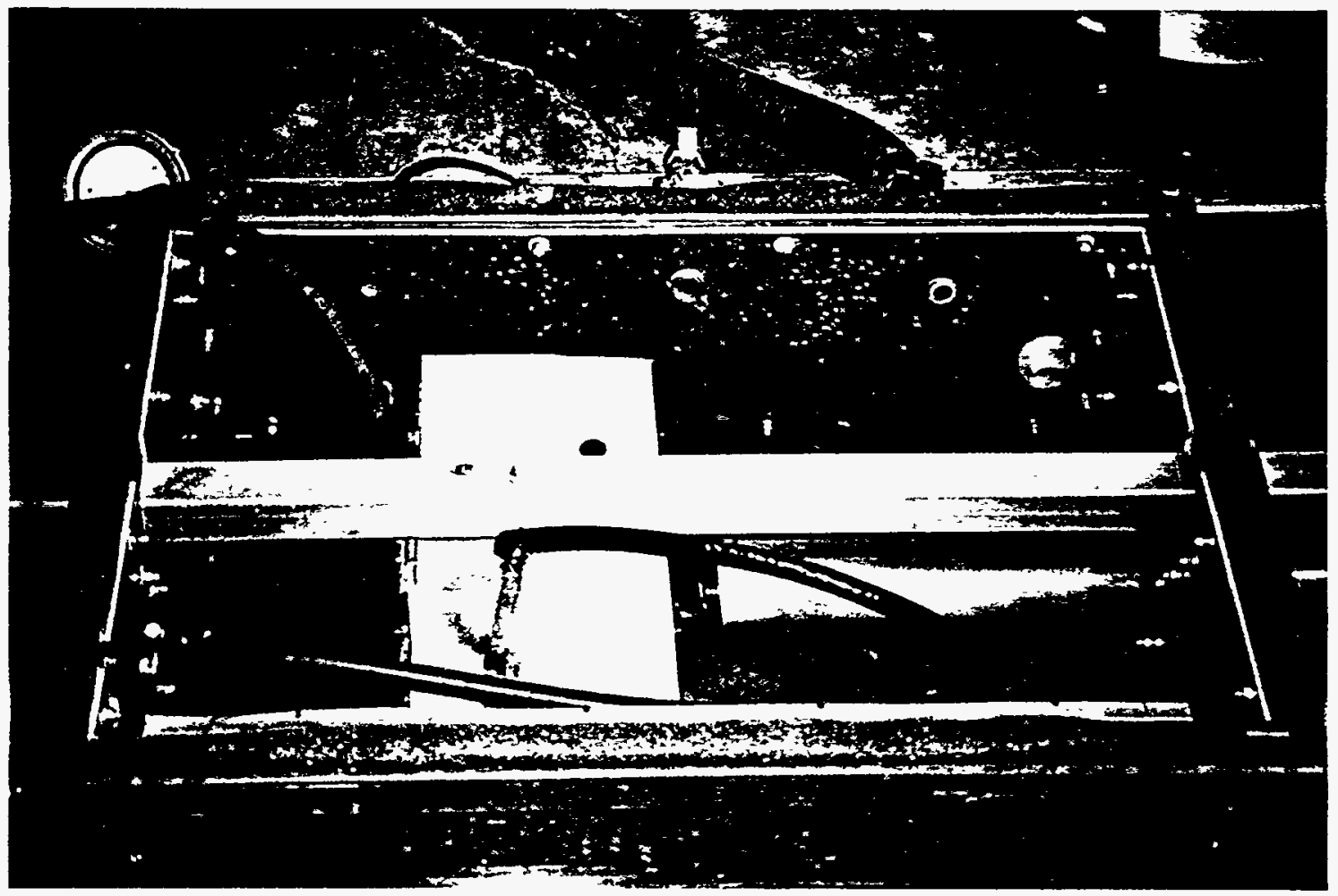

a)

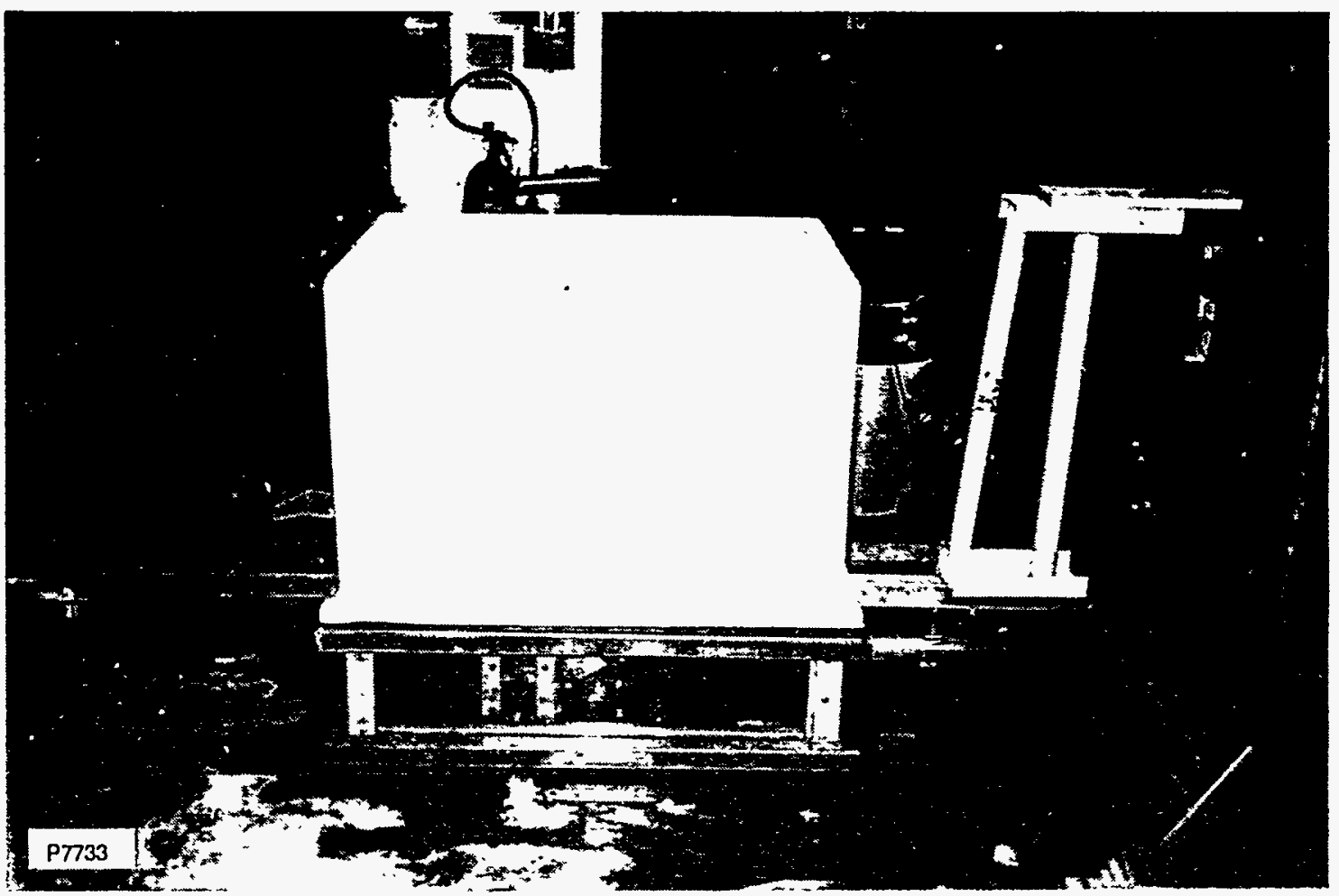

b)

Figure 3-21 First ("small") Water Enclosure/Scabbling Chamber Made for a Cycling Processing:

a) and b) enclosure with an exterior positioner

c) and d) enclosure with an interior electric and pneumatic positioners 


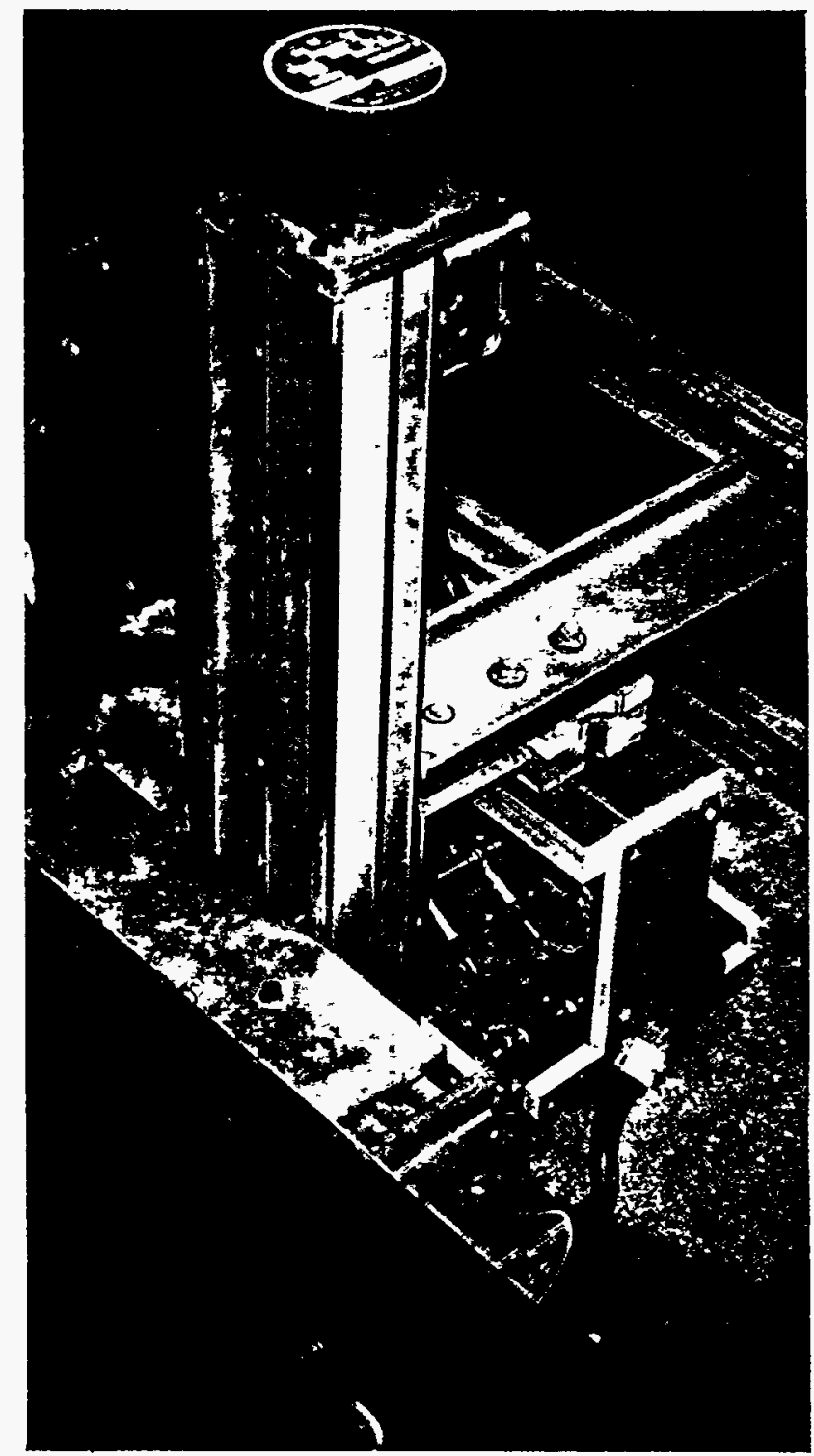

P7728

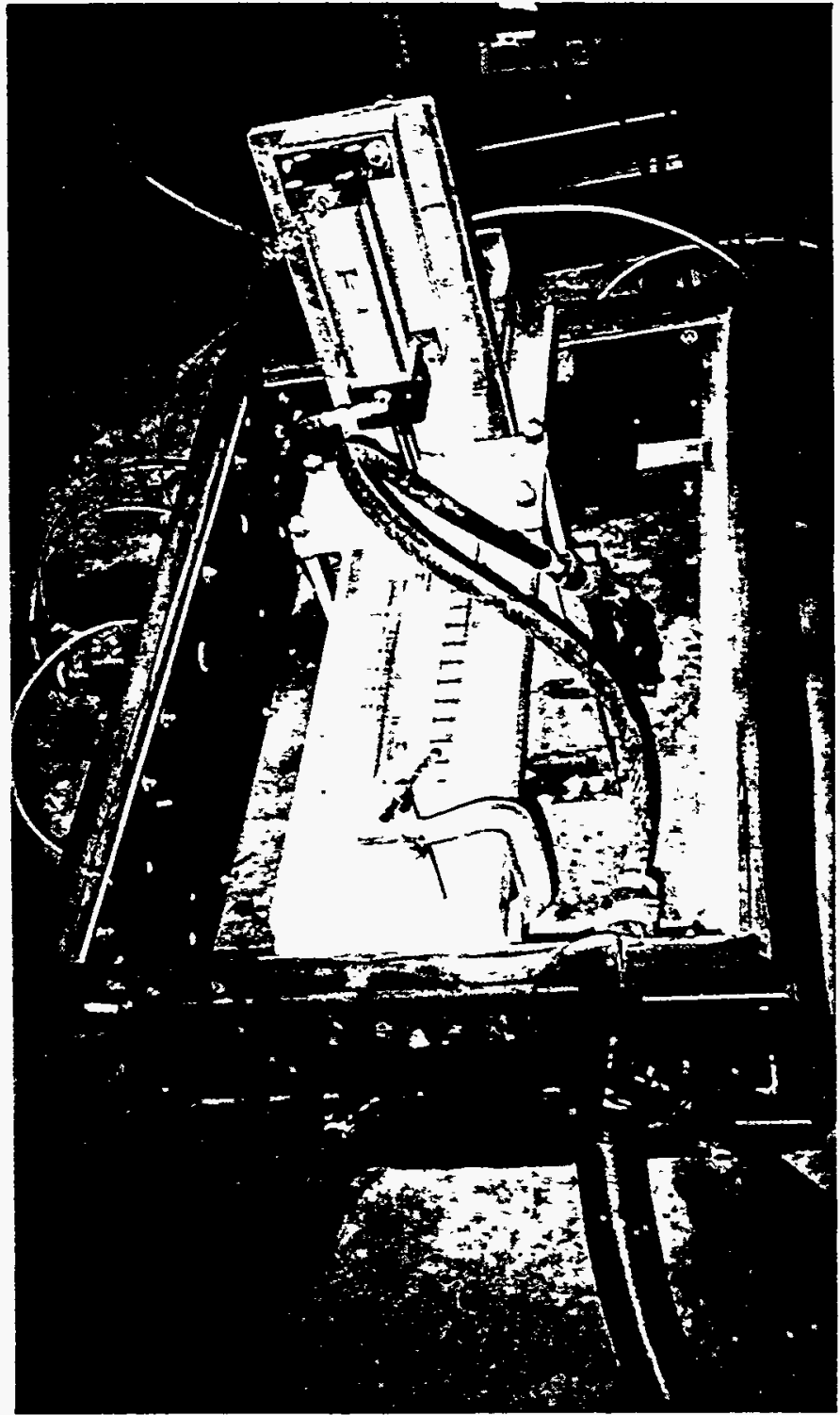

d) 
installed inside the enclosure on a XZ-positioner (see next section). Perimeter gaskets made of polyurethane foam tighten the base of the enclosure against the concrete floor and the plastic cover against the base. Water tightness is enhanced significantly by reducing pressure inside the enclosure using a wet vacuum unit to pump air.

The foam gasket/reduced pressure arrangement performs quite well. Air penetrating through the foam prevents water from leaving the chamber. To avoid water leak, especially over uneven scabbled concrete surfaces, the (negative) pressure in the enclosure should be sufficiently low (below -10"-12" $\mathrm{H}_{2} \mathrm{O}$ ). To reach this condition, the enclosure should be tight and the air blower should be capable of providing sufficient (up to $200 \mathrm{cfm}$ ) flow. With a short, large diameter air exhaust blower (or wet vacuum), a 2-3 HP motor is sufficient. To prevent gasket damage and to prolong their lifetime, the scabbling module should be equipped with waterreflecting screens (baffles).

The second scabbling chamber, shown, for instance, in Figure 3-22 and in many other figures below, was built and used in most scabbling trials at the Everett and Fernald sites. It is larger, stronger, tighter, and more convenient and reliable in operation. The main dimensions of the enclosure proper are 40"x42"x32" (LxWxH). It has a strong, argon arc welded aluminum (6" and 4" angles) frame (shown in Figure 3-23 on a welding stand) and a 1/4" thick G-10 fiberglass sheathing. The bottom perimeter has two rows of 1.5 " steel channels bolted together and holding polyurethane foam gaskets of 2" x 3" cross section (Figure 3-24). The top perimeter has thin rubber gaskets to tighten a $1 / 2$ " thick cover. Two welded aluminum brackets attached to the cover are used to connect (hang) the scabbling chamber with the forklift. Negative pressure (typically $8 \mathrm{H}_{2} \mathrm{O}$ ) inside the chamber is maintained by blower(s) (as in Figure 3-21) or by any other vacuum system capable of providing about $100 \mathrm{cfm}$ air flow. Air pumped from the chamber contains some water as a fine mist. An air filter can be installed on the top cover to remove the water; due to high flow, water is evaporated rapidly from the active filter surfaces (e.g., bag cloth). A HEPA wet vacuum system should be used where required by regulations.

Other design elements of the scabbling chamber are:

- Windows for interior observation.

- Lights for interior illumination.

- Openings for water and air supply hoses, blowers, low- and high-voltage wires and cables.

- Frame - positioner support (made of 8" PVC channels).

\subsubsection{Positioner}

The scabbling module positioner used in the first (small) scabbling chamber has a Model MA4000 UniSlide motor-driven assembly unit by Velmex Inc. (see Figure 3-21). It has a single 4" wide X-slide and a speed-controlled DC motor. A pneumatic cylinder (two-rod Speedair system to prevent cylinder rotation) operating with $50 \mathrm{psi}$ air pressure provides up and down ( $Z$ direction) positioning of the module. 


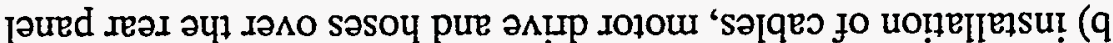

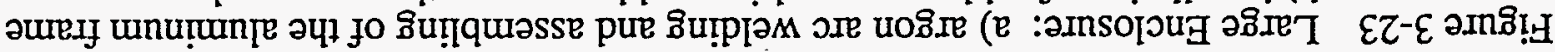

(a

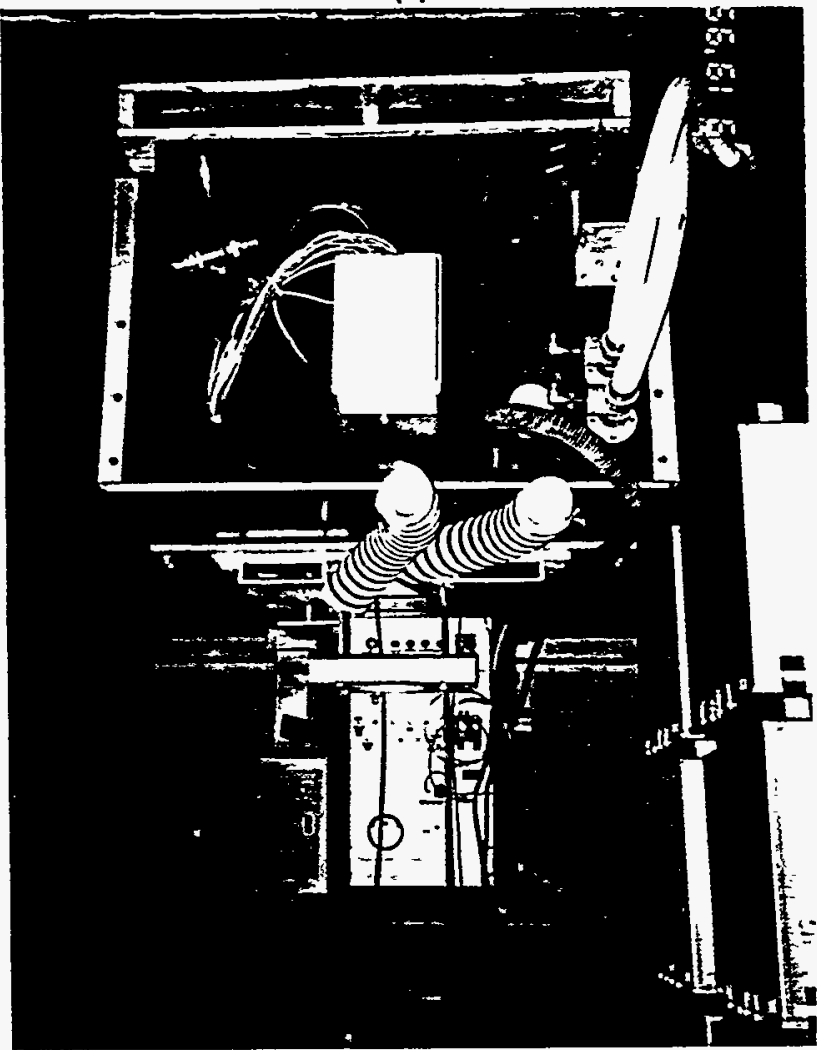

(e

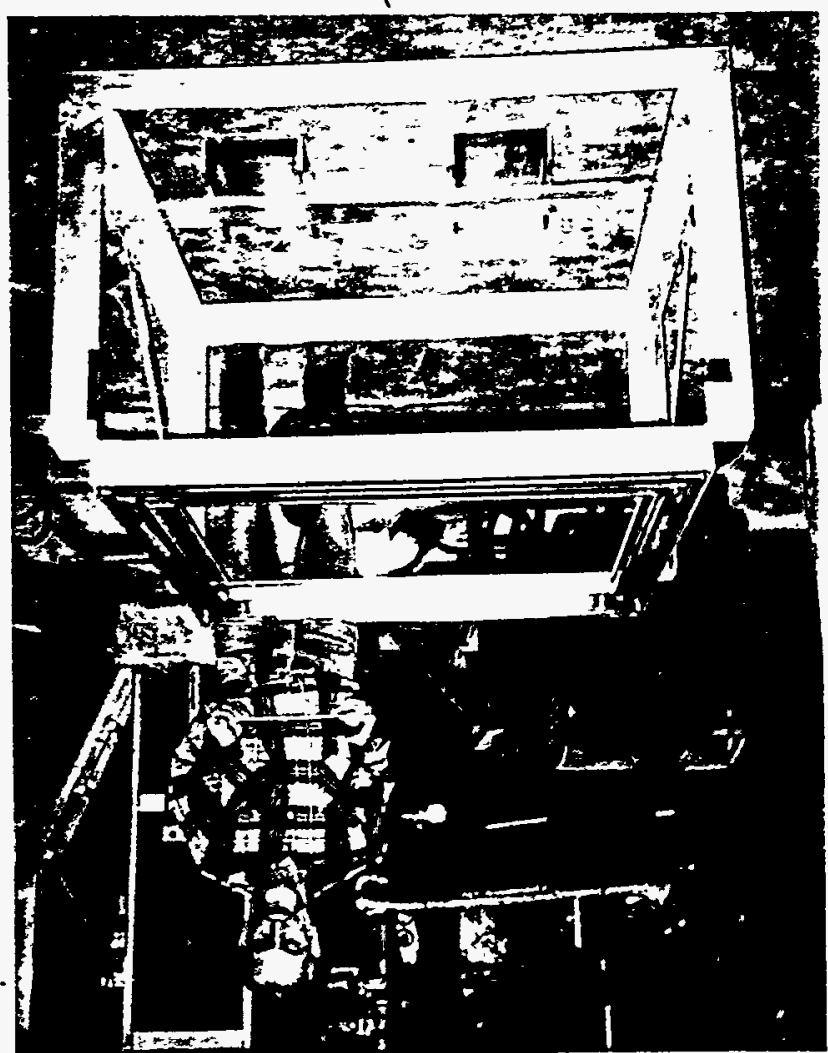

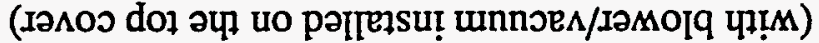

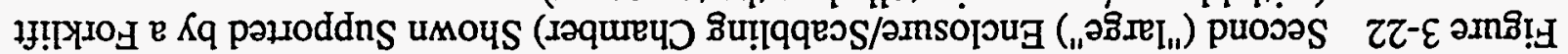

oseld

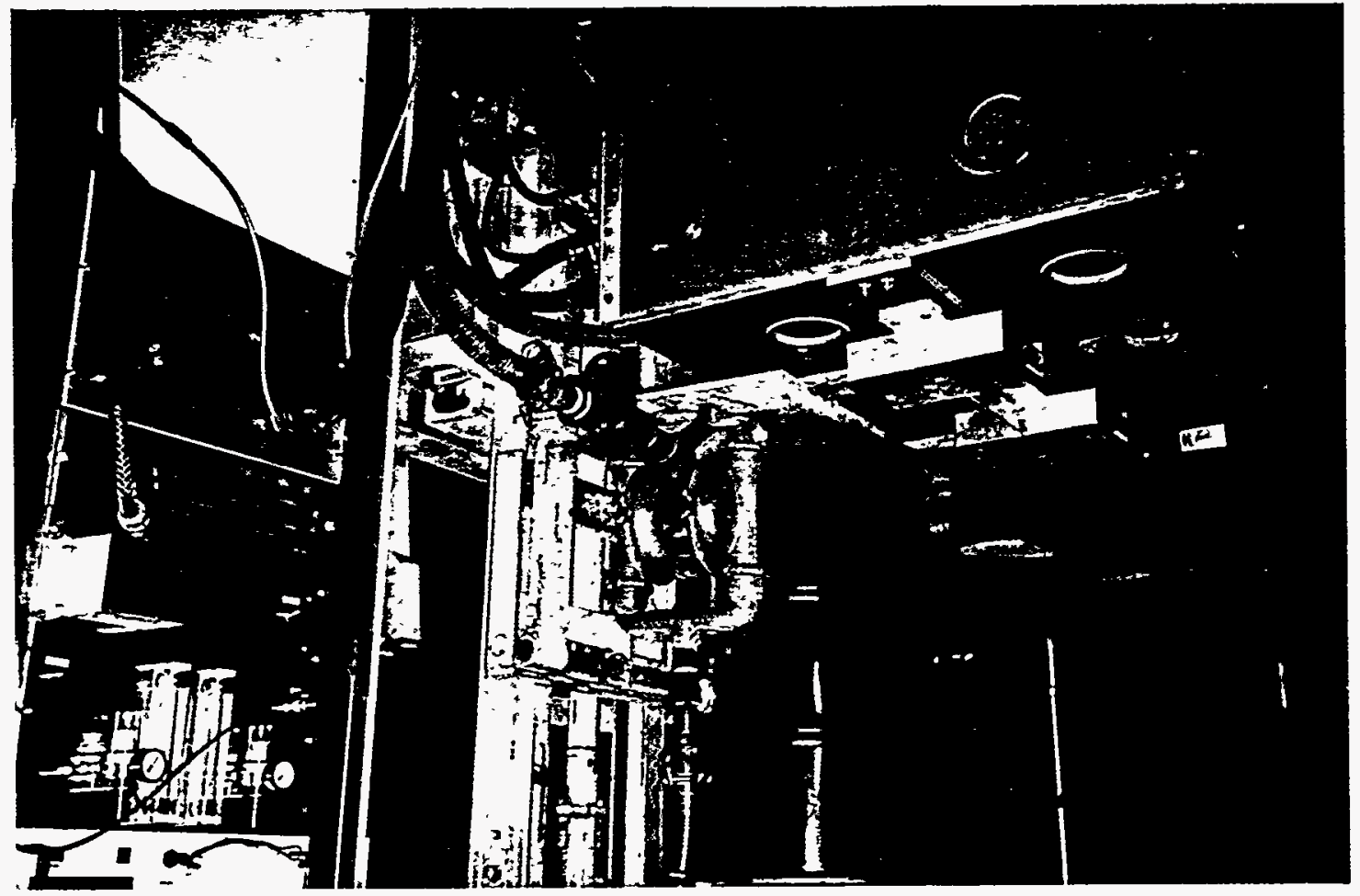




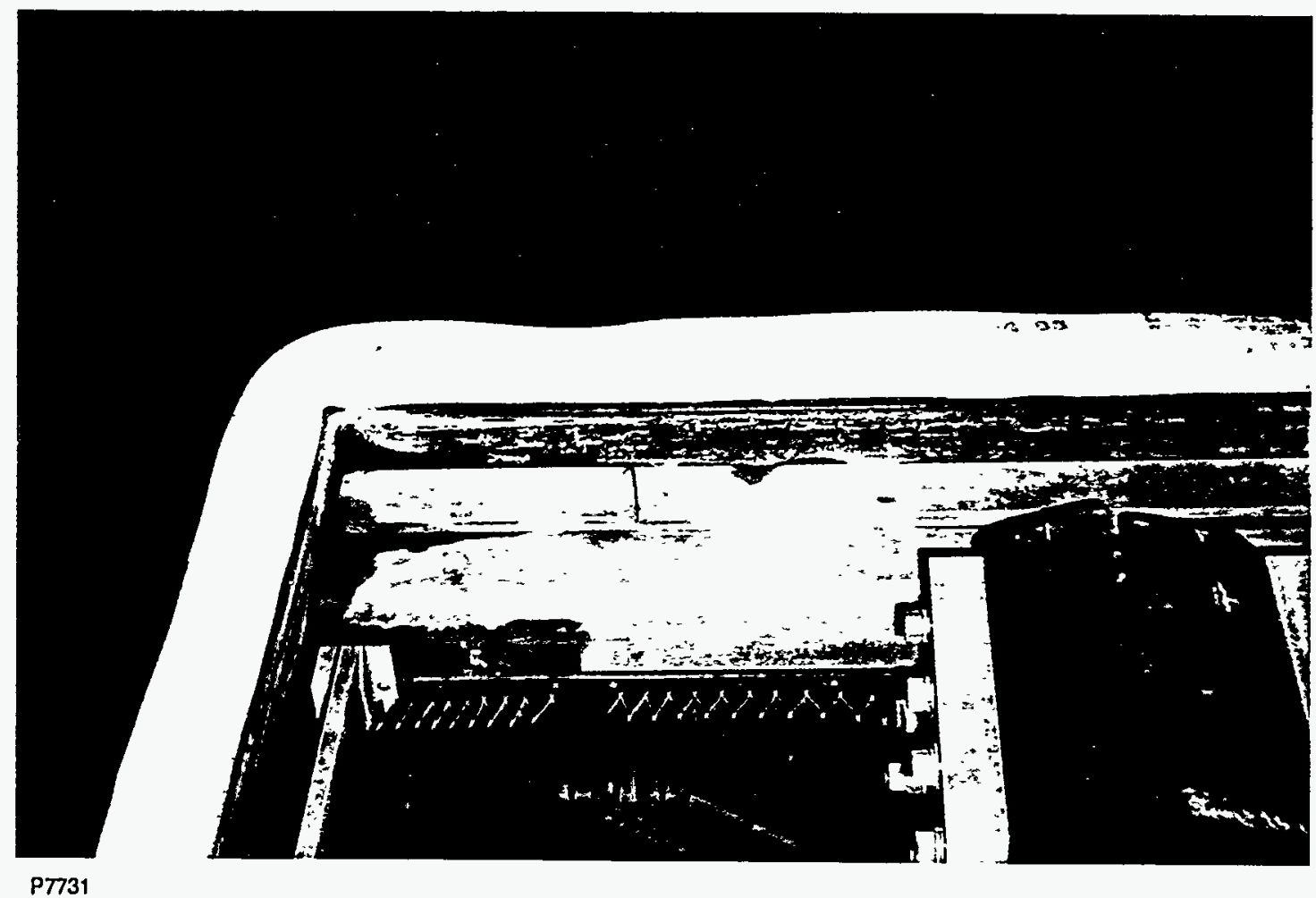

Figure 3-24 Two-Raw Polyurethane Foam Gaskets of Different Density (black and white) Installed in Metal Channels Along Bottom Perimeter of the Enclosure 
A mechanical arrangement of a scabbling module and $\mathrm{XZ}$ positioner inside the second (large) enclosure is shown in Figure 3-25. More mechanically solid positioners are used to support and move much heavier scabbling modules. It is also based on Velmex hardware, but has two coupled Unislides MA6000, 6" wide slides (see Figure 3-26). One of the slides has a variable speed DC motor drive, with the motion of the other slide being belt-synchronized. While two slides provide higher lateral stability, they are more vulnerable to misalignment due to uneven motion resistance (i.e., produced by concrete debris) of the two slides. As in the first positioner, $\mathrm{Z}$ (up and down) travel is exercised by pneumatic cylinders, one of them on each slide.

Total $\mathrm{Z}$ travel of the module is about $2^{\prime \prime}$, the lower position being limited by electrode contact with the concrete surface. While there is a certain freedom of movement at each pneumatic support, good initial alignment is essential to obtain equal electrode/concrete pressure and uniform scabbling over the full electrode length.

\subsection{PROCESS CONTROLS}

The process controls include control of scabbling, module traverses, carriage (forklift truck) transfer, and air/process water/debris flows. At the current level of the system integration and operation mode, some of these controls are concentrated in a separate control cabinet, while others still remain ăttached to specific hardware components.

The control cabinet (Figure 3-27) contains relays and electric actuators controlling operation within each scabbling cycle: timing and duration of pulsing, $X$ - and $\dot{Z}$-steps of module travel. A schematic of this system is shown in Figure 3-28. Parameters that could be preset include pulsing time and number of pulses at each module position, $\mathrm{X}$-traverse speed and time (or X-distance traveled); end switches limiting total travel, signal lights, and solenoid valves and relays controlling compressed air flow are also involved.

Parameters that have to be preset independently include HV voltage, HV pulse frequency, compressed air pressure and flow rate of compressed air used for spark gap flushing, cable cooling and pneumatic cylinder operation.

Control of the positioner's motor drives (or any other electric motors involved) deserves special discussion. An effort was made to employ stepper motors for module positioning purposes. Electronic units are used to control these motors. In more general cases, the PC can be programmed and interfaced to control not only motors but the whole pulsing/traverse sequence. Unfortunately, the electronic units and computer are adversely affected by strong HV discharge. The interfering pulses are propagating both ways - as wireless EM signals, and through AC and control circuits. Very accurate shielding and filtering are required to get rid of these effects. A protection schematic which was shown to be helpful in reducing interference with the motor controller and computer placed in a screened cage is shown in Figure 3-29.

The EM effects are attenuated significantly if HV pulsing traverses and any other motorized operations are separated in time. This fact provides additional justification for stepwise travel of the scabbling module. EM interferences mentioned here do not affect operation of simply-controlled DC motors, but should not be overlooked while designing complete computer-controlled operation. 

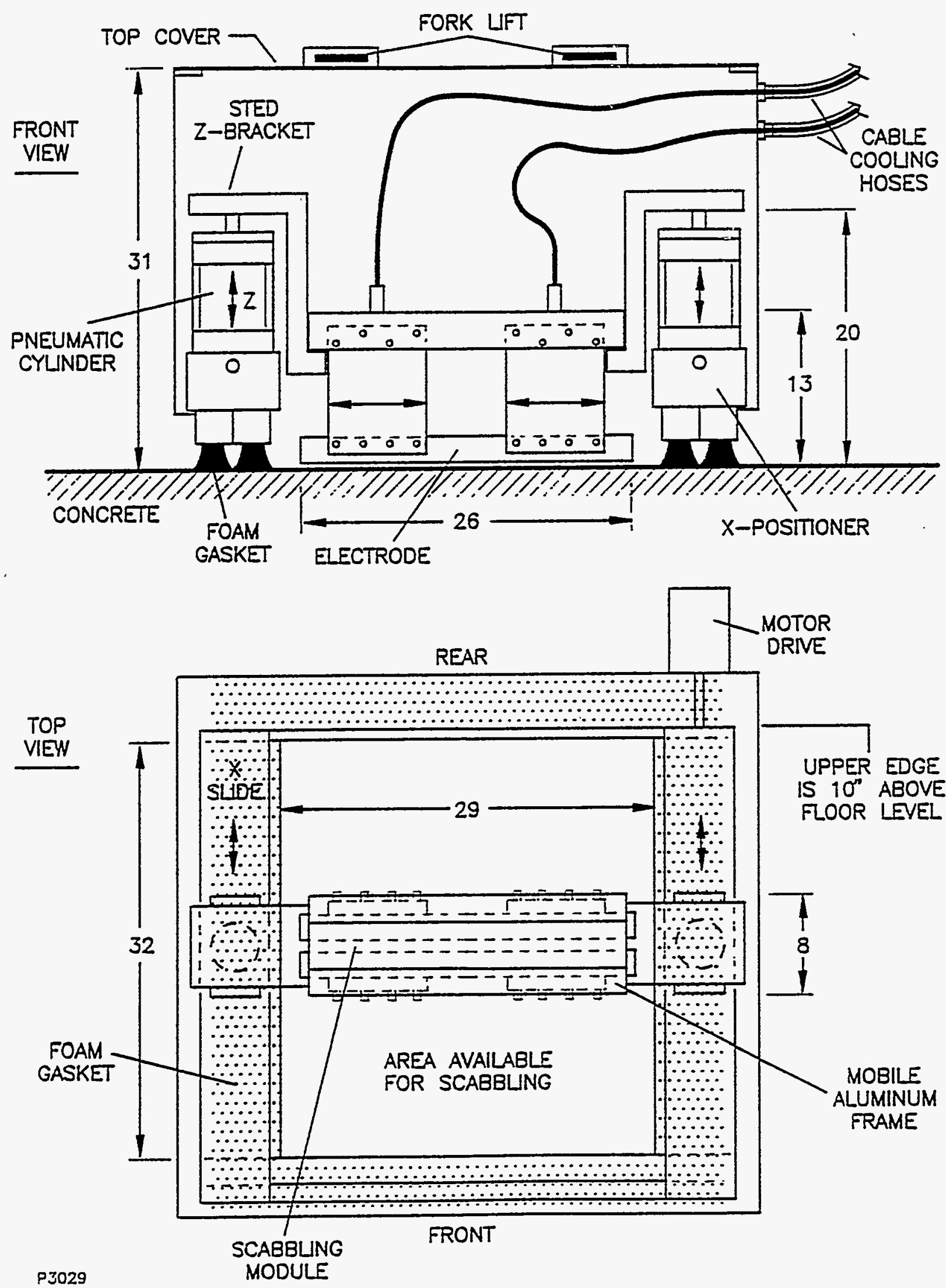

Figure 3-25 Mechanical Arrangement of a Scabbling Module and XZ Positioner Inside the Enclosure 


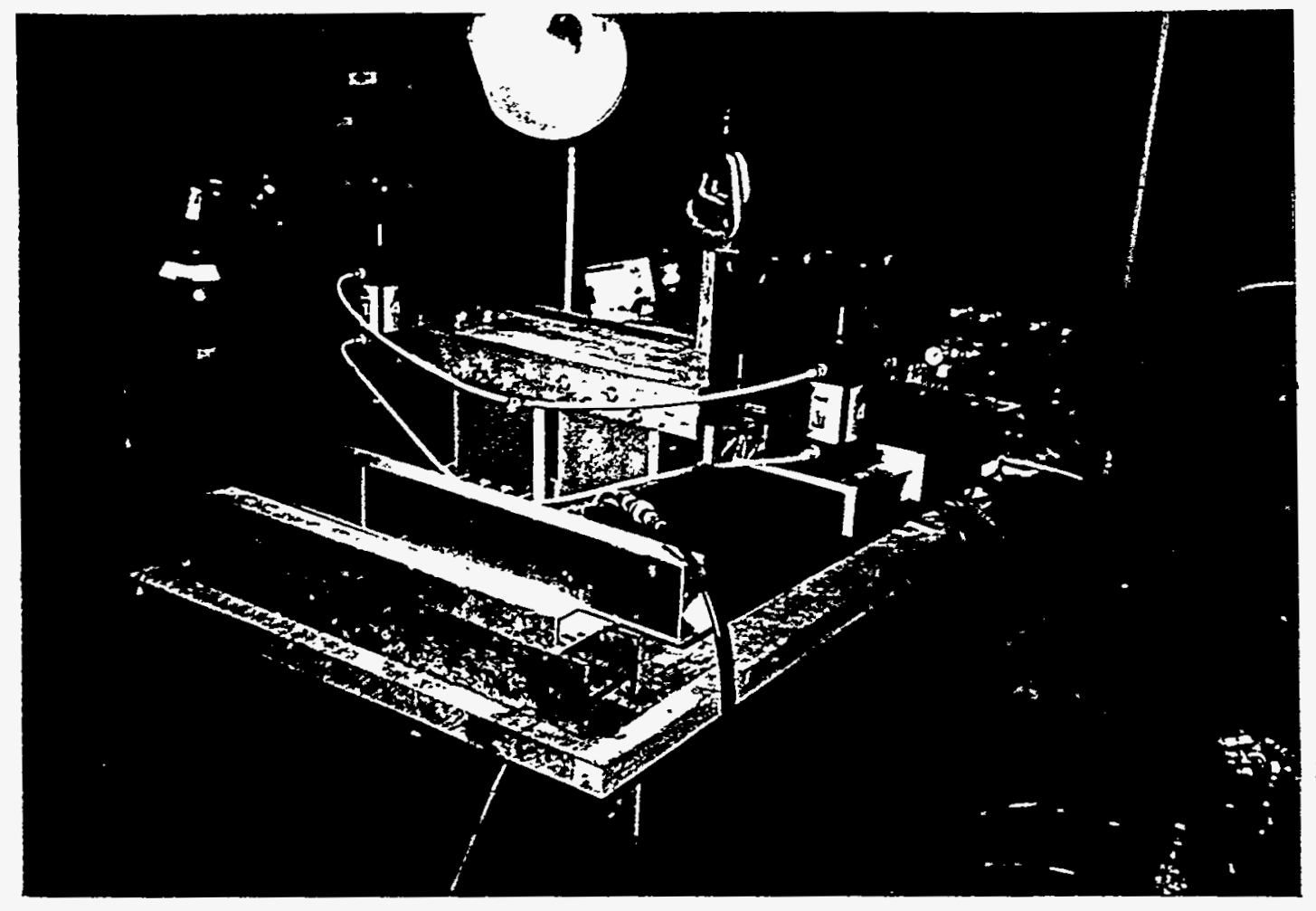

a)

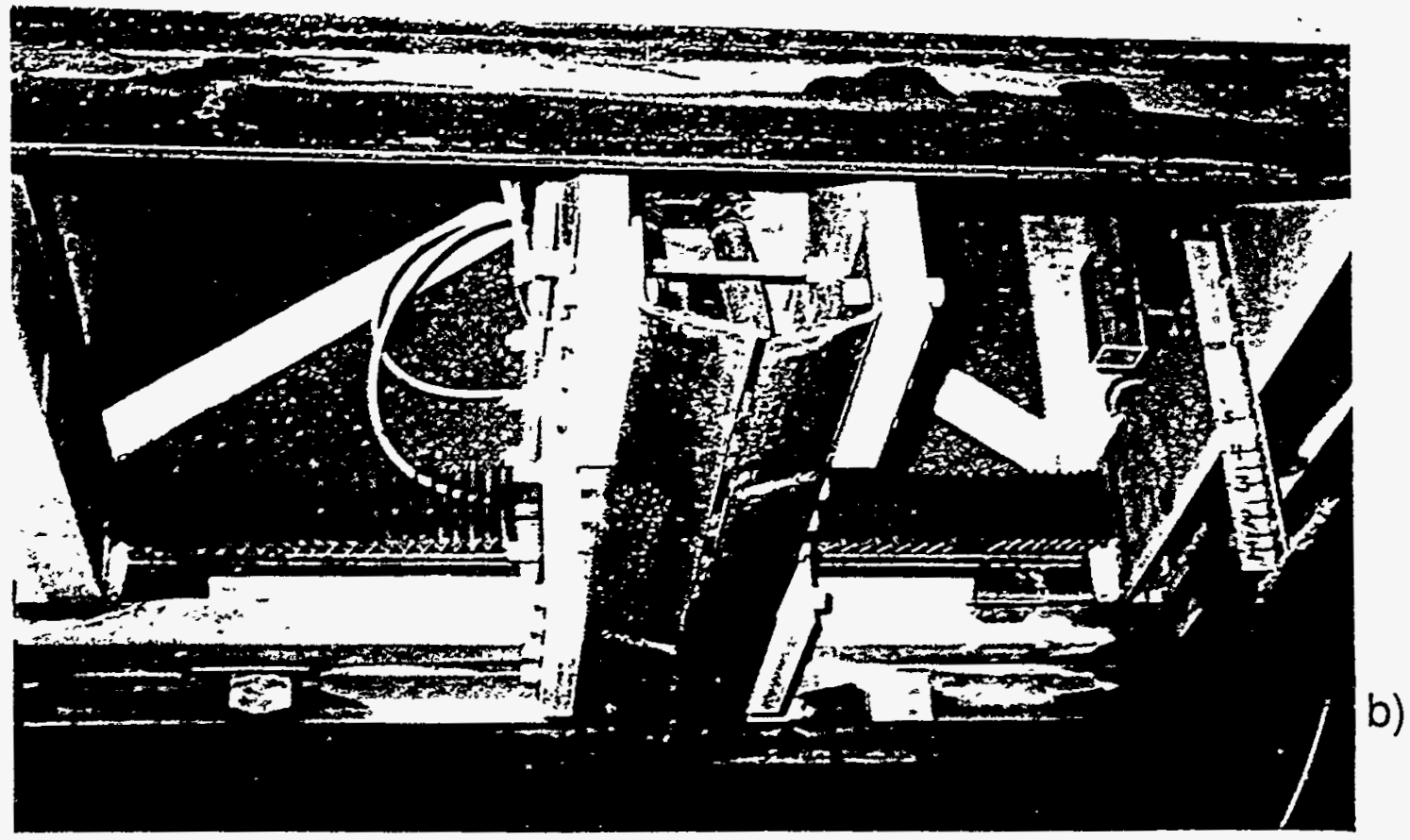

P7772

Figure 3-26 XZ Positioner with Motorized Coupled Unislide X-drive (by Velmex) and Pneumatic Z-drive

a) shown on assembly table

b) installed in the enclosure (bottom view) 


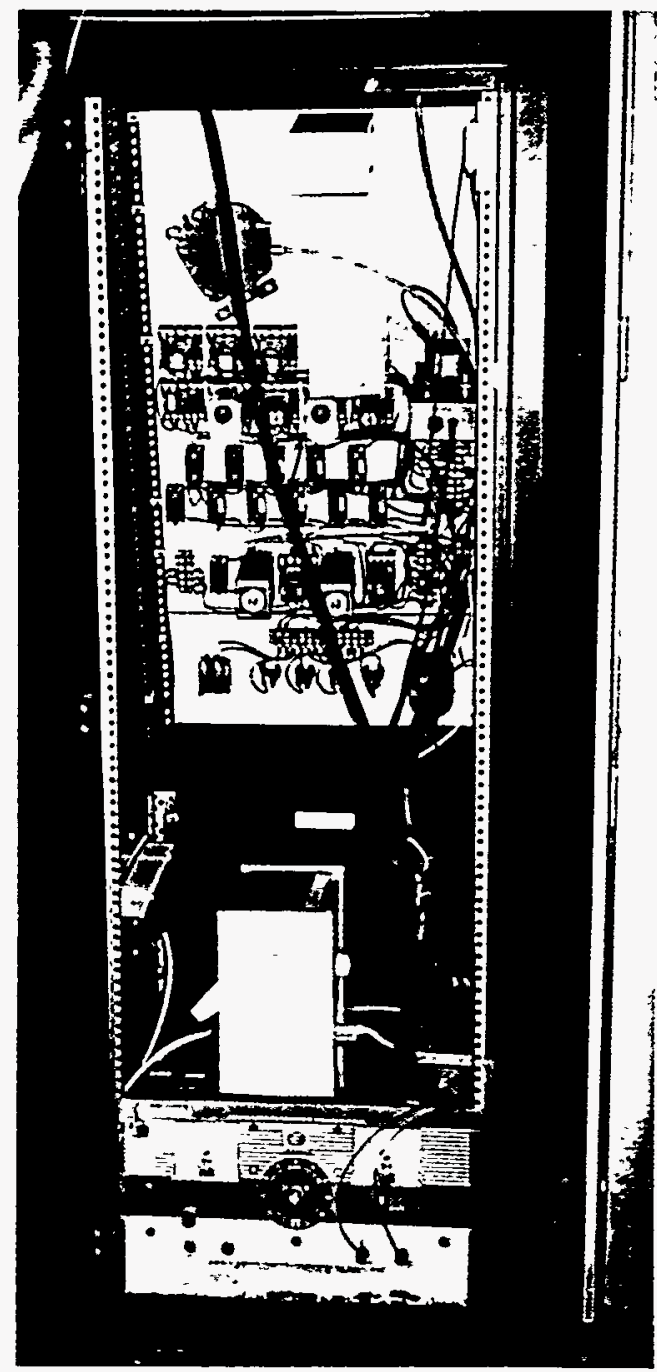

Figure 3-27 Interior of a Process Control Cabinet

\begin{tabular}{|l|l|l|}
\hline$S_{1}$ & Power ON/OFF & \\
\hline$S_{2}$ & Limit Switch & \\
\hline$S_{3}$ & ON/OFF/ON Switch & \\
\hline$R_{1}$ & Relay - Potter Brumfield & KRP14AN \\
\hline$R_{2}$ & Relay & KRP14AN \\
\hline$R_{3} \cdot$ & Relay & KRP14AN \\
\hline $\mathrm{D}_{1}$ & Time Delay Relay & X1OMINOMRON \\
\hline $\mathrm{DD}_{2}$ & Time Delay Relay & X1MINOMRON \\
\hline
\end{tabular}

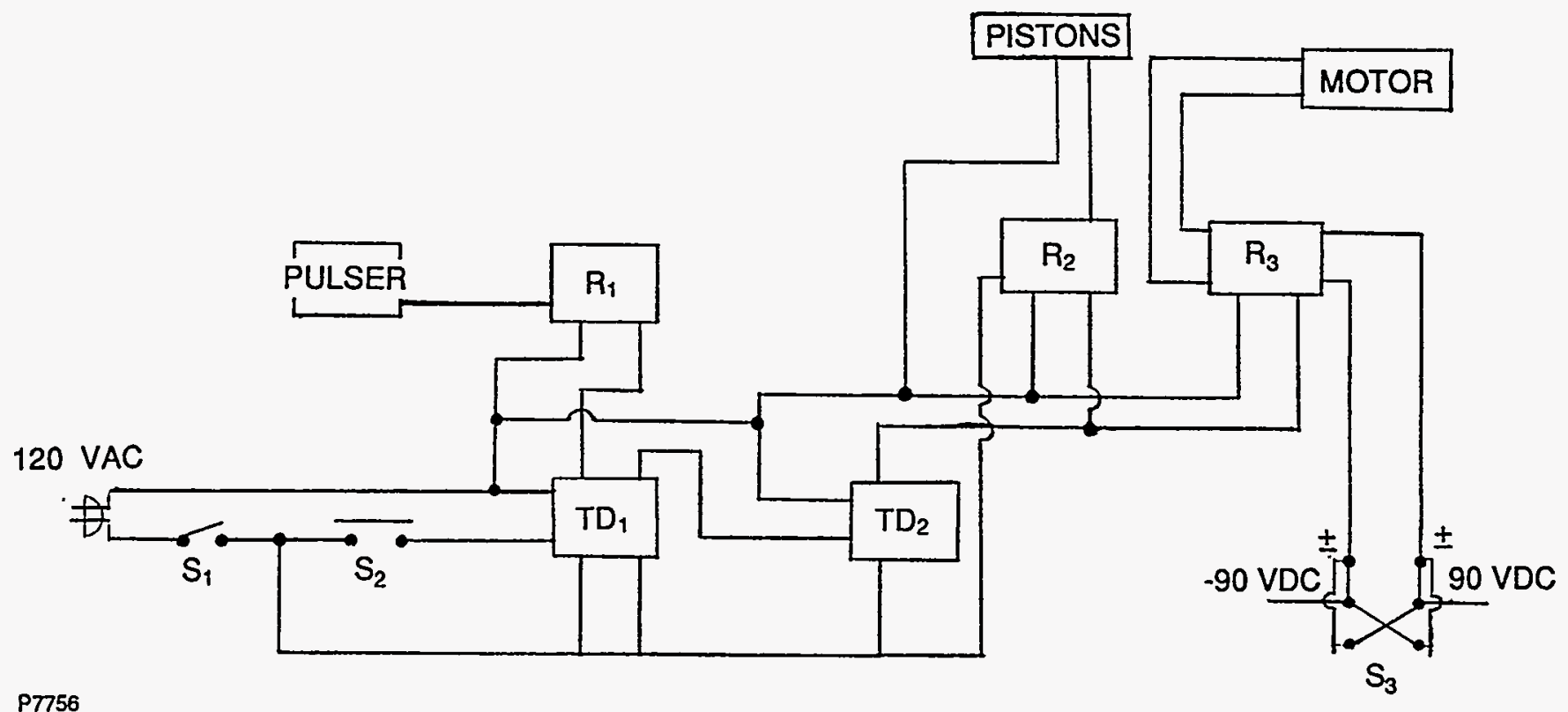

Figure 3-28 Electric Schematic of a Process (scabbling and positioning) Control System 


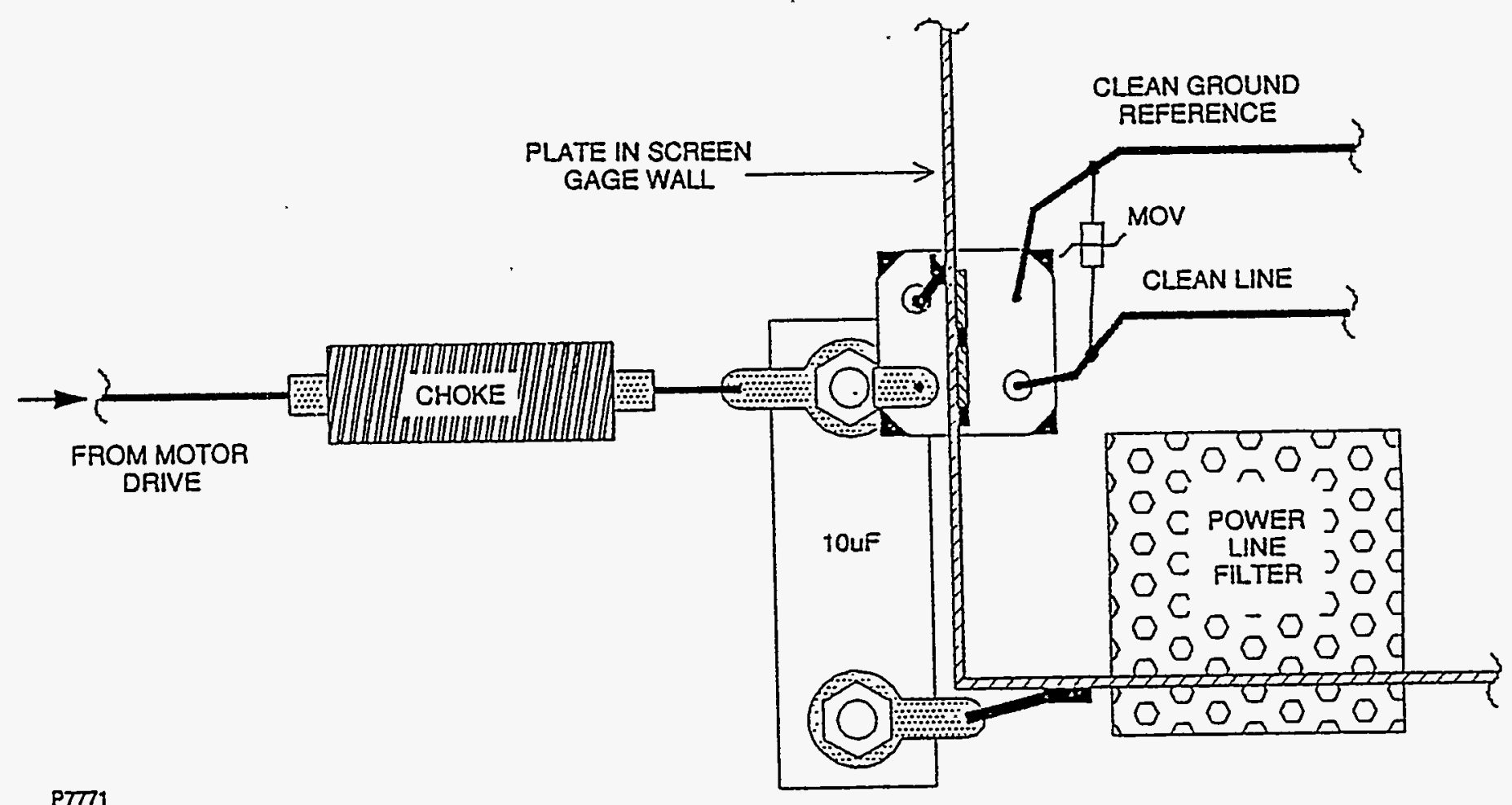

Figure 3-29 Electric Circuit used to Protect Motor Controller and Process Computer from the EH Discharge Interference 


\subsection{PROTOTYPE EHS SYSTEM DESIGN \\ B Water and Waste Flow Subsystem and EHS Carriage}

\subsection{GENERAL CONSIDERATIONS}

The EHS process takes place in a water medium. The water layer transfers pressure pulse and cavitation action to concrete, prevents damaging and useless electric breakdown through air, eliminates dust formation, and assists in removal of concrete debris. On the other hand, process water, if it contains contaminants which can not be completely and easily separated (which is almost always the case), adds to the total amount of waste. Therefore, the amount of water participating in the scabbling operation should be minimized. Even if the process water is recirculated as in Figure 4-1 schematic, for instance, losses are inevitable: some water is lost as droplets in the air pump from the enclosure, but most of the loss is with wet debris remaining over the scabbled floor area. When the debris is collected and transferred into a collection drum, water is separated by filtering under pressure or pump suction. Still, some water remains with wet debris and cannot be, at least in real processing time, returned into the scabbling chamber.

For short scabbling operation, the total amount of water in the system is most important. Practically, the total amount of water should be 1.5-2 times the amount of water in the scabbling chamber, which, for a given footprint area, depends on the water layer depth. The depth, in turn, depends on the design of electrodes and cable connectors which must be completely submerged.

With the current module design, the water layer depth is about 4", which results in about 9 liters (2.5 gal.) of water over one sq. ft. of concrete surface. Accordingly, our main scabbling chamber contains 100 liters ( 26 gal.) of water, and the total amount of water in the system is 40 50 gal., (conveniently matching a standard drum).

With recirculation, the necessary amount of makeup water is more important than the total amount. Under steady state conditions, i.e., for sufficiently long continuous operation, the fresh makeup water* is equal to the water loss. The recirculation coefficient (efficiency) is defined not by loss only: if the contaminant, or part of it, is soluble in water, or removal of fines from the return water is not complete, multiple recirculation may be limited by possible recontamination of concrete by the process water which accumulated a high concentration of the contaminant. The allowable degree of recirculation, minimum makeup, and amount of liquid waste generated by the scabbling process all depend on the nature and concentration of the concrete contamination.

\subsection{DESIGNS OF THE WATER FLOW SYSTEM}

Several modifications of the water flow system were used. In the experiments involving the small scabbling chamber, fresh water was released from a container and gravity-fed into the enclosure. After scabbling completion, water, together with fine debris passing a pump filter, was returned into the container using a small sump pump (submersible, with a minimum of $1 / 8^{\prime \prime}$ water pickup). After gravity-separation in the container, the process water could be reused. The remaining heavier debris was removed manually by a wet (shop) vacuum cleaner.

\footnotetext{
*It may be feasible to reduce the loss by extracting water from the concrete debris using some duration process, collecting extracted water and using it for the makeup.
} 


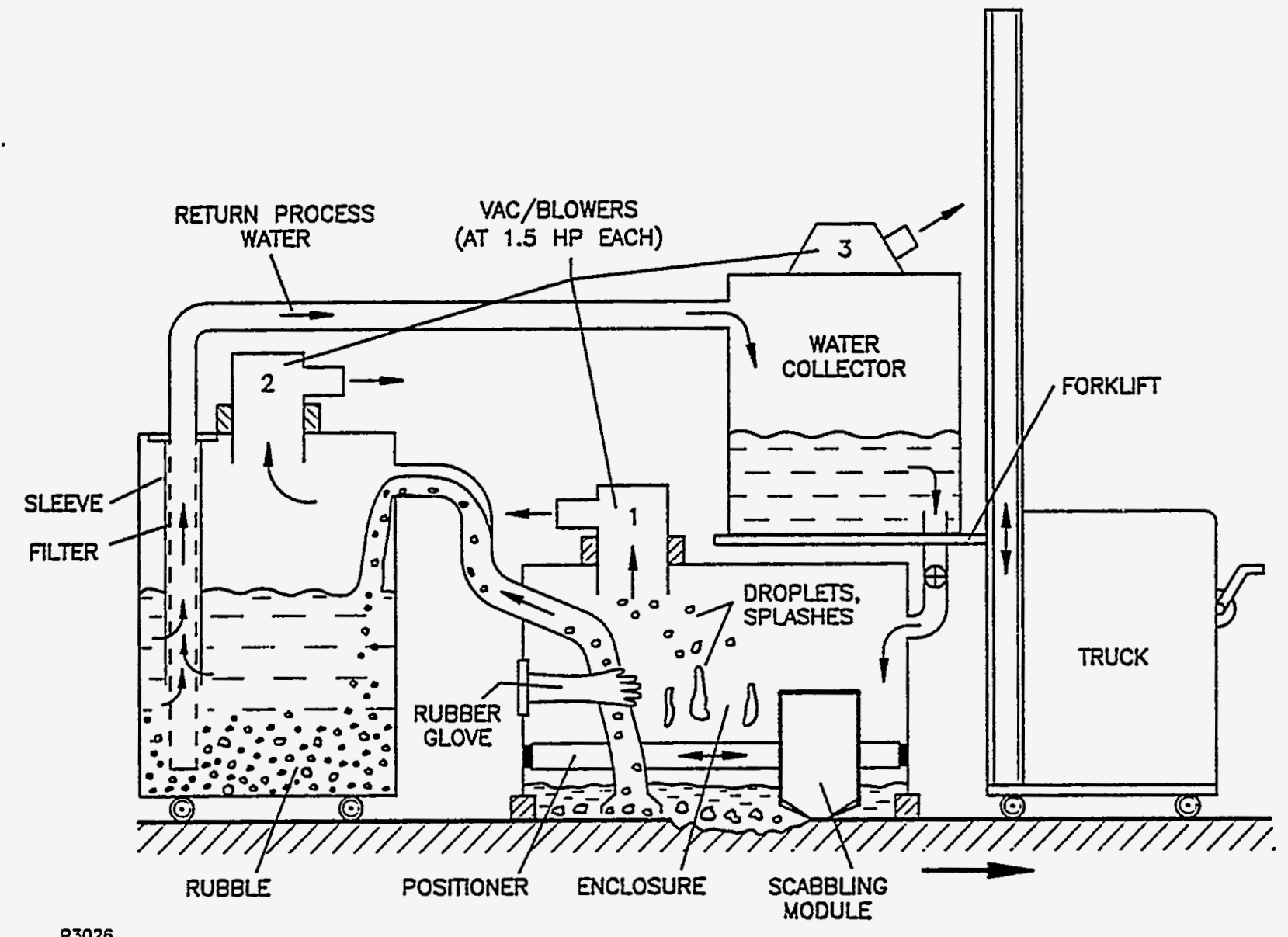

Figure 4-1 Schematic of Water/Debris Flow System for a Large Scabbling Chamber (the first two-container version) 
A somewhat more complete flow system shown schematically in Figure 4-1 was used in combination with the large scabbling chamber. In this arrangement, a 25 gal. fresh water container is placed on a platform attached to a forklift. Water is fed into the scabbling chamber by gravity. The process water is returned into a 55 gal. drum, pumped out by an air blower/vacuum. A collecting nozzle of the return hose can be moved manually over the scabbled segment to enhance removal of the concrete debris. A water filter (Filterite $3^{\prime} \times 2^{\prime \prime}$ cartridge) is placed off axis in a sleeve, admitting water into the lower part of a coaxial gap between the sleeve and the filter. Process water is sucked through the filter and returned into the upper water collector using suction provided by the second vacuum unit. Total (nominal) power of the two blowers is $3 \mathrm{HP}$.

The next flow system modification step involved a return to a more compact, forklift mounted, one water container configuration shown in Figure 4-2 schematic and in Figures 4-3 and 4-9 photos. The single 55 gal. drum/container supplies fresh or returned process water into the scabbling chamber; an air-driven diaphragm pump (also placed on the forklift) is used to provide pressure drop across the filter in the drum. After redirecting flow with a combination of two- and three-way valves, the same pump collects water and a fine fraction of concrete debris from the processed concrete floor and returns them into the drum. Coarse debris (larger than $1 / 8$ " not tolerated by the pump) is either not picked up by the stationary nozzle, or is settled in the in-line strainer.

This last modification was used during field experiments at Fernald. Some improvements to this system are straightforward:

1) A somewhat higher capacity (flow and pressure drop) diaphragm pump tolerable for larger size (e.g., 1/4") debris would be more reliable and capable of removing more debris with the water flow. Alternatively, when processing of specific concrete by the EHS generates mostly fine debris, a more compact, e.g., centrifugal, pump can be used.

2) Manually-operated valves should be replaced by air- or electrically-operated ones with appropriate relays incorporated in the general control system.

3) The system, including hoses, fittings, and valves, should be made more compact.

\subsection{REMOVAL OF EHS-GENERATED CONCRETE RUBBLE}

Removal of rubble (debris) constitutes a separate technical problem associated with $\mathrm{EH}$ concrete floor scabbling. Whereas suspended fine debris can be easily removed together with process water, removal of coarser rubble can be achieved only by strong suction provided locally by nozzle or scoop scanning the scabbled surface and reaching close proximity of the individual pieces of rubble. This procedure, even conducted after the scabbling cycle is completed, would require an auxiliary positioning device and complicate the module design. A regularly observed tendency of the debris is to form dense deposits along the perimeter of the enclosure bordering the foam gaskets. This deposit is especially dense and sticky when the concrete surface has a residual organic surface contaminant, e.g., oil.

Measures to prevent formation of these deposits (e.g., continuous directed water circulation, shielding of enclosure edges by baffles, wetting and/or turbulization and entraining of the debris in water with simultaneous strong suction) are envisioned, but it is doubtful that a reasonably simple and energy-consuming device is capable of removing all debris from within the scabbling chamber. While we are not excluding the possibility of designing and incorporating a sophisticated debris removal device in the future, we suggest, for the time being, that we subdivide the whole scabbling/rubble removal process into two sequential operations. In 


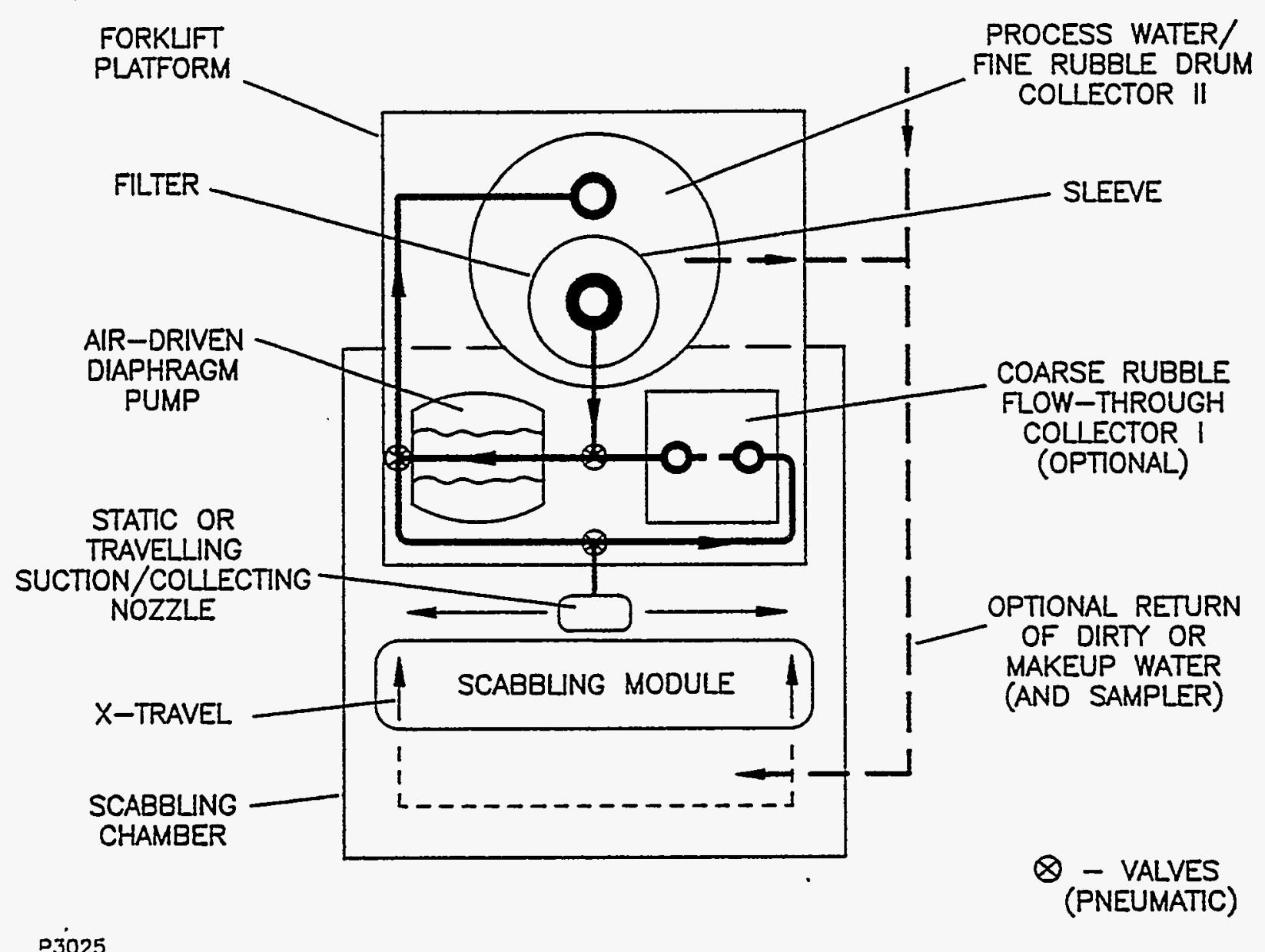

Figure 4-2 Single-Container Water/Debris Flow System (top view schematic) 


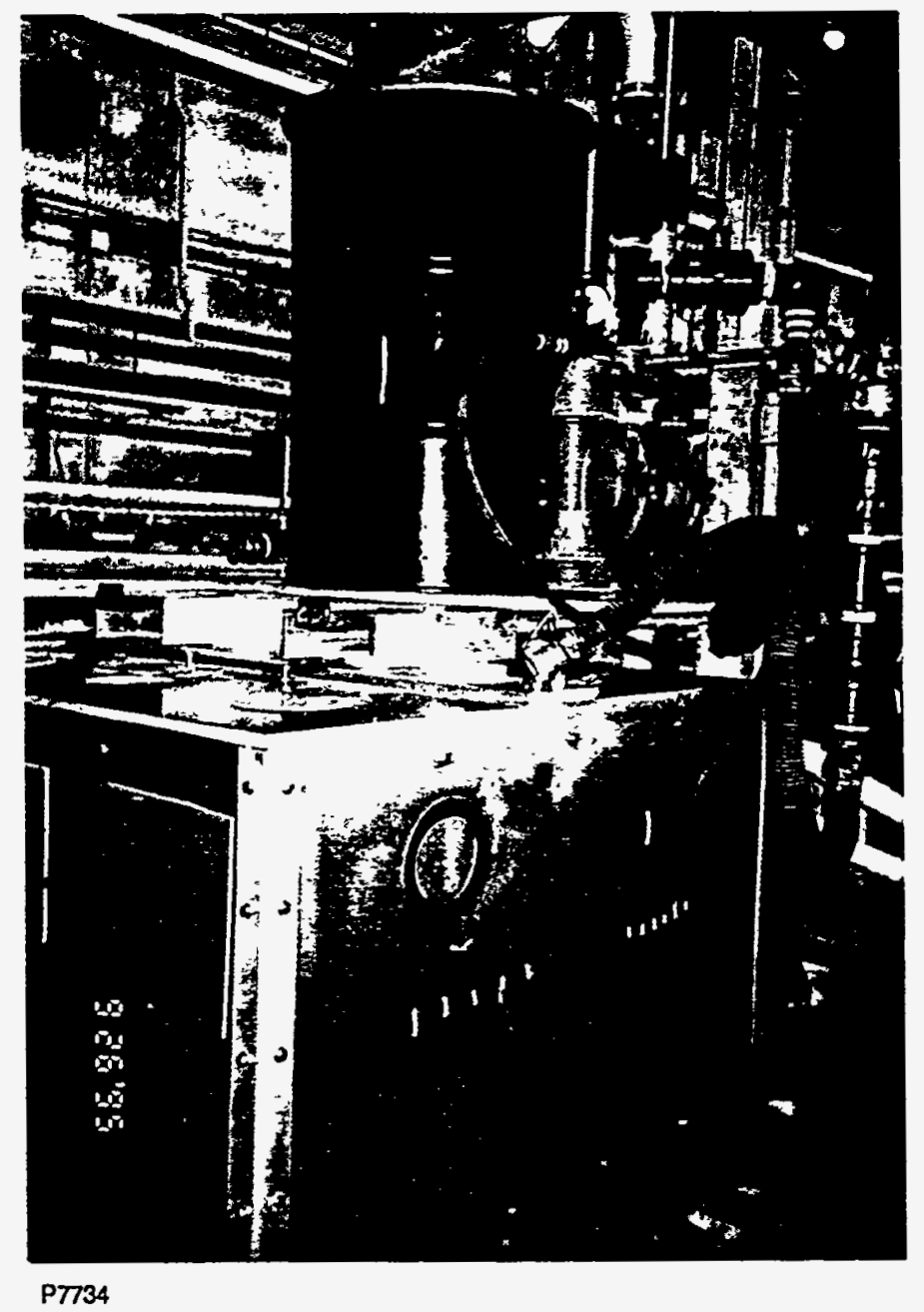

Figure 4-3 Single-Container Flow System Mounted on a Forklift 
this operating mode, the coarse rubble fraction is removed from the floor only after the floor surface, scabbled and basically free from water and fine debris, is made accessible by transferring the scabbling chamber to the next processing area (floor segment).

Under these easier conditions, the debris can be removed and transferred into a proper container (common with process water or separate) using an independent manually operated or, better, a mechanized wet vacuum unit equipped with a required exit air filtering system. If necessary, debris removal can be enhanced by using a vacuum system equipped with rotating brushes (or even a scraper). To prevent dust formation, the cleaning should be accomplished when the debris is still wet. It may be necessary, though, to finalize the cleaning after the surface is already dry: the heaviest sand particles tend to "hide" in "caves" formed in the concrete by scabbling. A strong suction provided by a high velocity nozzle is needed for removal of a limited number of these particles. It would be useful to accompany this finishing procedure by scanning ("frisking") the surface with a radioactivity counter.

The concrete debris removal procedure described here was tried at the Fernald site. A Radvac 2000 vacuum unit, equipped with a HEPA filter, was used to remove the debris (see Section 6 for more details).

\subsection{WATER/WASTE FLOW SUBSYSTEM SUGGESTED BY PENTEK}

Pentek, Inc. (Coraopolis, PA) was awarded a subcontract to design, fabricate, integrate, and test an "onboard" waste processing subsystem for the EHS process. The baseline design assumed a batch processing of waste, with the waste processing cycle commencing subsequent to the scabbling process. The system would require control of initial water levels, with subsequent collection of the waste slurry, separation of the waste products, and filtration of the water for recycling during the next batch operation. Sufficient water is to be stored in the system to allow for loss due to leakage, holdup within the slurry matrix, and evaporation. The subsystem would be composed of:

- Recirculation pumps, valves, filters, tanks.

- Scabbling chamber water level controls.

- Subsystem controls, safety warnings and alarms.

- Subsystem shutdown functions

- Pickup and recirculation discharge devices integrated directly into the scabbling chamber.

The complete subsystem was to provide the advantages of an integrated treatment of air, water, and waste flows of a basically closed-loop operation combined with a scabbling chamber vacuuming and filtration of the air exhaust. It was also envisioned that the system would be sufficiently compact to be placed on the forklift truck (EHS system carrier).

A preliminary design of the water/waste flow loop was developed by Pentek and discussed at a Pentek/TSD meeting in January 1995. It has been mentioned that the suggested subsystem has very high power requirements for its main drive - $90 \mathrm{psi}, 270 \mathrm{cfm}$ air compressor. The $\sim 100 \mathrm{HP}$ dedicated compressor would consume five times more energy than the scabbling process itself. Nevertheless, bearing in mind the possible future improvement (e.g., replacement of the air drive by a more economical and compact electric drive), as well as prospects for using the same or similar waste management subsystem together with a EHS unit of higher capacity, the concept and main features were approved as a design basis. 
A partially completed flow subsystem underwent limited testing at TSD in May 1995 (see Section 6). Some subsystem components can be seen in Figure 4-4; they have separate supports and are not organized as a unit. After certain shortcomings were revealed, Pentek withdrew the equipment for repairs and modifications.

The modified flow subsystem, delivered by Pentek to the TSD site for integration and further testing (see Figure 4-5), involved a few changes. It had a:

- larger water storage volume;

- a frame, holding some subsystem components on the forklift;

- separate mobile support for venturi air drive.

As in the first version, the waste collection drum remained as a separate unit. The whole unit still occupies a large floor space, far from being compact. Limited testing of this modification is described in Section 6.

\subsection{EHS SYSTEM CARRIAGE - FORKLIFT TRUCK AND SYSTEM INTEGRATION ISSUES}

To provide for convenient EHS system transfer between the sequential scabbling cycles/floor segments, as well as for transportation within various facility locations, it is desirable to arrange all, or at least most, of the EHS system components on a self-propelled carriage. After considering several other options (see, for instance, a system configuration shown in Figures 4-6 and 4-7, as well as some others suggested in the Phase I report), it was decided to use a forklift truck as the main carriage. There are several factors in favor of this carriage choice for at least some of the scabbling tasks:

- The forklift truck is standard, inexpensive equipment readily available at most sites.

- A variety of forklift makes, which do not differ substantially from each other, are common; if necessary, they may be modified to accommodate the system (or, vice versa, the system configuration can be modified to fit the forklift).

- In addition to providing travel in the horizontal direction, the forklift provides vertical travel which can be used for inspection, adjustment, and repairs of the scabbling module, for inspection of the concrete surface, and to access and remove concrete rubble.

Figure 4-8 illustrates one of the possible arrangements of the EHS subsystems on the forklift truck base. Alternatives include mounting the PFN section of the power supply (capacitors and switches in the first place) on the forklift above the scabbling chamber to shorten HV cables and reduce inductance of the discharge circuit. With this option, DC chargers and process controls would remain at remote locations. On the other hand, a rubble collector (e.g., interchangeable drums) may be positioned on a separate platform or truck.

An operating mode considered earlier assumed that module movement within the scabbling chamber and the chamber travel between sequential floor segments is executed by two different mechanisms - positioner and truck drive. The same was assumed to be true with respect 


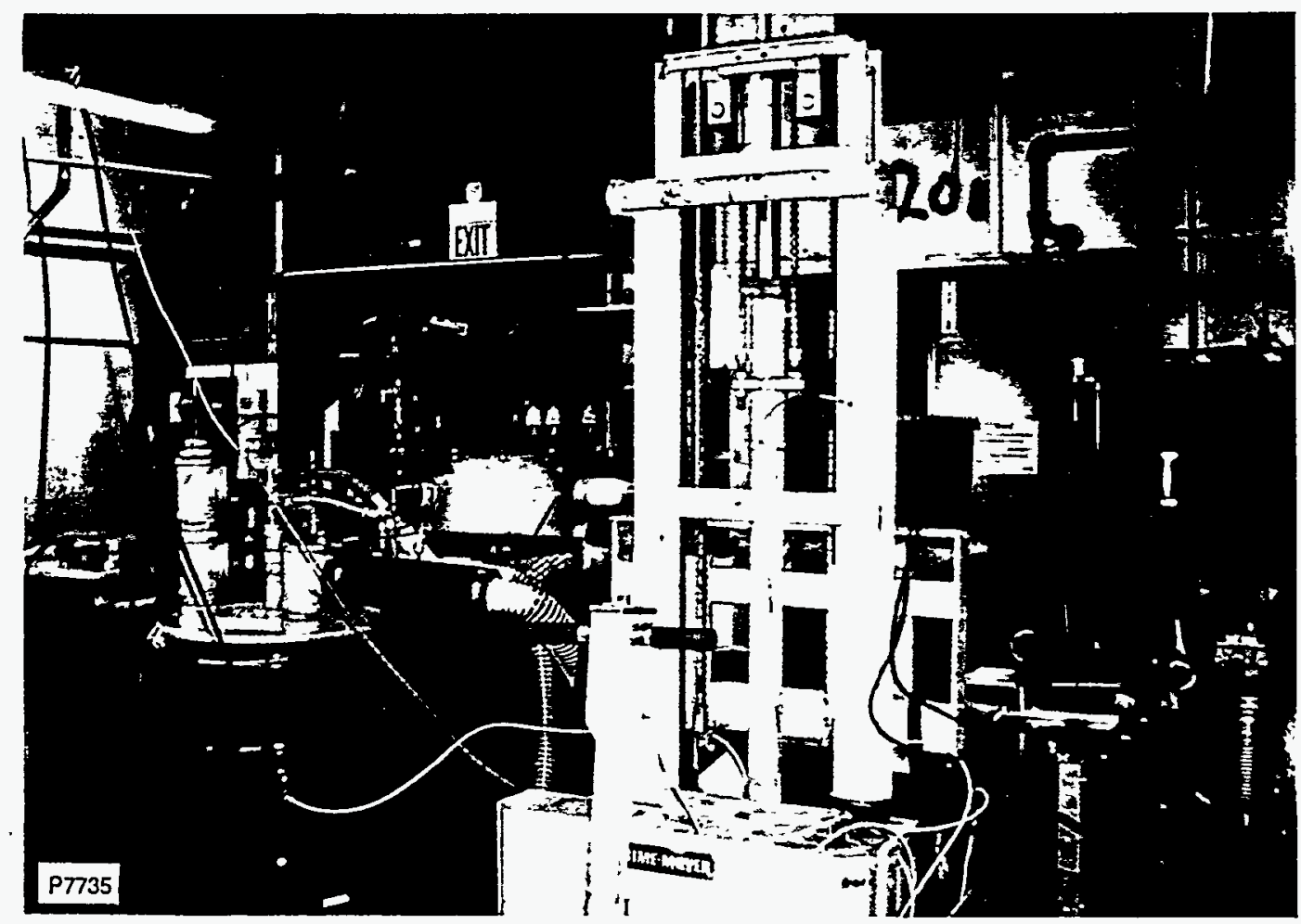

Figure 4-4 Pentek Water Flow Subsystem Components Assembled for Preliminary Testing at Everett Site (May 1995)

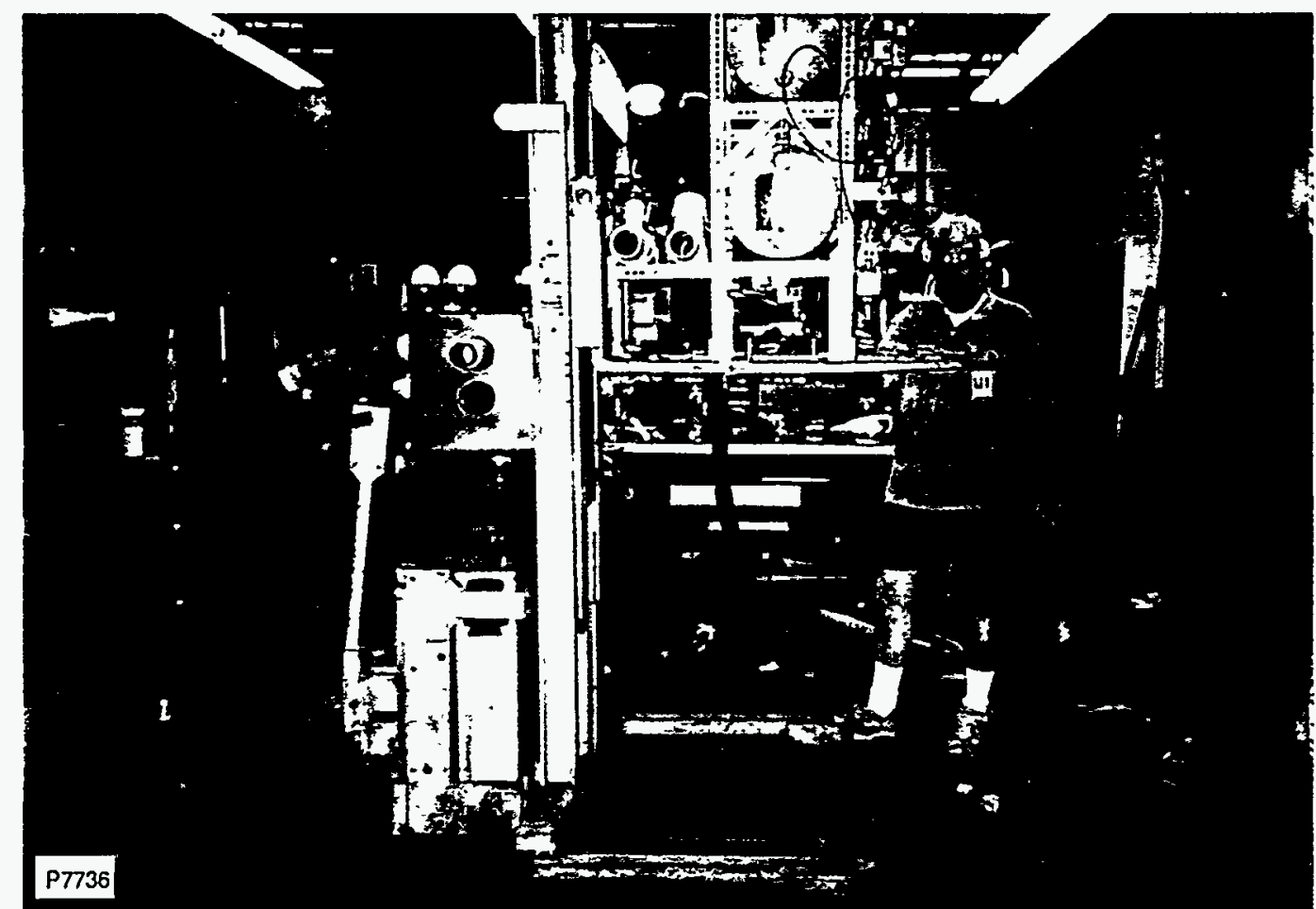

Figure 4-5 Components of Modified Pentek Water Flow Subsystem Prepared for Testing/Demonstration at Everett site (July 1995) 

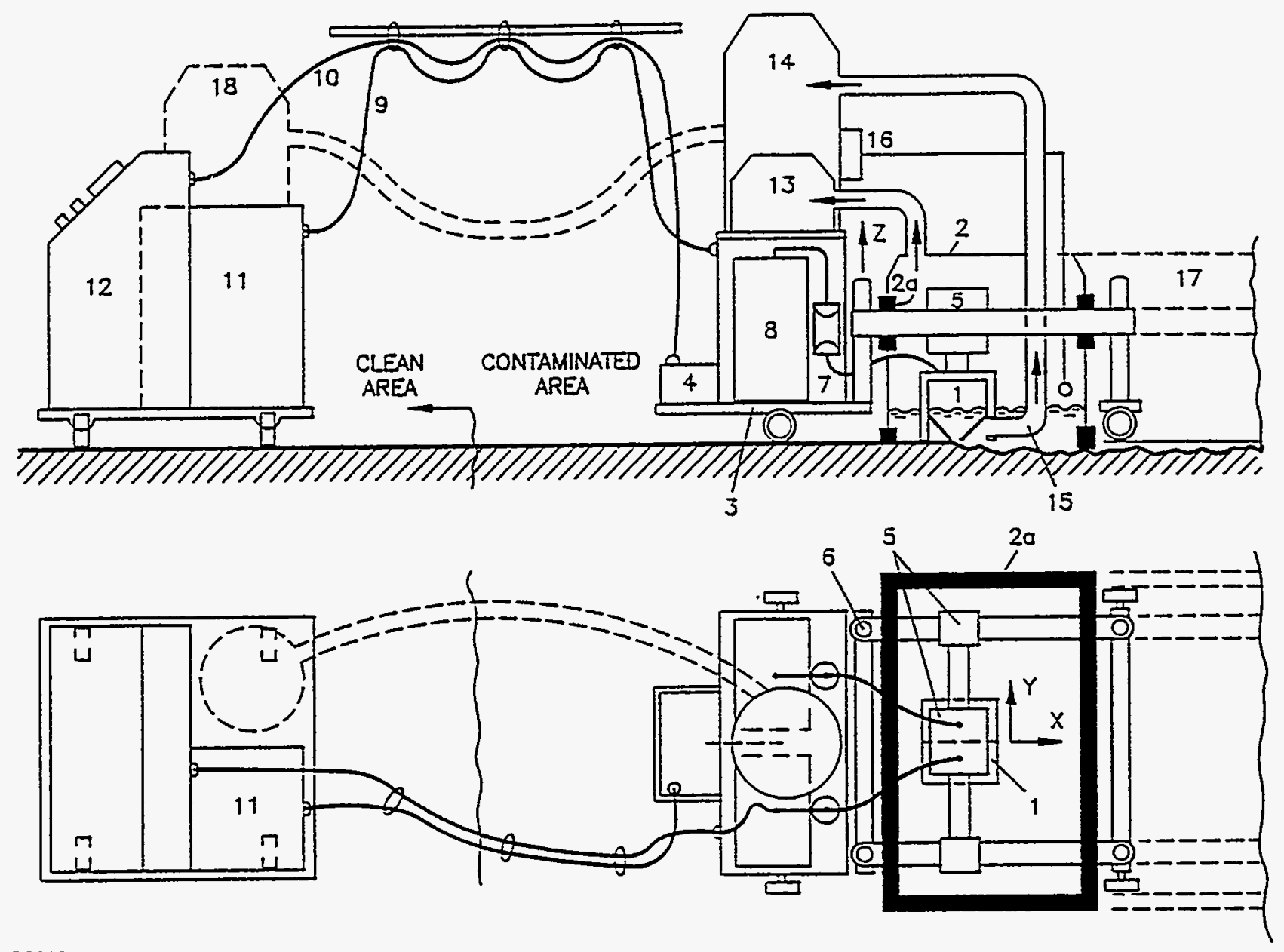

P2919

Figure 4-6 EHS System Concept Version. Two-chamber section is shown; optional (similar) second section operating with common enclosure and remote control section can be added.

1. Discharge Chamber

2. Enclosure

2a. Foam Gaskets

3. Cari

4. Motor Drive

5. X-Y Positioner

6. Z Positioner

7. Spark Gap

8. Storage Capacitor

9. HV Cable

10. Tether (controls)
11. DC Charger

12. Controls

13. Wet Vacuum System I

14. Wet Vacuum System.II and Pumps (Slurry Collector/Separator)

15. Scoop

16. Water Return Line and Filters

17. Optional Second EHS Unit (with common integrated enclosure)

18. Optional Remote Slurry Collector/Separator 
1-Discharge Chambers

2-X-slide

3-Z-slide

4-Enclosure

5-Foam Gasket

6-Motors

7-Sieel Frame

8-Load Wheels

9-Forks

10-Drive Wheel

11-Casters

12-Hydraulic Cylinder

13-Battery

14-Deck

ó 15-Capacitors

16-Spark Gap Switch

17-Barrel (Rubble Collector)

18-Pumps

19-Vacuum System

20-Scabbled Groove

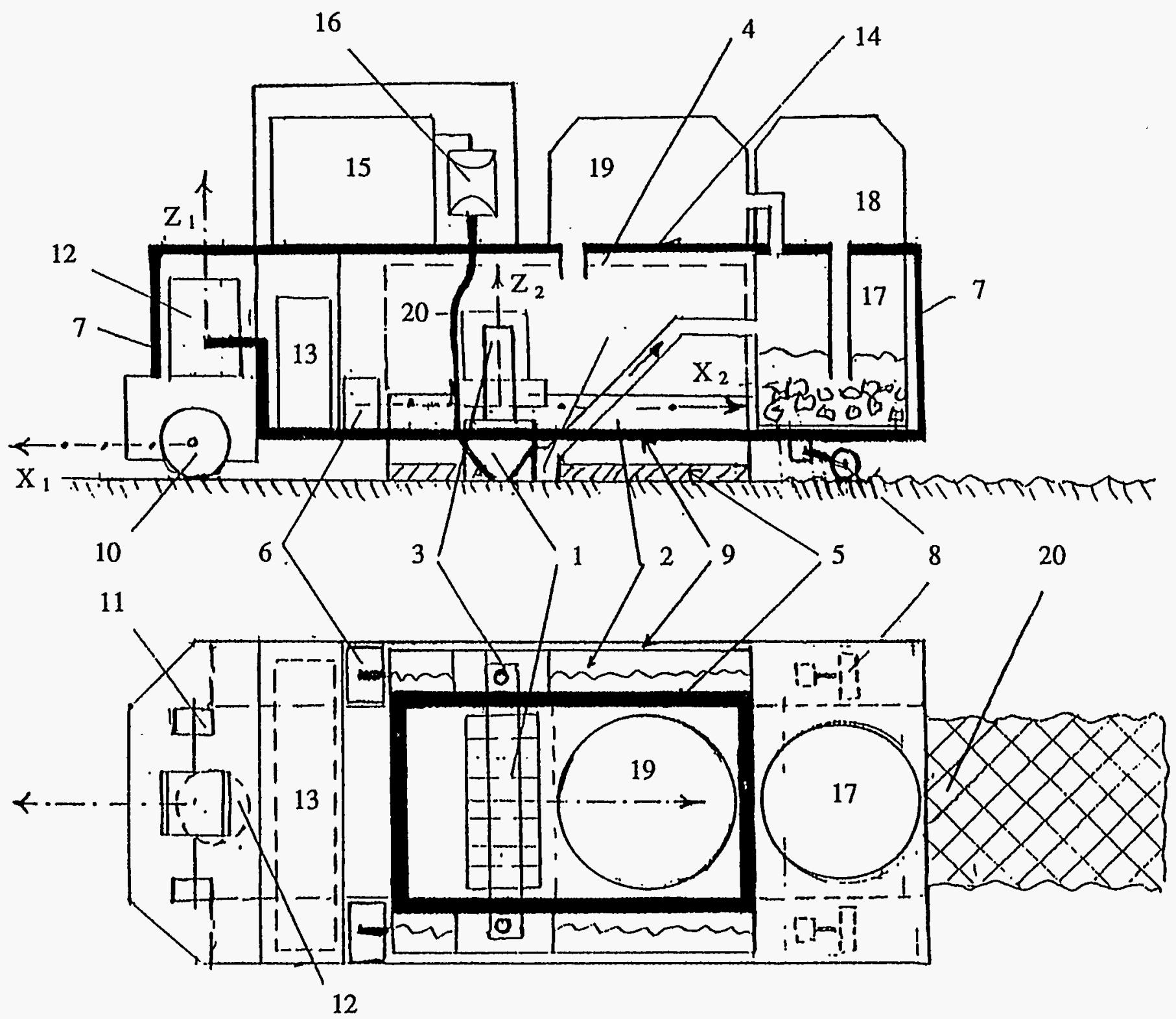

Figure 4-7 EHS System Concept Version using a Single Pallet Truck for all Components 


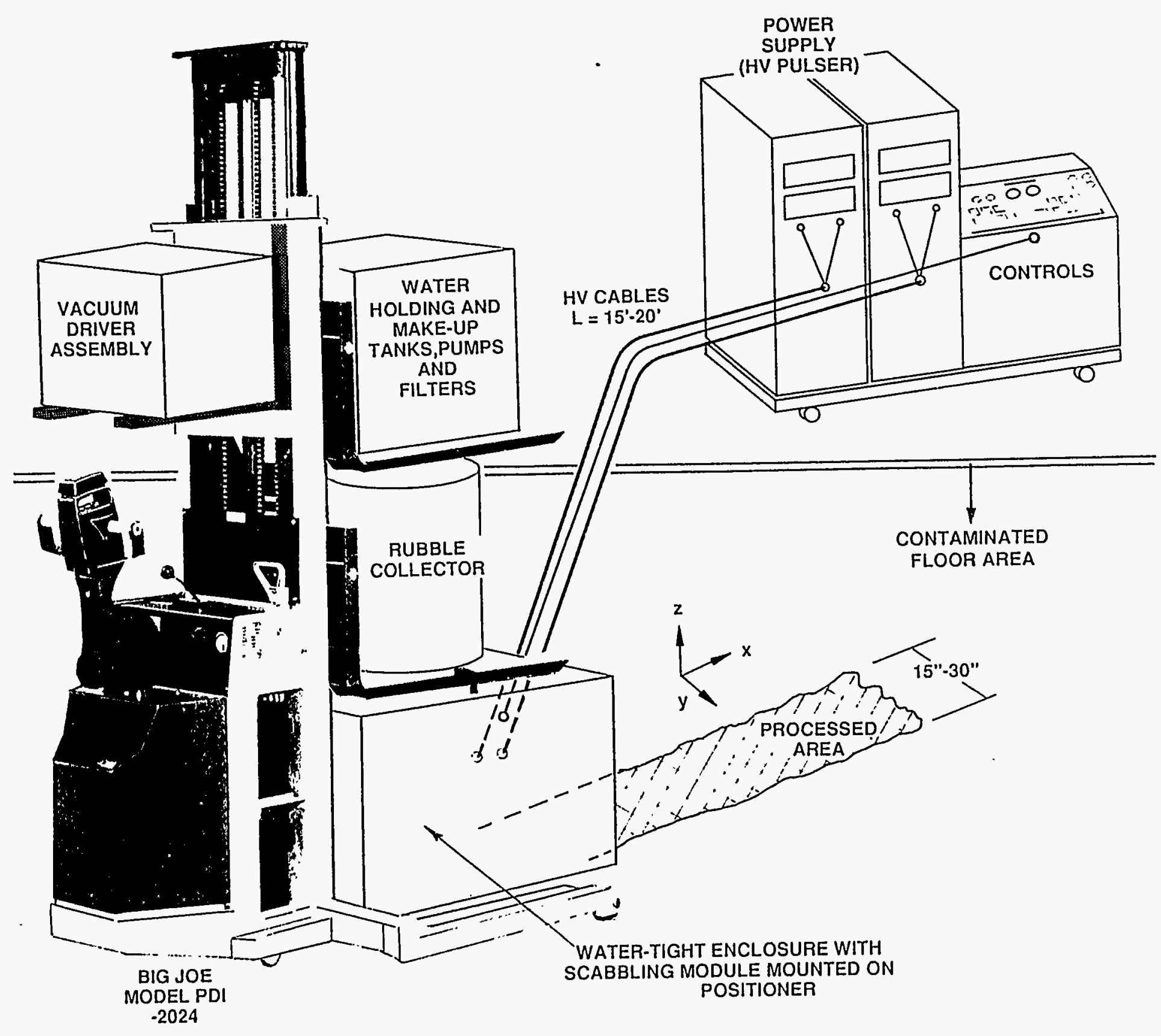

Figure 4-8 EHS System Concept Version using a Straddle Forklift Truck 
to the vertical module and scabbling chamber travels. An option is to use a single mechanism (truck motor and forklift hydraulic cylinder) to execute all these travels. With this option, the truck should be equipped with controls permitting slow, well-controlled stepwise or continuous $\mathrm{X}$-travel and stepwise Z-travel.

In scabbling trials at the TSD Everett site, Yale Corp., Model MPB Motorized Hand Truck was used initially in combination with a small scabbling chamber/enclosure (see Figure 4-9. A very small range of vertical positioning was inconvenient, and the pallet truck was later replaced by a straddle truck (by Big Joe, Inc.). The Big Joe trucks have various capacities starting at 1,500 lbs., which is sufficient for our needs. They also have other options for width and length of forks and straddles, lift heights, and power drives and controls. In selecting a specific forklift model, preference should be given to trucks without straddles. The straddles limit choice of width and length of a scabbling chamber, and are not necessary for rather low lift involved in scabbling and equipment handling.

The same Big Joe truck was used in field tests/demonstration at the DOE/Fernald site. There, in addition to the main functions directly involving scabbling, the forklift was used for loading/unloading and for on-site transportation of the EHS equipment.

At both sites, only part of the EHS components was installed on the truck, leaving electric power supply, controls, and some flow subsystem components on a separate platform (see Figures 4-10 and 7-6). This loose arrangement complicated the scabbling operation, especially at Fernald. A compact, truck-mounted unit should be much more convenient for operation over limited areas and congested spaces. 

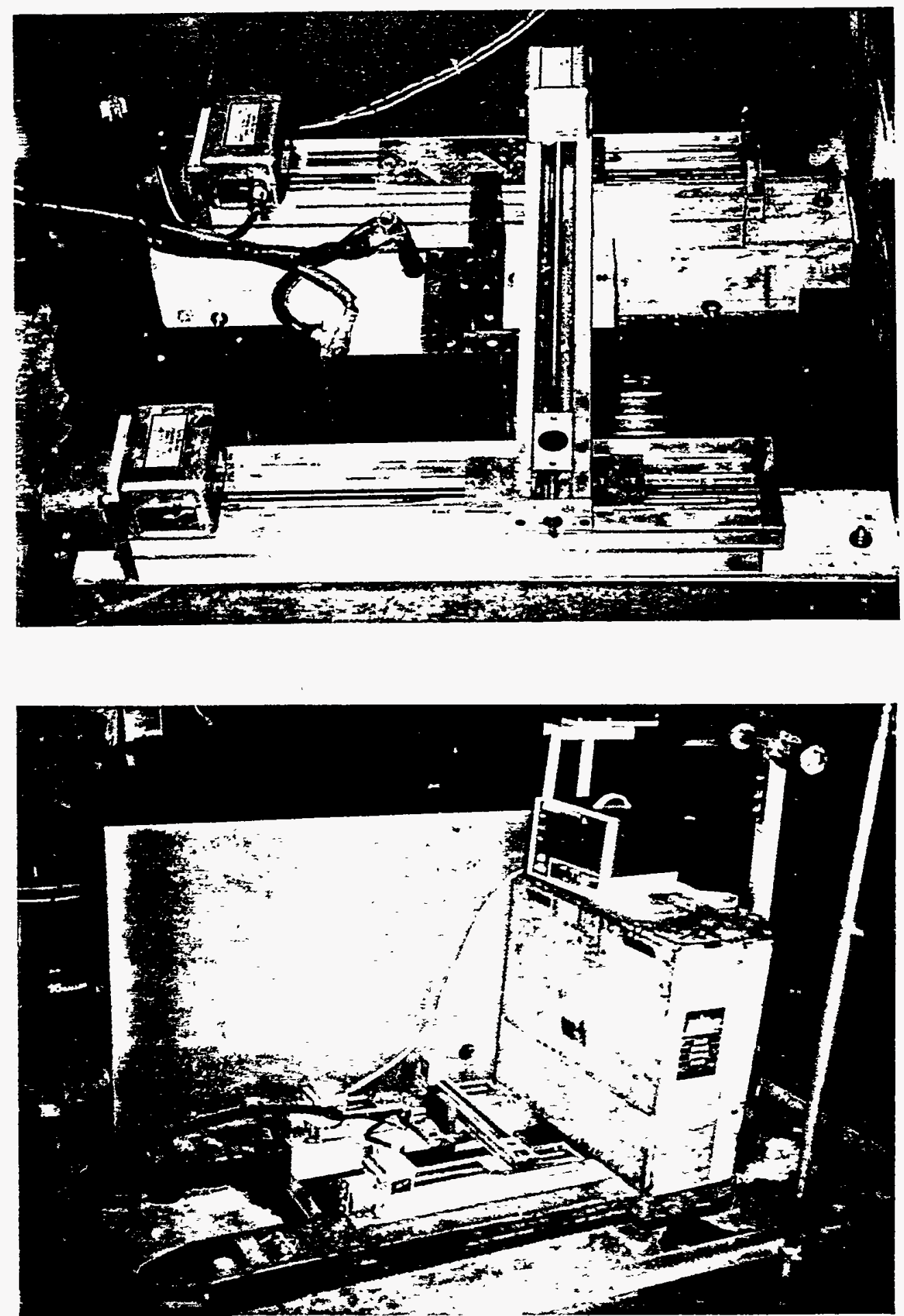

P7737

Figure 4-9 Arrangement of the Scabbling Module and Positioner (with water enclosure removed and close-up shown above) on a Pallet Truck used in the Initial Floor Scabbling Trials at Everett Site 


\subsection{DEVELOPMENT OF A SUPER-HIGH VOLTAGE SCABBLING SYSTEM}

Design and experimental work conducted in cooperation with St. Petersburg (Russia) Technical University (SPB TU) in Phase I of this project demonstrated positive prospects for a concrete scabbling technique using very high $(>100 \mathrm{kV})$ and very short (few microseconds) electric pulses propagating under a water cover (or other liquid) directly through surface concrete layer. Specifically, this technique promises to increase the scabbling rate and to reduce energy consumption. This work continued in Phase II, and its results are reported in this section.

\subsection{ELECTROMECHANICAL SYSTEM (EMS) DEVELOPED AND TESTED AT THE SPB TU SITE}

To develop the EMS technology and to test the scabbling module, an experimental test stand (Figure 5-1) has been assembled. The installation includes a High Voltage Generator (HVG), electrode module, and positioner. The HVG schematic and arrangement are shown in Figures 5-2 and 5-3. The two-cascade Marx generator based on IK 100-0.25 capacitors has effective $0.125 \mu \mathrm{F}$ capacitance and provides $150 \mathrm{kV}$ voltage pulses.

Open $25 \mathrm{~mm}$ and $35 \mathrm{~mm}$ spark gaps with hemispherical $(D=120 \mathrm{~cm})$ electrodes are used as switches. A typical electric pulse has $8 \mathrm{kA}$ current amplitude at $130 \mathrm{kV}$ voltage, and $1.5 \mu \mathrm{s}$ half-period of oscillation with $13 \mu \mathrm{s}$ fall time. One $\mathrm{kJ}$ energy is stored in the capacitors.

Preliminary experiments demonstrate that an electrode system integrated in a single Multielectrode Module (MEM) (see Figures 5-4 and 5-5) is most efficient and convenient. The module and HVG are connected by a flexible $1.5 \mathrm{~m}$ long two-cable line. A motor-driven positioner (Figure 5-6) provides for $25 \mathrm{~s}$ to $40 \mathrm{~s}$ stepwise traverse of the MEM between subsequent processing positions.

The concrete surface (floor) processing (scabbling) proceeds as follows. The MEM is fixed at an initial position with electrodes in contact with the concrete. The floor is covered by a water layer deep enough to cover electrodes $2-3 \mathrm{~cm}$ above their upper edge. The HVG is turned on and adjusted to deliver pulses at $2-3 \mathrm{~Hz}$ frequency. This frequency is defined by the rate of capacitor charging which can be current-controlled. Figure 5-7 photographs provide a top view of the EMS system in operation.

In the experiments with a $320 \mathrm{~mm}$ long electrode system (17 electrodes with $20 \mathrm{~mm}$ distance between electrode pairs), 20 pulses are typically required to produce a continuous scabbled strip. After the scabbling cycle is completed, an electro-magnetic (solenoid) vertical (Z)-positioner lifts the electrode system and moves it about $35 \mathrm{~mm}$ in the $\mathrm{X}$ direction (perpendicular to the module length). At the new location, the next scabbling cycle begins. In this operating mode, scabbled strips overlap, generating a rather uniform processed surface of concrete. 


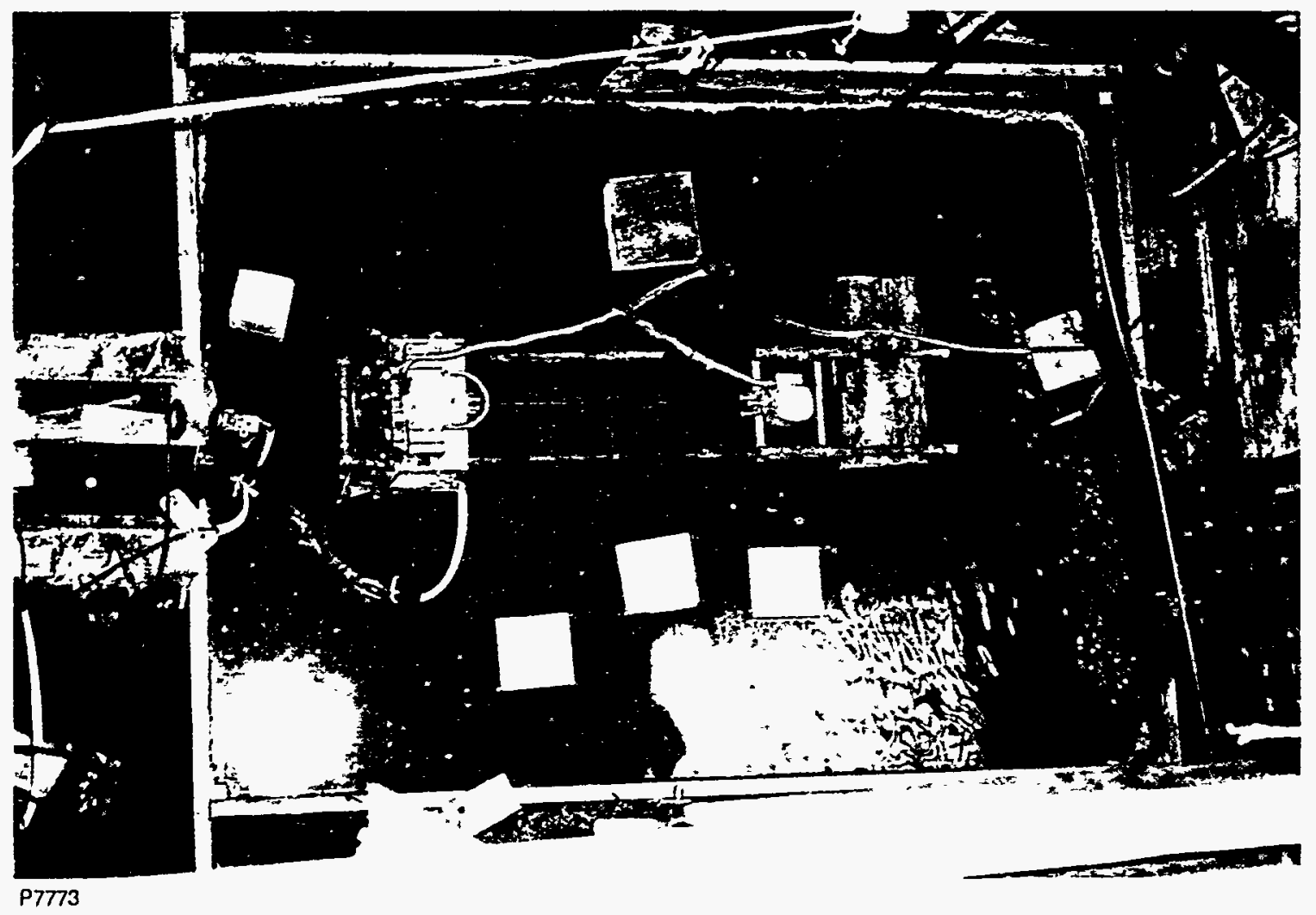

Figure 5-1 Scabbling System Installed in Open Water Pool over Concrete Floor at SPB TU Site 


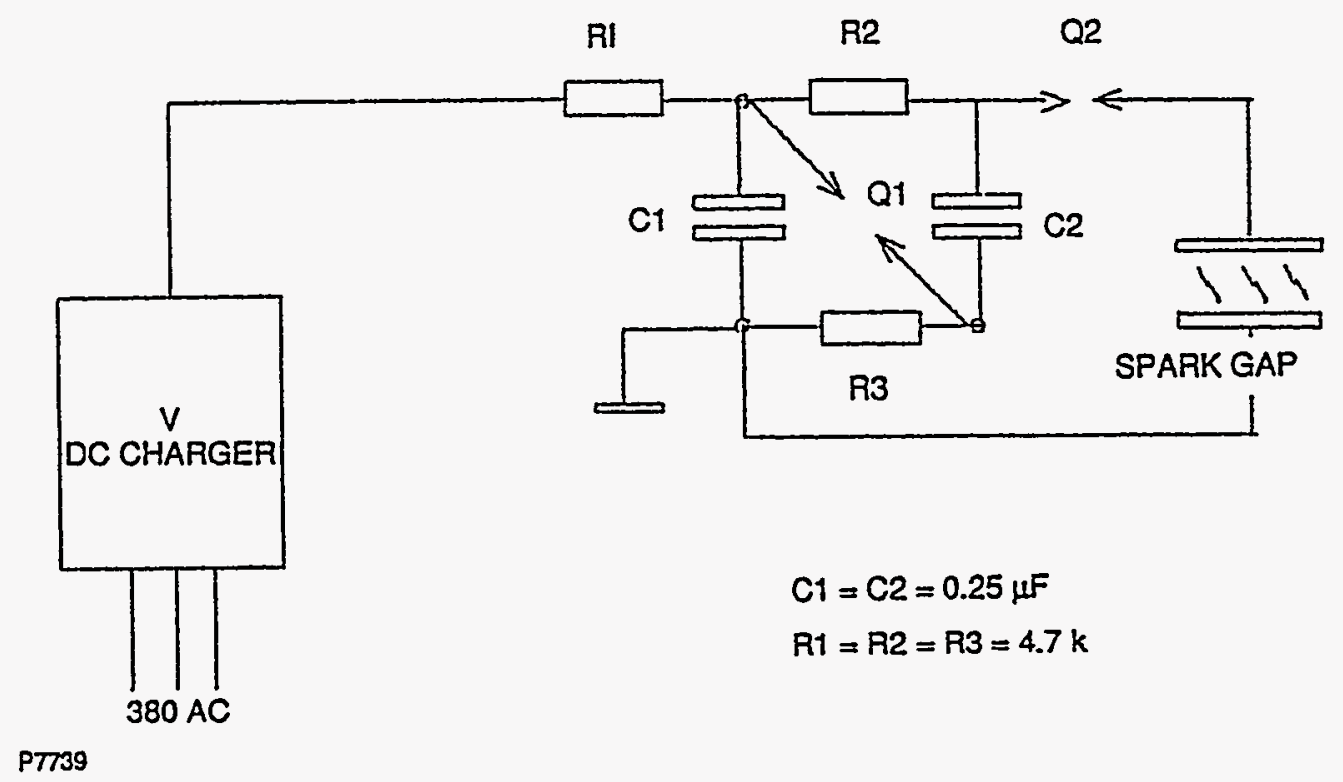

Figure 5-2 Electric Schematic of SPB TU High-Voltage Generator (HVG)

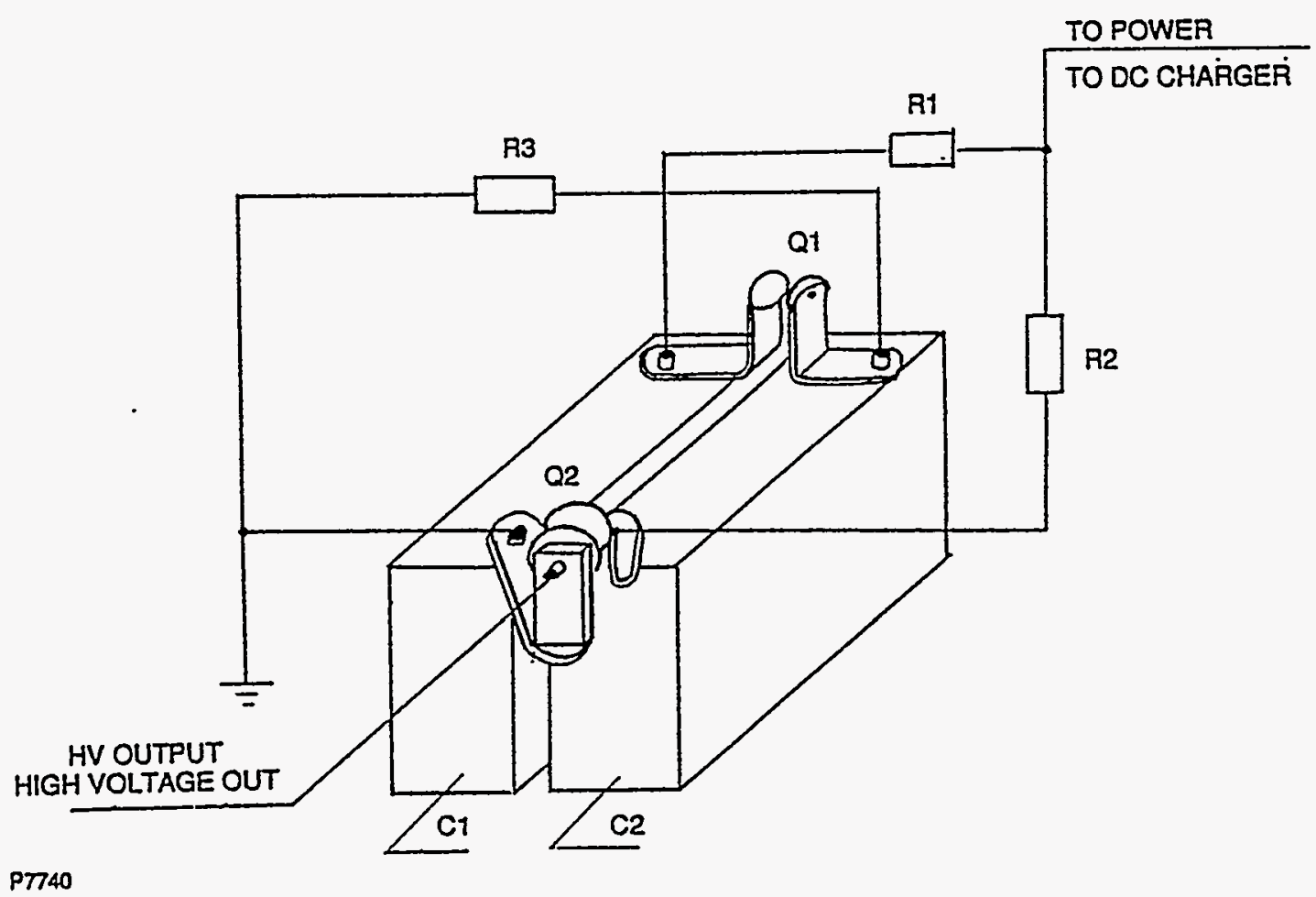

Figure 5-3 HVG Assembly Drawing 


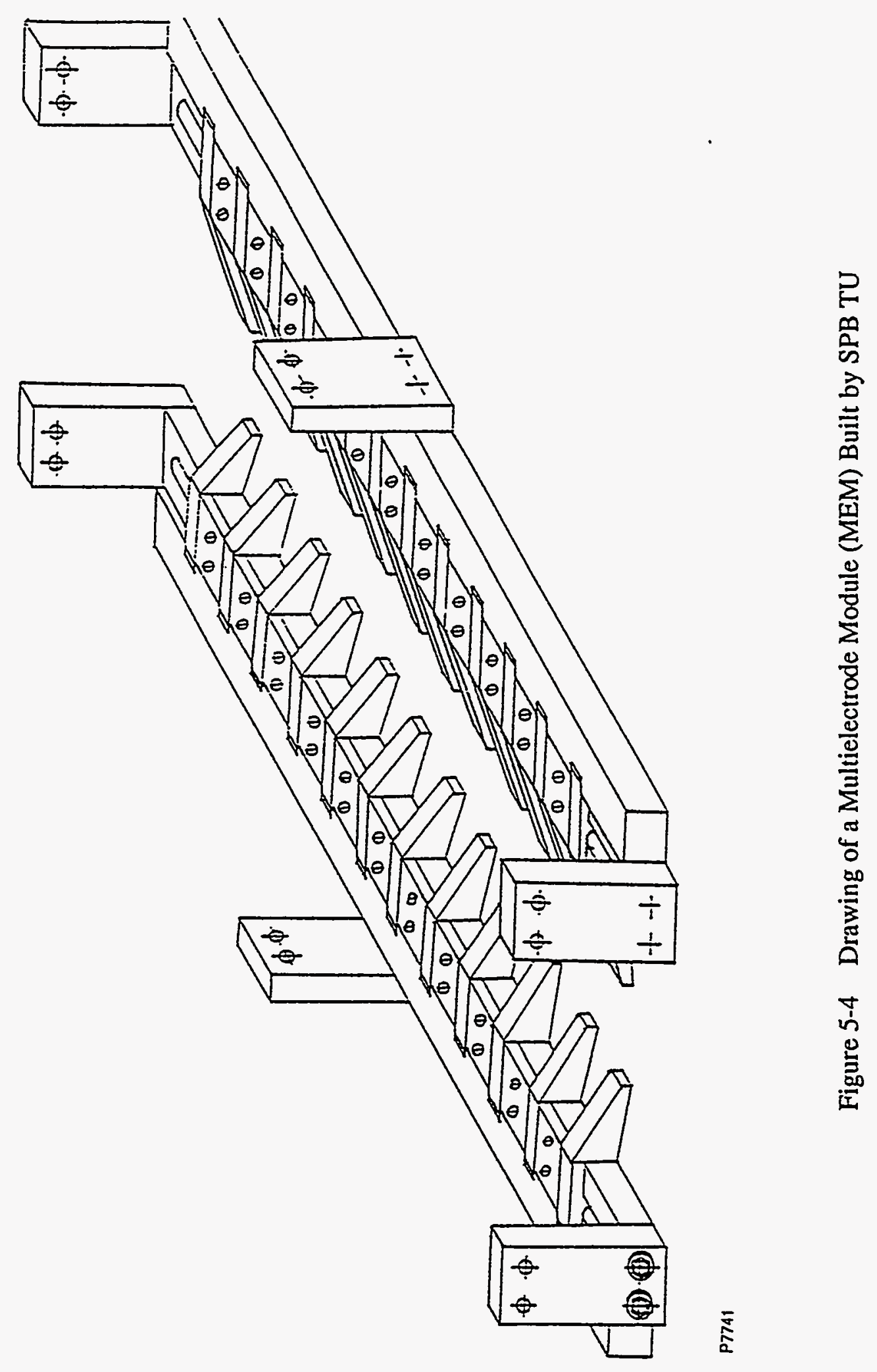




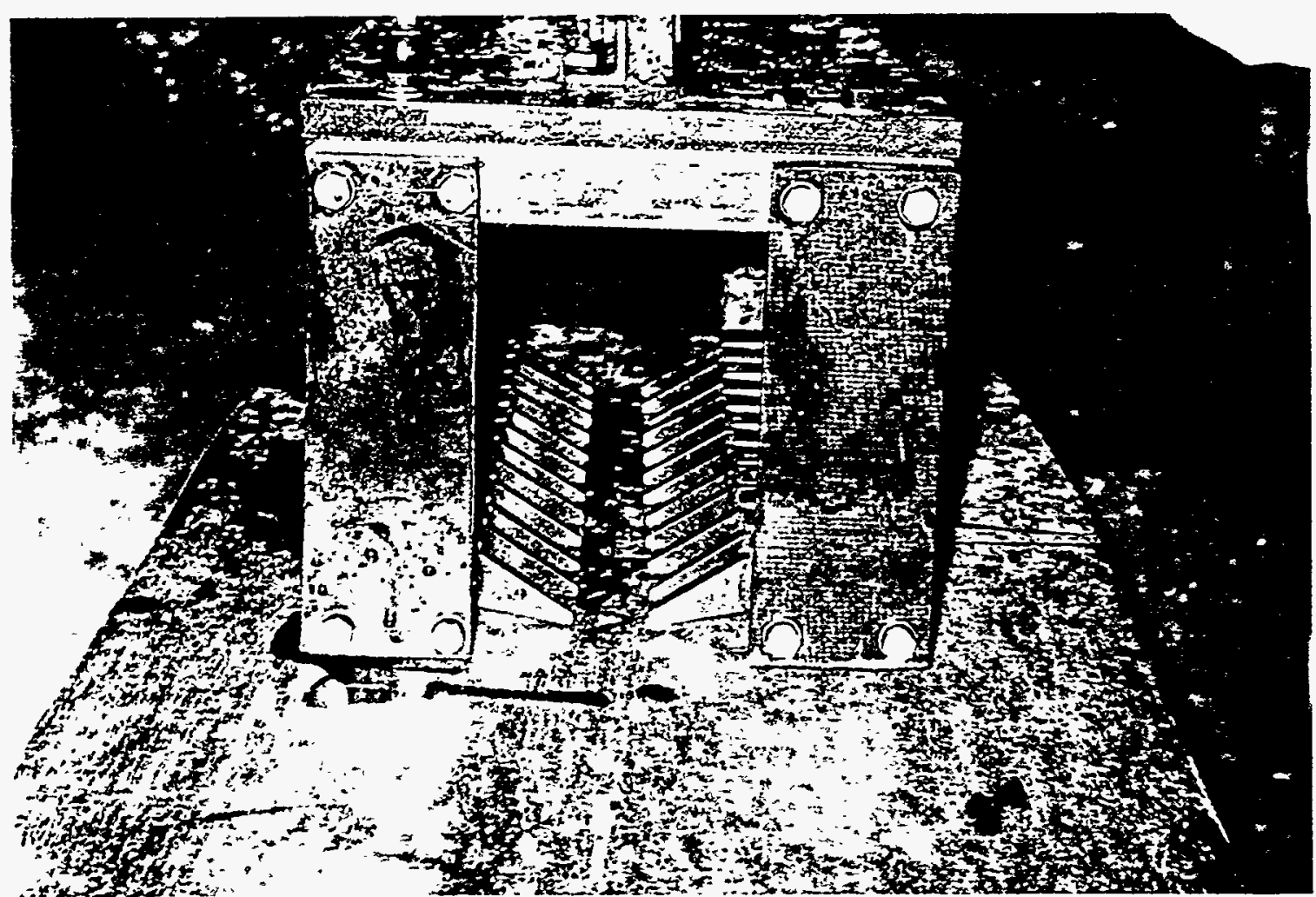

a)

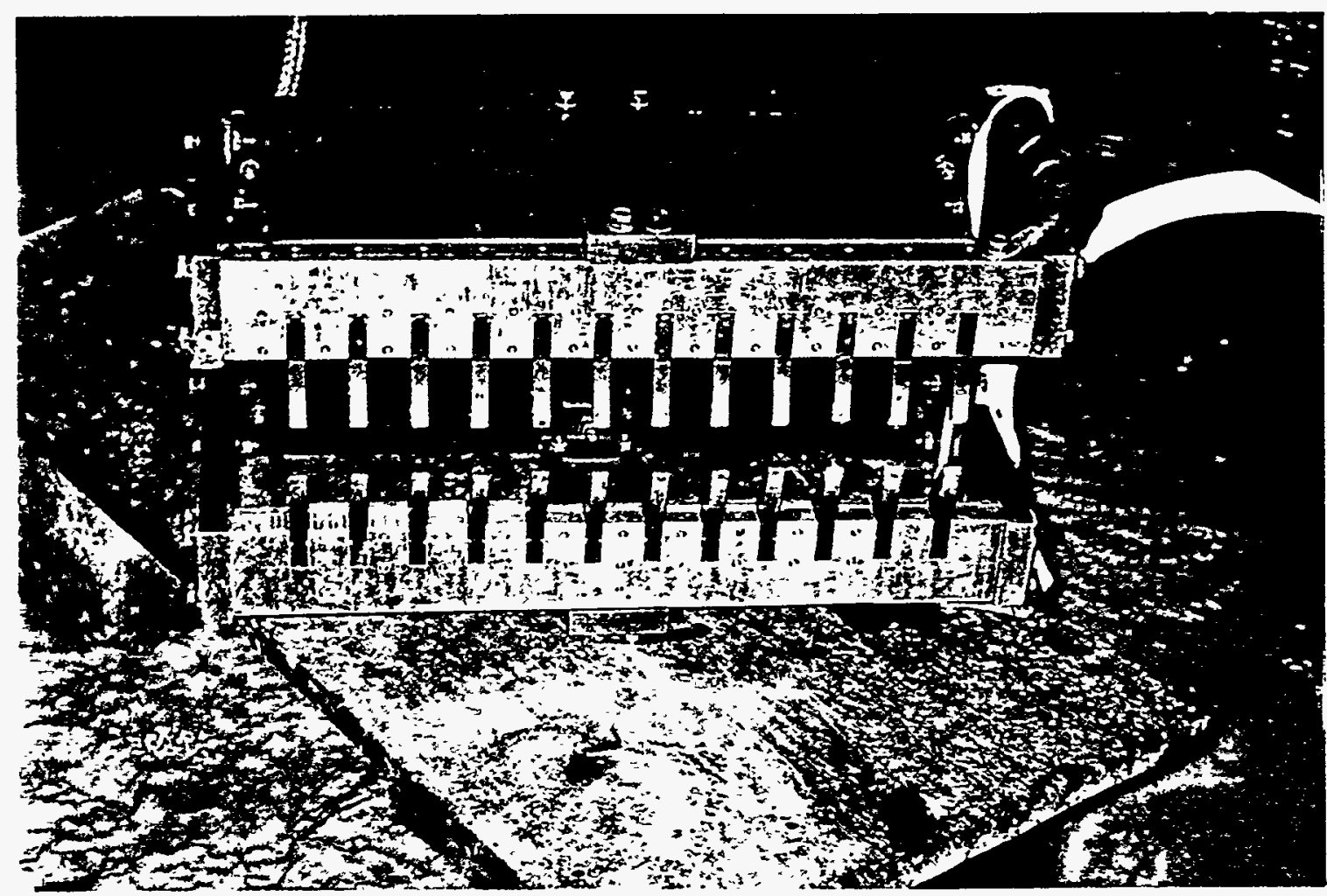

b) P7742

Figure 5-5 Side (a) and Bottom (b) Views of the MEM 

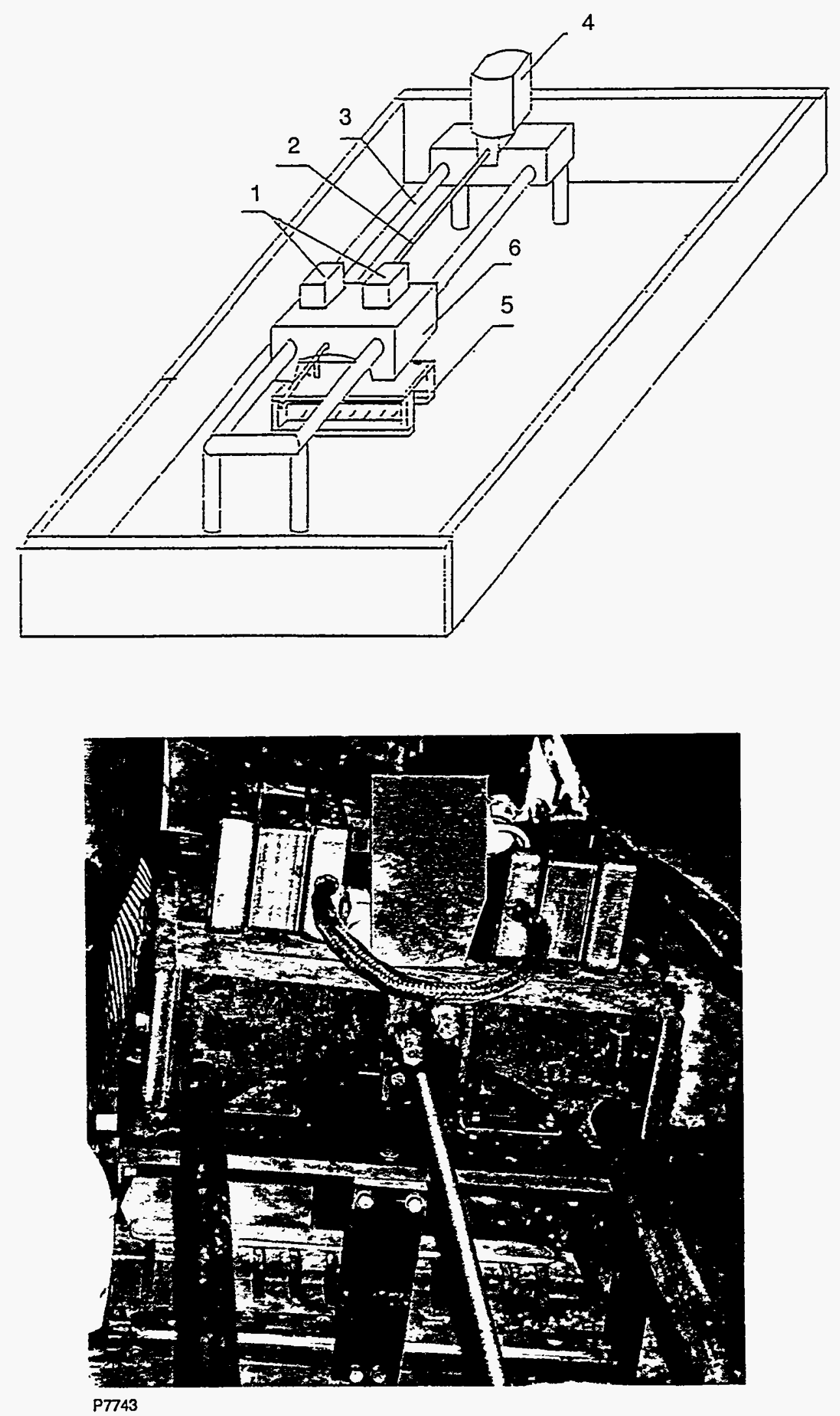

Figure 5-6 MEM Positioner Installed in the Water Pool at the SPB TU Site

a) schematic: 1-electromagnet for MEM vertical travel, 2-leading screw, 3-guides, 4- motor drive for MEM horizontal travel 5-MEM, 6-carriage b) side view 


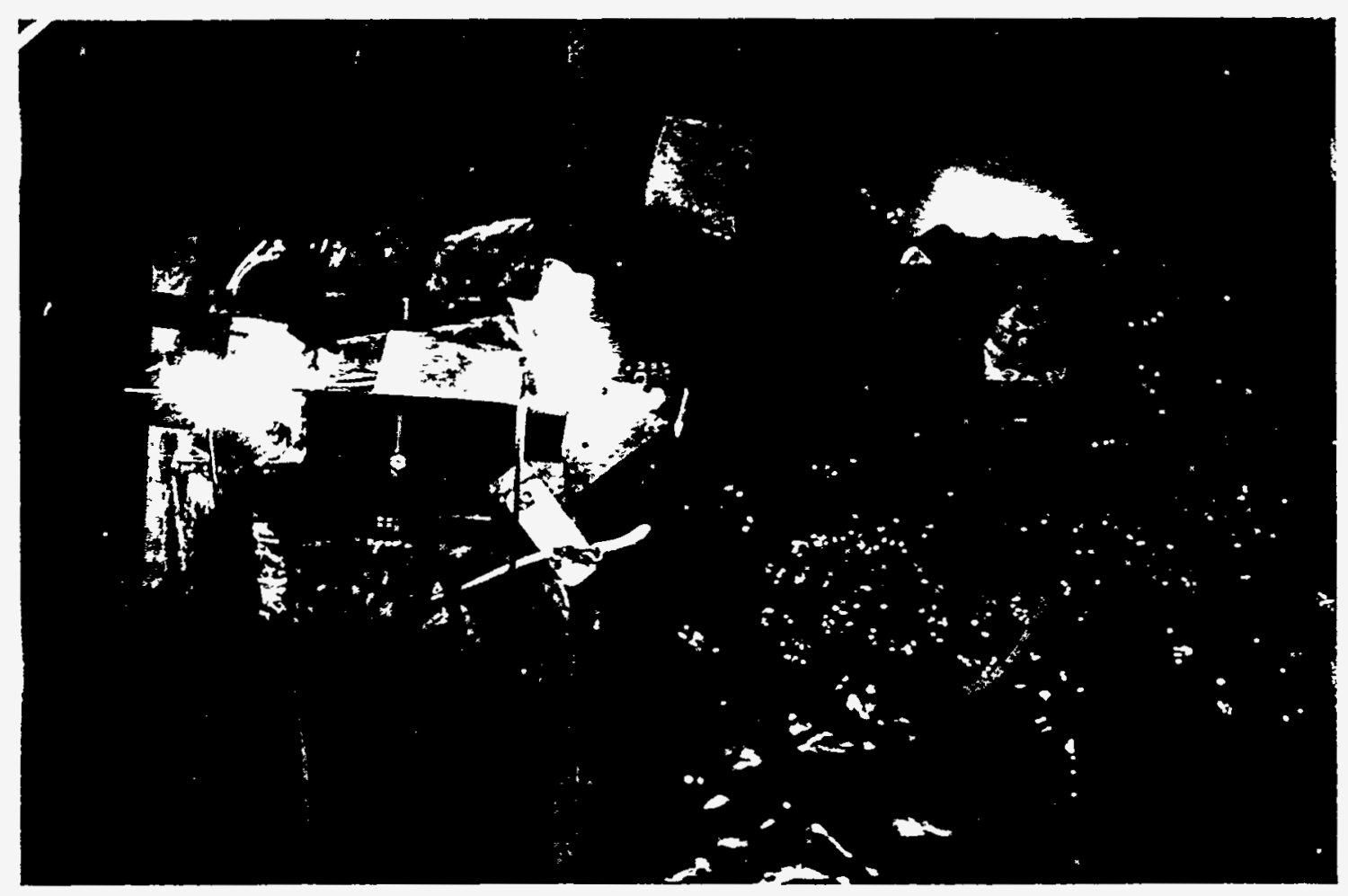

a)

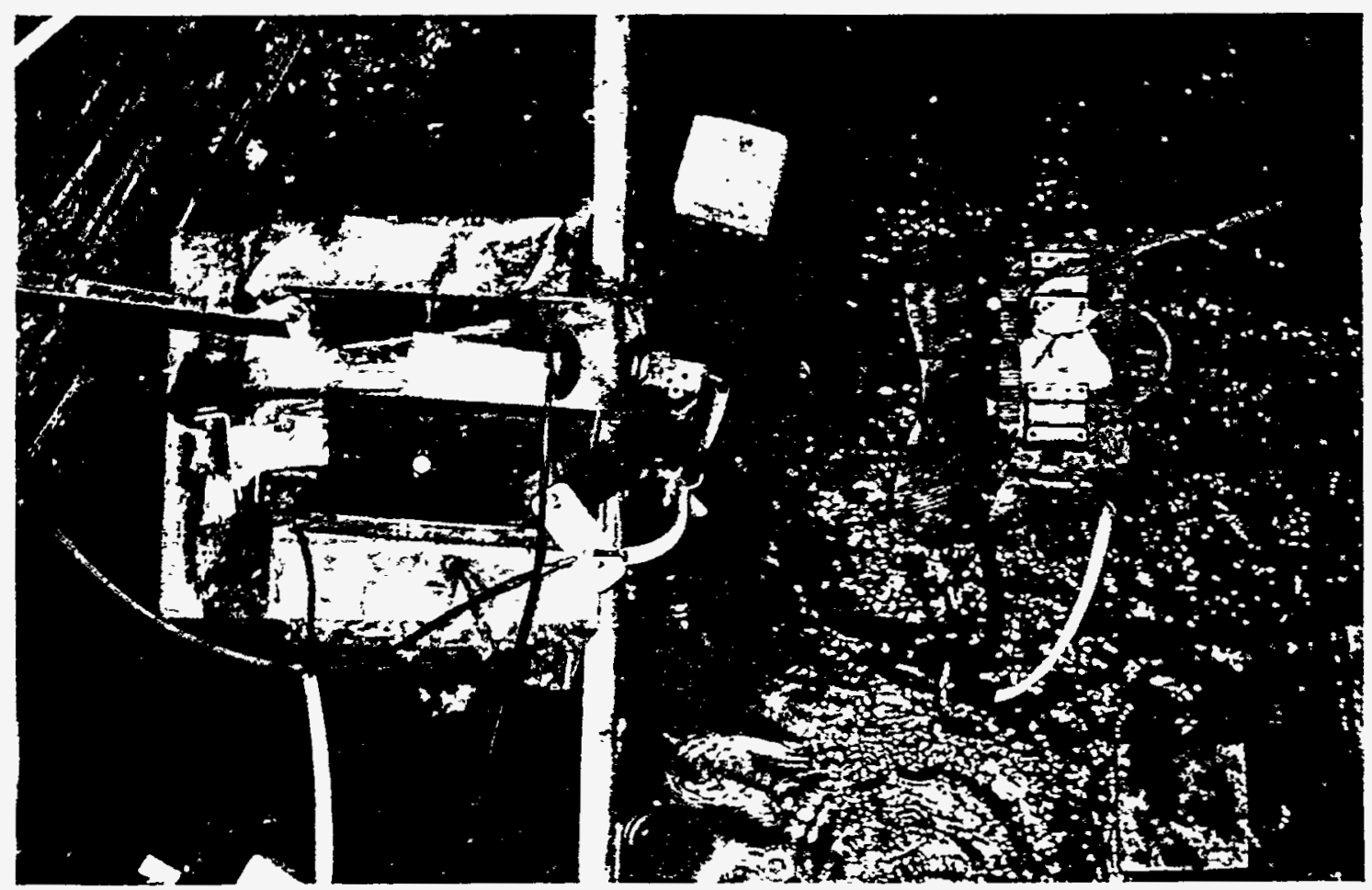

b)

P7744

Figure 5-7 Electromechanical System (EMS) in Operation: top-view photos during (a), and after (b) electrical pulse. Discharges through open spark gaps and waves generated over water surface are seen 
During these EMS trials, a 4.8 sq. $\mathrm{m}$ (50 sq. ft.) floor area was processed by 6,200 pulses. A total 0.04 cu.m of concrete was removed, which corresponds to an average $9.3 \mathrm{~mm}\left(3 / 8^{\prime \prime}\right)$ scabbling depth at about $30 \%$ depth uniformity. Average energy consumption was $165 \mathrm{~J} / \mathrm{cm}^{3}$ $(70 \mathrm{~J} / \mathrm{g})$. After the trials, inspection did not reveal measurable erosion of the electrodes.

An advantage of the multielectrode system is its ability to provide independent contact between each individual electrode and concrete surface, even when the surface is rough. For processing smooth concrete floor with roughness below $5 \mathrm{~mm}$, a simpler system of two parallel steel angles (Figure 5-8) is also adequate.

It has been discovered in the course of long-duration runs that, without replacement of the process water, discharge may become irregular. Instead of oscillating discharge through concrete, an aperiodic discharge through a water layer takes place from time to time. To restore normal mode, the operating voltage has to be increased. The reason for irregularities is the increase of water conductivity, resulting in the current leakage and electrode voltage drop. This effect is more pronounced with wider, large area electrodes. The simplest way to eliminate the irregular discharge is to increase the process water volume. According to SPB TU tests, regular operation is secured with 0.5-0.6 cu.m volumes of water. In this case, interelectrode resistance is stabilized at the 7 ohm level.

\subsection{DESIGN AND ASSEMBLY OF THE MOBILE EMS}

Based on results obtained in the SPB TU trials, two new compact High Voltage Generators were developed. These HVGs had to be assembled using hardware components available at TSD, with the additional requirement of being compatible with scabbling modules and positioners used by TSD for low-voltage concrete processing (EHS).

Both generators are based on the Marx configuration; they have the following main characteristics:

EHS-03R: two cascade generator with maximum voltage $U_{0}=140 \mathrm{kV}$, single-stage voltage $U_{S}=70 \mathrm{kV}$, effective capacitance $C_{e}=0.125 \mu \mathrm{F}$, and inductance $L_{0}=1.8 \mu \mathrm{H}$.

EHS-04R: four cascade generator with maximum voltage $U_{0}=120 \mathrm{kV}, U_{\mathrm{S}}=30 \mathrm{kV}$, $\mathrm{C}_{e}=0.165 \mu \mathrm{F}$, and $\mathrm{L}_{0}=2.8 \mu \mathrm{H}$.

Electric schematics of these generators are shown in Figures 5-9 and 5-10. Open spark gap switches are used in both devices. The EHS-03R pulse frequency, where overvoltagetriggered spark gaps are used, is defined by a charging rate limited by the available power of the $\mathrm{DC}$ power supply. The pulse voltage amplitude is defined by the interelectrode gap; for $135 \mathrm{kV}$ the pulse distance between switch $Q_{1}$ electrodes was $2.5 \mathrm{~cm}$, between switch $\mathrm{Q}_{2}$ electrodes it is $3.5 \mathrm{~cm}$.

The EHS-04R generator has three open spark gap switches with $1 \mathrm{~cm}$ interelectrode distance. A first stage requires a switch with a trigger control. A closed spark gap, GP-15B (by EG\&G), with a TM-11A trigger and timer is installed in this stage.

The HVG units are assembled in metal cabinets, with DC chargers mounted on the cabinet tops (see Figures 5-11 and 5-12). In addition, the EHS-03R generator, which requires 


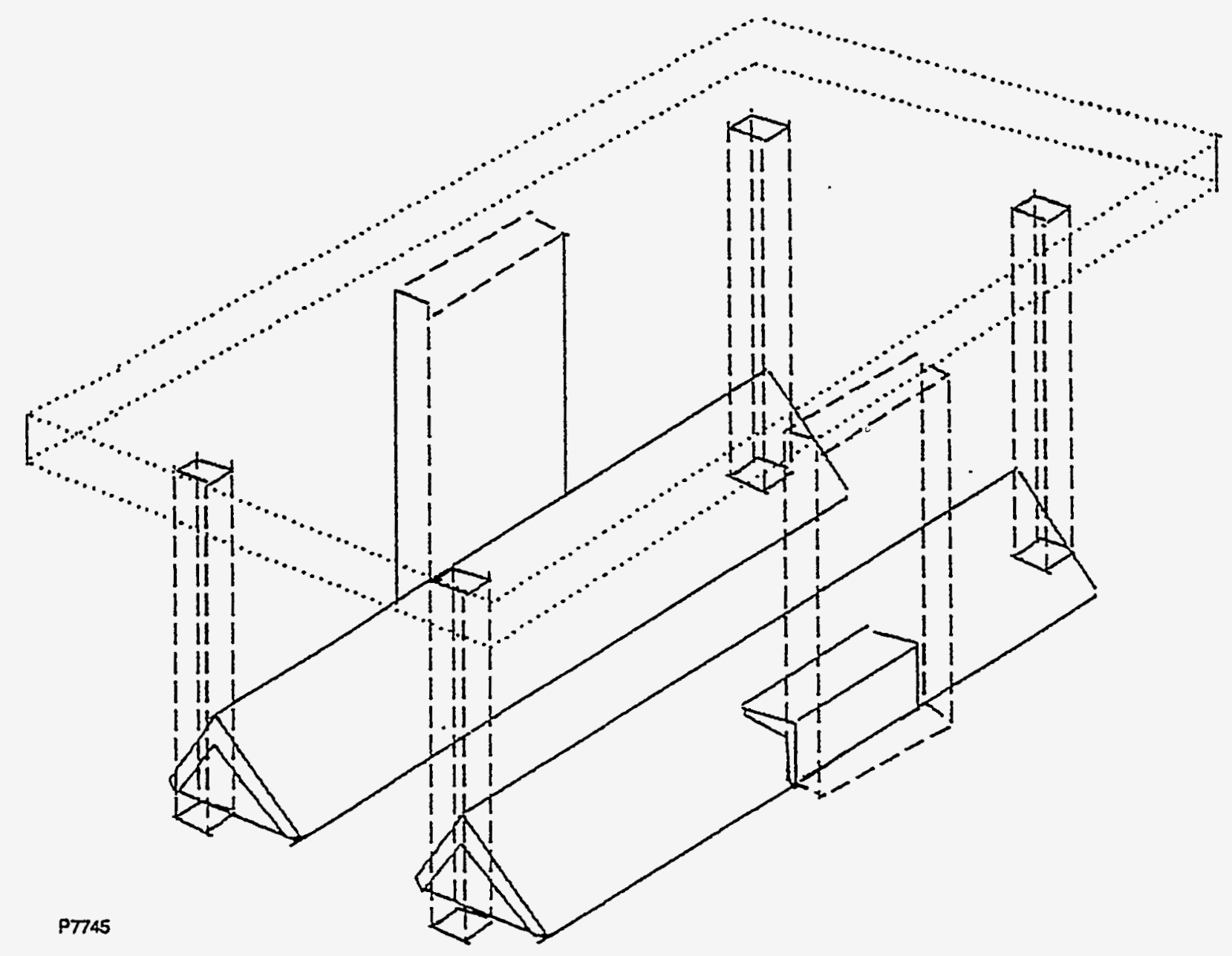

Figure 5-8 Schematic of an Alternative Electrode System with a Single Pair of Strip Electrodes 


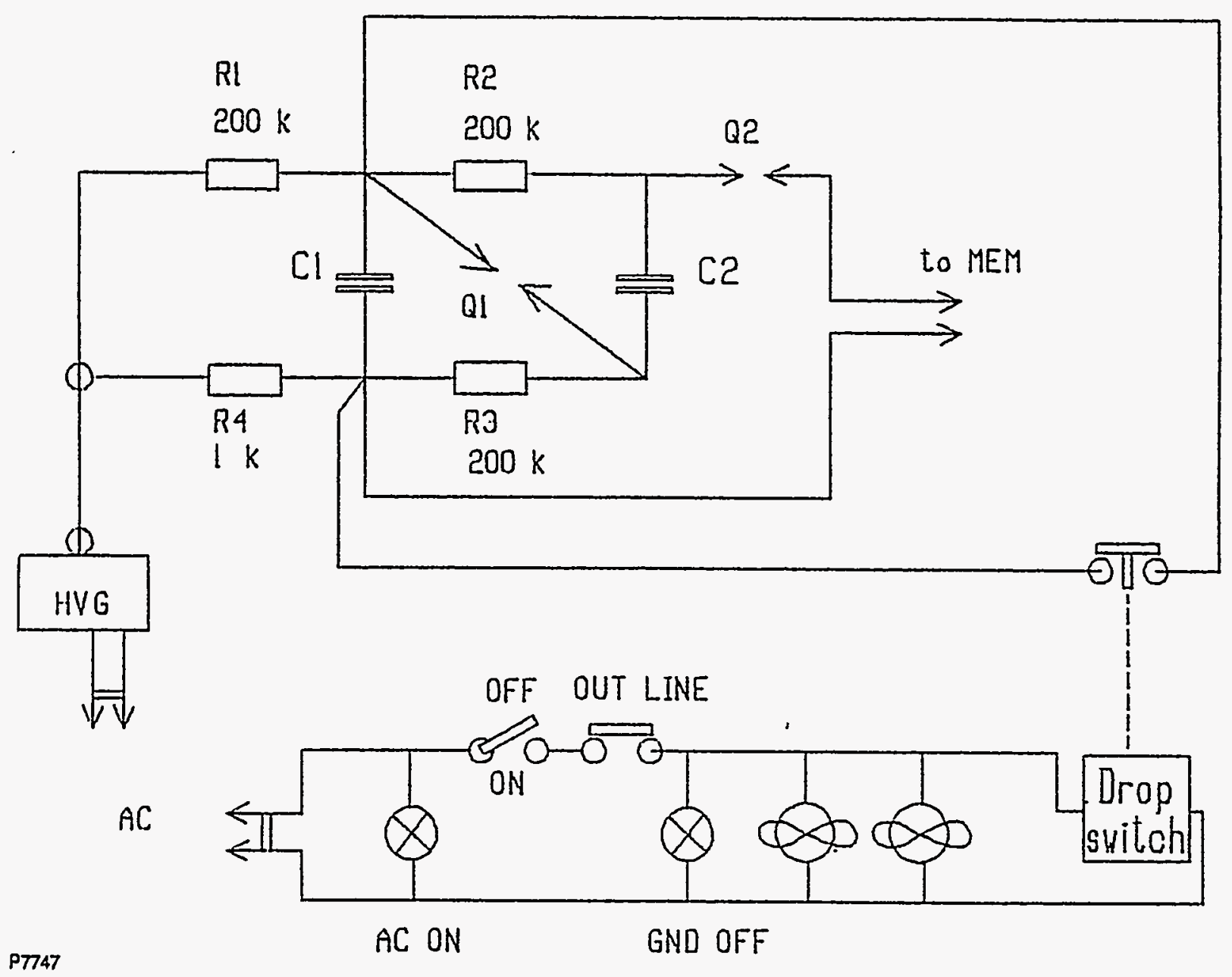

Figure 5-9 Electric Schematic of EHS-03R High Voltage Generator/Pulser 


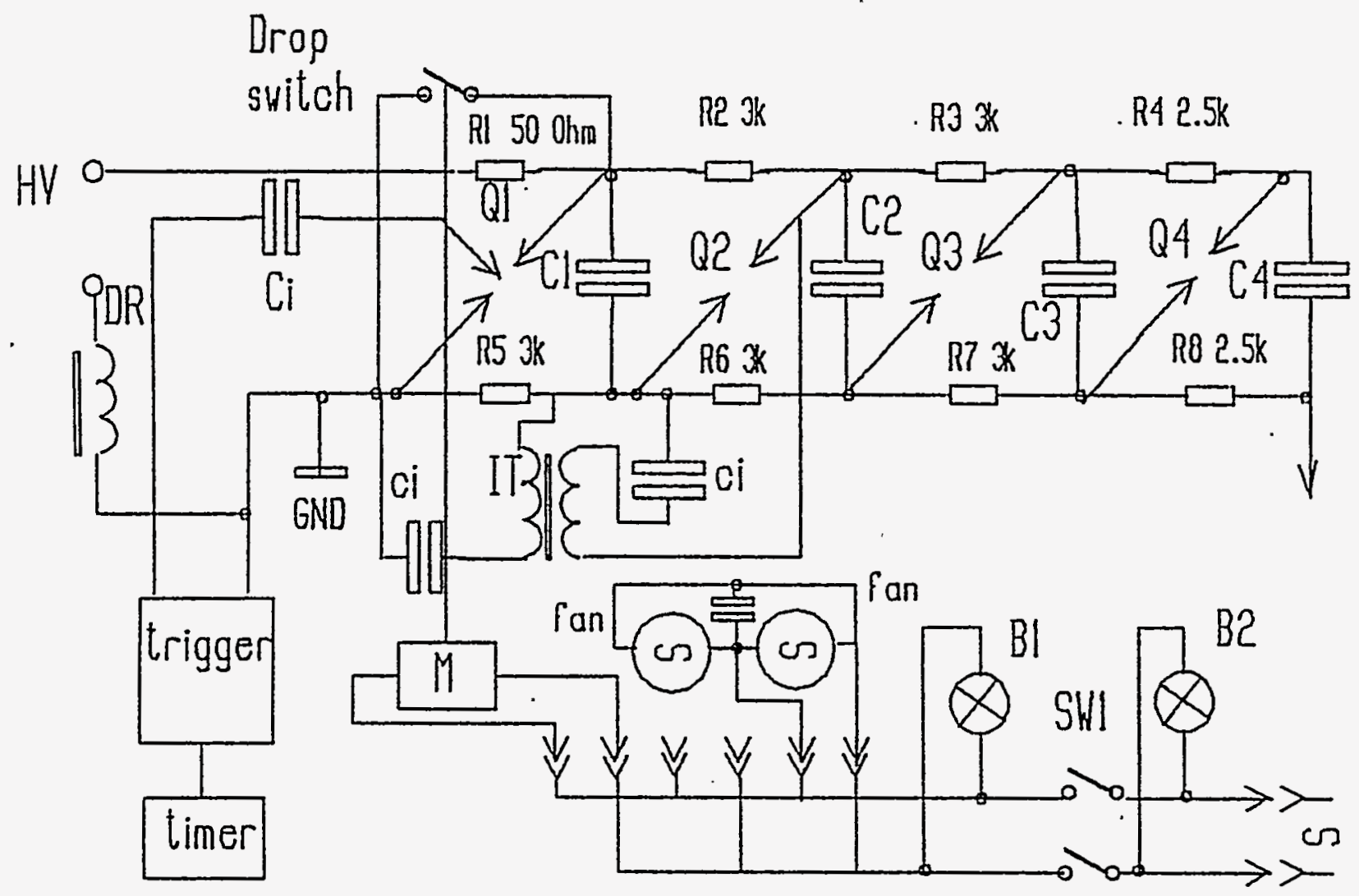

P7746

Figure 5-10 Electric Schematic of EHS-04R High Voltage Generator/Pulser 


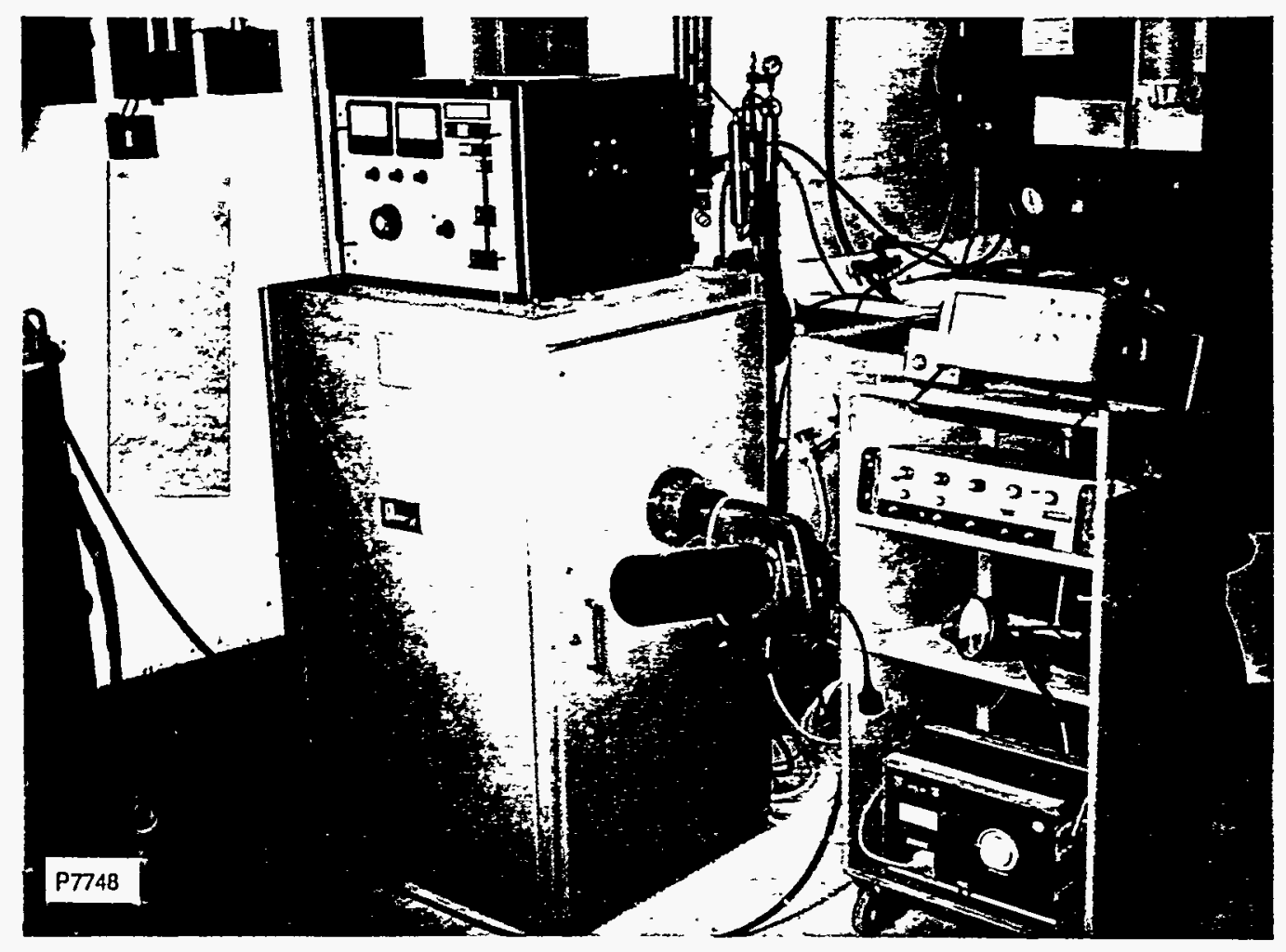

Figure 5-11 EHS-03R Unit Assembled at Everett site. PFN is in a blue cabinet; $70 \mathrm{kV} \mathrm{DC}$ charger includes oil transformer (drum in the left) and controls (at the cabinet top).

Figure 5-12 EHS-04R Unit (with DC charger on the top) Assembled at Everett Site 
higher charging voltage, has a separate HV oil transformer unit. Assembly drawings of the cabinet interiors are presented in Figures 5-13 and 5-14. HV connectors and charging cable connectors are located on the back covers (doors) of the cabinets. Flexible, $2 \mathrm{~m}$ long cables connect cabinets with scabbling modules. Pulse controls are located at the top cover. The cabinet interiors are covered by sound-absorbing materials. Exterior blowers are used to cool cabinet interiors and specific circuit components. To control current pulses, an induction loop ("Rogovsky belt") with a passive integrator is used. Safe operation is secured by interlocks and automatic grounding.

Typical current oscillograms are shown in Figure 5-15. In agreement with SPB TU experiments, active resistance of the load (scabbling electrode gap) affects the current pulses. When resistance is low, the discharge is aperiodic and the concrete surface remains unaffected scabbling does not take place. 


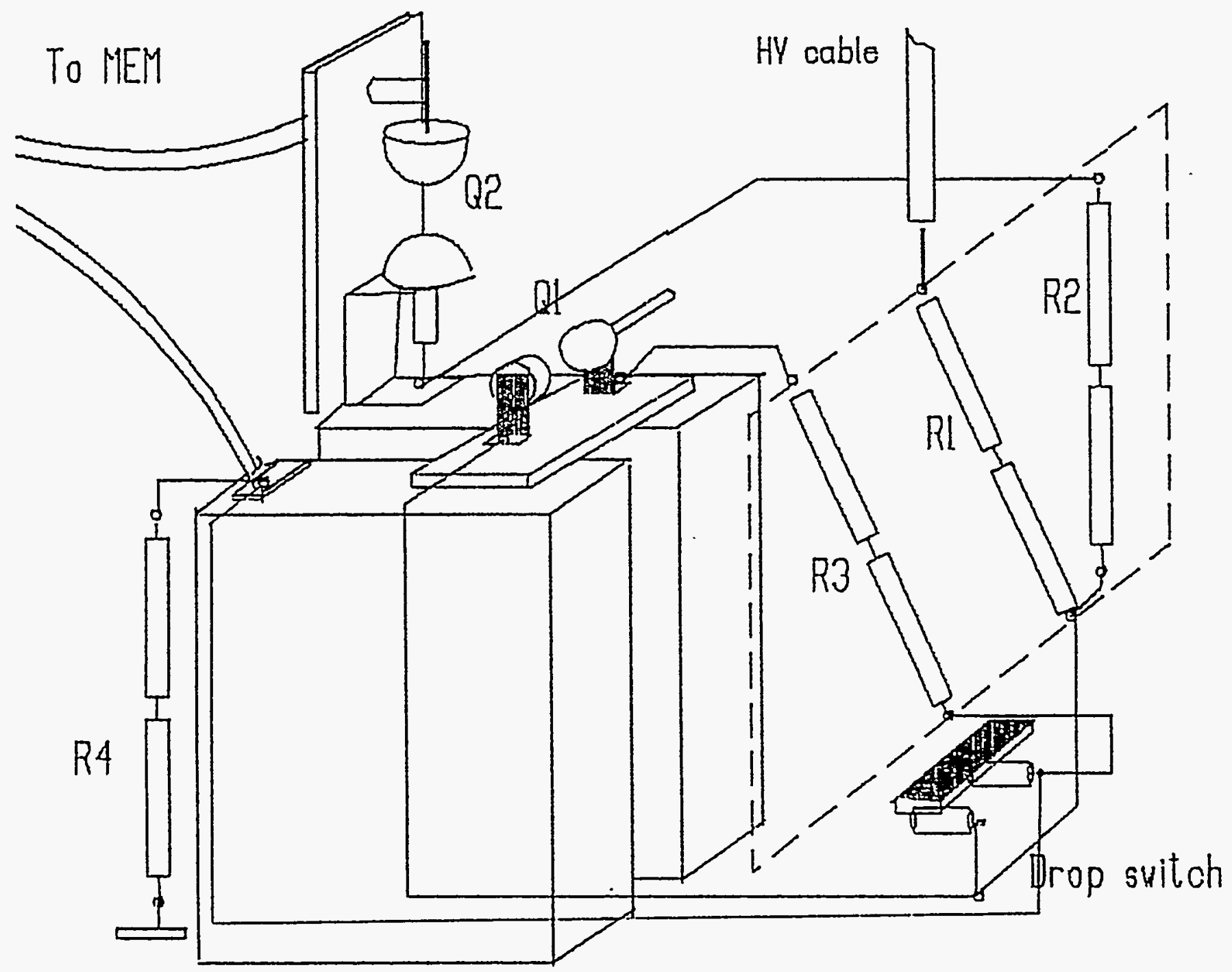

P7750.

Figure 5-13 Assembly Drawing of EHS-03R Cabinet Interior 


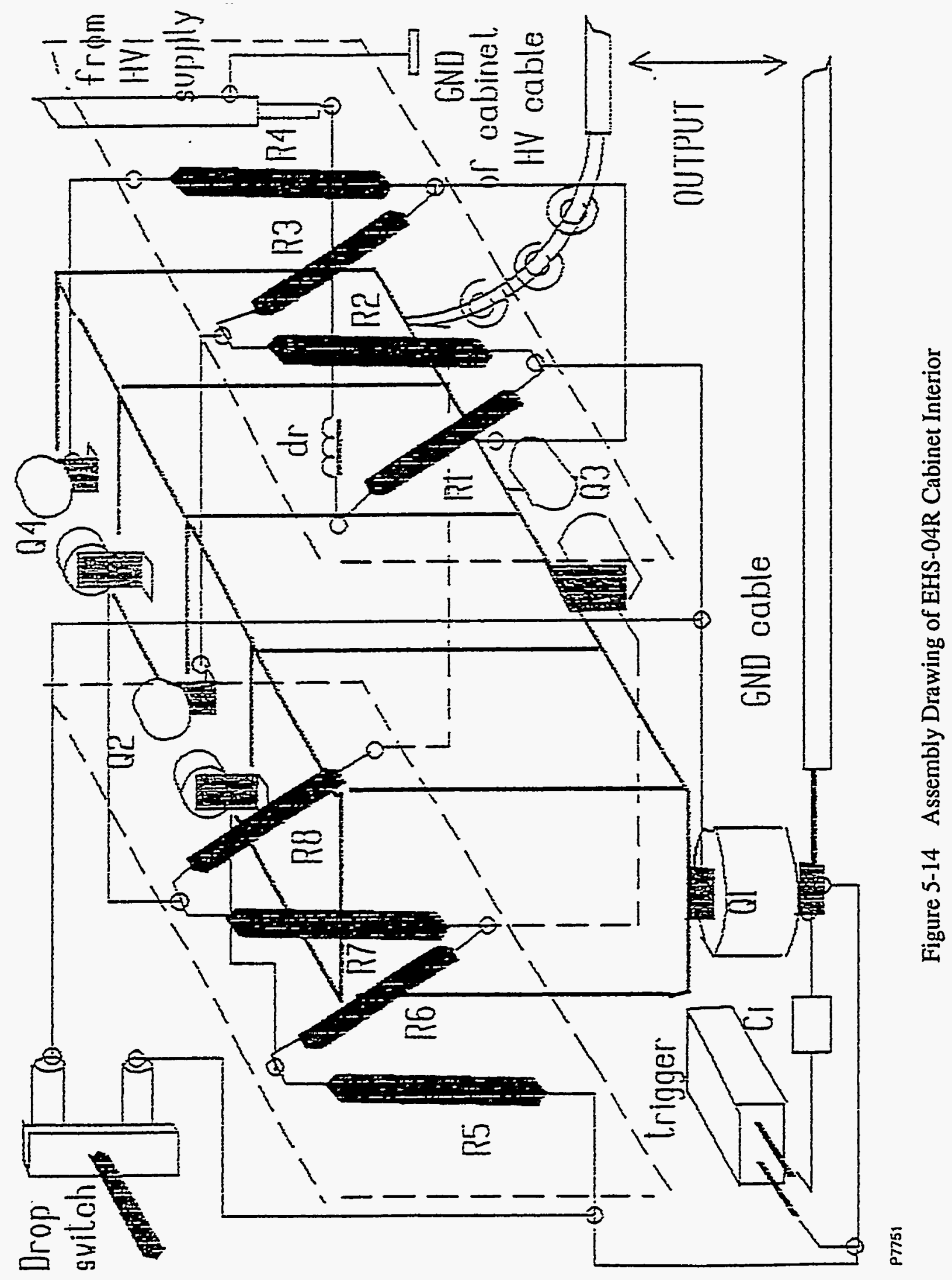




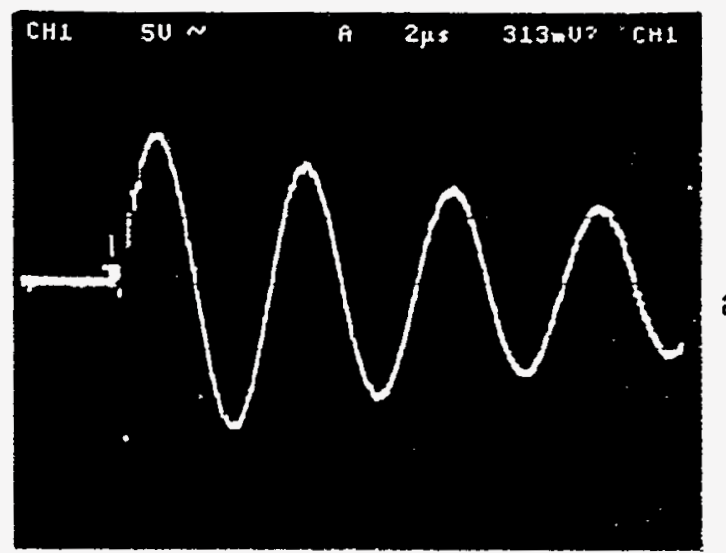

a)

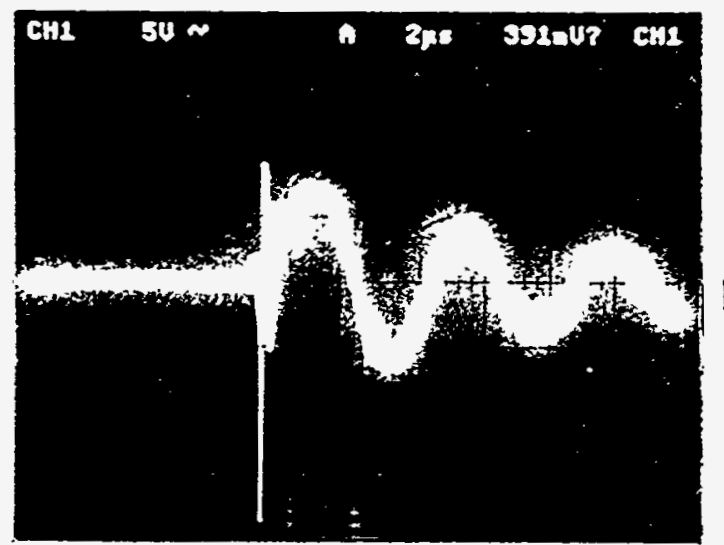

b)

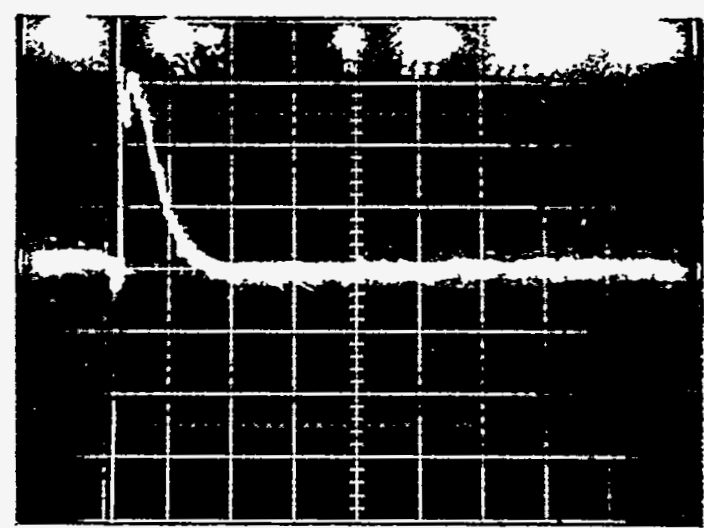

c)

P7752

Figure 5-15 Sample Oscillograms of EHS-03R Current Pulses

a) short circuit, b) regular EH discharge, c) aperiodic EH discharge through high resistance water gap 


\subsection{SCABBLING TRIALS AT TSD EVERETT SITE}

\subsection{INTRODUCTION}

Experiments and trials conducted at the Everett site were related to design, improvements, and modifications of the EHS components. Most of them were qualitative by nature. Only a limited number of quantitative performance characterization scabbling runs were made.

The area for scabbling trials located in Building 2 has an old floor made of 6 " thick concrete, with $3 / 4$ " aggregate (gravel) reinforced by bar at about a 2 " depth. In a few cases, the floor area processed by scabbling was later resurfaced by a "fresh" concrete overlay and scabbled again after concrete aging for 3-4 weeks. . Most trials were made over isolated floor segments. Within each position of the scabbling chamber, a 3 to 4 sq. $\mathrm{ft}$. area was processed. The total area processed in these trials was about 60 sq. $\mathrm{ft}$.

\subsection{QUALITATIVE DESCRIPTION AND EVALUATION OF SCABBLING OPERATION FEATURES AND PROBLEM AREAS}

\subsubsection{Electric Features: Factors Affecting Scabbling Efficiencv of the EH Discharge}

\subsubsection{Localization of Discharge Channel}

A good understanding of the behavior of the $\mathrm{EH}$ discharge in contact with a solid surface appeared to be crucial for designing a reliable scabbling module. Long-duration, broad-gauge scabbling became possible only with simple and rugged construction. Considerations on this issue are discussed below in some detail.

Discharge pulse shape, attachment/distribution of sequential discharges along electrodes, electrode erosion, and other phenomena taking place at the electrodes of EH discharge affect the scabbling process very strongly. In Phase I experiments with a single electrode (pair), it was demonstrated that scabbling efficiency is reduced significantly when electrodes are not in direct contact with concrete. This effect could only be expected for very high $(>100 \mathrm{kV})$ operation when discharge takes place through the concrete layer itself. For discharge through the water layer, this feature was rather surprising, because shock pressure and even cavitation intensity do not change drastically with distance from the discharge channel.

To explain the observations, we had to assume that concrete (or other) surface proximity helps the discharge initiation (e.g., by increasing local field strength). This allows capacitor discharging at lower initial voltage or for larger interelectrode distance. Also, shorter time delay reduces voltage drop due to leakage current. It is possible that, after the discharge channel is already formed, the supporting surface prevents the channel from traveling toward the upper electrode surface, i.e., about $1 / 2$ " from the concrete surface.

Whatever the actual mechanism is, we concluded that direct electrode/concrete contact is mandatory, and appropriate design features are needed to secure the contact by providing certain vertical pressure. For continuous (simultaneous with travel) pulsing/scabbling, the requirement of direct contact contradicts conditions for smooth, unobstructed electrode travel over the concrete surface, which is important to limit frictional erosion and to avoid electrode erosion, bending and misalignment. For stepwise XZ-travel, the problem can be solved by providing vertical pressure by gravity (heavy load), solenoid, spring, etc. 
Maintaining direct electrode/surface contact is even more important and challenging for wide (multielectrode or strip-type) scabbling modules. Without uniform (random or regular) engagement of individual electrodes (or strip electrode sections), uniform scabbling may be impossible because arcing might proceed at a single electrode pair or at a certain narrow sector of a strip electrode. With a multielectrode system, the issue can be resolved, in principle, by an individual spring-loaded (or otherwise flexible) support of each electrode. In practice, though, reliable,'long-duration operation of a system with more than a dozen electrode pairs affected by repetitive discharge-generated pulses is hard to achieve*.

Somewhat unexpectedly, the problem itself provided a solution. As soon as concrete is scabbled in the vicinity of an "active" electrode, the electrode/surface contact is lost, and the discharge moves to another electrode pair, where the contact is still intact. A sequence of these random discharge travels draws in all electrodes, which results in removal of concrete surface protrusions and, consequently, in uniform scabbling. Independent flexible electrode support becomes unnecessary, which substantially simplifies the design of the scabbling module.

Similar self-adjustment takes place with strip electrodes. Discharge breakdown starting deliberately at a certain location remains there until the electrode is in contact with concrete, and moves in a random fashion along the electrode gap width until a similar phenomenon takes place everywhere. After this stage is accomplished and strips come into contact with the concrete surface again, the next "cycle" of discharge travel begins, resulting in deeper scabbling.

In reality, this "regularly random" behavior can be complicated by at least two factors concrete nonuniformity, e.g., the presence of hard inclusions, like pieces of gravel, and initial skewness of the electrode with respect to the floor surface. The first situation is self-correcting. Discharge continues to run at the "special" location until the protrusion (or larger "bulging" floor area) is eventually removed. In the other case, the discharge may continue to run one-sided. If the preset number of pulses is not large enough, part of the floor segment may remain unscabbled; if the number of pulses is large, scabbling depth will differ systematically along the electrode width.

To avoid these scabbling deficiencies, a thorough initial adjustment of electrodes is needed. Alternatively, the module should be "soft"-supported in such a manner that electrodes are self-aligned parallel to the floor surface and exert even pressure on the concrete along their full width. The proper alignment is especially important for wide electrodes.

\subsubsection{Water Conductivity/Current Leakage Effects}

Another important EH discharge issue has its source in relatively high electric conductivity of water. Due to leaching and dissolution of the calcium-rich concrete debris formed by scabbling, the conductivity is rising from the initial value $10^{-4}(\mathrm{ohm} \cdot \mathrm{cm})^{-1}$ characteristic for clean tap water to a saturation level of about $10^{-3}(\mathrm{ohm} \cdot \mathrm{cm})^{-1}$. Most of the electric resistance of the EH discharge circuit can be attributed to the water gap; the total resistance of the other circuit elements is very low. The resistance of the water-filled space between electrodes depends on the space geometry - gap width and length, and electrode surface area - and on the water conductivity. The initial clean water resistance varies from 1,000 ohms for single rod electrodes to $300 \mathrm{ohms}$ for wide strip electrodes with about $1,000 \mathrm{sq} . \mathrm{cm}$ of surface area. After water conductivity increases, interelectrode resistance between strip electrodes can be as low as 100 ohms.

*The situation is better for the SHV system, where pulse energy and, accordingly, mechanical effects are about three times weaker. The multielectrode module with electrodes equipped with flexible rubber supports operated reliably in the medium duration trials. 


\subsubsection{Performance of HV Cables/Connectors}

High voltage cables and connectors (see Figure 3-17) are among the vulnerable EH system components. Duration tests indicated that coaxial cables of sufficient flexibility (i.e., moderate - below 1" OD) are overheated beyond the capability of the interior insulation in a few minutes. Cooling by $50 \mathrm{cpm}$ of compressed ( $50 \mathrm{psi}$ ) air blown through an external coaxial hose kept the temperature under $60^{\circ} \mathrm{C}$, allowing continuous operation.

Initially, there were problems with the integrity of cable-to-electrode connectors subject to water shocks, as well as with electrical breakdown between the outer cable shield and frame of the scabbling chamber, and the "split" location between two conductors of the coaxial. These issues were addressed and resolved by using heavy solid copper plates as connectors and thick wall insulating polyethylene tubing.

\subsubsection{Mechanical and Flow Features}

\subsubsection{Effect of Concrete Strength}

Old-age concrete of the Building 2 floor had only a few local defects - small cracks and some cut-off rods and pipes remaining from equipment used in the past. These defects did not adversely affect scabbling: there were no changes in frequency or distribution of pulses, no electric shorts or breakdown or mechanical problems.. The strength of this concrete was roughly equivalent to that of the new concrete blocks of $4000 \mathrm{lbs}$. compression strength material made specifically for scabbling tests and aged for approximately one year. Rubble formed by scabbling with strip electrodes was similar to that generated in the Phase I experiments with rod electrodes: the median rubble size was $4 \mathrm{~mm}\left(1 / 6^{\prime \prime}\right)$ with $20 \%$ under $1 \mathrm{~mm}$ in diameter.

Concrete of the same basic composition has been used for resurfacing floor areas scabbled earlier. Removal of this layer required much less time and energy/number of pulses. Despite the use of a special precoat over the old concrete surface, the new layer was separated quite easily. Rubble generated by scabbling of this concrete layer was coarser than the one formed from the old concrete - about $50 \%$ of the pieces being larger than $1 / 4^{\prime \prime}$.

\subsubsection{Air Flow, Water Flow, and Debris Removal and Separation Features}

Functioning of the flow subsystem components assembled to satisfy minimum operational requirements reveals the following features and problem areas:

- To prevent water loss from the scabbling chamber through the foam gaskets installed at the chamber/floor interface, a vacuum system should provide minimum $-5^{\prime \prime} \mathrm{H}_{2} \mathrm{O}$ pressure at a smooth concrete surface, and minimum $-10^{\prime \prime} \mathrm{H}_{2} \mathrm{O}$ at a rough (e.g., scabbled) concrete surface. With the foam gaskets currently in use, these negative pressure levels correspond to (approximately) $80 \mathrm{cfm}$ and $160 \mathrm{cfm}$ air flow, respectively. With further improvement of vacuum (to $-15^{\prime \prime} / 20^{\prime \prime} \mathrm{H}_{2} \mathrm{O}$ ) by using better (dense but flexible) gasket material and/or stronger air suction, it may be possible to transfer the scabbling chamber to the next floor segment without water removal. Eventually, after several hours of operation, the foam gaskets at the enclosure sides perpendicular to the electrode gap (i.e., opposing the short side of the module) are damaged. To reduce the damage, baffles should be installed to reduce water shock impact.

- Several efforts were made to remove scabbling-generated rubble from within the enclosure. The devices employed include static and traveling nozzles of circular or 
linear uptake, water suction pumps, and wet vacuums - regular or equipped with (snorkel-type) controls for water/air flow ratio. Also, it was attempted to remove debris simultaneously with the bulk of the water or after the main amount of water was already removed. In addition, water spray over the debris in the vicinity of the traveling nozzle was attempted.

Some of these approaches were able to remove part of the debris (in addition to fine fraction readily removable with main water suction), but complete removal (say, more than $90 \%$ of the total) was never achieved. Even at high suction capability, static nozzle removes all debris from within a circle $4^{\prime \prime}-6^{\prime \prime}$ in diameter. The problem could probably be resolved if the scabbling chamber/module design is substantially changed, providing an unobstructed scan of the concrete surface. As mentioned in Section 4 , removal of the concrete debris by a separate after-scabbling operation seems, currently, more practical (see also discussion in Section 8).

- In spite of substantial heat release by the $\mathrm{EH}$ discharge, amounting to $50 \%$ of the total electric power or about $2 \mathrm{~kW}$ in most of our experiments, no substantial water heating takes place. Maximum heating of a 100 liter water pool in the chamber observed for $30 \mathrm{~min}$. operation was $1.5^{\circ} \mathrm{C}$. Without thermal losses, $10^{\circ} \mathrm{C}$ heating should occur. It is evident that heat losses through the enclosure walls, concrete floor, and with air flow remove $80-90 \%$ of the energy input. Consequently, there is no need for heat exchange in the water recirculation loop.

- Process water and fine concrete debris are spread all over the interior of the scabbling chamber, including slides and leading screws of the positioner. The debris deposits did not create problems, at least with anodized surfaces and way covers used in the Velmex design. Water and air shocks and vibration did not affect the $X$ positioner or pneumatic Z-positioner either. On the other hand, even minor mutual misalignment of the two Velmex slides is damaging to the positioner's drive. As already mentioned in Section 3, electric pulses do not affect the DC motor drive and its controls when the motor is installed outside the scabbling chamber and is electrically isolated. A $1 / 4 \mathrm{HP}$ motor is sufficient for positioning a $100 \mathrm{lb}$. scabbling module.

\subsection{QUANTITATIVE CHARACTERIZATION OF TSD SCABBLING TRIALS}

In May 1995 the main design features of the EHS system (HV pulsers and scabbling module in the first place) were well defined. After these key components, as well as the positioner and scabbling chamber were assembled, a limited number of scabbling trials were made. The primary goal was to measure the main performance parameters - scabbling rate and energy consumption - for a rather narrow range of conditions available without changes or readjustments of the hardware. In most cases, the 3-4 sq. ft. floor area available for scabbling at fixed positions of the enclosure was subdivided into two parts, each processed at a somewhat different combination of operating parameters. In addition to preset values, the net scabbling time (pulsing time), total processing (pulsing + positioning ) time, total number of pulses, and number of scabbling positions for each run (or each "half-run") were registered. After the run was completed, areas of scabbled segments were measured, and average scabbling depth defined by measuring the volume of sand required to fill the scabbling-generated depression. A range of conditions and operating parameters for these performance characterization trials is shown in Table 6-1. Figures 6-1 to 6-2 show the EHS system configuration used in these tests. Photographs of typical scabbled areas, taken under different illumination and magnification conditions, are presented in Figures 6-3 and 6-4. 
TABLE 6-1

\section{RANGE OF CONDITIONS AND OPERATING PARAMETERS FOR SCABBLING TRIALS AT TSD EVERETT SITE}

\begin{tabular}{|l|l|}
\hline DC Power Supply & a) ALE-402, or \\
& b) Maxwell Lab \\
Maximum (nominal) Available Power & $4 \mathrm{~kW}$ \\
PFN Main Components & a) $13 \mu \mathrm{F}$ Capacitor, EGG GP-41B Switch \\
& b) $10 \mu \mathrm{F}$ Capacitor, EGG GP-15B Switch \\
\hline & XZ Positioning with Automated Cycle Control \\
Operating Mode & \\
Ranges: & $20<\mathrm{U}_{\mathrm{O}}<26 \mathrm{kV}$ \\
Charging Voltage & $2.5<\mathrm{E}<3.7 \mathrm{~kJ}$ \\
Stored Energy & $3 / 16^{\prime \prime}<\mathrm{L}<3 / 8^{\prime \prime}$ \\
Electrode Gap & $18^{\prime \prime}<\mathrm{W}<24^{\prime \prime}$ \\
Electrode Width & $13<\mathrm{f}<2.2 \mathrm{~Hz}$ \\
Pulse Frequency & $1 "<\mathrm{X}<2 "$ \\
X-positioner Step & $50<\mathrm{n}<150$ \\
No. Pulses per Position & $18 "<\mathrm{W}<24^{\prime \prime}$ \\
Scabbled Area - Width & $20^{\prime \prime}<\mathrm{e}<24^{\prime \prime}$ \\
\multicolumn{1}{|c|}{ Length } & \\
\hline
\end{tabular}




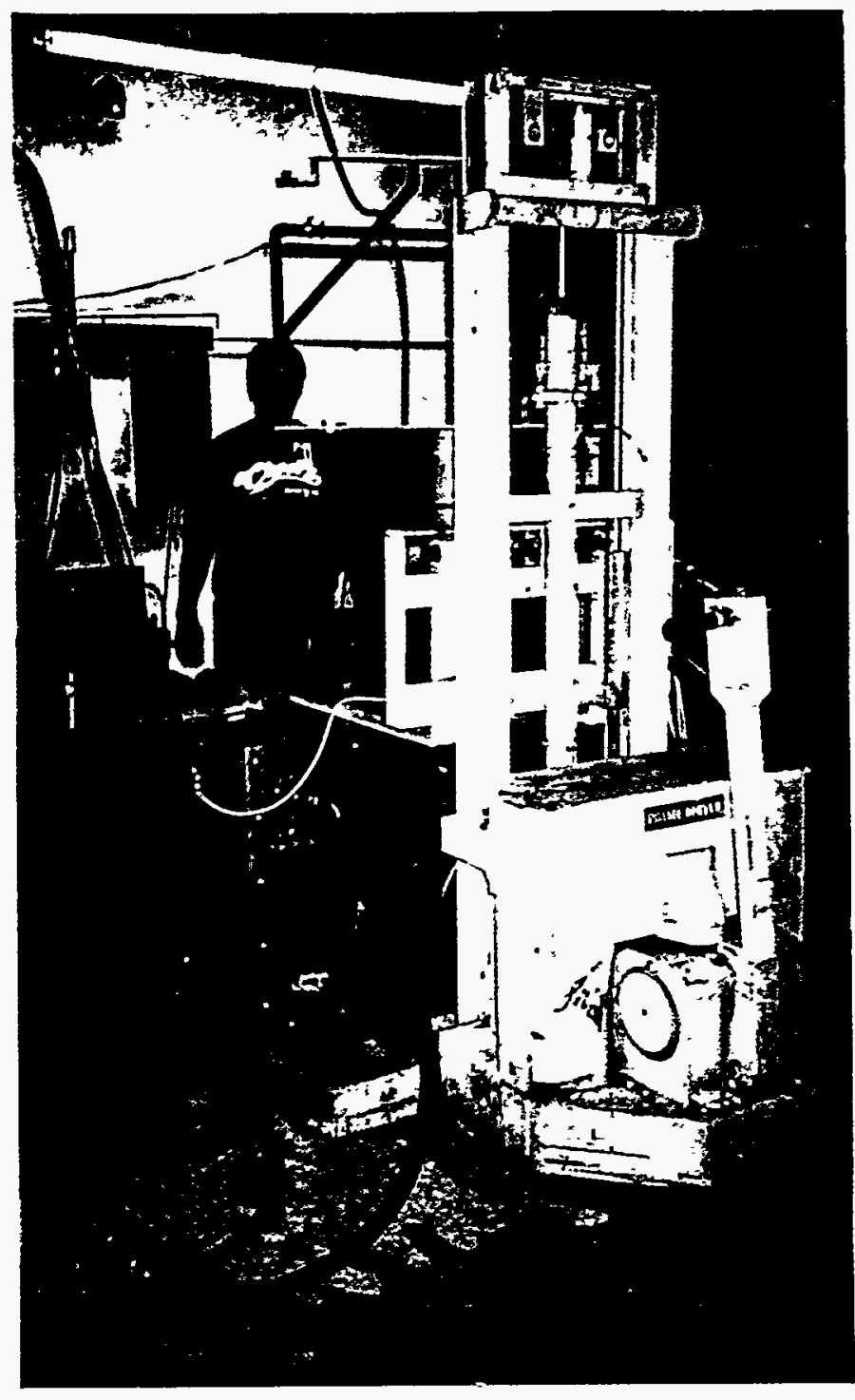

a)

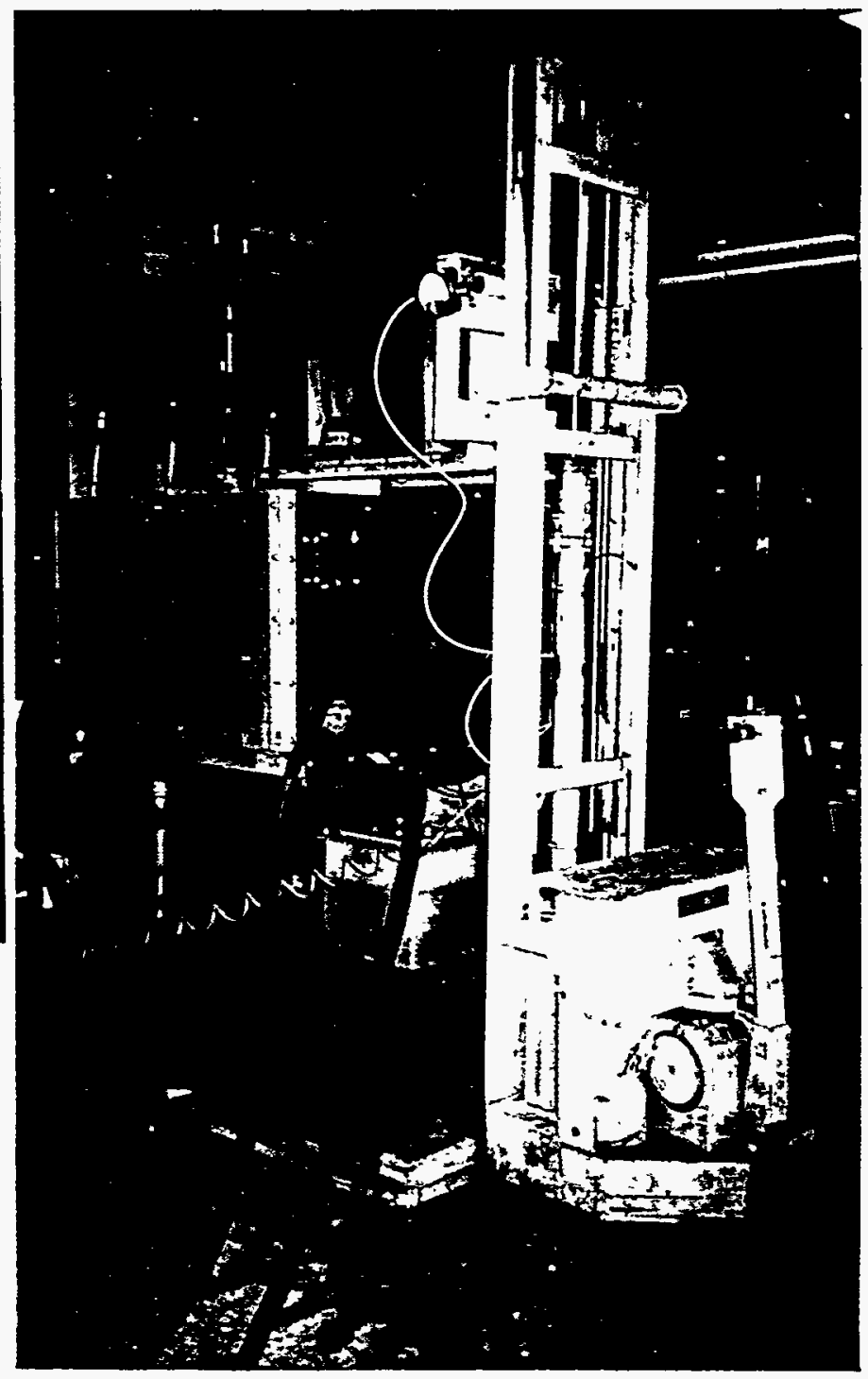

P 7763

Figure 6-1 Scabbling Chamber/Flow System Configurations used in the April and May Everett Site Trials. Scabbling chamber is: (a) in lower (scabbling) position, (b) in upper (inspection, rubble removal and travel) position 

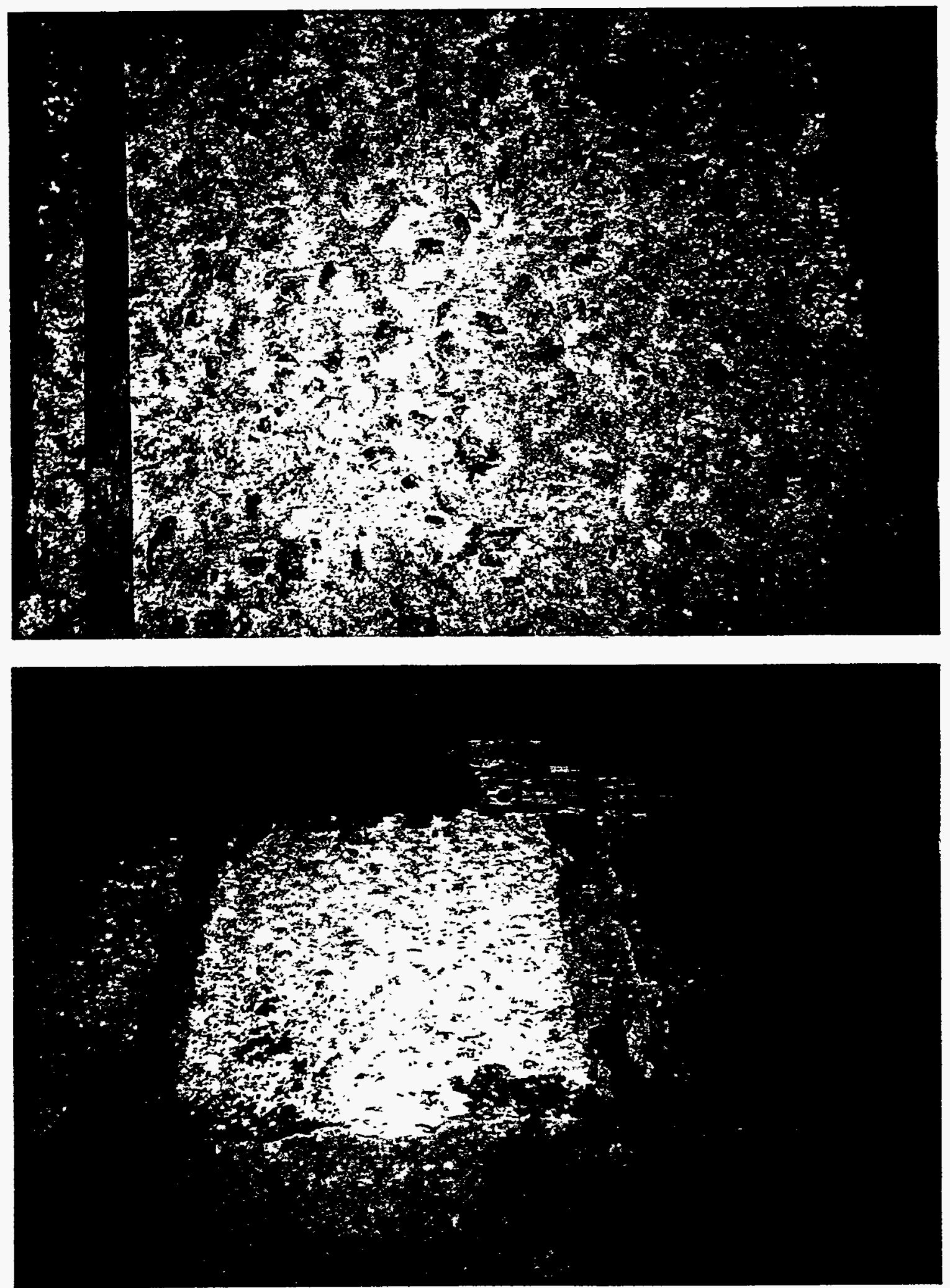

P7774

Figure 6-3 Scabbled Concrete Floor Areas at Everett Site 
Table 6-2 provides conditions for successfully completed trials (i.e., runs without equipment malfunctioning or other complications) and scabbling performance data obtained. Notwithstanding a rather small area processed and a narrow range of conditions and operating parameters, the scabbling performance can be evaluated and certain trends revealed. The main results are as follows:

\section{With respect to energy consumption:}

- Consumption of electric energy per unit processed area is 0.47-0.95 kWh/sq. ft. and $0.32-0.67 \mathrm{kWh} / \mathrm{sq}$. ft. if calculated on the basis of "nominal" and "actual" stored energy, respectively.

- The difference between the nominal and actual values of stored energy is due to incomplete capacitor charging for short time intervals between the sequential pulses; the difference is larger for higher pulse frequency.

- Consumption of electric energy per unit concrete mass removed is $1100-1500 \mathrm{~kJ} / \mathrm{kg}$ and $700-950 \mathrm{~kJ} / \mathrm{kg}$ for nominal and actual stored energy values.

- The difference between "per area" and "per mass" energy consumption reflects, as could be expected, higher energy required for deeper scabbling. Due to this factor, the range of energy consumption values is narrower when calculated on a "per mass' basis.

- For a given scabbling depth, the difference between energy consumption under a different set of operating parameters is not significant. The average value is about $100 \mathrm{~kJ}$ ( $28 \mathrm{~W}$-hours) of the actual storage energy per $1 \mathrm{~mm}$ depth, per 1 sq. $\mathrm{ft}$. area.

- If concrete contamination is limited to a thin concrete layer (as is known to be the case in many instances), the EHS operating parameters can be selected to provide about $4 \mathrm{~mm}$ scabbling depth (due to scabbling nonuniformity, shallower processing may leave local unscabbled areas). Under these conditions (as well as for concrete strength equal to the one at the Everett site), actual energy consumption is expected to be about $0.1 \mathrm{kWh} / \mathrm{sq}$. $\mathrm{ft}$.

2. With respect to the scabbling rate:

- The scabbling rate varies between 6 and 15 sq. ft./hour, and depends only weakly on the specific energy input.

- The rate is higher for higher pulse frequency. The increase takes place until the actual pulse energy stays above the scabbling threshold (i.e., until the increase of frequency makes $U_{\text {ef }}$ and $\mathrm{E}_{\mathrm{ef}}$ too low to break concrete).

- When the number of pulses per scabbling position (or per unit length) increases, the scabbling rate decreases somewhat (while the scabbling depth increases).

- For shallow (under 1/4" deep) scabbling sufficient for removing surface contaminant, the scabbling rate of about 15 sq. ft./hr. can be expected. For deeper (say 1/2") scabbling, a rate of about $10 \mathrm{sq}$. ft./hr. can be achieved, but at about two times higher energy input (i.e., at higher installed power). 

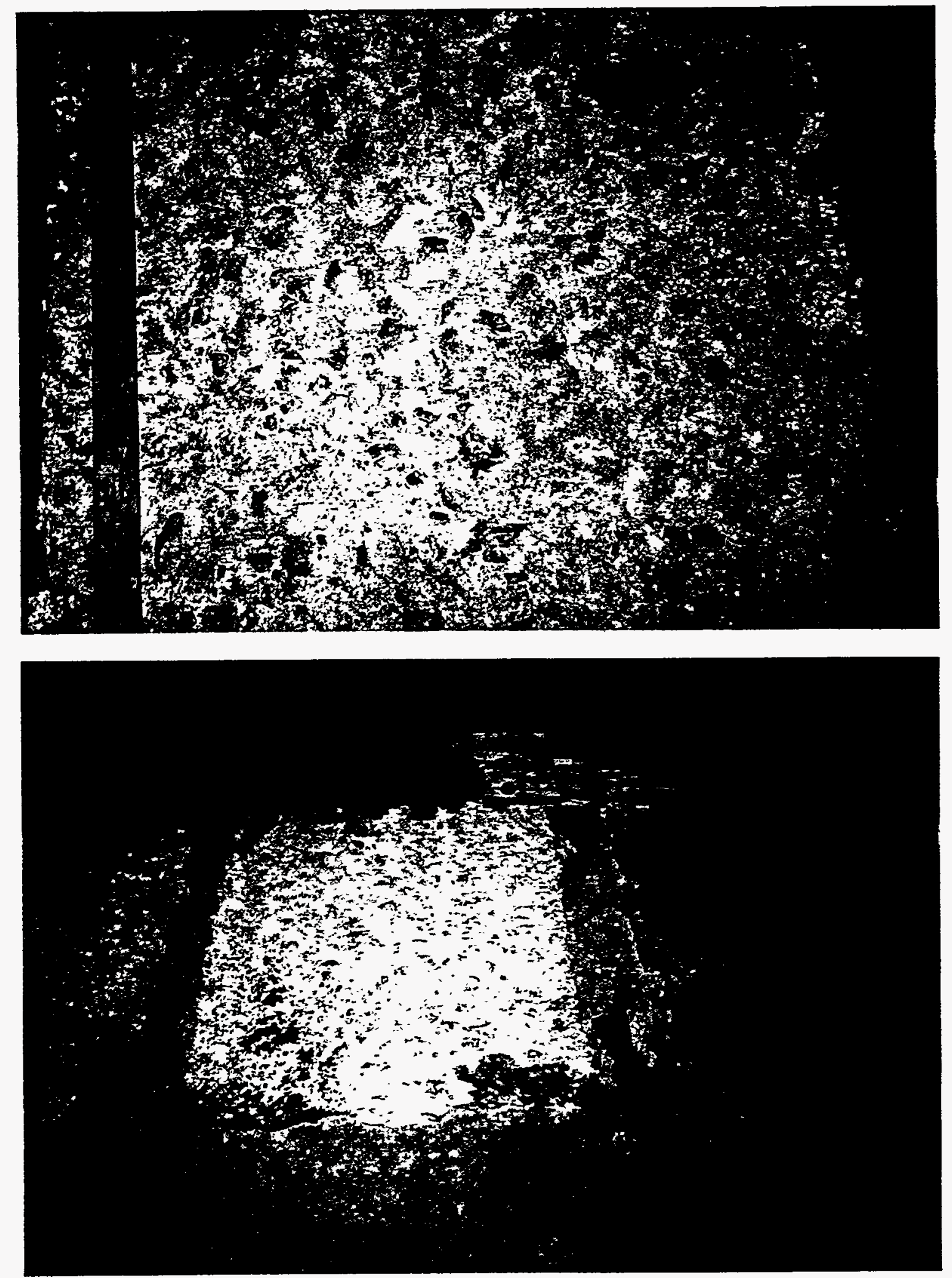

PT774

Figure 6-3 Scabbled Concrete Floor Areas at Everett Site 


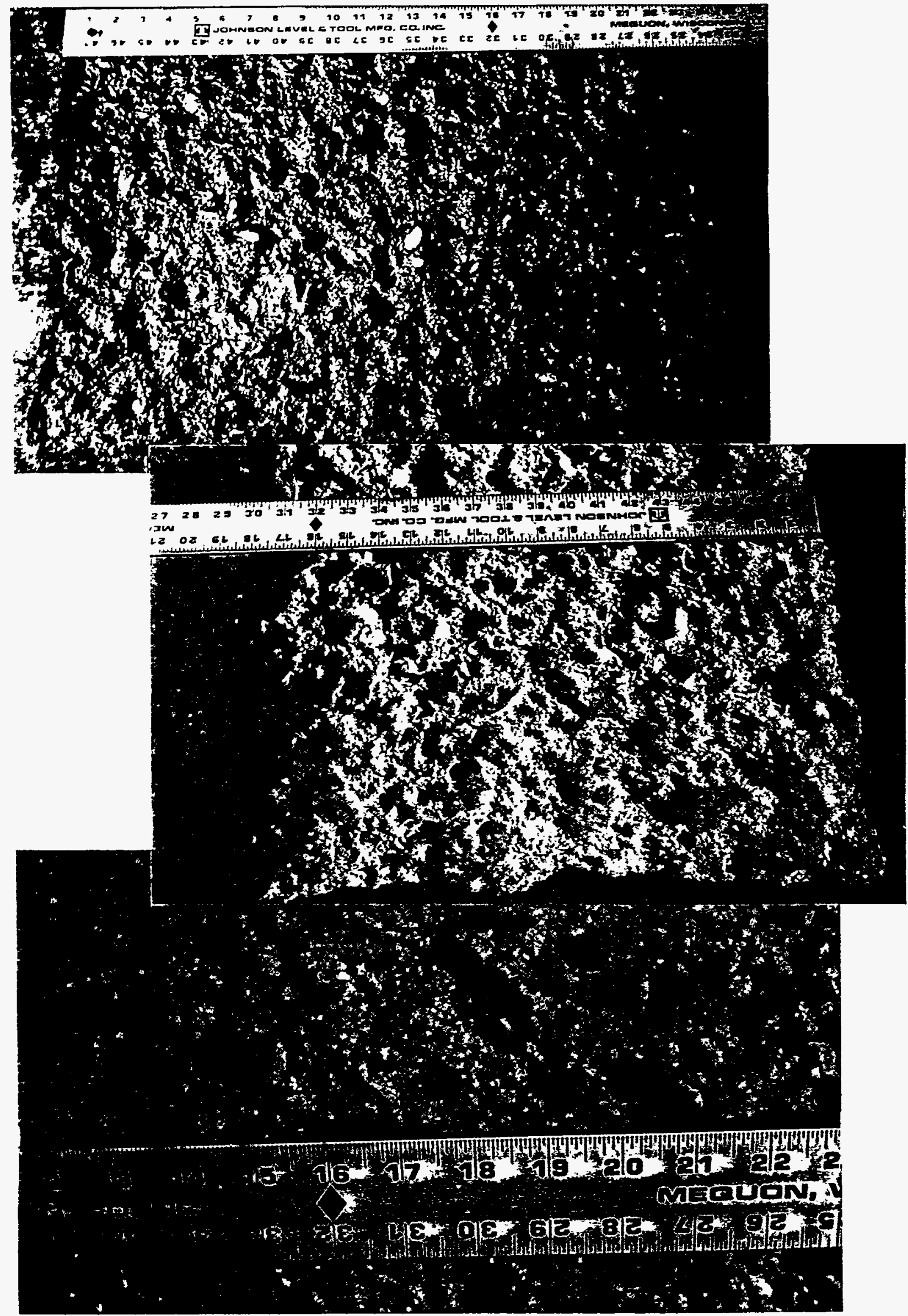

P7765

Figure 6-4 Surface of Scabbled Concrete Areas at Everett Site - views with side illumination at different magnifications 
Table 6-2 provides conditions for successfully completed trials (i.e., runs without equipment malfunctioning or other complications) and scabbling performance data obtained. Notwithstanding a rather small area processed and a narrow range of conditions and operating parameters, the scabbling performance can be evaluated and certain trends revealed. The main results are as follows:

\section{With respect to energy consumption:}

- Consumption of electric energy per unit processed area is $0.47-0.95 \mathrm{kWh} / \mathrm{sq}$. ft. and $0.32-0.67 \mathrm{kWh} / \mathrm{sq}$. ft. if calculated on the basis of "nominal" and "actual" stored energy, respectively.

- The difference between the nominal and actual values of stored energy is due to incomplete capacitor charging for short time intervals between the sequential pulses; the difference is larger for higher pulse frequency.

- Consumption of electric energy per unit concrete mass removed is $1100-1500 \mathrm{~kJ} / \mathrm{kg}$ and $700-950 \mathrm{~kJ} / \mathrm{kg}$ for nominal and actual stored energy values.

- The difference between "per area" and "per mass" energy consumption reflects, as could be expected, higher energy required for deeper scabbling. Due to this factor, the range of energy consumption values is narrower when calculated on a "per mass' basis.

- For a given scabbling depth, the difference between energy consumption under a different set of operating parameters is not significant. The average value is about $100 \mathrm{~kJ}$ (28 W-hours) of the actual storage energy per $1 \mathrm{~mm}$ depth, per 1 sq. ft. area.

- If concrete contamination is limited to a thin concrete layer (as is known to be the case in many instances), the EHS operating parameters can be selected to provide about $4 \mathrm{~mm}$ scabbling depth (due to scabbling nonuniformity, shallower processing may leave local unscabbled areas). Under these conditions (as well as for concrete strength equal to the one at the Everett site), actual energy consumption is expected to be about $0.1 \mathrm{kWh} / \mathrm{sq}$. $\mathrm{ft}$.

2. With respect to the scabbling rate:

- The scabbling rate varies between 6 and 15 sq. ft./hour, and depends only weakly on the specific energy input.

- The rate is higher for higher pulse frequency. The increase takes place until the actual pulse energy stays above the scabbling threshold (i.e., until the increase of frequency makes $U_{\mathrm{ef}}$ and $\mathrm{E}_{\mathrm{ef}}$ too low to break concrete).

- When the number of pulses per scabbling position (or per unit length) increases, the scabbling rate decreases somewhat (while the scabbling depth increases).

- For shallow (under 1/4" deep) scabbling sufficient for removing surface contaminant, the scabbling rate of about $15 \mathrm{sq}$. ft./hr. can be expected. For deeper (say 1/2") scabbling, a rate of about $10 \mathrm{sq}$. ft./hr. can be achieved, but at about two times higher energy input (i.e., at higher installed power). 

CHARACTERIZATION T

\begin{tabular}{|c|c|c|c|c|c|c|c|c|c|c|c|c|c|c|}
\hline No. & $\begin{array}{l}U_{\mathrm{o}} \\
\mathrm{kV}\end{array}$ & $\begin{array}{l}\mathrm{E}_{\mathrm{o}} \\
\mathrm{kJ}\end{array}$ & $\begin{array}{c}\mathrm{L} \\
\mathrm{mm}\end{array}$ & $\begin{array}{l}\mathrm{X} \\
\mathrm{cm}\end{array}$ & $\mathrm{n}$ & $\mathrm{n} / \mathrm{x}$ & $\begin{array}{c}\mathrm{f} \\
\mathrm{Hz}\end{array}$ & $\begin{array}{l}\mathrm{U}_{\mathrm{ef}} \\
\mathrm{kV}\end{array}$ & $\begin{array}{l}\mathrm{E}_{\mathrm{ef}} \\
\mathrm{kJ}\end{array}$ & $\begin{array}{l}\mathrm{E}_{\mathrm{o}} / \mathrm{x} \\
\mathrm{kJ} / \mathrm{cm}\end{array}$ & $\begin{array}{l}\mathrm{E}_{\mathrm{ef}} / \mathrm{x} \\
\mathrm{kJ} / \mathrm{cm}\end{array}$ & $\begin{array}{c}\mathrm{t}_{\mathrm{p}} \\
\mathrm{sec}\end{array}$ & $\mathrm{M}$ & $\mathrm{N}$ \\
\hline 1 & 21 & 2.8 & 5 & 2.5 & 100 & 40 & 1.2 & 17 & 1.9 & 1.1 & 0.68 & 83 & 10 & 1000 \\
\hline 2 & 21 & 2.8 & 5 & 2.5 & 150 & 60 & 1.2 & 17 & 1.9 & 1.1 & 0.68 & 125 & 12 & 1800 \\
\hline 3 & 24 & 3.7 & 8 & 3.3 & 100 & 30 & 1.2 & 19 & 2.35 & 1.1 & 0.57 & 83 & 9 & 900 \\
\hline 4 & 24 & 3.7 & 8 & 3.3 & 150 & 45 & 1.2 & 19 & 2.35 & 1.1 & 0.57 & 125 & 9 & 1350 \\
\hline 5 & 21 & 2.8 & 8 & 3.3 & 180 & 55 & 1.2 & 17 & 1.9 & 0.85 & 0.51 & 150 & 9 & 1620 \\
\hline 6 & 24 & 3.7 & 8 & 3.3 & 150 & 45 & 1.75 & 17 & 1.9 & 1.1 & 0.51 & 86 & 8 & 1200 \\
\hline 7 & 24 & 3.7 & 8 & 3.8 & 180 & 55 & 1.2 & 19 & 2.35 & 1.0 & 0.62 & 150 & 15 & 2700 \\
\hline 8 & 25 & 3.1 & 5 & 3.3 & 130 & 40 & 1.2 & 21 & 2.2 & 1.05 & 0.67 & 108 & 8 & 1040 \\
\hline 9 & 25 & 3.1 & 5 & 2.5 & 130 & 40 & 1.75 & 19 & 1.8 & 1.25 & 0.72 & 74 & 12 & 1560 \\
\hline 10 & 25 & 3.1 & 8 & 2.5 & 100 & 40 & 2.0 & 20 & 2.0 & 1.25 & 0.80 & 50 & 12 & 1200 \\
\hline 11 & 25 & 3.1 & 8 & 2.5 & 180 & 72 & 1.2 & 21 & 2.2 & 1.25 & 0.88 & 150 & 10 & 1800 \\
\hline 12 & 27 & 3.6 & 8 & 3.3 & 150 & 45 & 1.75 & 21 & 2.2 & 1.1 & 0.67 & 86 & 19 & 2850 \\
\hline
\end{tabular}

$\begin{array}{ll}\mathrm{U}_{0} & \text { Nominal charging voltage } \\ \mathrm{E}_{0} & \text { Nominal stored energy } \\ \mathrm{U}_{e f} & \text { Effective discharge voltage for reperitive pulses } \\ \mathrm{E}_{\mathrm{ef}} & \text { Effective stored energy } \\ \mathrm{L} & \text { Interelectrode gap } \\ \mathrm{X} & \text { Distance (step) between scabbling positions } \\ \mathrm{n} & \text { Number of pulses per position } \\ \mathrm{n} / \mathrm{x} & \text { Number of pulses per step } \\ \mathrm{f} & \text { Pulse frequency } \\ \mathrm{E}_{\mathrm{d}} / \mathrm{x}, \mathrm{E}_{\mathrm{ef}} / \mathrm{x} & \text { Energy input per step } \\ \mathrm{t} & \text { Net pulsing time per position } \\ \mathrm{M} & \text { Number of scabbling positions over processed segment } \\ \mathrm{N} & \text { Total number of pulses over processed segment } \\ \mathrm{NE}_{\mathrm{o}}, \mathrm{NE}_{e} & \text { Total energy input } \\ \mathrm{T} & \text { Total processing time (including module travel time) }\end{array}$

$\ell$ $\mathrm{S}$ V $<d>$ $\mathrm{S} / \mathrm{T}$ m $\mathrm{NE}_{\mathrm{d}} / \mathrm{S}, \mathrm{NE}$

Conditions ar

- Width of :

- Storage ca 
BLE 6-2

PERFORMANCE PARAMETERS FOR

RIALS AT TSD EVERETT SITE

\begin{tabular}{|c|l|l|l|l|c|c|c|c|c|c|c|c|}
\hline $\begin{array}{l}\mathrm{NE}_{\mathrm{o}} \\
\mathrm{kJ}\end{array}$ & $\begin{array}{l}\mathrm{NE}_{\mathrm{ef}} \\
\mathrm{kJ}\end{array}$ & $\begin{array}{l}\mathrm{T} \\
\mathrm{min}\end{array}$ & $\begin{array}{l}\ell \\
\mathrm{in}\end{array}$ & $\begin{array}{l}\mathrm{S} \\
\mathrm{ft}^{2}\end{array}$ & $\begin{array}{l}\mathrm{V} \\
\mathrm{cm}^{3}\end{array}$ & $\begin{array}{l}<\mathrm{d}> \\
\mathrm{mm}\end{array}$ & $\begin{array}{l}\mathrm{m} \\
\mathrm{kg}\end{array}$ & $\begin{array}{l}\mathrm{S} / \mathrm{T} \\
\mathrm{ft}^{2} / \mathrm{hr}\end{array}$ & $\begin{array}{l}\mathrm{NE}_{\mathrm{o}} / \mathrm{S} \\
\mathrm{kWh} / \mathrm{ft}^{2}\end{array}$ & $\begin{array}{l}\mathrm{NE}_{\mathrm{ef}} / \mathrm{S} \\
\mathrm{kWh} / \mathrm{ft}^{2}\end{array}$ & $\begin{array}{l}\mathrm{NE}_{\mathrm{d}} / \mathrm{m} \\
\mathrm{kJ} / \mathrm{kg}\end{array}$ & $\mathrm{NE}_{\mathrm{ef}} / \mathrm{m}$ \\
\hline 2800 & 1900 & 16 & 10 & 1.65 & 920 & 6 & 2.15 & 10 & 0.47 & 0.32 & 1300 & 880 \\
\hline 5040 & 3420 & 28 & 12 & 2.0 & 1680 & 9 & 3.95 & 7 & 0.70 & 0.47 & 1280 & 860 \\
\hline 3320 & 2110 & 16 & 11 & 1.8 & 1250 & 7.5 & 2.95 & 11 & 0.51 & 0.32 & 1120 & 710 \\
\hline 5000 & 3170 & 21 & 11 & 1.8 & 1660 & 10 & 4.05 & 8.5 & 0.78 & 0.49 & 1270 & 810 \\
\hline 4520 & 3080 & 25 & 11 & 1.8 & 1500 & 9 & 3.50 & 7 & 0.70 & 0.47 & 1280 & 910 \\
\hline 4450 & 2280 & 14 & 10 & 1.65 & 1230 & 8 & 2.90 & 12 & 0.75 & 0.38 & 1520 & 780 \\
\hline 10000 & 6330 & 42 & 22.5 & 3.75 & 3140 & 9 & 7.40 & 9 & 0.74 & 0.52 & 1350 & 850 \\
\hline 3230 & 2290 & 21 & 10 & 1.65 & 1060 & 7 & 2.55 & 8 & 0.54 & 0.39 & 1270 & 900 \\
\hline 4850 & 2820 & 18 & 12 & 2.0 & 1670 & 9 & 3.90 & 11 & 0.67 & 0.40 & 1230 & 720 \\
\hline 3720 & 2400 & 13 & 12 & 2.0 & 1310 & 7 & 3.10 & 15 & 0.52 & 0.34 & 1200 & 770 \\
\hline 5580 & 3950 & 28 & 10 & 1.65 & 1750 & 11.5 & 4.10 & 6 & 0.95 & 0.67 & 1350 & 960 \\
\hline 10240 & 6250 & 32 & 24 & 4.0 & 3540 & 9.5 & 8.30 & 12.5 & 0.73 & 0.46 & 1250 & 750 \\
\hline
\end{tabular}

Length of processed segment

Area of processed segment

Volume of concrete removed

Average scabbling depth

Scabbling rate

Mass of removed concrete

$5, \mathrm{NE}_{\mathrm{d}} / \mathrm{m}, \mathrm{NE}_{\text {ef }} / \mathrm{m} \quad$ Energy consumption per unit area and per unit mass, respectiveiy

id constant parameters for this series of trials:

cabbled segment - 24"

pacitance: For runs 1-7 with ALE power supply - $13 \mu \mathrm{F}$; runs 8-12 with Maxwell power supply - $10 \mu \mathrm{F}$

$\mathrm{Z}$ travel time between scabbling positions - $15-25 \mathrm{sec}$; total travel time is included in the processing ime $T$. 


\subsection{OPERATION OF EM SHV SYSTEM AT TSD SITE}

At the TSD Everett site, HVG were tested in the scabbling operation with multielectrode and linear (strip) electrode modules. EHS-04R/MEM combination runs were made at $27 \mathrm{kV}$ charging voltage, $1 \mathrm{~kJ}$ stored energy in two modes:

a) With interelectrode distance $\mathrm{L}=15 \mathrm{~mm}, 25$ pulses per position and $25 \mathrm{~mm}$ distance between positions, the average scabbling depth was $10 \mathrm{~mm}$, and energy consumption $195 \mathrm{~J} / \mathrm{cu}$. cm $(80 \mathrm{~J} / \mathrm{g})$.

b) With $\mathrm{L}=8 \mathrm{~mm}$ and 40 pulses per position, the scabbling depth was $8 \mathrm{~mm}$ and energy consumption increased to $625 \mathrm{~J} / \mathrm{cu}$. cm $(260 \mathrm{~J} / \mathrm{g})$. Evidently, the longer interelectrode gap is beneficial; it requires, though, higher operating voltage and is more vulnerable to current leakage.

EHS-03R/ strip electrode combination runs were made with $40 \mathrm{~cm}$-long linear electrodes and $12 \mathrm{~mm}$ interelectrode distance. To reduce leakage, electrodes were covered by silicon rubber (RTV). At. $63 \mathrm{kV}$ charging voltage, $1 \mathrm{~kJ}$ pulse energy, $3.8 \mathrm{~ms}$ pulse duration, a concrete floor area $40 \times 18 \mathrm{~cm}$ sq. (16" $\left.\times 7^{\prime \prime}\right)$ has been processed by 220 pulses with 30 pulses per position and $25 \mathrm{~mm}$ between positions. The average scabbling depth was $6 \mathrm{~mm}$, and energy consumption amounted to $520 \mathrm{~J} / \mathrm{cm} \mathrm{cu}$. $(220 \mathrm{~J} / \mathrm{g})$. The operating parameters, especially interelectrode distance and number of pulses per position, still have to be optimized.

At the energy input comparable with that of the EHS technique, super-high voltage mode provides a higher scabbling rate (mainly due to a smaller number of pulses required per processing position/concrete surface area), i.e., productivity and lower energy consumption. Within the short runs, the HVG units demonstrated satisfactory operation, but their longer-term reliability and capability to operate with highly conductive process water remains untested. Also, additional trials should be conducted with stronger concrete (e.g., similar to that at the Fernald site).

\subsection{DEMONSTRATION OF EH SCABBLING TECHNIQUE AT TSD}

Concrete scabbling operation was demonstrated to FERMCO and DOE/METC at the Everett site on August 2 and 3, 1995. The main goals of these trials were to:

- Show EHS system availability for more extensive evaluation at the Fernald site.

- Familiarize FERMCO representatives with specifics of the EH scabbling operation and to assist in finalizing the Fernald test plan, including items related to Health and Safety requirements.

Several design versions of electric, mechanical, control, and flow hardware were shown and explained. Generation of pulsed discharges in water and associated EH phenomena were demonstrated using both high voltage and super-high voltage units. Finally, concrete scabbling runs were conducted. Figure 6-5 shows the EHS-01 unit in preparation for a scabbling run.

The runs were sufficient to demonstrate the scabbling operation, but too short and incomplete to evaluate condition and performance of a flow/waste management subsystem by Pentek, Inc. The subsystem (some components were shown in Figure 4-5) was delivered at the last moment and could not be properly integrated and shaken down (see also Section 4). Therefore, a simplified flow system assembled by TSD was used in a final demonstration trial. 


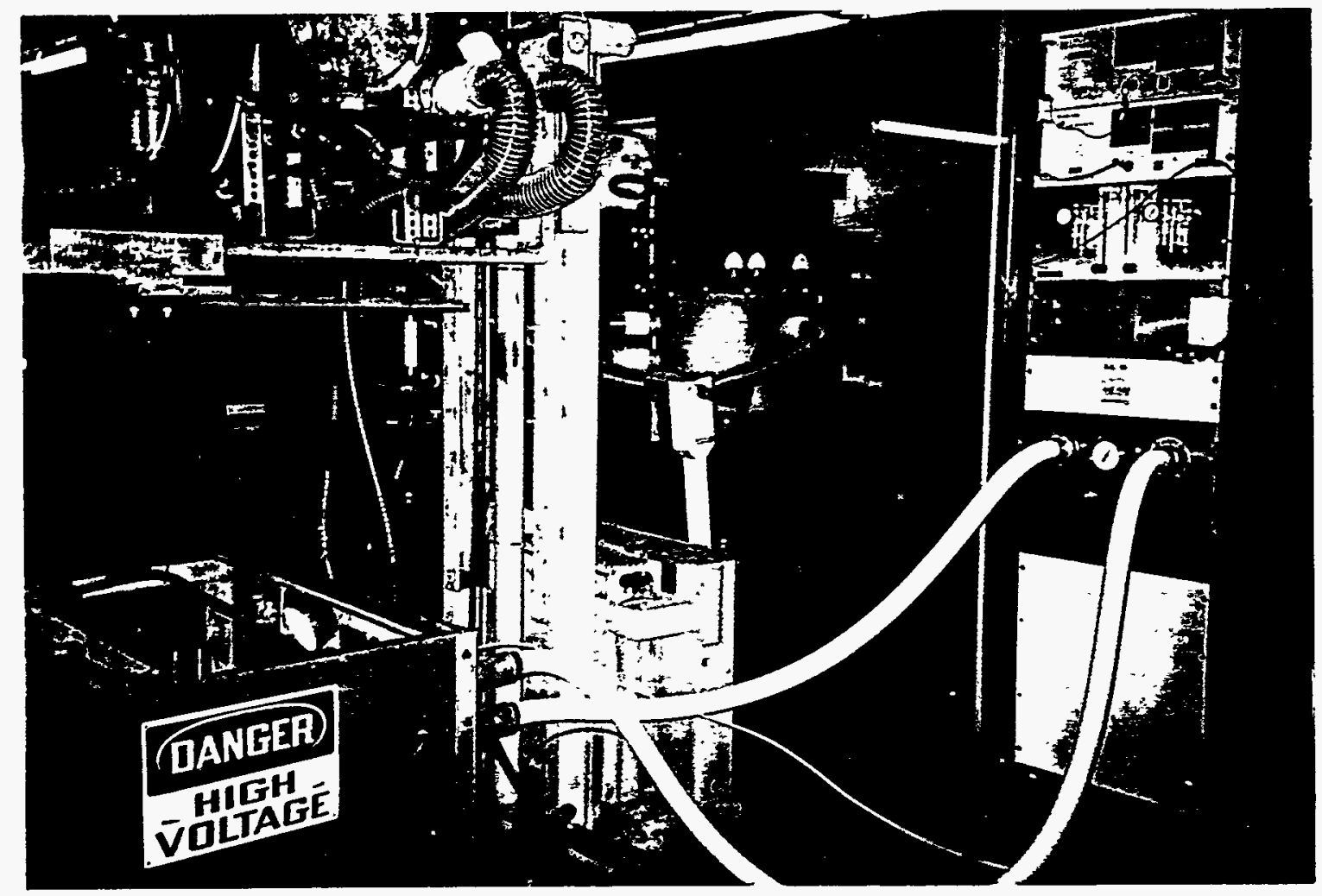

a)

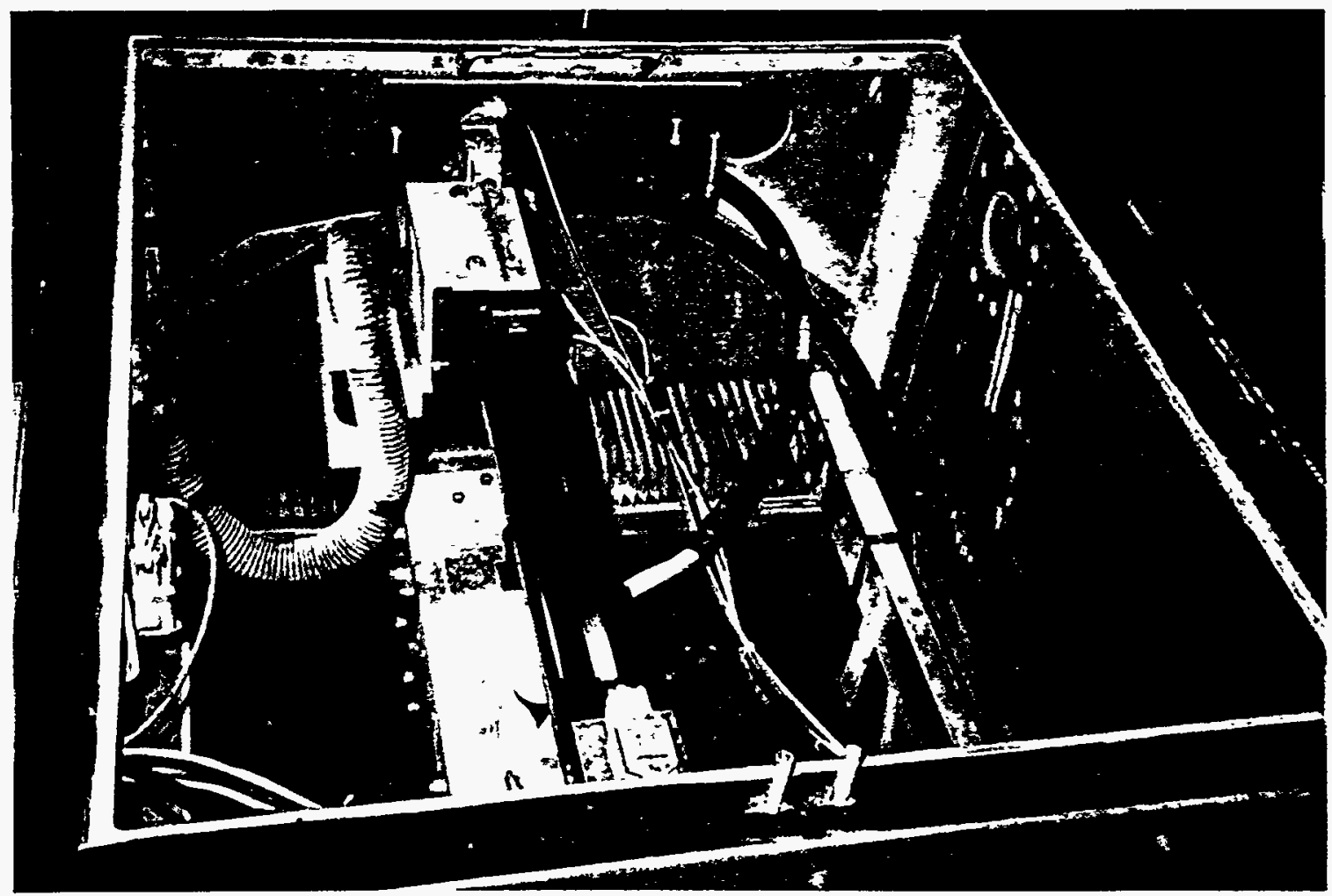

b)

P7766

Figure 6-5 EHS-01 Unit at Everett Site in July Preliminary Demonstration

a) Preparation for scabbling operation

b) Scabbling chamber interior with traversing rubble collecting nozzle in place 
A conclusion was made that after addressing some operating problems, the EHS equipment could be brought to Fernald for more comprehensive testing involving contaminated concrete. 


\subsection{FIELD TEST/DEMONSTRATION AT DOE FERNALD SITF,}

\subsection{OBJECTIVES OF FERNALD FIELD TEST/DEMO}

The Field Test at the Fernald site has a general objective to demonstrate technical feasibility of the EHS technology for a specific task - decontamination of a concrete floor having fixed uranium contamination.

These demonstration experiments being conducted with a subscale prototype are not a substitute for more comprehensive field testing of a full-scale unit (which is still to be designed and built) for a projected Phase III DOE site demonstration.

Specific objectives of the Fernald test program are as follows:

- Evaluate level/quality of decontamination by EHS:

- $\quad$ reduction of "total uranium" concentration

- reduction of total (surface) radioactivity level

- measuring quantity of "total uranium" and radioactivity level of a collected concrete rubble

- Demonstrate smooth, reliable, and safe operation of the EHS system (prototype unit) as a whole, and its individual subsystems:

- power supply/pulser

- carriage/enclosure/positioner

- scabbling module

- slurry (process water and concrete rubble) collection, flow, and recirculation subsystem

- controls for EH discharge, positioning, water, and airflow

- Evaluate main scabbling characteristics:

- scabbling rate

- nominal, i.e., scabbling process proper

- actual, which includes time for all operations (e.g., positioning) involved

- scabbling depth

- width of scabbling path

- scabbling uniformity

- electric energy consumption

- water flow rate and consumption

- airflow rate

- Determine reliability and lifetime of EHS components and convenience of the system operation to recommend and implement design changes necessary for the development of a full-size unit.

- Determine the amount of waste materials produced by EHS and the level of crosscontamination: 
- measure quantity of concrete rubble produced

- measure quantity of water contained in collected wet solid/liquid mix

- measure quantity of contaminated consumables generated

- estimate level of contamination which may be spread over adjoining surfaces, and released with the EHS system liquid discharge

- Establish technique and evaluate effort and cost of decontamination of EHS equipment.

- Evaluate decontaminating capability of the EHS technology under complicated "reallife" conditions:

- for irregular concrete floor surfaces

- for floors containing metal elements

- $\quad$ in the vicinity of walls and obstacles

- On the basis of data collected from scabbling of clean and contaminated concrete:

- .project performance

- project capital cost

- project operating cost of a full-size EHS system

\subsection{SITE BACKGROUND}

The FEMP is a government-owned, contractor-operated federal facility (see Figure 7-1) that produced high-purity uranium metal products for the U.S. Department of Energy (DOE) and its predecessor agencies during the period from 1952 to 1989 . The throughput capacity of the FEMP was 10,000 metric tons of uranium per year.

Over the more than 35 years of operations, the various structures/buildings forming the Process Area of the site became radioactively contaminated with uranium and, to a much lesser degree, thorium. This contamination resulted from the routine steps within the process of producing high-purity uranium metal which involve uranium powder compounds of various kinds that could become airborne during transfer steps, as well as liquids which could drip from vessels and process components when opened. In addition, solid metal components were rolled and machined to the proper configuration which again resulted in the generation of fine particulate uranium contaminates. The 232 structures and support facilities (components) within the Production Area contain over 2,000,000 $\mathrm{ft}^{2}$ of contaminated floors. Decontamination of these floors will facilitate the decommissioning of these components, reduce the volume of waste requiring disposal, and thus potentially reduce the total decommissioning cost.

\subsection{TEST/DEMO AREA}

It was decided to conduct the subject demonstration in Plant 6A at the FEMP. Plant 6A (Metals Fabrication Plant) is a single-level building of irregular shape, measuring approximately $620^{\prime} \mathrm{L} \times 350^{\prime} \mathrm{W} \times 50^{\prime} \mathrm{H}$. This facility was constructed using a structural steel frame on a reinforced poured concrete base and floor with transite siding and roofing.

This facility was designed to perform major uranium metal fabrication processes, including rolling, machining, heat treating, pickling, scrap metal briquetting, and inspection/ packaging of products. All processes were discontinued in 1989; however, the process equipment has not been dismantled or removed from the building. Some machining equipment has been removed to clear the building for drum storage. 


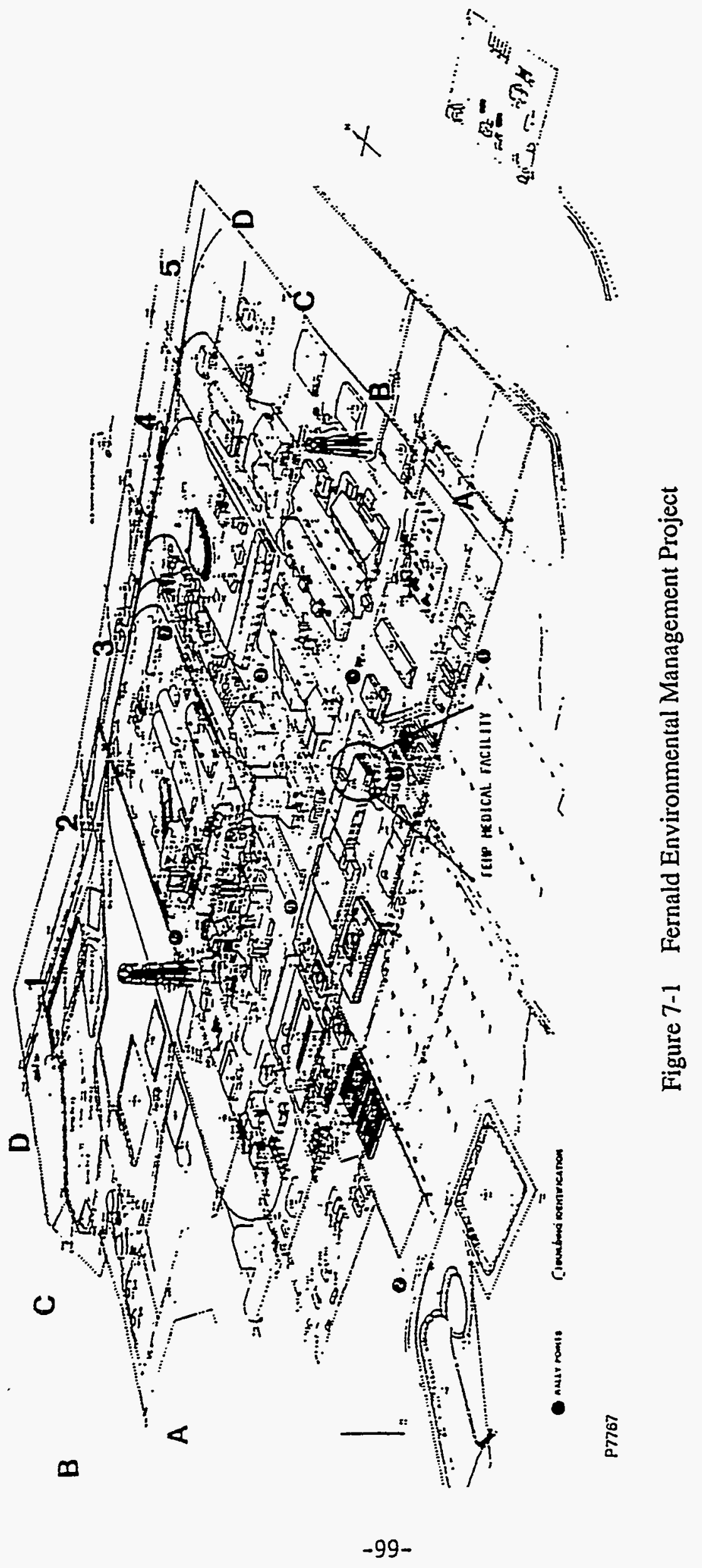


The general arrangement for Plant $6 \mathrm{~A}$ as well as the available locations for the scabbling demonstrations are shown in Figure 7-2.

\subsection{REGULATORY ISSUES/DOCUMENTATION}

Presently DOE Orders require the D\&D of excess facilities. There is, however, no required (regulatory imposed) deadline for the $D \& D$ for these surplus facilities. On the other hand, regulatory issues involving both the Federal government and the State of Ohio require the timely D\&D of the Fernald Site. The regulatory drivers at the FEMP are as follows:

- The FEMP is listed as a CERCLA NPL site

- The 1991 Amended Consent Agreement with the U.S. EPA

- The Consent Decree with the State of Ohio

This demonstration was performed under the umbrella of the Operable Unit 3 Treatability Study amended by FERMCO to incorporate Final Test Plan. Supporting documents such as Health \& Safety Plan and Sampling and Analysis Plan were included as appendices to the Test Plan.

A Project-Specific Plan has been prepared in cooperation between TSD and FERMCO. Similarly, a Health \& Safety Plan and a Sampling and Analysis Plan were included as appendices.

\subsection{TEST/DEMO PREPARATION AND MMPLEMENTATION}

In addition to the planning and composition of all necessary documentation, the field test/demo preparatory work included:

- Site visits and meetings to identify technical issues (such as utilities and supplies required for EHS operation, precise location of working areas, time schedules).

- Training of TSD personnel (including General Employee Training, Radiological Worker Training, Site Worker Training, Hazardous Energy \& Material Control Training) participating in the field test.

- Physical (medical) examination of the TSD personnel.

The field test/demo itself took two weeks (September 17-29, 1995) and included the following activities.

- Transportation of EHS equipment (by rented truck) from Everett, MA to Fernald, $\mathrm{OH}$.

- Unloading of equipment (main and spare EHS units, spare components and parts, tools and instruments) at the uncontaminated Building 6 area.

- Finalizing H\&S training of TDS personnel.

- Physical (medical) examination of TDS personnel (including pre- and post-work in vivo checkup). 


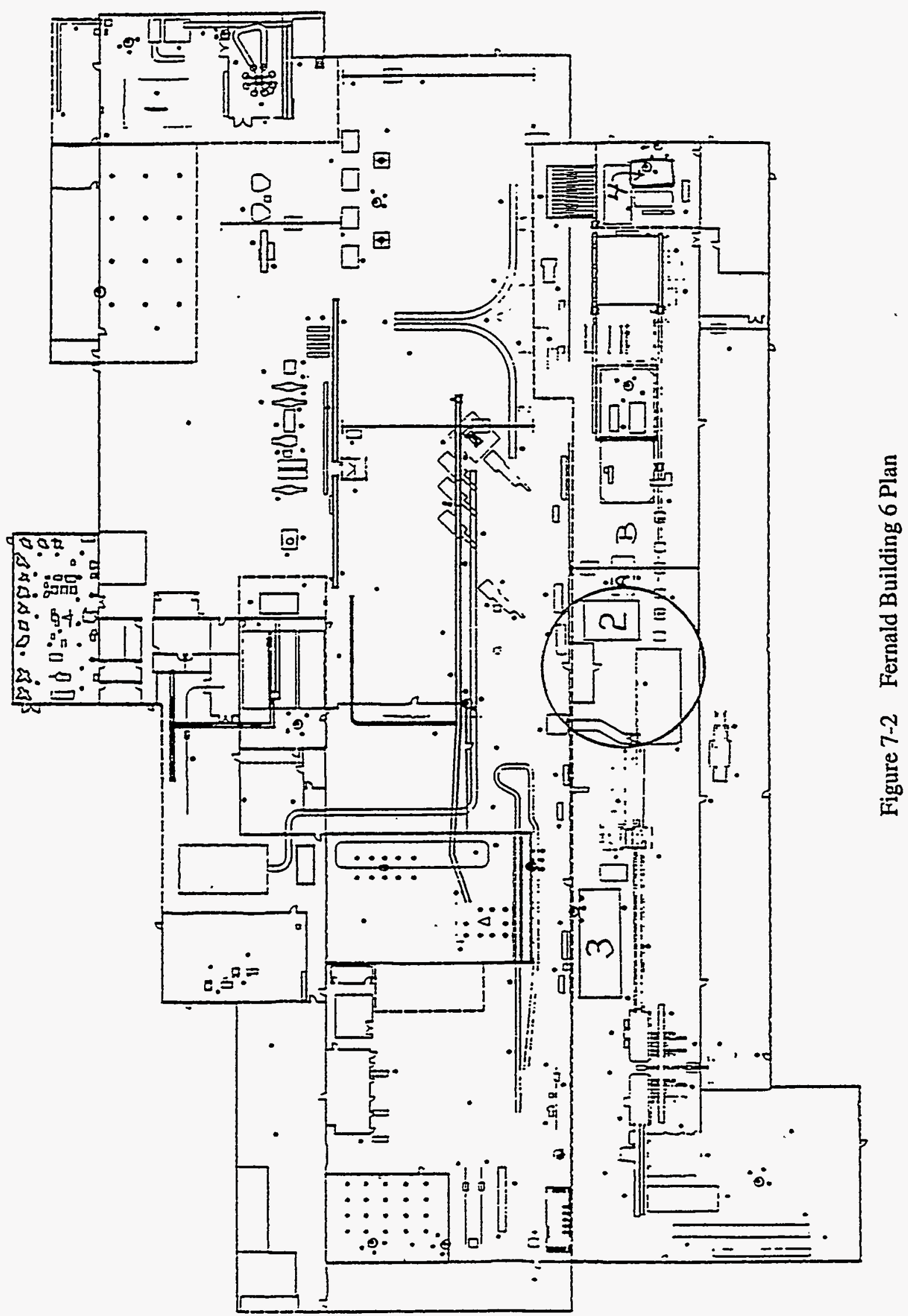


- Assembly and transfer of main EHS unit to Building 6 area designated for scabbling trials.

- Engaging on-site utilities (electric, compressed air, water supplies, and waste handling auxiliaries).

- Meetings with FERMCO support team for detailed discussions on regulations, schedules, characterization/evaluation of scabbling results, and for planning of everyday activities.

- Performing scabbling experiments and preliminary evaluation of scabbling/ decontamination performance (see Section 7.1.6).

- Disassembling of EHS unit.

- Checkup of equipment contamination, and release of "clean" components.

- Decontamination of components with radioactivity level above regulated limits. After trials at Fernald were completed, levels of contamination of all system components were checked by FERMCO personnel. Some components (e.g., power supply and control cabinet) were not contaminated at all or had minor contamination that could be removed by simple measures. These components were returned to the TSD Everett site without any delay. Some other components, especially belonging to the water recirculation system, required more extensive treatment. They were returned to the TSD facility in about two months. Lastly, there were a few parts (e.g., diaphragm pump, some hoses) that would require a serious decontamination effort not justified by the value of these parts. These parts were left at Fernald and properly discarded.

- Loading released EHS equipment (on rented truck), obtaining off-site release permit.

- Transportation of the released EHS equipment to Everett, MA.

Substantial time and effort were required to accomplish the Fernald test/demonstration program. It took two visits of three TDS team members (V. Goldfarb, A. Dunton, R. Budny) and 24 calendar days, including transportation. Of 15 working days at the Fernald site, 7 days were spent on training, and 8 days (an average 10 hours per day) on activities directly related to the program. One half of the latter time involved only equipment assembling, moving to and over the area, and disassembling. Scabbling trials were done within 5 days only, with EHS equipment. The following activities, conducted by TDS personnel only, occupied about 15 hours: scabbling, sampling, measurements, and recording. Scabbling proper took about 7 hours, or less than $10 \%$ of the total 80 hours.

Bearing in mind that many regulatory, safety, equipment transfer, utilities arrangements, and other site requirements had to be satisfied to make these first EHS field tests possible, the low processing-to-total time ratio should not be surprising. The test program could be completed only with effective preparation and help (before and during the TDS visit) from the FERMCO support team. No doubt that due to experience gained by both TDS and FERMCO personnel from this first field test, any further Fernald site work can be conducted in a more time-efficient manner. 


\subsection{SCABBLING OPERATION}

\subsubsection{Scabbling Equipment Used}

Concrete scabbling has been conducted over area 2 in Building 6 (see Figure 7-2). Eight floor segments of 3.7 sq. ft. ( $\left.26^{\prime \prime} \times 2.1 "\right)$ each, about 30 sq. ft. total surface area, were scabbled in the work area. Location and designation of these segments are shown in Figure 7-3. Segments $\mathrm{A}, \mathrm{B}, \mathrm{C}, \mathrm{D}$ and I were at isolated locations, whereas segments $\mathrm{F}, \mathrm{G}$ and $\mathrm{H}$ formed an overlapping sequence-strip.

The floor in this area did not have a paint layer. It was washed in order to remove at least most of the loose uranium contamination (dust). The concrete surface was dark and somewhat oily, which was obvious from the presence of a colored film over the collected process water. An additional intense "wash" provided by water circulation within the scabbling chamber (but beyond the scabbled floor sections) reduced the surface CPM number by $10-15 \%$ from the original characteristic 1000 to 2000 CPM, i.e., the "wash" removed "semi-loose" contamination. The floor had some defects in the form of minor cracks and cavities (about 1/4" deep); a few deeper interslab joints/ grooves were also present in the area. At these locations, the initial CPM were higher: from $2500 \mathrm{CPM}$ over shallow cavities to 20,000 CPM over joints.

Background radiation in the area is dominated by the contaminated process equipment (uranium rolling mill) located just several feet from the scabbling segments. This background radiation varied with height, increasing with the distance from the floor surface from (average) 250 to $800 \mathrm{CPM}$.

The scabbling equipment was unloaded and stored (see Figure 7-4) in the uncontaminated part of Building 6. Only one scabbling unit (EHS-01 - see description in Section 3), was assembled, moved to the working area, and used in the experiments. The other unit available (EHS-02) and spare/replacement components remained in storage.

The EHS-01 unit was operating with either one or two $4 \mathrm{~kW}, 25 \mathrm{kV} \mathrm{DC}$ chargers and a single open spark gap switch. A modification used at Fernald is shown in Figure 7-5. In the switching mode used in these experiments (see Section 3.1 for details), the energy and frequency of pulses were defined by the pre-adjusted gap, and could be controlled only by the voltage and current provided by the chargers. With $24 \mathrm{kV}$ maximum pre-selected voltage; actual charging voltage varied in 15 to $19 \mathrm{kV}$ range, while maximum charging current was $0.2 \mathrm{~A}$. The pulse repetition rate was $1.4 \mathrm{~Hz}$ with one and $2.3 \mathrm{~Hz}$ with two chargers in operation. Under these conditions, energy was about $2 \mathrm{~kJ}$ per pulse and the effective average AC power was about $2 \mathrm{~kW}$ per power supply (i.e., about $50 \%$ of the nominal).

A portable transformer (provided by FERMCO) was used to reduce $440 \mathrm{VAC}$ available in the building to $220 \mathrm{VAC}$ needed for the power supply. The EHS-01 and process control cabinets were located on a single-wheeled platform, as shown in Figure 7-6. Six-foot long HV cables and low voltage/current AC cables connect the cabinets to a scabbling module mounted on a XZ-positioner within a water-tight enclosure - scabbling chamber (see Figure 7-7). Compressed air available from the shop line at $50 \mathrm{psi}$ was sufficient for cooling purposes and to operate the air cylinder of the positioner. The scabbling chamber and components of a water flow subsystem were mounted on a battery-powered forklift truck.

The scabbling module used in these tests had two 26 " wide strip electrodes The interelectrode gap was initially $5 \mathrm{~mm}$. During a total of seven operating hours it increased by $1-2$ $\mathrm{mm}$; the increase did not affect operation. The positioner had electric $\mathrm{X}$-drive and pneumatic Zdrive. The X steps were $3 \mathrm{~cm}$ (about 1.15") long, the vertical lift was about 2". 


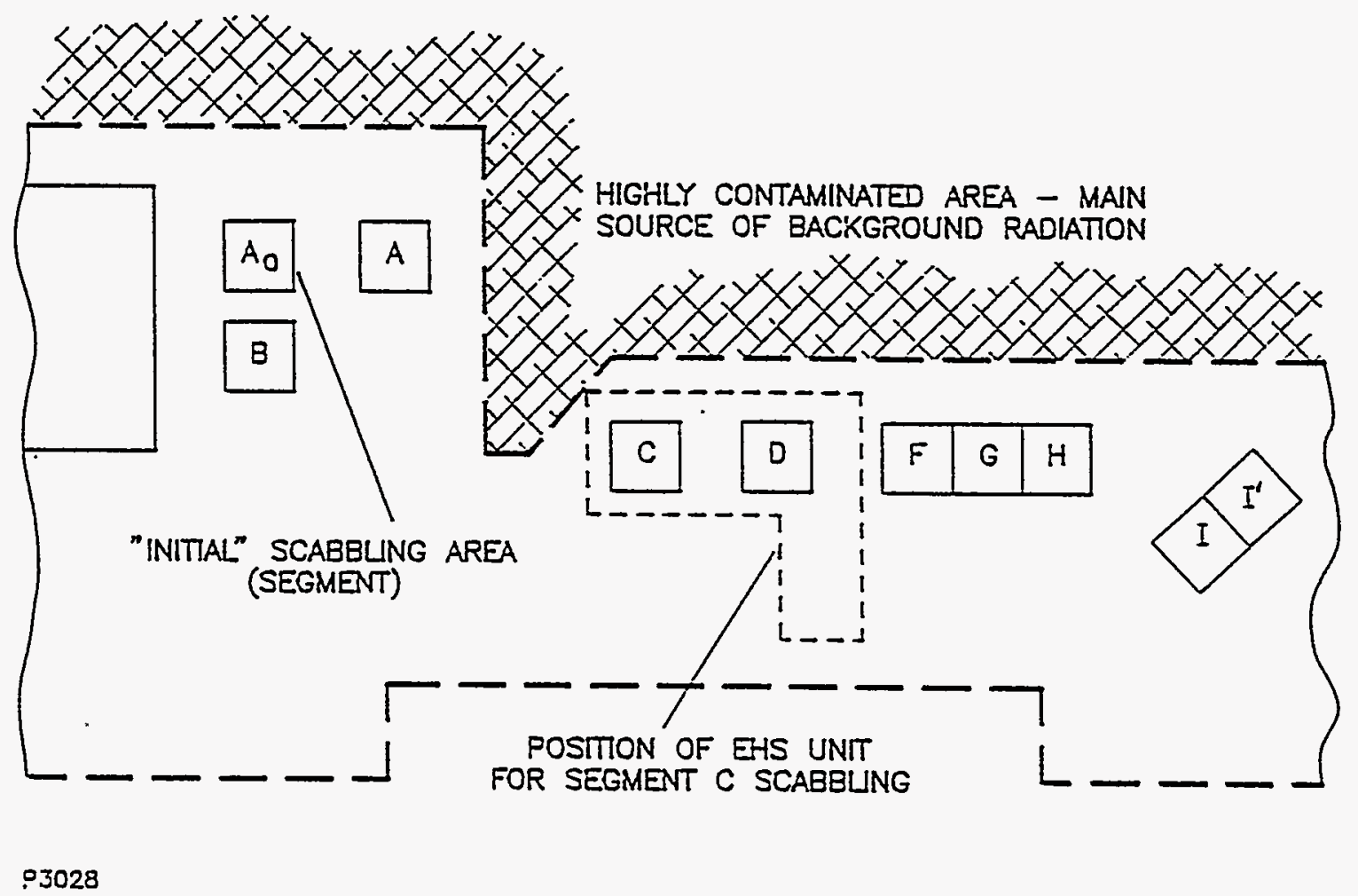

Figure 7-3 Building 6 Work (Scabbling) Area - arrangement of floor segments 


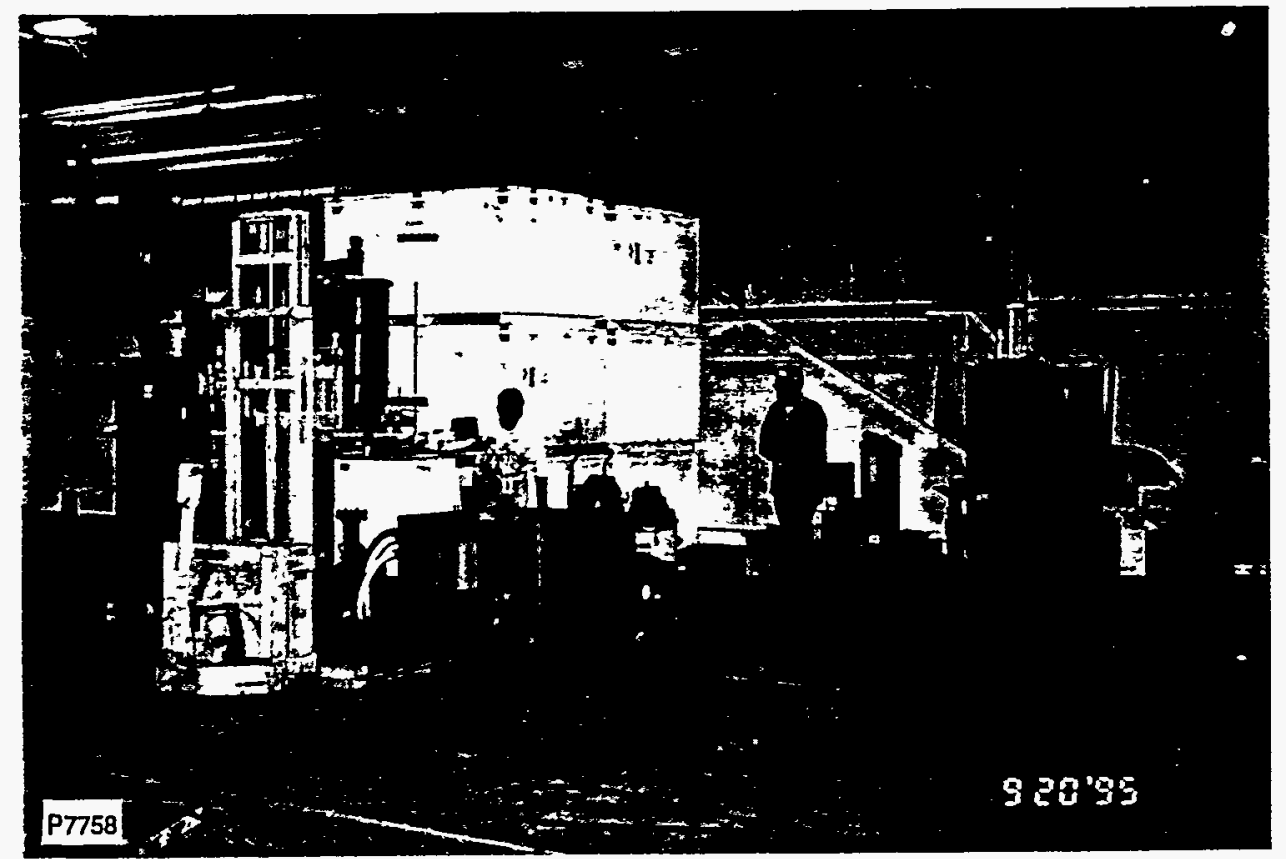

Figure 7-4 Scabbling Equipment in Building 6 Unloading/Storing Area

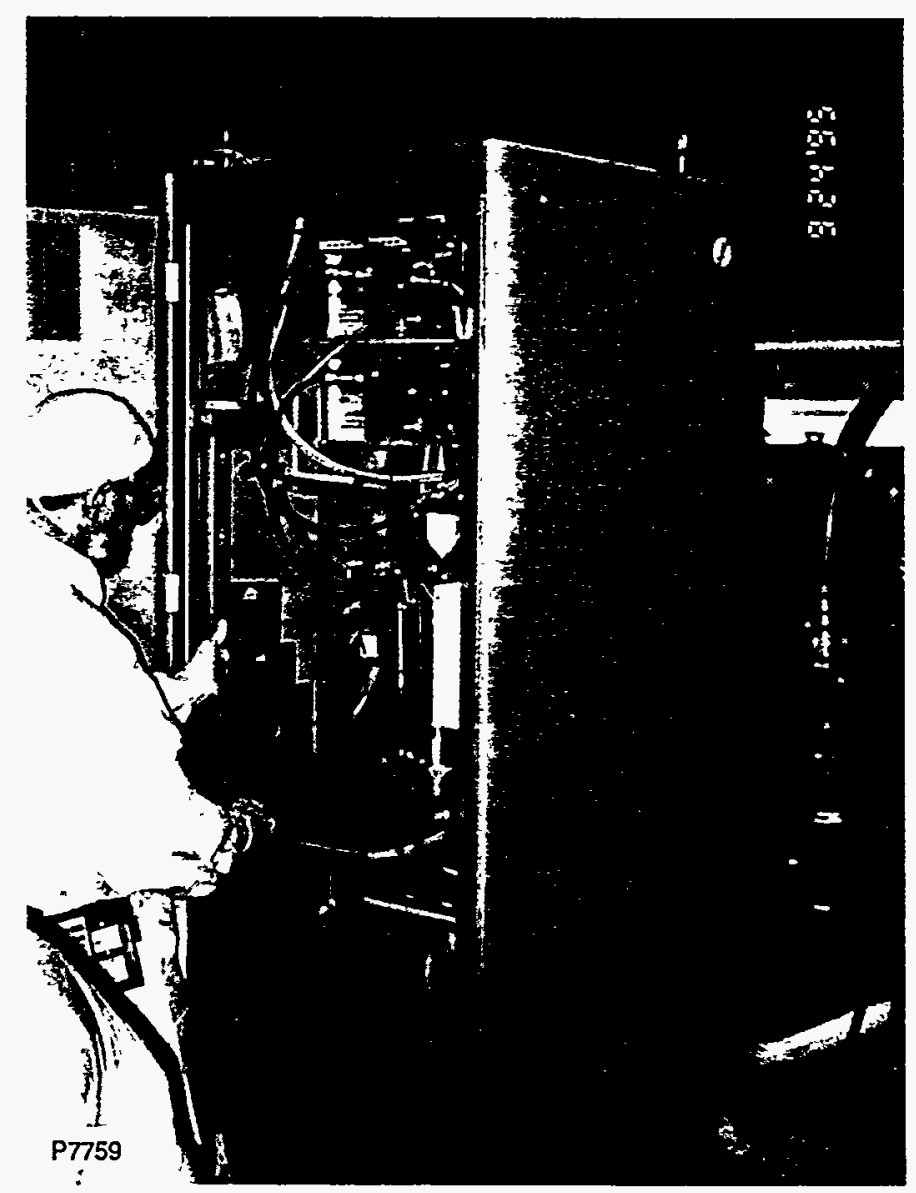

Figure 7-5 Preparation of EHS-01M Power Supply for Scabbling Operation at Fernald 


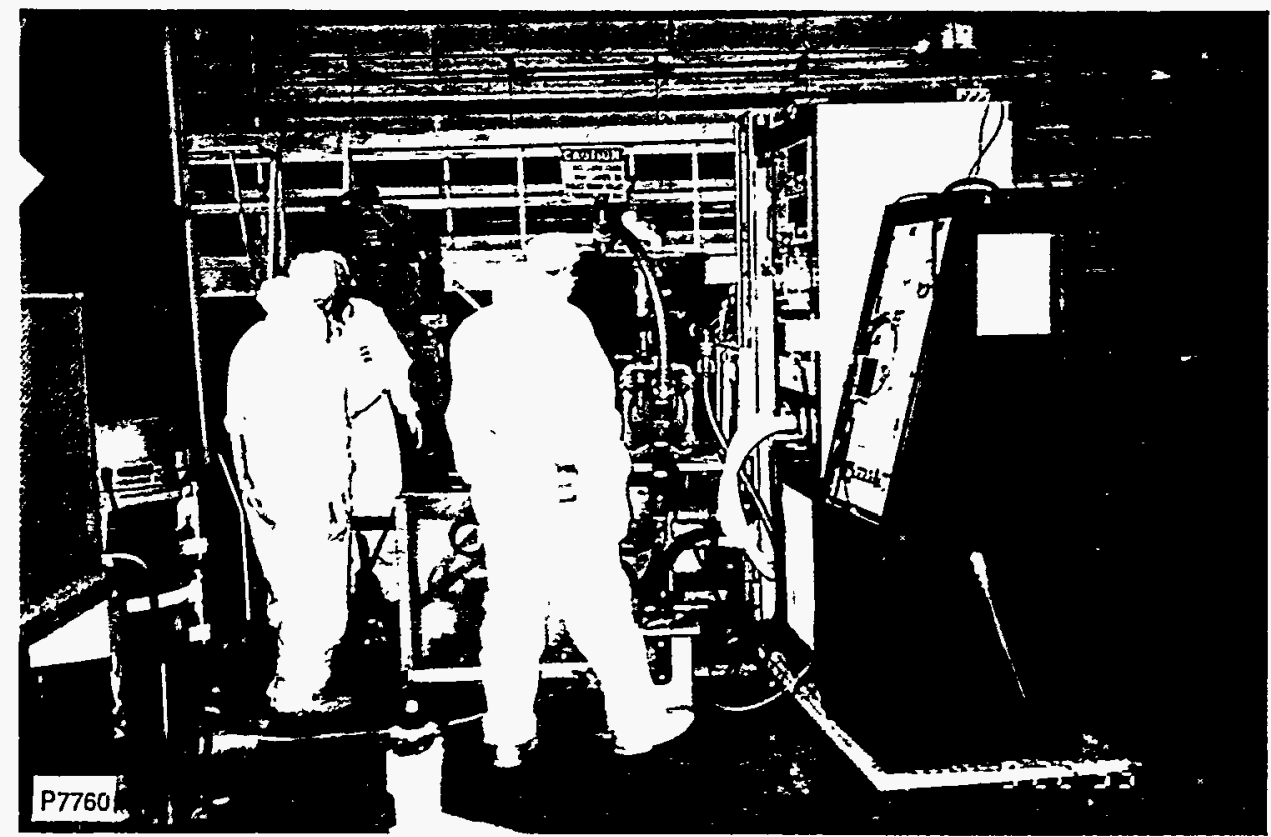

Figure 7-6 Arrangement of Scabbling Equipment for Fernald Trials

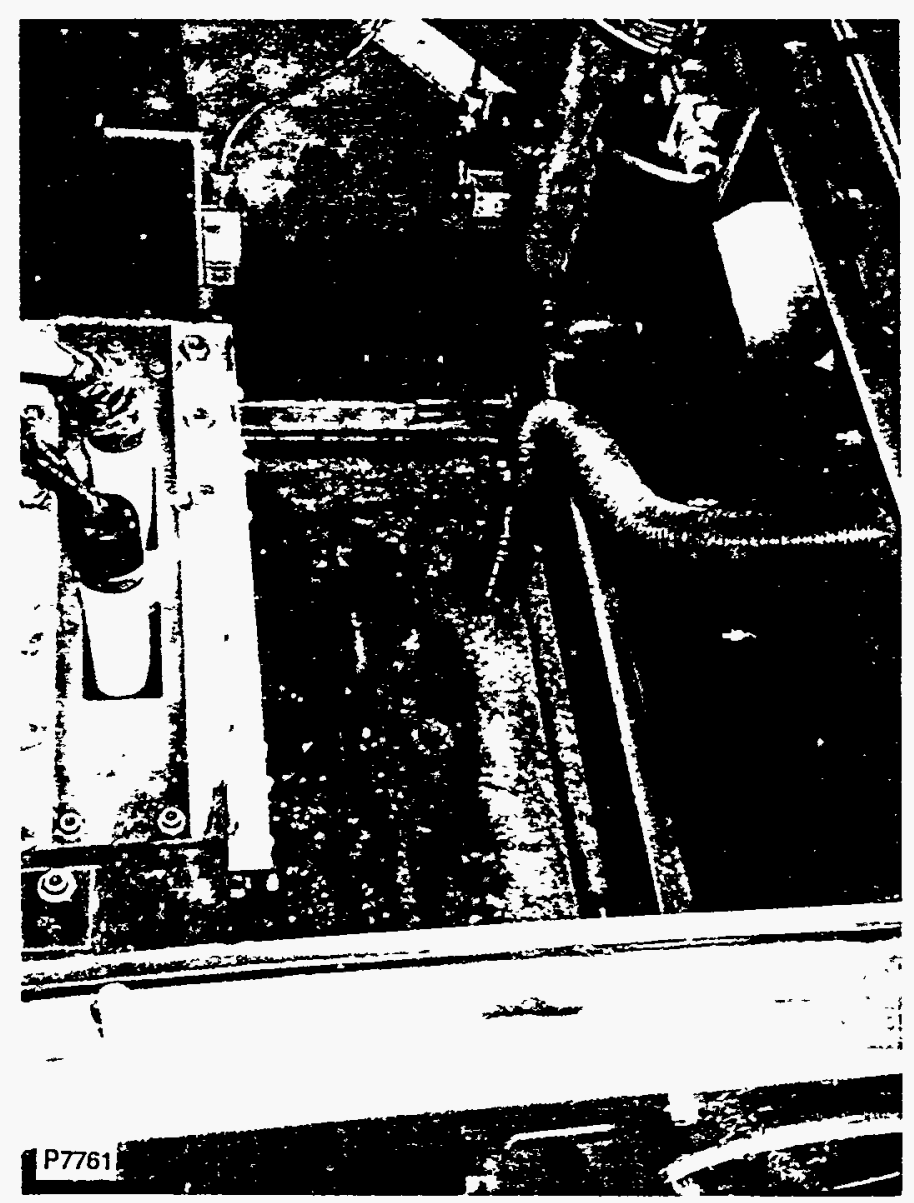

Figure 7-7 Flow System used in Fernald Trials. Interior of scabbling chamber with a fixed position water-suction nozzle. 
The flow system (see Figure 7-6) used in these trials had a standard 55 gal. drum filled to a 40 gal. level with fresh water (delivered by FERMCO personnel in 55 gal. drums) by a small sump pump. Water (about 25 gal.) was fed into the scabbling chamber by gravity or, when recirculation was used, by a diaphragm pump and water filter. After the end of the scabbling cycle, water and fine suspended debris were transferred into the drum using the same diaphragm pump; the flow direction was reversed by $1.5^{\prime \prime}$ valves operated manually. In the first three experiments, water was not recirculated, and contaminated slurry was transferred into waste drums. In the first two experiments with water recirculation, an intermediate container (visible in Figures 7-6) with screen filter was installed to prevent clogging of the diaphragm pump with debris. It was discovered, though, that only a very few coarse debris particles were produced by scabbling a strong, fine gravel concrete floor in Building 6. Therefore, this filter was not used in subsequent experiments.

To generate negative pressure in the scabbling chamber, a HEPA filter-equipped wet vacuum (made by Power Products and Services Co., Model \#0201110, $1.4 \mathrm{~kW}$ AC power) was used. With a short connecting hose these vacuums provided strong suction, reducing pressure to about $-10^{\prime \prime} \mathrm{H}_{2} \mathrm{O}$. Another wet vacuum of the same type was used to collect and retain wet debris collected from the processed floor.

Even with the rather fine debris from Fernald concrete, a substantial part of the scabbling product was not removed with process water, using a fixed or even moving collection nozzle. Most of the remainder is concentrated at the foam gaskets along the chamber perimeter, being pushed there by EH-generated water streams. "Stickiness" of the debris was enhanced by the "oily" residue or residual lime present over the floor surface. This part of the debris was removed with the help of another wet vac after the chamber was lifted, and, finally, after the chamber was moved to the next scabbling position. The debris was collected in a plastic bag, which is a standard wet vac component. In a larger-scale operation, manual collection of the wet debris should be replaced by mechanized collection.

\subsubsection{Test Conditions and Preliminary Evaluation of Performance}

The EHS unit is shown in Figure 7-8 in the operating position. The unit operated flawlessly throughout the trial period. There was no malfunction of either the electric power supply or controls, positioner, and scabbling module.

Table 7-1 characterizes test conditions and specific features. A total of 18 steps/ repositioning of the scabbling module were made within each scabbling cycle, forming 21 "-long scabbled segments. In these trials, repositioning was controlled by the operator (by turning motor and air valve actuators ON/OFF), but the relay system for automation of the scabbling/ repositioning cycle is readily available. In different experiments, a number of pulses varied between 150 and 360 . The first five $(A, B, C, D$, and $F$ ) segments were scabbled with only one charger in operation (i.e., with about $2 \mathrm{~kW} \mathrm{AC}$ power). In this case, pulse frequency was about 1.5 Hz and segment scabbling took an average of one hour, including $40-50 \mathrm{~min}$. of pulsing/scabbling proper and the rest for positioning. The last three segments $(G, H$, and $I)$ were scabbled with both chargers in operation; the pulse frequency was $2.5 \mathrm{~Hz}$ and the processing (pulsing plus positioning) time was one-half hour.

In addition to scabbling proper and module positioning within the scabbling chamber, time was spent for moving the equipment to the next location (segment), recirculating process water, and removal of remaining wet debris from the floor. These operations took about a total of three hours working time, because of the manual debris removal operation and time spent for 
a)
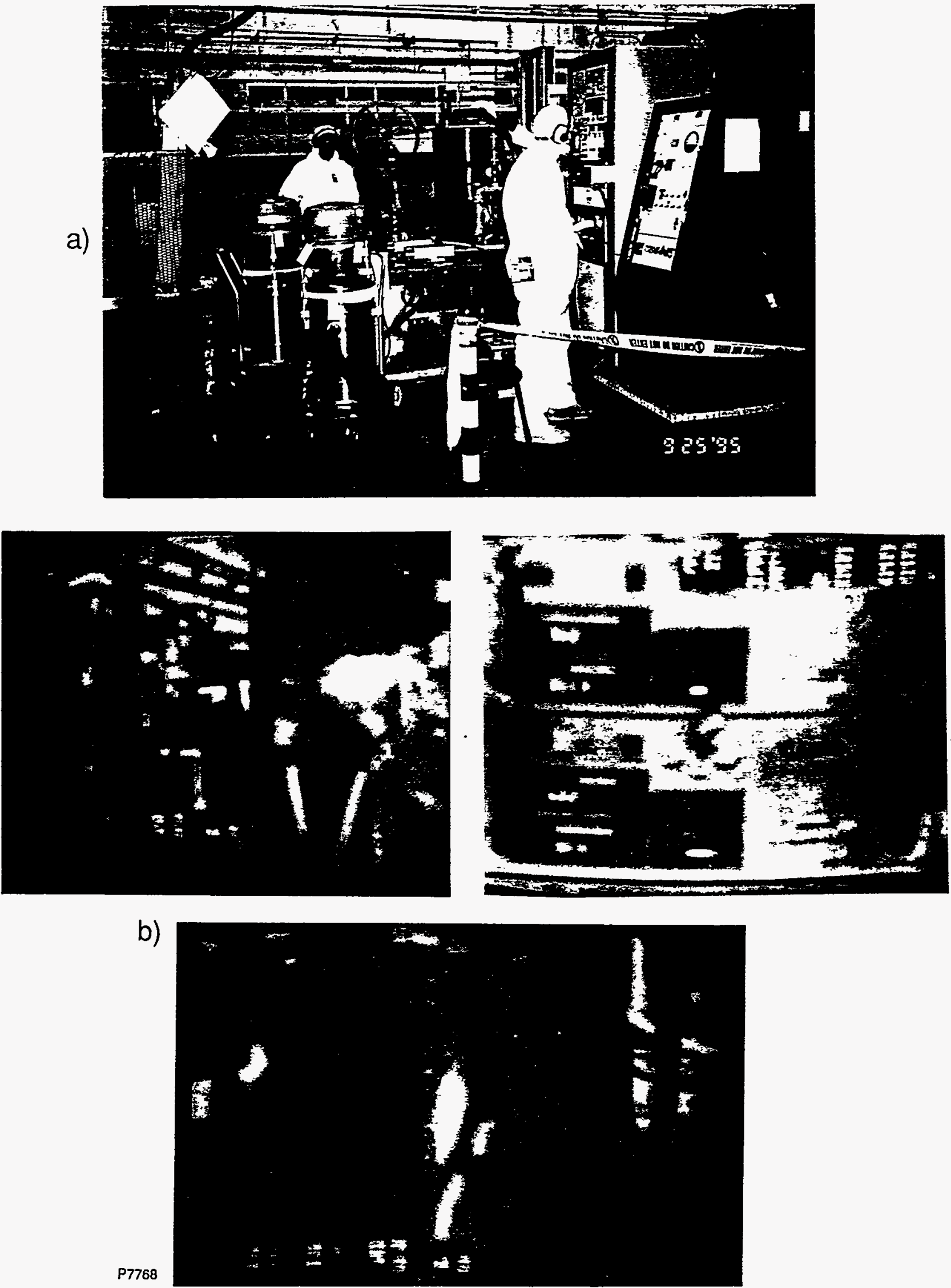

Figure 7-8 EHS-01 Unit in Scabbling Operation Position at Fernald

a) General view, floor segment $C$ scabbling; one $\mathrm{DC}$ charger active. Contaminated uranium rolling mill equipment is in the background

b) Video (available upon request) frames of scabbling at Fernald.

Operates with two DC chargers; EH discharge light splash in the enclosure is visible -108- 
TABLE 7-1

DESCRIPTION OF FERNALD SCABBLING TRIALS

\begin{tabular}{|c|c|c|c|c|c|c|c|c|}
\hline \multirow[b]{2}{*}{ Date } & \multirow[b]{2}{*}{ Test\# } & \multirow[b]{2}{*}{$\begin{array}{c}\text { Floor } \\
\text { Segment }\end{array}$} & \multicolumn{4}{|c|}{ Power Supply Operation } & \multirow[b]{2}{*}{$\begin{array}{c}\text { Scabbling } \\
\text { Duration/min. }\end{array}$} & \multirow[b]{2}{*}{ Remarks } \\
\hline & & & $\begin{array}{l}\text { No. of } \\
\text { Chargers } \\
\end{array}$ & $\begin{array}{l}\text { Frequency } \\
\mathrm{Hz}\end{array}$ & $\begin{array}{l}\text { No. of } \\
\text { Pulses* }\end{array}$ & $\mathrm{U}_{0}{ }^{* *}, \mathrm{kV}$ & & \\
\hline $10 / 22$ & 1 & A & 1 & 1.33 & 200 & 22 & 64 & Preliminary Test; 16 steps ${ }^{\dagger}$; fresh water \\
\hline $10 / 25$ & 2 & B & 1 & 1.35 & $180 / 360$ & 23 & 70 & $\begin{array}{l}18 \text { steps }{ }^{\dagger} \text {; steps } 14-18360 \text { pulses; fresh } \\
\text { water }\end{array}$ \\
\hline $10 / 25$ & 3 & $\mathrm{C}$ & 1 & 1.36 & 190 & 23 & 50 & Fresh water \\
\hline $10 / 26$ & 4 & D & 1 & 1.5 & 250 & 24 & 65 & Recirculated water \\
\hline $10 / 26$ & 5 & $F^{\#}$ & 1 & 1.5 & 225 & 24 & 60) & Second pass through steps $1-6$ \\
\hline $10 / 27$ & 6 & G & 1 & 2.5 & 200 & 24 & 28 & Recirculated water \\
\hline $10 / 27$ & .7 & $\mathrm{H}$ & 2 & 2.5 & 250 & 24 & 36 & Second pass over cracks (steps 12-14) \\
\hline $10 / 28$ & 8 & $I^{\prime}$ & 2 & 2.5 & 250 & 24 & - & $\begin{array}{l}\text { Only } 2 \text { steps; water leak through floor } \\
\text { joint }\end{array}$ \\
\hline $10 / 28$ & 9 & I & 2 & 2.5 & 200 & 24 & 30 & Fresh water \\
\hline
\end{tabular}

*Per each electrode position (step)

**Initial charging voltage

$\dagger 18$ steps all other tests

\#Segment $\mathrm{E}$ was not scabbled 
multiple sampling. Under "real" operating conditions, the time spent between subsequent cycles (segments) should not exceed 5-7 min.

Scabbling and debris removal were accompanied by several diagnostic/performance evaluation methods listed below (a more detailed description is provided in Section 8):

- Scabbling depth measurements and maapping.

- Radioactivity (concrete surface CPM) measurements (pre- and post-scabbling).

- XRF (concrete surface) measurements of total uranium concentration (pre- and postscabbling).

- Sampling for subsequent measurements of radioactivity and total uranium concentration in the multiple water and concrete rubble samples.

Auxiliary characterization includes measurements of surface areas, water consumption, and debris weight. Concrete floor core samples were taken and analyzed to evaluate in-depth penetration of the contaminants. 


\subsection{RESULTS OF FERNALD CONCRETE DECONTAMINATION TRIALS}

A general description of the field test/demonstration conducted at the DOE Fernald facility in September 1995 was given in the previous section. Provided here is the scabbling performance data, as well as data characterizing EHS efficiency of the floor decontamination (removal of the uranium-containing surface layei of concrete), obtained by several diagnostic techniques.

\subsection{SCABBLING PERFORMANCE}

To characterize the EHS performance with respect to the efficiency of concrete surface layer removal (scabbling rate and energy consumption), electric energy input, processing time, area, and depth of scabbling have to be measured. The relevant data are provided in Tables 7-1 and 8-1.

Some issues related to these measurements and results obtained are discussed below:

- Nominal energy input ${ }^{*}$ ( $\mathrm{NE}_{\mathrm{O}}$ in the tables) can be obtained directly as $\mathrm{NE}_{0}=\mathrm{N} \times \mathrm{CU}^{2} / 2$, where $\mathrm{N}$ is the number of pulses per processed area and the second factor is a nominal energy stored in capacitors per each charging cycle (pulse). As already mentioned in Section 3, beginning from certain pulse repetition rates (about $1 \mathrm{~Hz}$ for our circuit parameters), the DC power supply could have insufficient time to recharge the capacitors up to the "static" $U_{0}$ level. With increasing frequency, the effective charging voltage $U_{\text {ef }}$ and, accordingly, effective stored energy $E_{\text {ef }}$ diminish more and more from the static values. Because completeness of the capacitor's discharging by each EH pulse fluctuates (while maintaining a rather regular pattern - see Figure 3-4), the $E_{\text {ef }}$ values do not remain constant either. Consequently, $E_{\text {ef }}$ numbers in Table 8-1 could have up to $15 \%$ uncertainty. In addition, the number of pulses (at each scabbling position, as well as total per segment) is also not defined precisely because a pulse counter may miss a few pulses or may be triggered by the electric "noise." As a result, about a $20 \%$ random, as well as systematic, error may be involved in the total energy input values. Two approaches can be used to reduce these errors: real-time recording (by the oscilloscope) of charging/recharging sequences, or direct measurements of the AC power consumption by a power meter equipped with an integrating (summarizing) device.

The second approach has been used recently (January 1996) to supplement tests at the Everett facility. A conventional power meter was installed and energy consumption (in $\mathrm{kWh}$ ) was measured for 30 minute runs using two parallel chargers with total nominal power of $8 \mathrm{~kW}$. With circuitry similar to that used at Fernald and $\mathrm{U}_{\mathrm{o}}=24 \mathrm{kV}$, actual energy consumption was only $40 \%$ of the nominal, i.e., $3.2 \mathrm{~kW}$. This corresponds to $U_{\text {eff }} \simeq 0.63 U_{0}=15 \mathrm{kV}$. The number is even lower than estimated for the transient voltage readings. It also indicates that single pulse energies in Table 1-1 were overestimated by about $20 \%$, and so are total energy values $\left(\mathrm{NE}_{\mathrm{ef}}\right)$ and the energy consumption values $N E_{\mathrm{ef}} / \mathrm{S}$ and $N E_{\mathrm{ef}} / \mathrm{M}$.

\footnotetext{
*This energy is not to be confused with energy actually delivered to the water discharge gap, and eventually to concrete. The last amounts to only a few percent of the energy input (see TR-1 for details of energy partition).
} 
The reason for low efficiency of the installed power supplies utilization has been determined. It was the result of artificial shortening of the capacitor charging time by the power supply control limitations which are not compatible with the discharge circuit containing spark gap operating in overvoltage mode.

There are two possibilities for better utilization of full installed power:

a) increase spark gap interelectrode distance to raise breakdown voltage and, subsequently, single pulse energy; and

b) leave the spark gap unchanged but operate at higher pulse frequency.

Using the second approach, we obtained $3.6 \mathrm{~Hz}$ pulse frequency and about $6 \mathrm{~kW}$ (75\% of the nominal) utilized "wall plug" power.

- The total scabbling time has two components - scabbling time proper (pulsing time), and time for repositioning of the scabbling module within the scabbling chamber. The total pulsing time per each floor segment is defined simply as $T_{p}=N \times m \times 1 / f$, i.e., the number of pulses per position times the number of scabbling positions times reciprocal of the pulse frequency. The repositioning time $T_{r}=t_{r}(m-1)$ could be relatively short $\left(t_{r}=10-15 \mathrm{sec}\right.$ per step) when automatic process controls are used (as in TSD site experiments), or comparable to the pulsing time when the process control is manual (as in the Fernald trials). At Fernald, additional time was spent to check the equipment conditions and for other auxiliary tasks. For these reasons, the scabbling rate was defined on the basis of the pulsing rate only. To take into account the minimum necessary repositioning time, the rates in Table 8-1 (column 9) should be increased by a factor $\mathrm{mT}_{\mathrm{p}}+(\mathrm{m}-1) \mathrm{T}_{\mathrm{r}} / \mathrm{mT}_{\mathrm{p}}$, which, for scabbling parameters used, is in the 1.1-1.6 range, depending mainly on the pulse frequency.

- The scabbling depth measurements, being straightforward in principle, in practice are rather cumbersome due to scabbling nonuniformity. The nonuniformity results from two factors - specifics of concrete structure, and EH discharge/pulse properties (see below). In the TSD site trials, the scabbling depth, averaged over each processed floor segment, was derived from a volume of sand (or water) filling in the scabbling depression. At Fernald, this technique was not used (with one exception). Instead, either point-by-point measurements of the depression depth were made with a mechanical depth gauge, or elevation readings were taken by a laser-based instrument (Geodimeter) over multiple locations (about 50) over the processed floor segment.

In Figure 8-1, depth distributions along one cross section of an A segment obtained by the mechanical gauge are shown. Figure 8-2 presents elevation maps obtained with the Geodimeter for segments B and D.

Leaving more detailed discussions on the scabbling depth measurement and concrete surface features until the end of this section, we are using only the average depth numbers in Table 8-1 to estimate per volume/per weight scabbling efficiency. It should be recognized that the average depth of scabbling could be aggravated by up to $10-15 \%$ error (see below). Together with a similar error in the energy input numbers, we can expect up to $25-30 \%$ scatter in the specific (per volume/mass) energy consumption values, notwithstanding the real differences due to the different operating parameters.

\footnotetext{
*Both types of measurements were made by FERMCO personnel.
} 

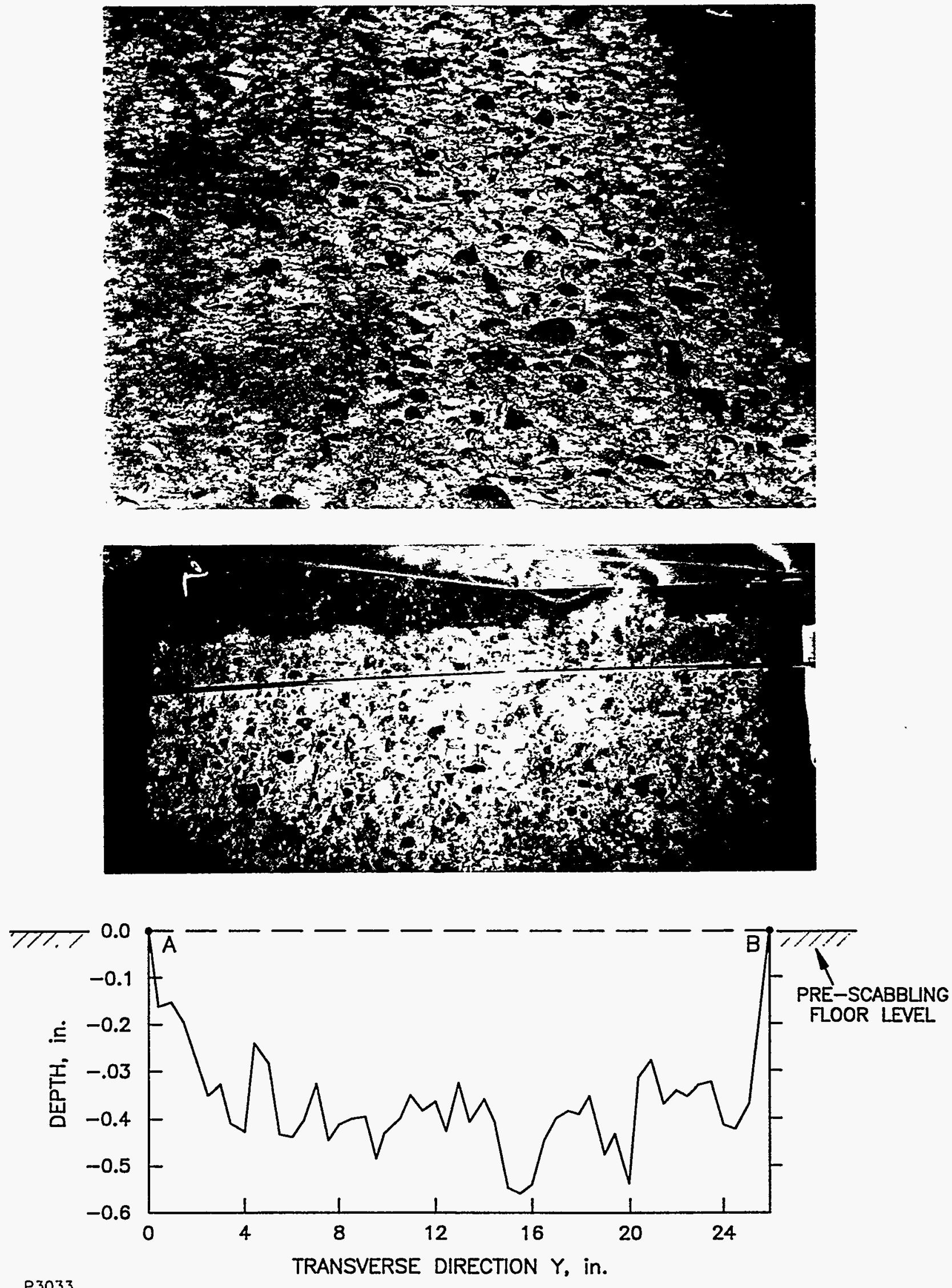

Figure 8-1 Scabbling Depth Distribution for Floor Segment A Cross Section (mechanical gauge measurements) 

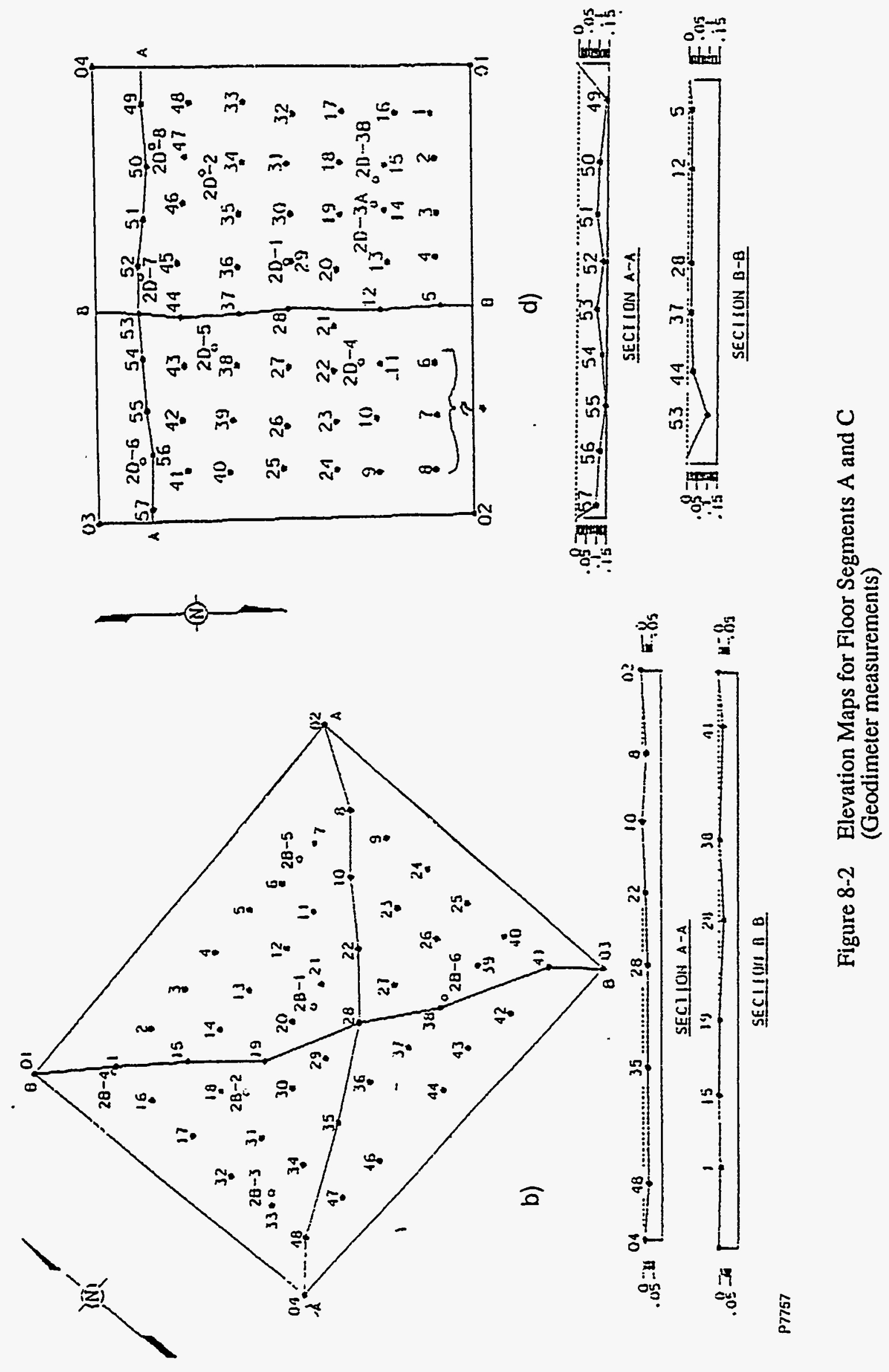
TABLE 8-1

OPERATING AND PERFORMANCE DATA FOR FERNALD SCABBLING TRIALS

\begin{tabular}{|c|c|c|c|c|c|c|c|c|c|c|c|c|}
\hline \multirow{2}{*}{$\begin{array}{l}\text { Test } \\
\text { No. }\end{array}$} & \multirow[t]{2}{*}{$\bar{N}$} & \multirow{2}{*}{$\begin{array}{l}\mathrm{T}_{\mathrm{p}} \\
\min \end{array}$} & \multirow{2}{*}{$\begin{array}{l}\mathrm{T}_{\mathrm{r}}^{+} \\
\mathrm{min}\end{array}$} & \multicolumn{2}{|c|}{ Input Energy, kJ } & \multirow{2}{*}{$\begin{array}{l}<\mathrm{d}> \\
\mathrm{cm}\end{array}$} & \multirow{2}{*}{$\begin{array}{c}\mathrm{V} \\
\mathrm{cm}^{3} \\
\end{array}$} & \multirow{2}{*}{$\begin{array}{l}\mathrm{M} \\
\mathrm{kg}\end{array}$} & \multirow{2}{*}{$\begin{array}{l}\mathrm{S} / \mathrm{T}_{\mathrm{p}} \\
\mathrm{ft}^{2} / \mathrm{hr} \\
\end{array}$} & \multicolumn{2}{|c|}{ Specific Energy Consumption } & \multirow{2}{*}{$\begin{array}{l}\mathrm{V} / \mathrm{T} \\
\mathrm{ft} \mathrm{t}^{3} / \mathrm{hr}\end{array}$} \\
\hline & & & & $\overline{E_{\text {ef }}}$ & $\mathrm{NE}_{\mathrm{ef}}$ & & & & & $\begin{array}{c}\mathrm{NE}_{\mathrm{ef}} / \mathrm{S} \\
\mathrm{kWh} / \mathrm{ft}^{2}\end{array}$ & $\begin{array}{c}\mathrm{NE}_{\mathrm{ef}} / \mathrm{M} \\
\mathrm{kJ} / \mathrm{kg}\end{array}$ & \\
\hline 1 & 3200 & 41 & 23 & 2.3 & 7400 & 0.79 & 2500 & 6.0 & 4.8 & 0.63 & 1240 & 0.13 \\
\hline 2 & $3080^{*}$ & 40 & 24 & 2.4 & 7800 & 0.38 & 1420 & 3.4 & 5.6 & 0.58 & 2160 & 0.07 \\
\hline 3 & 3420 & $\overline{42}$ & 8 & 2.5 & 8250 & 0.68 & 2350 & $\overline{5.65}$ & 5.3 & 0.62 & 1450 & 0.12 \\
\hline 4 & 4500 & 30 & 35 & 2.4 & 10800 & 0.63 & 2170 & 5.2 & 7.4 & 0.81 & 2070 & 0.15 \\
\hline 5 & 4500 & 30 & 30 & 2.4 & 10800 & $0.51 * *$ & 1760 & 4.2 & 7.4 & 0.81 & 2520 & 0.12 \\
\hline 6 & 3600 & 15 & 13 & 2.05 & 7400 & $0.51 * *$ & 1760 & 4.2 & 14.8 & 0.56 & 1730 & 0.24 \\
\hline 7 & 4500 & 18 & 18 & 2.05 & 9200 & $0.51^{* * *}$ & 1760 & 4.2 & 12.3 & 0.70 & 2150 & 0.20 \\
\hline 9 & 3600 & 15 & 15 & 2.15 & 7800 & 0.81 & 2800 & 6.7 & 14.8 & 0.59 & 1160 & 0.38 \\
\hline
\end{tabular}

$\stackrel{1}{\stackrel{\leftrightarrow}{*}}$

$\mathrm{N} \quad$ Total number of pulses

$\mathrm{T}_{\mathrm{p}} \quad$ Total pulsing time

$\mathrm{T}_{\mathrm{r}}{ }^{+} \quad$ Total repositioning plus auxiliary time

V Volume of concrete removed

M Mass of concrete removed

$\mathrm{S} / \mathrm{T}_{\mathrm{p}} \quad$ Scabbling rate

$<d>\quad$ Average scabbling depth

* Local crack scabbling not counted

** Average for F, G and $\mathrm{H}$ segments 
The following quantitative conclusions follow from the Table 8-1 data.

- The scabbling rate varies in a rather broad range between 5 and $15 \mathrm{ft} .2 / \mathrm{hr}$. This range becomes narrower when the difference in the pulse repetition rate is taken into account. For instance, a scabbling rate reduced to $2.3 \mathrm{~Hz}$ frequency would remain in the 9 to $15 \mathrm{ft} .{ }^{2} / \mathrm{hr}$. range; when projected repositioning time is taken into account, the range becomes 8 to $11 \mathrm{ft}$. $/ \mathrm{hr}$. For the same pulse frequency, these numbers are 20 to $40 \%$ lower than those observed in TSD site experiments.

- Energy consumption per unit area was initially estimated as being in the 0.5 to 0.8 $\mathrm{kWh} / \mathrm{ft}{ }^{2}$ range. According to recent reevaluation of the actual $\mathrm{AC}$ power consumption, these numbers should be reduced to 0.4 and $0.65 \mathrm{kWh} / \mathrm{ft}$. ${ }^{2}$, respectively. On average, these numbers are 1.2 times higher than those for the Everett site. Because the average depth of scabbling was larger at Everett, the increase of per unit volume/mass energy consumption at Fernald is about 1.5 times higher.

At this point, it is proper to discuss in more detail possible approaches to the average scabbling depth estimation, and degree and reasons for the scabbling-generated concrete surface nonuniformity. The numerous Geodimeter elevation data points cover the entire scabbled areas. These measurements provide a good basis for deriving average scabbling depth. Several approaches are possible here: from arithmetic averaging of all data points to a graphic presentation of the depression relief (see examples in Figure 8-3) based on area-weighted depths of certain horizons.

Numbers obtained by both techniques can be used to compare these approaches and to estimate probable depth uncertainties. The comparison shows that precision of the average depth determination by each of these approaches does not exceed $15 \%$. A systematic error may also be present due, for instance, to a certain surface texture, such as regular specific shapes of "hills" and "valleys." It would be desirable, therefore, to compare the average depth numbers to the ones obtained by the "sand backfill" technique used at TSD.

Because the Geodimeter elevation measurement locations are distanced more than 2", they do not reveal a fine structure of the concrete surface. Mechanical gauge measurements are cumbersome and can be hardly practiced for many cross sections. On the other hand, being taken every $1 / 4^{\prime \prime}$, they reveal strong spatial depth variations present over short distances. Even averaging over two adjacent locations significantly smoothes the depth distribution. Statistical processing of the data may be useful. Figure 8-4 presents distribution of depth values over two (I and II) cross sections of segment $A$. With median depth $\mathrm{d}_{\mathrm{m}}$ equal to 0.92 and $0.62 \mathrm{~cm}$, respectively, $70 \%$ of all local depth readings are within $2 / 3<\mathrm{d}_{\mathrm{m}}<3 / 2$ interval and $94 \%$ within $1 / 2<\mathrm{d}_{\mathrm{m}}<2$ interval.

We recommend simple additional average depth control measurements by: a) total debris weight measurements; and/or b) "sand backfill" measurements in future scabbling trials.

Two main factors are responsible for the nonuniformity of scabbling: specifics of the concrete structure, and variations of the EH discharge property and, especially, discharge localization. The first factor seems to be most important, reflecting inhomogeneous structure of concrete with alternating hard (stone/gravel) and soft (sand/cement) areas. The inhomogeneity

*More detailed depression reliefs are provided in FERMCO's Report. 


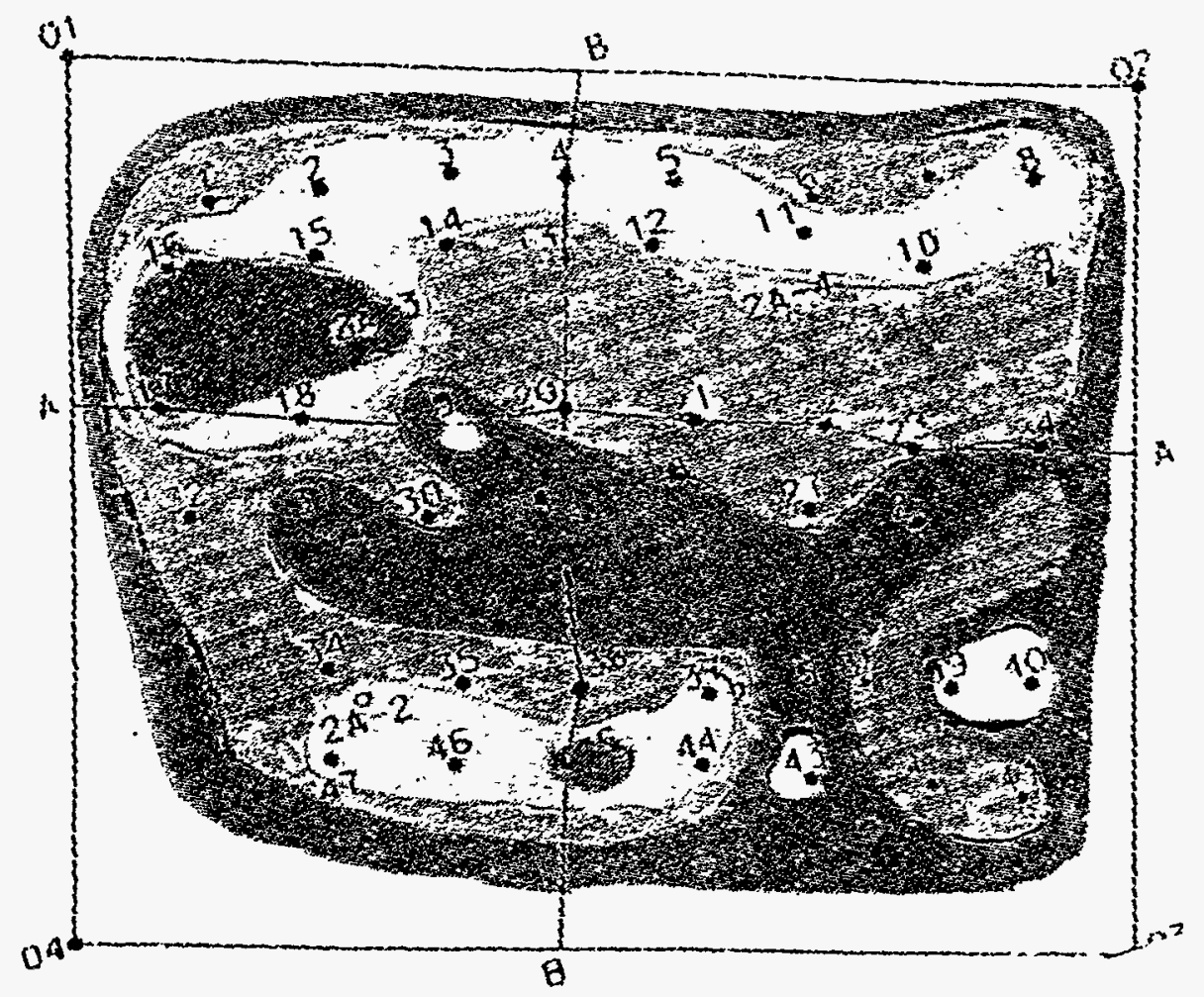

SCABBLINंG DEPTH, $\mathrm{mm}$
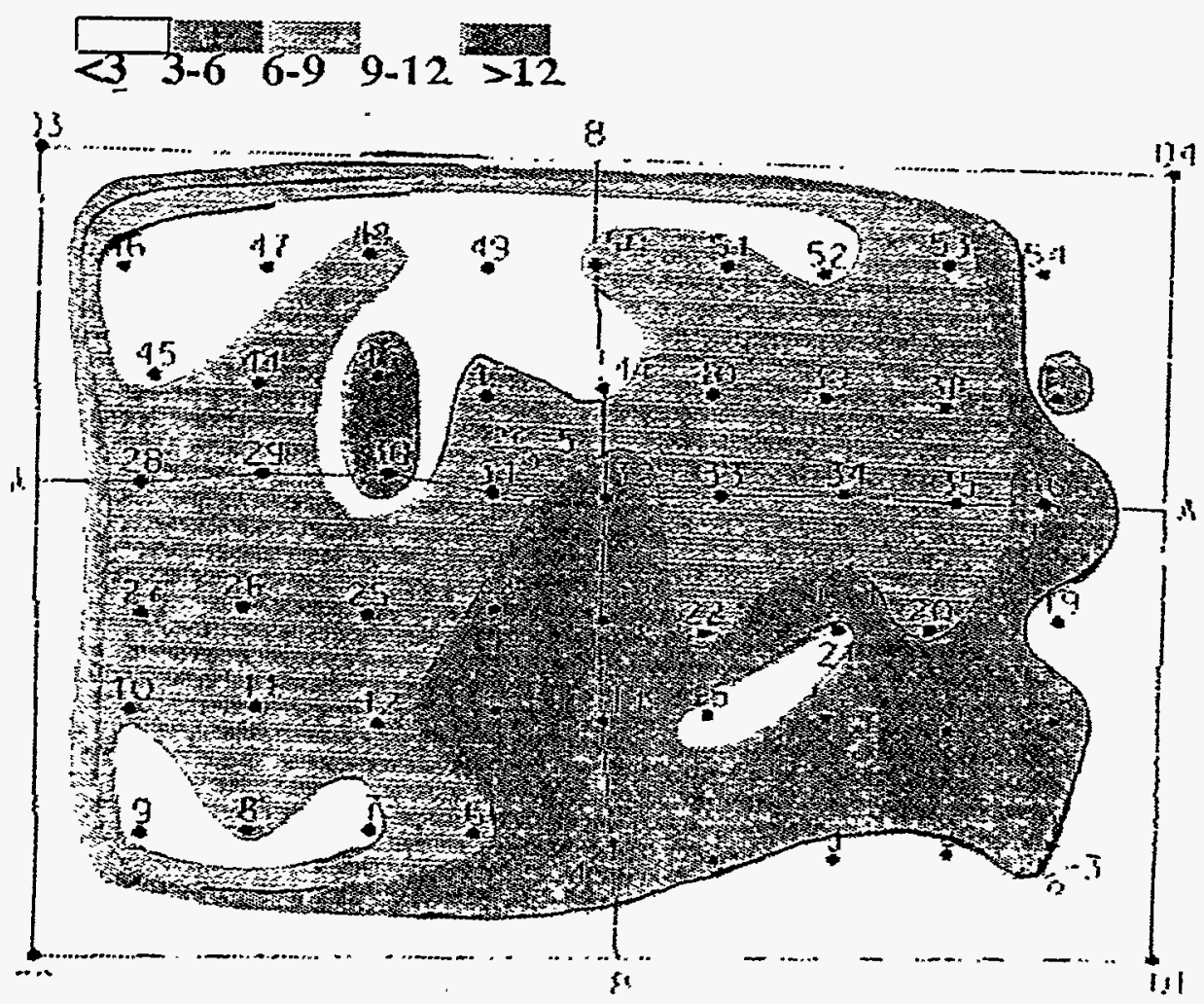

C

Figure 8-3 Elevation Relief for Floor Segments A and C 


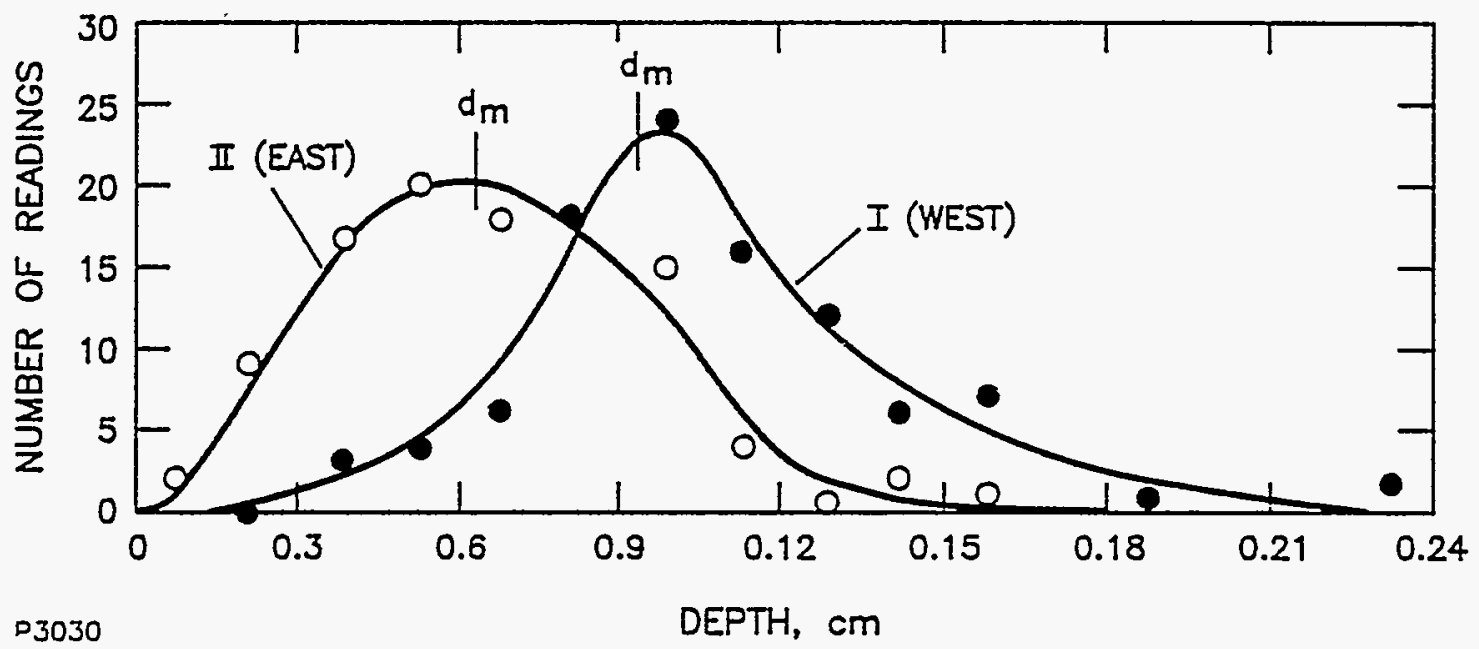

Figure 8-4 Depth Distribution Function for Floor Segment A, Cross Section 
effect is enhanced by the fact that a two-dimensional (i.e., relatively thin surface layer) rather than volumetric distribution of the mechanical properties defines resistance to EH pulses. The local variations of these properties should be less "smooth" in a two-dimensional case.

The second factor involves: a) pulse-to-pulse fluctuations of the discharge energy and discharge channel position, which affects the strength of shock waves and cavitation streams reaching the concrete surface; and b) distribution of discharges along the width of an electrode gap, which depends, in turn, on variances of the interelectrode distance, of the electrode surface condition, of the contact/clearance with respect to concrete, and of the local conductivity of the water gap. All these are hardly controllable factors; while random in principle, the pulse distribution may have regions of lower and higher concentrations along the electrodes. Concrete structure is correlated with concrete mechanical strength, and the last one defines concrete resistance to the EH pulses. Specifically, Fernald concrete required somewhat higher energy input to achieve the same scabbling depth as concrete at the Everett site. The difference could be visualized by the surface appearance (compare Figures $6-3,6-4$, and $8-1$, for instance). While scabbling of the Everett concrete reveals large stones by withdrawing them from the sandy matrix, scabbling at Fernald left most of the stones intact, even when most of surrounding sand was removed. It is possible that stone/sand bonding in the Fernald concrete was stronger.

\subsection{DECONTAMINATION PERFORMANCE}

\subsubsection{Introduction}

Removal of a concrete surface layer is a precondition for successful decontamination, but still does not assure decontamination quality. There are several factors affecting efficiency and completeness of removal of the uranium contaminant. The most important factors are:

- Correct selection of the scabbling depth.

The optimum depth is limited by the following two conditions:

a) it should be sufficient for a complete removal of the uranium-carrying concrete layer, but

b) should not substantially exceed the minimum required depth to assure low scabbling cost and small volume of scabbling-generated waste.

- Negligible penetration of a surface layer-bond uranium into the bulk concrete due to shocks, crack formation, water penetration, and other possible EHS-related phenomena.

- Absence of the recontamination of a newly-formed concrete surface/surface layer by the uranium recirculated with the process water and/or fine concrete debris.

- Insignificant contamination of the surrounding space (floor, walls, equipment, and air) during the EHS operation.

To evaluate the decontamination quality and to address specific issues listed above, a survey, sampling and sample analysis program, has been developed by a joint FERMCO-TSD effort. The program was implemented without major changes. Several issues related to the preand post-scabbling surface surveys, as well as results of the survey, are considered in this section. 


\subsubsection{Radioacrivity Meter Survey}

Concrete surface radioactivity (counts-per-minute) measurements were made by meters sensitive to $\beta$ and $\gamma$ radiation. Independent measurements were made by a FERMCO Rad. Tech. using a Ludlum Geiger counter and by a TSD team member using a Ludlum Model 2221 portable scaler/ratemeter, which is basically a similar Geiger counter supplemented by a pulseintegrating device.

The radioactivity data are provided in the FERMCO Report. The readings were taken at five to eight locations over scabbling floor segments (A to I), with a detector head positioned about 6" above the floor level. The TSD data results are presented in Figure 8-5.

There are some differences in the techniques used by the teams. Both sets of data are affected by a strong radioactivity background generated mostly by fixed and/or loose contamination of the uranium-processing equipment located nearby (as close as 6-10 ft.) the scabbling area. The background level varied not only with horizontal distance from the contaminated equipment, but, as shown in Figure 8-6, also with a distance from the floor level.

In the FERMCO measurements, a radioactive background was not measured independently (and not subtracted), but could be reduced to some extent (not explicitly stated) by using a shielded probe (Model HP-210L). When pre- and post-scabbling CPM numbers are compared, the background is partially taken into account, but pre/post cpm ratio is still not properly corrected. Pre- and post-scabbling readings ( $<\mathrm{cpm}>_{1}$ and $\left\langle\mathrm{cpm}>_{2}\right.$, respectively) averaged over floor segments are presented in Table 8-2a. Values of a ratio $\left.\mathrm{Q}=\langle\mathrm{cpm}\rangle_{2} /<\mathrm{cpm}\right\rangle_{1}$ which can be used to characterize the quality of decontamination are in 3 to 8 range.

In the TSD measurements, a Geiger counter equipped with the ratemeter provides more precise count numbers than the analog reader used by FERMCO. The cpm readings are taken very close (about $1 / 2$ " above) to the concrete surface, where the background is lower. In addition, the background is measured directly. For this purpose, a 1/4" rubber sheet (which reduces $\beta$ and $\gamma$ counts more than 20 times) is placed on the concrete floor; cpm readings taken with a detector placed on the sheet provide background levels at a certain scabbling segment. The background readings $<\mathrm{cpm}>0$ are subtracted from both pre- and post-scabbling readings. A ratio $\left.\mathrm{Q}=<\mathrm{cpm}>_{2}-<\mathrm{cpm}>_{0} /<\mathrm{cpm}\right\rangle_{1}-<\mathrm{cpm}>_{0}$ ) is used to characterize the quality of decontamination.

On average, the QTSD values shown in Table 8-2b are higher than QFERMCO values presented in Table 8-2a. This could be expected because distorting background effect is eliminated. In either case, the data indicate that $\mathrm{EH}$ scabbling results in a several times reduction of the concrete radioactivity.

\subsubsection{XRF Spectrometer Survey}

An X-Ray Fluorescence (XRF) spectrometer (Model 900 FP) was used by the FERMCO team to determine "total" (U-238, U-235, + ...) uranium concentration present in concrete layer pre- and post-scabbling. For each floor segment, at least five measurements were made. In addition, readings were taken at specific locations involving surface defects (cracks, etc.). The readings were taken at the floor level for both the pre- and post-scabbling survey. In preliminary tests, dependence of instrument readings on the sensor-to-floor distance was evaluated to find out if concrete surface roughness might affect the measurements. The effect is substantial for short elevations (see Figure 8-6), but the XRF signal change with sensor-to-floor distance is regular and uniform. For this reason it was decided to eliminate lengthy procedures of pulverizing the 

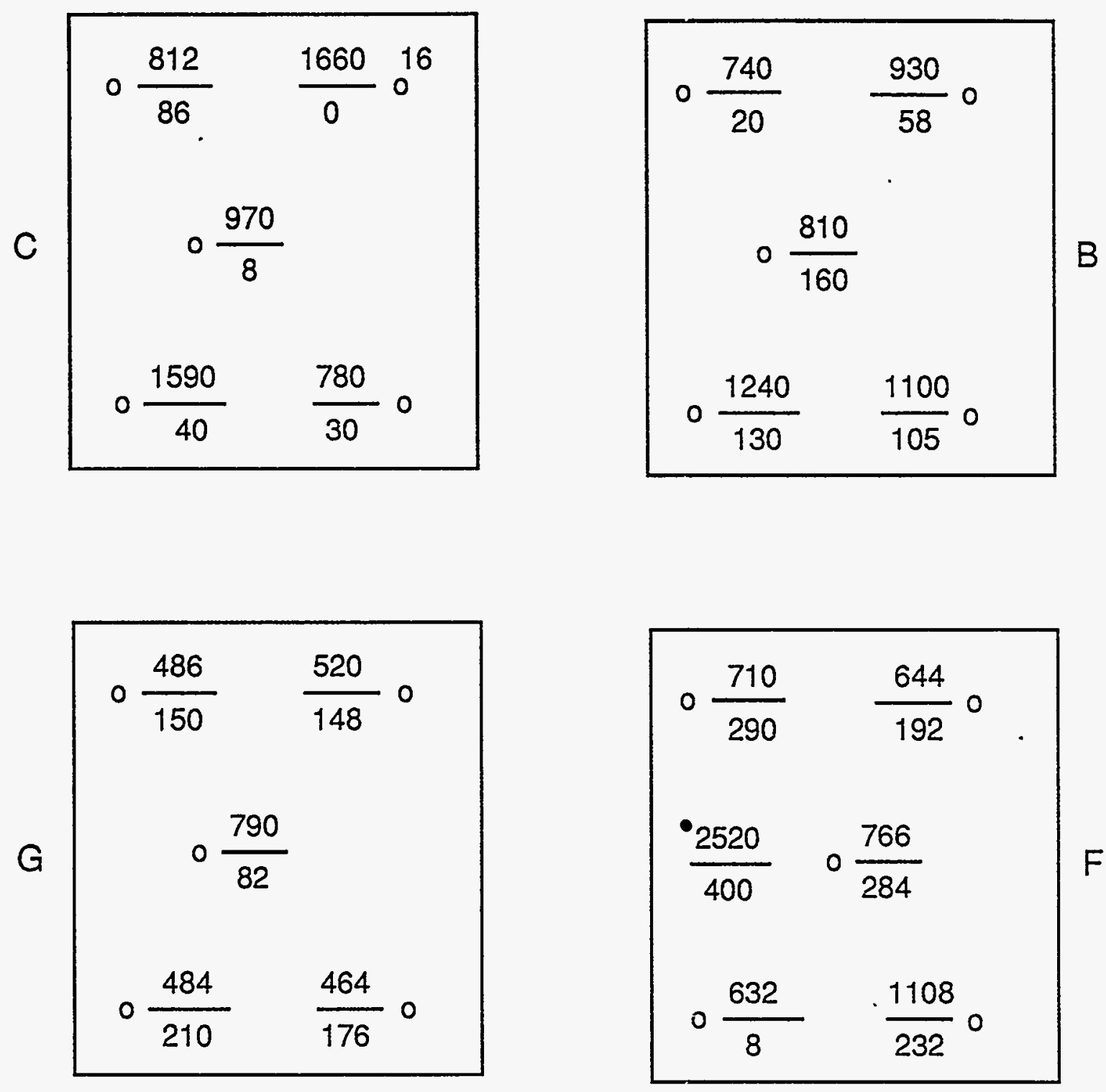

Figure 8-5 Results of Pre- and Post-Scabbling Radioactivity Measurements over Floor Segments B, C, F, and G (TSD data) 


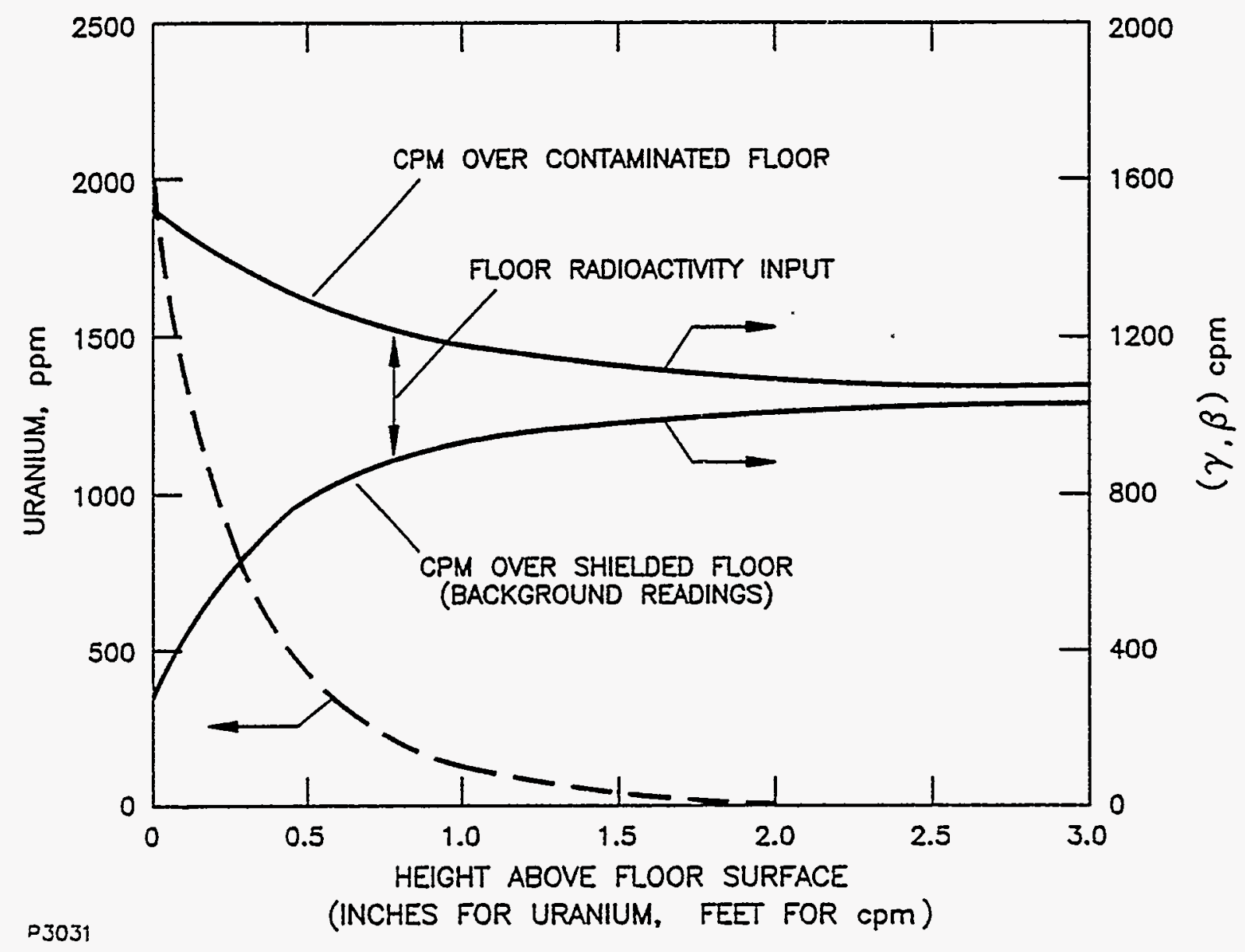

Figure 8-6 Radioactivity $\beta \gamma$ (in CPM) and XRF (in ppm) Signals vs. Sensor-to-Floor Distance 
TABLE 8-2 a

PRE- AND POST-SCABBLING RADIOACTIVITY READINGS AVERAGED OVER FLOOR SEGMENTS, TAKEN BY FERMCO

\begin{tabular}{|c|c|c|c|}
\hline \multirow{2}{*}{ Floor Segment Designation } & \multicolumn{2}{|c|}{ Average Radioactivity, CPM } & \multirow{2}{*}{ CPM Ratio } \\
& & P. & \\
\hline & Pre-Scabbling & Post-Scabbling & \\
\hline A & 720 & 233 & 3.1 \\
\hline B & 2500 & 570 & 4.4 \\
\hline C & 1640 & 202 & 8.1 \\
\hline D & 1180 & 275 & 4.3 \\
\hline F,$H$ & 1120 & 212 & 5.3 \\
\hline Average & 3100 & 560 & 5.5 \\
\hline & 1710 & 340 & 5.1 \\
\hline
\end{tabular}

TABLE 8-2 b

PRE- AND POST-SCABBLING RADIOACTIVITY READINGS AVERAGED OVER FLOOR SEGMENTS, TAKEN BY TSD

\begin{tabular}{|c|c|c|c|}
\hline \multirow{2}{*}{ Floor Segment Designation } & \multicolumn{2}{|c|}{ Average Radioactivity, CPM } & CPM Ratio \\
\hline & Pre-Scabbling & Post-Scabbling & \\
\hline B & 370 & 26 & 14.2 \\
\hline C & 1130 & 19 & 59.0 \\
\hline D & 3060 & 210 & 15.5 \\
\hline F & 1280 & 280 & 4.6 \\
\hline G & 450 & 122 & 3.7 \\
\hline H & 860 & 78 & 11.0 \\
\hline I & 1240 & 25 & 49.0 \\
\hline Average & 1200 & 109 & 11.0 \\
\hline
\end{tabular}


surface layer of scabbled concrete for collecting the sample as proposed earlier, and to make pre/post XRF measurements in a similar direct way.

Table 8-3 provides XRF pre- and post-scabbling results for one of the floor segments; more data can be found in the FERMCO Report. Specific points where XRF measurements were taken are shown also in the Geodimeter plots (see Figure 8-2). Table 8-4 summarizes the XRF data. On average, EH scabbling reduces the total uranium content by an order of magnitude.

\subsubsection{Scabbling of Concrete Floor Areas with Defects}

Concrete floor segments scabbled at Fernald had some defects - cracks of various depths and widths, joints, inclusions and indentations. As mentioned above, while these defects did not affect* the scabbling process per se, effectiveness of decontamination in these regions may be different. No systematic and defect-specific study was made, but in general the pre/post decontamination ratio was higher than over smooth concrete areas. With pre-scabbling contamination levels usually high, the post-scabbling levels did not exceed those at smooth surfaces too much.

Whatever the appearance of the crack, it usually is the area where concrete structure has various structure/strength defects. Consequently, $\mathrm{EH}$ processing results in removal of more or less loose material and in the widening of the crack ("opening up"). As a consequence, debris packed in the crack (probably for years) is removed by the turbulent water streams. Because the debris is rich in contaminants (usually counts/XRF signals over the crack area are ten or more times higher than over the smooth concrete), the whole process of crack widening/old debris removal is beneficial for decontamination. Because the crack width, depth, and edge strength, as well as amount/contamination level of the old debris varies widely, it is difficult to predict efficiency of crack decontamination quantitatively.

The observations and available limited data allow the conclusion that EH treatment is able to effectively remove contaminants from the wide, debris-filled cracks even without removing surrounding undamaged concrete by scabbling.

It may also be of a practical interest that intense turbulent water circulation generated by the EH effect within the scabbling chamber can probably be used as a technique for removal of "semi-fixed" surface/crack contamination, providing an improved version of a power wash.

\subsubsection{Core Samples Analysis}

Cores were taken by FERMCO at scabbling locations to determine the uranium contamination level in the concrete floor at the depth to which the floor was scabbled, and (for cores taken inside the perimeter of the scabbling chamber) to determine if the scabbling process might drive decontamination deeper into the concrete.

Samples were obtained by drilling the concrete floor at several points located within areas covered by the scabbling chamber (enclosure), either within the 2 'x2' segments assigned for scabbling ("in" samples) or outside these segments, close to their borders ("out" samples) - see Figure 8-7. The XRF readings were taken before the scabbling (1) from the top of the cores, and (2) from the surfaces formed by cuts made at various ( 0.24 " to 0.32 ") core depths.

*With the exception of one "ultimate" case where a large diameter hole leading to the sub-floor area was present and, after filling debris had been removed by water streams, resulted in a complete loss of water from the scabbling chamber. 
TABLE 8-3 PRE- AND POST-SCABBLING XRF ("TOTAL URANIUM") READINGS
FOR FLOOR SEGMENTS F AND G

\begin{tabular}{|c|c|c|}
\multicolumn{3}{|c|}{ SQUARE 2F } \\
\hline & PRE-SCABBLING & POST-SCABBLING \\
\hline $2 \mathrm{~F}-1$ & 1193 & 201 \\
\hline $2 \mathrm{~F}-2$ & 2204 & 227 \\
\hline $2 \mathrm{~F}-3$ & 3378 & 440 \\
\hline $2 \mathrm{~F}-4$ & 1202 & 370 \\
\hline $2 \mathrm{~F}-5$ & 3430 & 311 \\
\hline
\end{tabular}

SQUARE 2G

\begin{tabular}{|c|c|c|}
\hline & PRE-SCABBLING & POST-SCABBLING \\
\hline $2 \mathrm{G}-1^{* * *}$ & 8570 & 99 \\
\hline $2 \mathrm{G}-2$ & 918 & 281 \\
\hline $2 \mathrm{G}-3$ & 750 & 265 \\
\hline $2 \mathrm{G}-4$ & 734 & 121 \\
\hline $2 \mathrm{G}-5$ & 776 & 87 \\
\hline $2 \mathrm{G}-6^{* * *}$ & 8226 & 101 \\
\hline $2 \mathrm{G}-7^{* * *}$ & 8898 & $<\mathrm{MDL}$ \\
\hline
\end{tabular}

***2G-1, 2G-6, and 2G-7 were taken over a construction joint. 
TABLE 8-4

PRE- AND POST-SCABBLING XRF DATA AVERAGED OVER FLOOR SEGMENTS

\begin{tabular}{|c|c|c|c|}
\hline \multirow{2}{*}{ Floor Segment Designation } & \multicolumn{2}{|c|}{ Average Uranium Content, PPM } & PPM Ratio \\
& \multicolumn{2}{|c|}{} & \\
\hline & Pre-Scabbling & Post-Scabbling & \\
\hline A & 846 & 133 & 6.4 \\
\hline B & 2570 & 652 & 3.9 \\
\hline C & 1210 & 158 & 7.6 \\
\hline D & 2090 & 61 & 34.0 \\
\hline F & 2280 & 310 & 7.4 \\
\hline H & 5770 & 191 & 30.0 \\
\hline Average & 5090 & 407 & 12.4 \\
\hline & 2840 & 273 & 10.4 \\
\hline
\end{tabular}




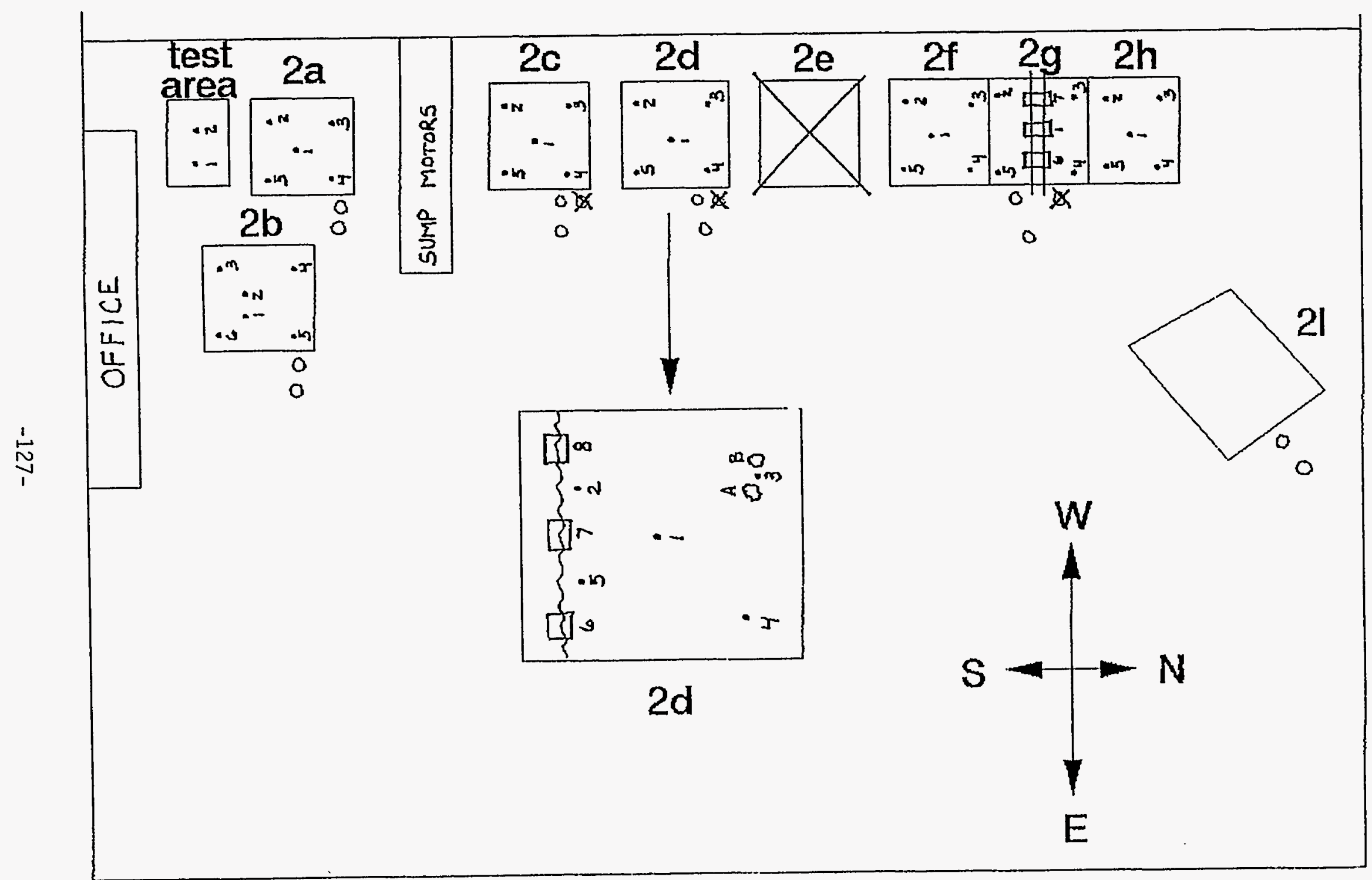

Figure 8-7 Locations of Scabbled Floor Segments, XRF Measurement Points $(\cdot)$ and Concrete Core Sampling (o) in Building 6 
The top readings vary in a broad 17 to 1730 ppm range, with average value of $850 \mathrm{ppm}$. For most core cuts, uranium content was below the detection limit. One hundred to $400 \mathrm{ppm}$ readings obtained in a few instances for cut surfaces result, most probably, from acciciental contamination during cutting.

The data provide an indication that in Building 6 areas explored under this program, uranium does not penetrate into concrete floors deeper than $0.15^{\prime \prime}$.

In our opinion, the core technique (in the form used at Fernald) did not meet the expectations. The following shortcomings were evident:

- Tools used for core "slicing" were not adequate to provide precise determination of location (depth) and to avoid contaminant transfer and core damages.

- Number/quality of useful (multidepths) samples was not enough for meaningful statistics and conclusions.

- Post-scabbling cores were taken close to but not within the scabbled area.

- $\mathrm{XRF}$ and $\beta / \gamma$ radiation. readings were taken from the core slice surfaces corresponding to the average scabbling depth, while minimum scabbling depth would be more purposeful.

The last "bullet" deserves more explanation. Consider an example: at an average 1/4" scabbling depth, there are spots/locations where scabbling is as shallow as 1/8"; initial contamination at this depth could still be substantial enough to provide contamination signal much higher than the one obtained from the $1 / 4$ " core depth surface. In other words, to be characteristic, the core should be sliced at lower depth (i.e., shorter distance from the top). Two other factors to be taken into account are the size of the sensor's window and the radioactivity of residual fines. Figure 8-8 illustrates these considerations.

Also, the core data can not be used to make a judgment about "EHS driving uranium into the depth of the concrete." There is no evidence or physical reason for that at all; the cores were not even taken from the scabbled segments. The "hydraulic forces" generated by the discharge are at least 100 times lower beyond the scabbling area proper. It is also unlikely that contaminants are forced into fissures - they are rather washed out. The only (though also questionable) mechanism that might work here (and only within the scabbled areas) is "opening" of the existing defects that may enhance radioactivity signals registered by the sensors.

In summary, to provide guidance for preselection of scabbling depth and data useful for understanding the origins and mechanisms of the residual contamination, the concrete core technique should be (and can be) improved.

\subsubsection{Radioactivity and XRF Data Comparison and General Conclusions}

Survey data lead to the following conclusions:

- Both survey methods reveal more than an order-of-magnitude reduction in the uranium contamination level at the concrete floor level. The decontamination takes place for regular, defect-free surfaces, as well as for localized defects (cracks, joints, and point-like indentations). The degree of the contaminant reduction varies significantly over the surface. The variation can represent the actual difference in the content, but, more likely, imprecise pre/post probe positioning, presence of residual loose contaminants, local variation of background, and other secondary factors. 
HYPOTHETICAL

INITIAL URANIUM

DISTRIBUTION

( $\approx$ EXPONENTIAL)

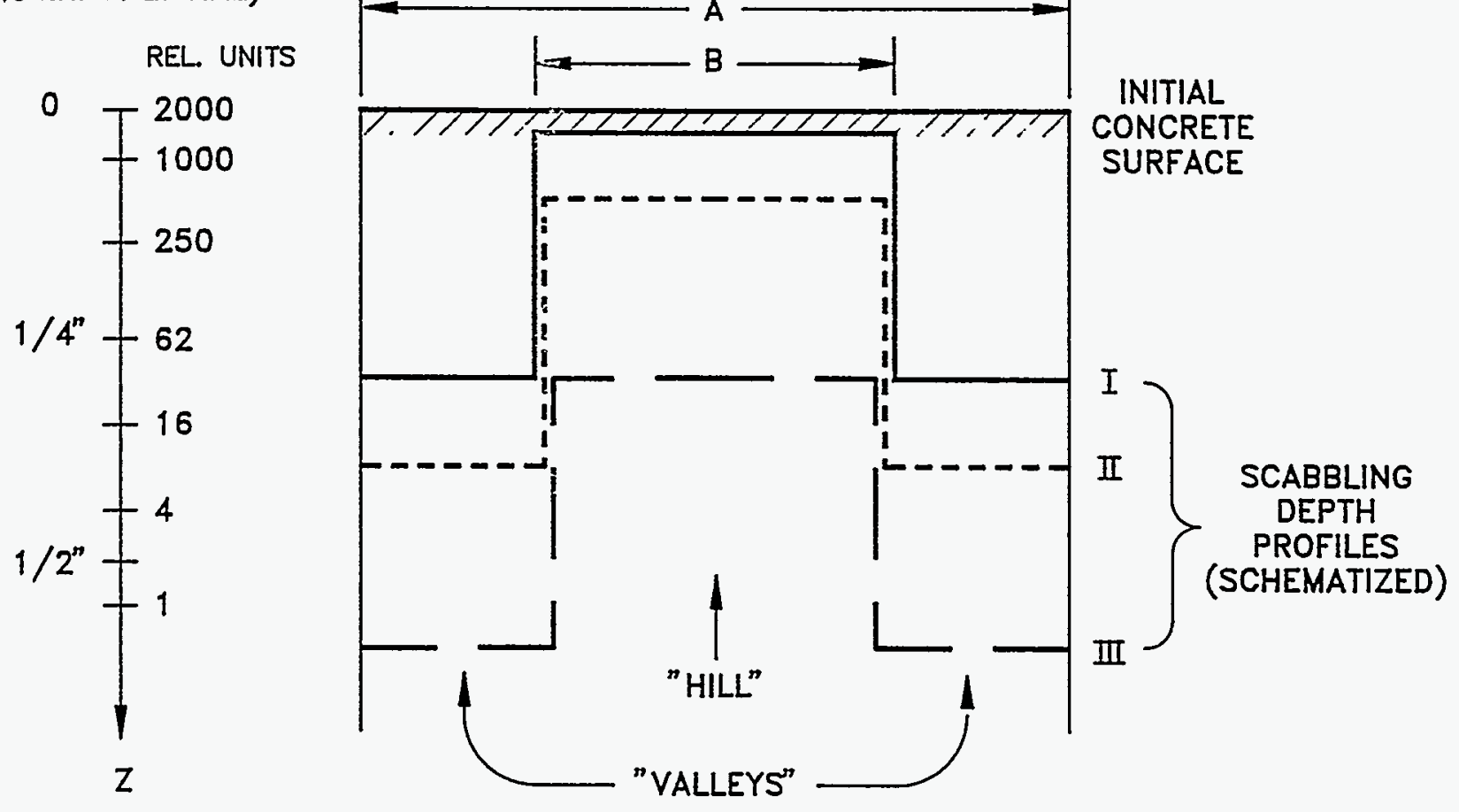

POST-SCABBLING URANIUM CONTAMINATION (REL. UNITS)

\begin{tabular}{|c|c|c|c|c|c|c|}
\hline \multicolumn{3}{|c|}{$\begin{array}{c}\text { "RECONTAMINATION" } \\
\text { LEVEL }\end{array}$} & \multicolumn{2}{|c|}{0} & \multicolumn{2}{|c|}{200} \\
\hline & SENSOR'S & WINDOW & A & $B$ & A & B \\
\hline I & SCABBLING & 0.20 & 500 & 1000 & 716 & 1200 \\
\hline II & DEPTH & $0.30 \quad\left( \pm 0.15^{n}\right)$ & 133 & 250 & 333 & 450 \\
\hline III & & 0.50 & 8 & 16 & 208 & 216 \\
\hline
\end{tabular}

P3053

Figure 8-8 In Reference to the Discussion on the Evaluation of Uranium Contaminart Distribution 
- As follows from the comparison of data in Tables $8-2 b$ and $8-4$, there is a reasonable semi-quantitative correlation between the average $\mathrm{XRF}$ and radioactivity data (with respect to pre/post counts and fluorescence signal ratios). On the other hand, as illustrated by.Figure 8-9, correlation of local readings is relatively poor. Because of substantial local variations of both sets of data over the surface and imprecise location of both types of sensors for pre- and post-measurements, a better correlation should not be expected. It should also be taken into account that $\beta$ and $\gamma$ radioactivity and U-fluorescence signals may differ because they could emanate from the different depths of concrete or from the residual loose surface contamination.

- The loose contamination relates to particles not completely removed from a rough concrete surface by the post-scabbling wet vacuuming. The small, but heavy, residual sandy particles "hiding" in the surface cavities have been observed rather frequently. They can be responsible for the abnormally high local post-scabbling counts or XRF readings. Usually, removal of these particles by a local high velocity air nozzle results in reduction of the high counts/signals.

- There is no meaningful correlation between radioactivity or XRF signals and local scabbling depth readings. The correlation is rather weak even for.signals averaged over full areas of the scabbled segments. This indicates that the secondary factors (considered above) leading to variation of the local signals are more important than specific local scabbling depth values.

- It appears that EH scabbling to $1 / 4$ " average depth is adequate for an order-ofmagnitude reduction of the uranium content with a characteristic initial level of at least several thousand $\mathrm{dpm} / 100 \mathrm{~cm}^{2}$ or several thousand $\mathrm{ppm}$ of the total uranium. Evidently, input of local "islands" of very shallow scabbling, or even small islands not scabbled at all, is insignificant for signals averaged over more than about one sq. ft. floor area. In our opinion, radioactivity or XRF readings averaged over at least one sq. ft. are both more reliable and more representative as parameters characterizing a radioactive and/or chemical health hazard.

\subsection{CHARACTERIZATION OF EHS-GENERATED WASTE}

\subsubsection{Introduction}

EH scabbling is generating contaminated concrete debris (rubble) and contaminated process water, as well as smaller amounts of other non-EHS specific waste materials. Knowledge of uranium content in the process water and solid rubble is of importance, allowing:

- To understand physical and chemical features of uranium contaminant, its water solubility and partition between water, fine (suspended) and coarse concrete rubble.

- To check material balances involved in the EHS operation.

- Using this information to design an optimized separation and flow recirculation system.

- To predict the degree of waste recirculation that can be tolerated without leading to a significant recontamination of the concrete surface.

- To estimate the necessary amount of water makeup and the total water consumption and waste water volume. 


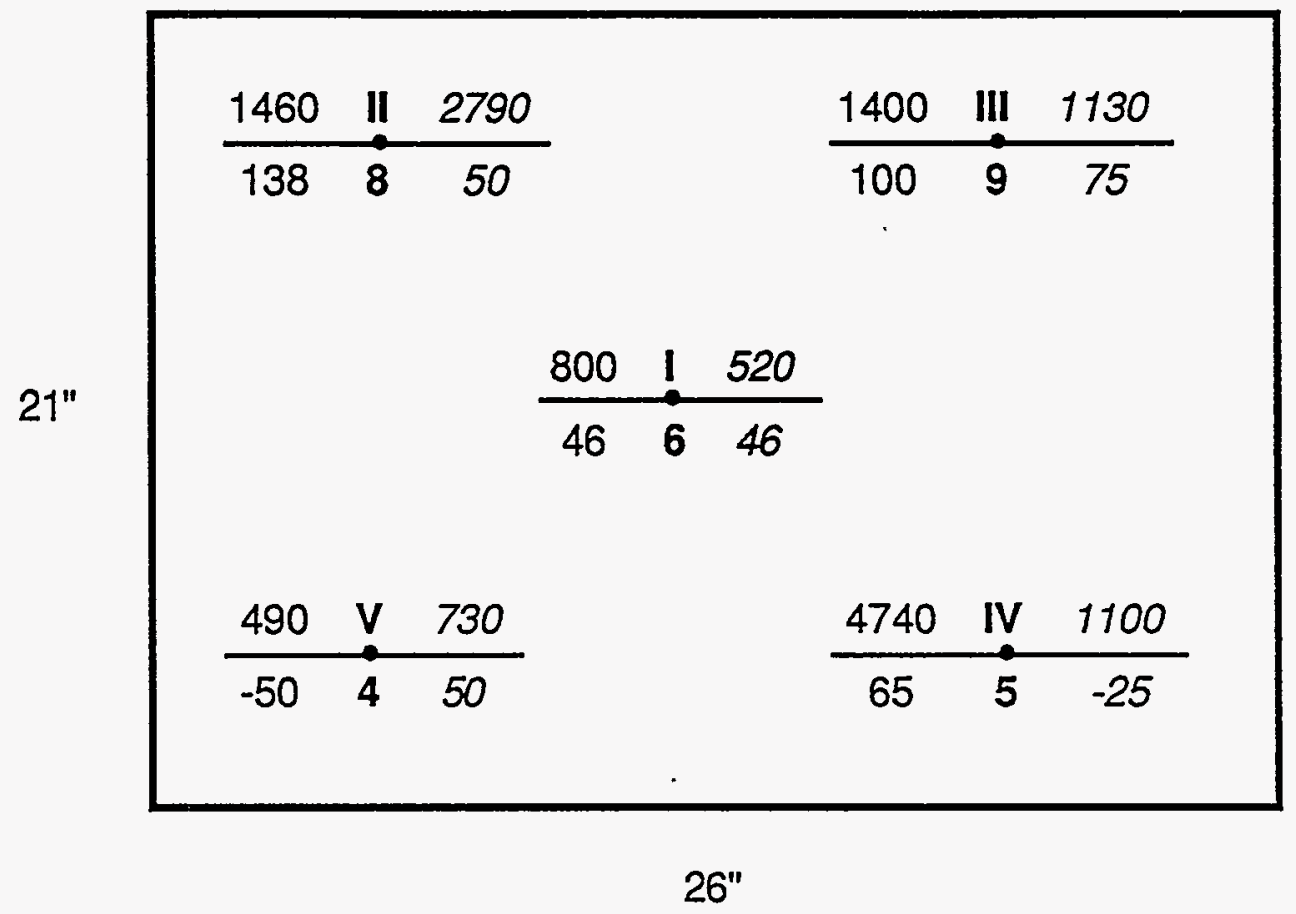

\begin{tabular}{|c|c|c|c|c|}
\hline Location & $\begin{array}{l}\text { CPM } \\
\text { Ratio }\end{array}$ & $\begin{array}{l}U_{\text {ppm }} \\
\text { Ratio }\end{array}$ & \multicolumn{2}{|c|}{ Legend: } \\
\hline 1 & 17.3 & 17 & pre & Loc \\
\hline II & 10.6 & 57 & $\longrightarrow$ & \\
\hline III & 15.2 & 15 & post & $d$ \\
\hline IV & $>20$ & 72 & & \\
\hline V & $>20$ & 14 & & \\
\hline
\end{tabular}

Figure 8-9 Comparison of Radioactivity and XRF Data for Floor Segment D 
To address these issues, multiple water and concrete samples were collected and analyzed in a FERMCO laboratory. A separate issue is the quality of air entering the scabbling chamber and removed from the chamber by a wet vacuum system equipped with a HEPA filter. It is of interest to measure the content of the contaminant in the filter deposit as well as in the (presumably) clean air leaving the filter. These measurements should provide information for the optimization and, if possible, simplification of the air flow equipment.

\subsubsection{Process Water and Concrete Rubble (Sludge) Analysis}

\subsubsection{Waste Sampling and Classification}

Locations for sampling of liquids and solids involved in the process of scabbling and accompanying waste generation are shown in Figure 8-10 schematic. Not all samples were taken for each run/floor segment, and there were minor differences in sampling depending on operating details (e.g., with/without process water recirculation, with/without pump strainer, etc.).

The characteristic, regularly taken samples are as follows:

- $\mathrm{L}_{1}$ - "clean" (tap) water.

- $\quad \mathrm{L}_{2}$ - water from the scabbling chamber (enclosure) filled either a) from a fresh-filled drum, or b) from the drum filled (by pump) with process water from the previous scabbling run and pumped to the scabbling chamber through a filter.

- $\quad \mathrm{L}_{3}$ - water collected by (and retained in) the wet vacuum unit together with concrete rubble, forming a sludge.

- $\quad S_{1}$ - solid rubble collected (mechanically removed) from the floor surface isolated (during scabbling) by the enclosure.

- $S_{2}$ - solids from the sludge remaining in the pump strainer.

- $S_{3}$ - solids from the sludge collected by the wet vacuuming of the floor surface.

- D - dust collected from dried scabbled floor segments by a brush sweep. $\mathrm{L}(\mathrm{F})$.

The water $(L)$ samples were analyzed as collected: unfiltered - L(U), and after filtration -

Water samples and samples of liquid solutions of solids prepared by the acid digestion were analyzed for uranium content using two techniques:

a) Kinetic phosphorescence method 256-S-6023, which is based on the measurements of decaying phosphorescence of uranium complexes excited by a laser light pulse.

b) Colorimetric measurements of light absorption at $580 \mathrm{~nm}$ wavelength and uranium extraction with formation of (light-absorbing) BROMOPADAP complex.

The analytical results are averaged and summarized in Table 8-5.

In addition to the total uranium determination by the BROMOPADAP method, $\beta$ - and $\gamma$ radioactivity of the dried and ground concrete sludge and concrete dust samples has been 


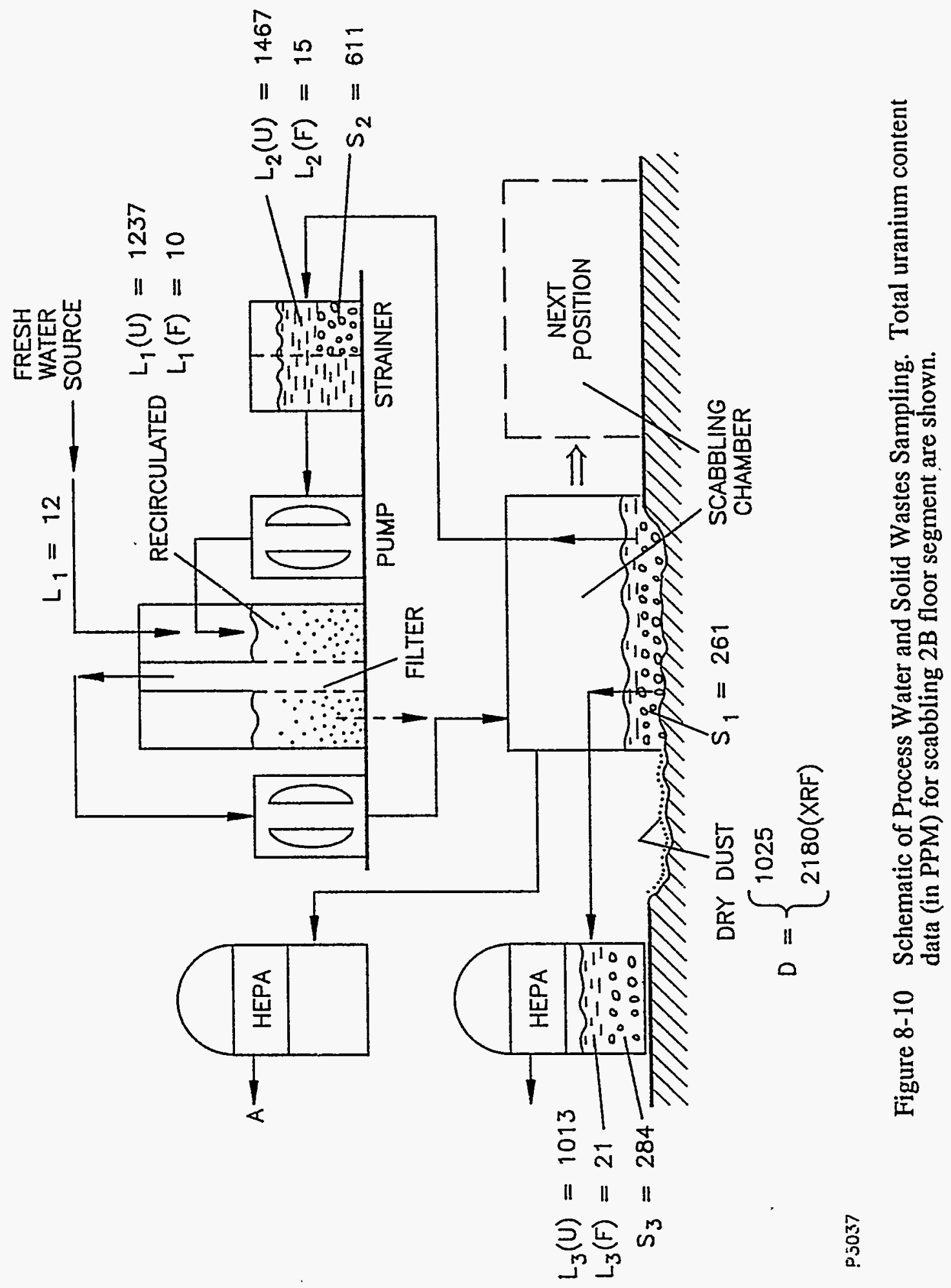


measured. Sludge CPM numbers are in a 100 to 600 range, while that of dust are in a 200 to 1000 range. Corresponding DPM/100 $\mathrm{cm}^{2}$ numbers between 400 and 4000 can be obtained by using a calibration factor equal to four. It may be noted that numerical correspondence between $\mathrm{CPM}$ and uranium ppm numbers for ground samples is approximately the same as for concrete floor surface survey by radioactivity counts and "total uranium" methods, respectively.

It follows from this data complex that scabbling generates:

a) Liquid waste: unfiltered (containing concrete fines) process water with typical several hundred ppm of uranium. Fines (sizes above $0.45 \mu \mathrm{m}$ in our case) could be easily removed from the process water, reducing its radioactivity to a fresh water level. The filter deposits can be added to a solid waste.

b) Solid waste: relatively coarse concrete rubble with typical uranium content of several hundred ppm and corresponding radioactivity of 1000-2000 DPM.

c) Solid waste: concrete (presumably, mostly cement) dust remaining as isolated dry particulates over the scabbled concrete surface after removal of wet sludge by wet vacuuming. This waste could be removed manually by brush or, preferably, by a sufficiently strong dry vacuum cleaner (e.g., equipped with a rotating brush).

Weights of (dried) coarse rubble collected from some wet vacuum bags ( $\mathrm{S}_{3}$ samples) are given in Table 8-6. The total weight of solid waste, i.e., $S_{1}+S_{2}+S_{3}+$ weight of fines filtered out from the process water, has not been measured. This weight could be approximated from the volume of concrete floor depressions formed by scabbling. For an average (0.3") scabbling depth, the total weight of the (de-watered) waste should be $6 \mathrm{~kg}$. At average $500 \mathrm{ppm}$ uranium content, the amount of uranium removed is expected to be about $1 \mathrm{~g} / \mathrm{sq} . \mathrm{ft}$.

\subsubsection{Residual Fines}

Radioactivity measurements made at a few selected scabbled floor areas demonstrate that manual removal of the dry dust results in radioactivity reduction by 60 to $120 \mathrm{CPM}$, which constitutes a substantial part of the total post-scabbling floor radioactivity. On the other hand, according to the measurements made by the FERMCO team (see Table 8-7), 20 to $60 \mathrm{~g}$ (or 5 to $15 \mathrm{~g} / \mathrm{sq} . \mathrm{ft}$.) of dust remains over the dried floor. Assuming, for estimation, that an average diameter of the dust particles is $200 \mu \mathrm{m}$, we obtain 20 to $40 \%$ "single layer" surface dust coverage. With all $\beta$ and $\gamma$ radiation escaping small dust particles, and $2 \mathrm{~mm}$ effective thickness of the bulk floor contamination (see below), we may expect that the dust generates a CPM signal which equals $5-10 \%$ of that from the unscabbled floor. This rough estimate agrees with the observations. It should be evident that without dry dust removal, scabbling might not achieve better than about $90 \%$ decontamination efficiency.

The nature and origin of the residual contamination (we prefer this term vs. "recontamination") are of interest to both process developer and customer. Specifically, it is important to know:

- If the active residue is loose or fixed (or something in between).

- If it forms a continuous layer or consists of individual particles. 
- If there are particles, then what is their size and composition.

- How is the residual contamination distributed on a micro-scale (e.g., with resolution better than the gravel size).

When residual fine particles are mechanically removed from the dried concrete, the radioactivity counts decrease 30 to $50 \%$. The origin of the remaining signals is still unknown. Is it dried film formed by precipitation, remaining individual particulates, or some continuous defect-related original uranium penetration to the depth, corresponding to the minimum (but not the average) scabbling depth over areas viewed by the sensor?

It is not clear if uranium is "preferentially bonded" to the fines. Higher average concentration may also result from a) larger surface area (and, accordingly, easy "escape" of radiation from the individual particles); b) presence of fine metallic uranium particles which may readily precipitate from water due to their high density; c) not complete equivalency (by structure, solubility, etc.) of samples of fine and coarse debris analyzed by XRF and other techniques.

Relatively high contamination signals (1000-2000 ppm XRF uranium readings) obtained from the dried fines collected from the scabbling segments by brush sweeping can be misleading. When comparing samples of dry fine samples (15 $\mathrm{g}$ tablets) and similar samples of coarse wetcollected debris, a "concentrating effect" should be taken into account: the tablet samples accumulate/concentrate dust from large (1-2 sq. ft.) scabbled floor areas, which are sparsely covered by particles (see Figure 8-11). Even when the signal obtained from the "fines" is 10 times higher than from the rubble samples, the total amount of uranium in the fines is still 100 times larger in the rubble collected from the same floor area. The absolute amount of uranium in the fines collected from the scabbled area is under $10 \mathrm{mg}$, compared to about 1 gram contained in the rubble.

A surface survey with better spatial resolution, comparable to that provided with a Geodimeter, would be helpful. It would show if any correlation between pre- and post-scabbling contamination signal and local scabbling depth values takes place.

Redistribution rather than removal of contaminants by a post-scabbling "power wash" provides an indication that the residual contaminant is not completely fixed but is still not easy to remove. It must be precipitating readily from the turbulent water and trapped by/attached to the rough concrete surface. If EHS fines are similar to a regular cement dust, their size should be in a 5 to $200 \mu \mathrm{m}$ range. These particles could originate from the fresh concrete surface and/or coarser debris grinded by a turbulent cavitating water flow. Among the fines-removal techniques to explore are high velocity suction and use of surfactants. Characterization of fines by size distribution and other properties (including composition, because even very heavy uranium particulates may be present) would be helpful for resolving the "fines" issue.

When considering separation of fines from coarser concrete rubble, we have to take into account that they constitute only a very small fraction (less than $1 \%$ ) of the whole debris. Meanwhile, the initial weight of, say, less than $100 \mu \mathrm{m}$ fraction may be over $10 \%$ of the total (due to strong action of $\mathrm{EH}$ discharges known for the concrete grinding applications). It may be difficult to avoid trapping a small proportion of fines within the bulk of concrete debris which forms a sticky floor deposit. If complete removal of wet coarse debris and fines from the 
TABLE 8-5

\section{AVERAGED TOTAL URANIUM CONTENT IN WATER, SLUDGE SOLIDS, AND DRY DUST SAMPLES}

\begin{tabular}{|l|c|c|}
\hline \multicolumn{1}{|c|}{ Sample Source } & Symbols & $\begin{array}{c}\text { Uranium Concentration } \\
\text { C(U), PPM }\end{array}$ \\
\hline $\begin{array}{l}\text { Water Fill, Fresh } \\
\text { unfiltered } \\
\text { filtered }\end{array}$ & $\mathrm{L}_{1}(\mathrm{U})$ & 8 \\
\hline Water Fill, Recirculated & $\mathrm{L}_{1}(\mathrm{~F})$ & \\
& $\mathrm{L}^{\mathrm{R}_{1}(\mathrm{U})}$ & 780 \\
& $\mathrm{~L}_{1}(\mathrm{~F})$ & 6 \\
\hline Water from Pump Strainer & $\dot{\mathrm{L}}_{2}(\mathrm{U})$ & 720 \\
and Wet Vacuum & $\mathrm{L}_{2}(\mathrm{~F})$ & 8 \\
\hline Sludge Solids: & & 360 \\
from scabbled floor & $\mathrm{S}_{1}$ & 500 \\
from strainer & $\mathrm{S}_{2}$ & 660 \\
\hline from vacuum & $\mathrm{S}_{3}$ & 1600 \\
\hline Dry Dust from Scabbled Floor & $\mathrm{D}$ & \\
\hline
\end{tabular}

TABLE 8-6

WEIGHT OF CONCRETE RUBBLE

\begin{tabular}{|c|c|c|c|c|}
\hline Location & $\begin{array}{c}\text { Weight of } \\
\text { Rubble }\end{array}$ & $\begin{array}{c}\text { Scabbled } \\
\text { Area }\end{array}$ & $\begin{array}{c}\text { Average } \\
\text { Depth }\end{array}$ & $\begin{array}{c}\text { Volume } \\
\text { Removed }\end{array}$ \\
\hline 2B & $2959 \mathrm{gr}$ & $557 \mathrm{in}^{2}$ & $0.14^{\prime \prime}$ & $78 \mathrm{in}^{3}$ \\
\hline 2C & $2516 \mathrm{gr}$ & $518 \mathrm{in}^{2}$ & $0.27^{\prime \prime}$ & $140 \mathrm{in}^{3}$ \\
\hline 2D & $3112 \mathrm{gr}$ & $538 \mathrm{in}^{2}$ & $0.25^{\prime \prime}$ & $135 \mathrm{in}^{3}$ \\
\hline 2FGH & $15613 \mathrm{gr}$ & $15582 \mathrm{in}^{2}$ & $0.20^{\prime \prime}$ & $316 \mathrm{in}^{3}$ \\
\hline 2I & $3899 \mathrm{gr}$ & $543 \mathrm{in}^{2}$ & $0.32^{\prime \prime}$ & $174 \mathrm{in}^{3}$ \\
\hline
\end{tabular}

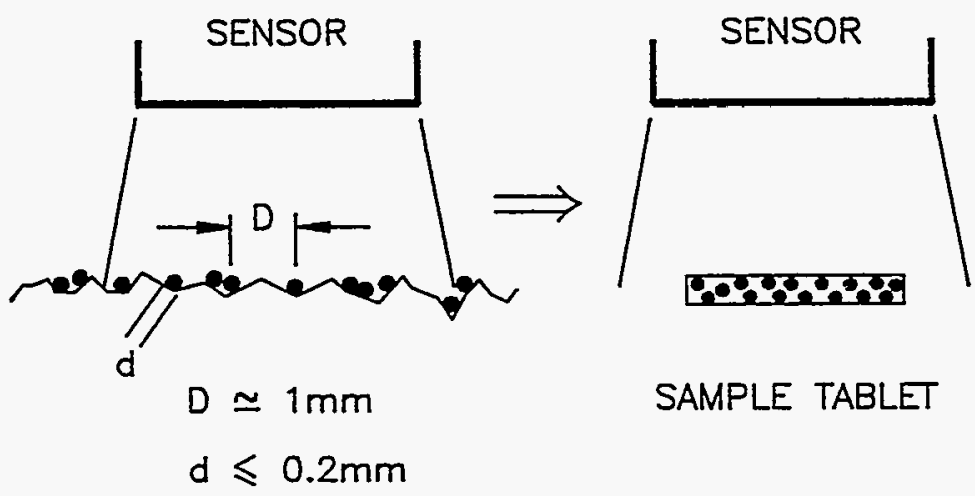

Figure 8-11 In Reference to the Measurement of Concrete Surface Contamination by Residual Fines 
scabbling chamber using strong suction assisted by water agitation can not be achieved, a dry finishing decontamination step has to be added. Among the fines removal techniques, high velocity suction, probably in combination with "sticky" lime dissolving solution, deserve attention.

\subsubsection{Other Sampling and Analysis Data}

\section{- 8.3.3.1 Estimation of Effective Thickness of (Radioactive) Concrete Layer}

Penetration of uranium and other contaminants into concrete is usually unknown. It depends on the concrete properties (including actual structures containing various defects) and, even more, on the chemistry, solubility, etc. of the specific contaminant. The $\beta, \gamma$ radioactivity and XRF signal $S$ registered by the sensor depends on the in-depth distribution of the contaminant $N(z)$ and on the penetration ability of the corresponding electrons and ( $\gamma$ and $X$-ray) photons which can be characterized by a linear absorption coefficient $\kappa$ or mass-absorption coefficient $\mathrm{k} / \mathrm{\rho}$. In Figures 8-12 and 8-13, concrete "half-thickness" $D_{1 / 2}$ (corresponding to $S=$ $S_{0} / 2$ where $S_{0}$ is a signal in the absence of absorbing medium) for photons and maximum range for $\beta$ particles penetration are shown. The concrete half-thickness $D_{1 / 2}$ numbers for the $\beta$ decaying uranium/radium family members are given in Table 8-8. Evidently, $\beta$ radiation escapes

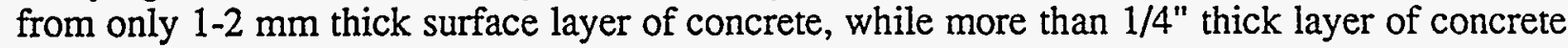
may still make an input in $\gamma$-radiation reaching the sensor.

Relatively coarse (about $1 \mathrm{~mm}$ in diameter) concrete rubble (if unpacked) is transparent for $\gamma$ and partially transparent for $\beta$ radiation. Fines suspended in the process water and dust remaining on the concrete floor are "efficient" (unhindered) emitters of both $\gamma$ and $\beta$ radiation.

Effective thickness of concrete making input in the XRF signal depends on the electron beam energy and wavelength of the stimulated X-ray fluorescence. It would be useful to determine the effective thickness for specific XRF instruments used by FERMCO.

\subsubsection{Effect of Post-scabbling Floor Washing and Drving}

Additional XRF total uranium determination was made to compare concrete surface layer uranium content over segments A to I (see Figure 8-7) for the following four conditions:
a) pre-scabbling
b) post-scabbling: no additional treatment
c) post-scabbling: water/soap wash
d) post-scabbling: wash and dry.

Table 8-9 provides XRF readings obtained for five locations within segment $C$, as well as readings averaged over seven segments. In agreement with results provided in Section 8.2, these data show an average order-of-magnitude reduction of surface layer uranium content by scabbling. It is also quite evident that subsequent washing does not result in the uranium content reduction, but may only lead to a minor redistribution of the contamination or, more likely, in a transfer of only the loose contamination over the floor surface. 


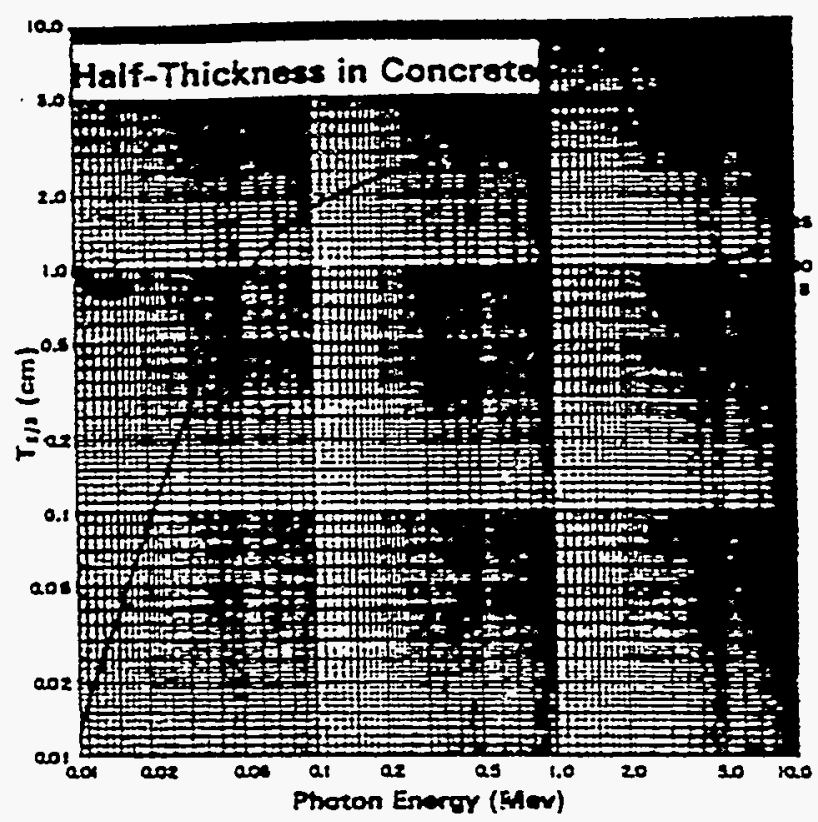

Figure 8-12 Half-Thickness vs. Photon Energy for Concrete

(Centimeters of concrete of density $2.35 \mathrm{~g} / \mathrm{cm}^{3}$ necessary to

reduce the number of gamma rays in a broad beam by a factor of 2 .)

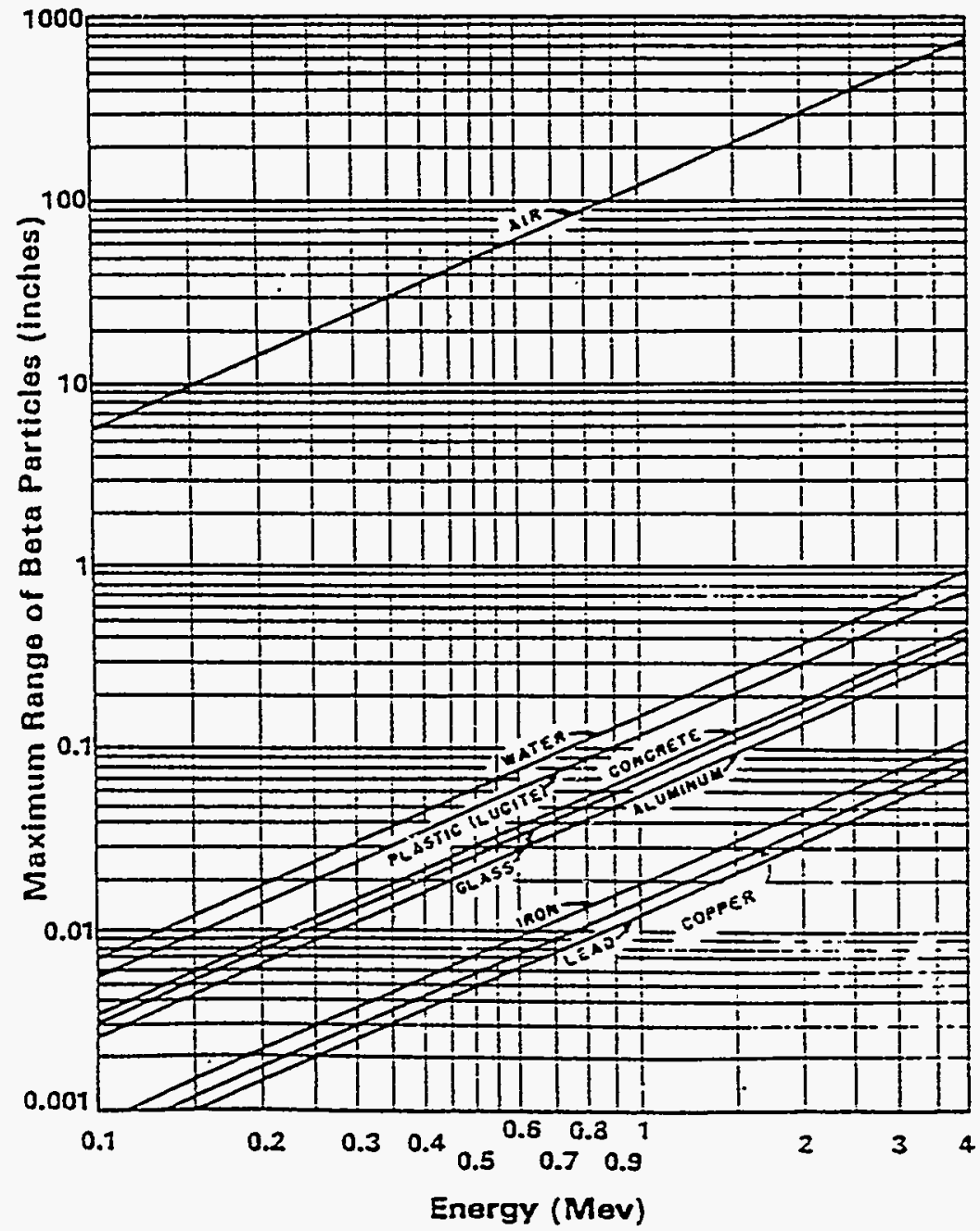

Figure 8-13 Maximum Range of Beta Particles vs. Energy 
TABLE 8-7

\section{AMOUNT OF DRY DUST COLLECTED AFTER SCABBLING}

\begin{tabular}{|c|c|}
\hline $\begin{array}{c}\text { Scabbled Area } \\
\text { (segments) }\end{array}$ & $\begin{array}{c}\text { Total Dust Collected } \\
(\mathrm{g})\end{array}$ \\
\hline A & 48.150 \\
\hline B & 18.893 \\
\hline C & 38.536 \\
\hline D & 34.985 \\
\hline F & 40.672 \\
\hline G & 62.285 \\
\hline H & 24.061 \\
\hline I & 30.830 \\
\hline
\end{tabular}

TABLE 8-8

CONCRETE PENETRATION PARAMETERS FOR URANIUM RADIATION

\begin{tabular}{|c|c|c|c|c|}
\hline \multirow{2}{*}{ Element } & \multicolumn{2}{|c|}{$\beta$} & \multicolumn{2}{|c|}{$\gamma$} \\
\cline { 2 - 5 } & $\mathrm{E}, \mathrm{MeV}$ & $\mathrm{D}_{1}, \mathrm{~mm}$ & $\mathrm{E}, \mathrm{MeV}$ & $\mathrm{D}_{1} 2, \mathrm{~mm}$ \\
\hline $\mathrm{UX}_{1}\left(9 \mathrm{Th}^{234}\right)$ & 0.19 & 0.02 & 0.09 & 0.35 \\
\hline $\mathrm{UX}_{2}\left(91 \mathrm{~Pa}^{234}\right)$ & 2.3 & 0.5 & 1.0 & 6.5 \\
\hline
\end{tabular}


TABLE 8-9

TOTAL URANIUM XRF READINGS (PPM) FOR

SCABBLED CONCRETE FLOOR SEGMENTS

\begin{tabular}{|c|c|c|c|c|c|}
\hline & & Pre-scabbled & \multicolumn{3}{|c|}{ Post-scabbled } \\
\hline Segment & Location & & Non-wash & Wash & Wash \& Dry \\
\hline C & 1 & 1370 & 131 & 200 & 152 \\
& 2 & 864 & 209 & 169 & 85 \\
& 3 & 716 & 386 & 228 & 337 \\
& 4 & 1429 & 29 & 83 & 75 \\
& 5 & 2671 & 38 & 84 & 71 \\
\hline C & & 1400 & 159 & 153 & 144 \\
A & & 800 & 132 & 147 & 159 \\
B & \multirow{2}{*}{ Segment } & 1970 & 540 & 600 & 730 \\
F & & 2100 & 61 & 56 & N/A \\
G & Averaged & 2300 & 310 & 250 & N/A \\
H & & 4100 & 137 & 101 & N/A \\
\hline \hline & & 5100 & 407 & 388 & N/A \\
Average & & & & & \\
\end{tabular}




\subsubsection{General Area Air Quality During Concrete Scabbling}

Several air samples were collected for a few hours near to the operating scabbling unit using the LB-5100 instrument. Sample radioactivity was under or at $10^{-11} \mu \mathrm{Ci} / \mathrm{cc}$. This level corresponds to about $19 \%$ of a Derived Airborn Concentration (DAC) level, or five times lower than an upper air radioactivity level allowed for operation without a respirator.

\subsubsection{Summary and Recommendations}

\subsubsection{Summary of Decontamination Results}

The results of the EH scabbling concrete decontamination capabilities can be briefly summarized as follows:

- EH scabbling of the concrete floor to a depth of $3 / 16^{\prime \prime}-3 / 8^{\prime \prime}$ results in an average factor of ten reduction of uranium content (as measured by $\beta / \gamma$ radioactivity and XRF) in the surface layer.

- According to (limited) statistical data (see Figure 8-14), at more than half of the locations, the percent of uranium removal exceeds $90 \%$. This includes $30 \%$ location where uranium content is below detection limit and locations with deep surface defects and high initial uranium content. Analysis of the concrete rubble indicates that 0.5 to $1.0 \mathrm{~g}$ of uranium was removed for each square foot of floor scabbled.

- Of more practical interest (e.g., comparison with authorized limits for residual radioactive materials) are contamination levels averaged over certain areas. When $\mathrm{CPM}$ or XRF signals are averaged over 2-4 sq. $\mathrm{ft}$. areas, greater than $90 \%$ uranium removal is achieved at $2 / 3$ of the locations.

- There are strong indications that typical residual (post-scabbling) readings of a few tens to a few hundreds DPM are due to isolated dust particles remaining in the surface "cavities." Removal of these particulates by an appropriate dry vacuuming is expected to eliminate apparent low uranium removal areas (left "tail" in Figure 8-12) and assure compliance with both <average $>$ and <maximum $>$ allowable surface contamination levels of $\mathrm{DOE} / \mathrm{CH}-8901$ guidelines.

- EH scabbling generates solid rubble and process water. The rubble contains uranium at several hundred ppm level (corresponding to several hundred CPM).

- The radioactive uranium species were shown to be insoluble in water and thus is easily removed by filtration so that the water can be recirculated without concern of recontamination.

- It is important that the EHS treatment does not generate liquid waste producing only solid waste by amounts equal to the amount of concrete removed and with radioactivity similar to radioactivity of the top concrete layer. Minor amounts of a dry dust (about $1 \%$ of the total solid waste) and filtered-out fines could be added to the bulk of concrete rubble. 


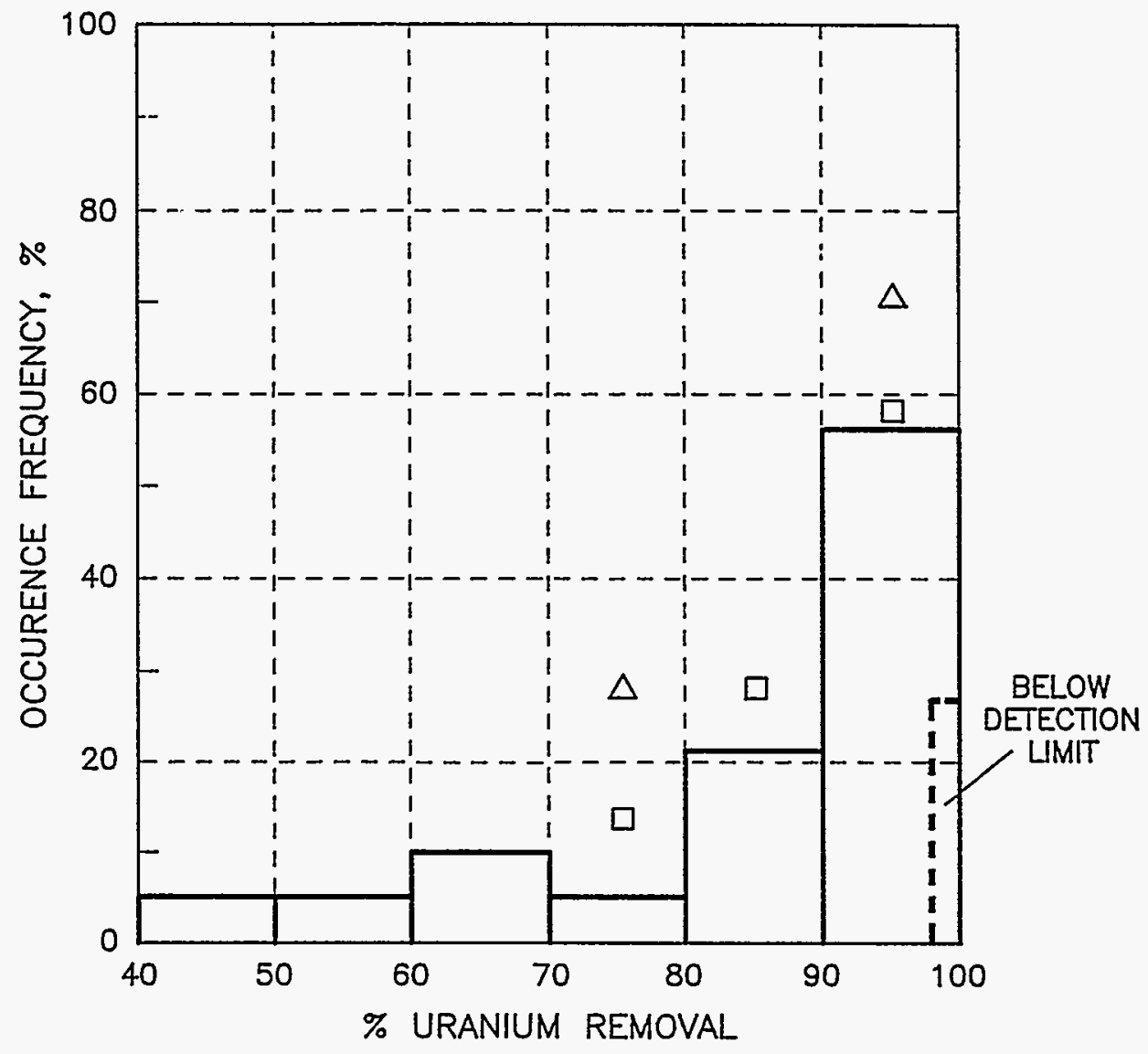

P3038

Figure 8-14 Occurrence Frequency for Concrete Decontamination

- Histogram for individual XRF measurements (5 to 7 per segment)

Data averaged over each segment ( 4 sq. ft. area):

$\square$ - XRF readings, $\triangle$ - CPM readings 
- Recirculation of the process water (either filtered or unfiltered) does not result in recontamination of the concrete floor surface.

- EHS does not generate airborne uranium contaminants. There is no need, therefore, for respirators in the processing area, including close-to-EHS equipment zone frequented by the operator.

- Absence of the airborne contamination and effective enclosure of the processing floor segments ensure negligible cross-contamination of the surrounding space

\subsubsection{Recommendations}

More comprehensive characterization of decontamination provided by EH scabbiing of concrete surfaces will require processing of larger floor areas, variation/optimization of scabbling parameters for specific floor conditions, and of the post-scabbling waste treatment. It would also be desirable to supplement and improve sampling and analysis procedures. Specifically, the following would help to better characterize factors involved in the decontamination and to optimize the EHS processing:

- Material balance determination, including weights/volumes of process water and all generated liquid and solid wastes.

- Characterization of individual solid waste fractions (including particle size arıalysis, weighing, and analysis of water filter deposits, etc.).

- Separate registration of $\beta$ and $\gamma$ radiation (using appropriate counters/windows), and direct measurements of the penetration depths.

- More complete study (e.g., by slicing) of pre- and post-scabbling core samples to obtain in-depth distribution of contaminants.

- Better accounting for radiation background (or its elimination); systematic use of survey meters with a scaling ability.

- Analysis of process air and materials collected by HEPA (or other) filters.

- Use of sand "fill-in" technique for independent determination of the floor depression/ concrete waste volume, and/or use of mechanical profilometer for scabbling depth profile measurements

Better knowledge of these factors would be helpful for the EHS development and optimization. 


\section{0 . CONCEPTUAL DESIGN, PERFORMANCE PROJECTIONS, AND ANTICIPATED ECONOMICS OF THE FULL-SCALE EHS SYSTEM}

\subsection{CONCEPTUAL EHS-III SYSTEM DESIGN}

This section provides a review of the main EHS configuration/component design issues that should be addressed and resolved to convert the workable prototype to a more functional, reliable, integrated unit. Some of the necessary changes and improvements are already obvious. A conceptual EHS system design was developed in the fall of 1995. This configuration already includes some necessary changes and the designated EHS-III is shown in Figure 9-1. Since that time, experience gained from the Fernald trials was summarized and additional experiments were performed at TSD. The projected modifications include (but may be not limited to) the following:

- General configuration of the EHS unit will be changed to make it more compact, convenient for transfers, and to process a larger floor area at a given position. To achieve these goals:

a) The power supply unit will be divided into two blocks, one including chargers and controls and the other capacitors and switches (spark gaps). The capacitor block should be mounted directly over the scabbling chamber, while the charger/ controls block may be located remotely.

b) The scabbling chamber (water enclosure) will be reshaped to allow a longer scabbling path (without changing the chamber's position). A single-screw $\mathrm{X}$ positioner will replace a bulky double-slider.

d) A more compact (lower and narrower) forklift truck with variable speed controls will be used. Big Joe PDC Model is among the probable candidates.

An artist's rendering of this configuration referenced below as a "commercial prototype" system (or EHS-IV) is shown in Figure 9-2. An elevated runway configuration (see Figure 9-3) suggested earlier for large open areas may be considered in the future.

- The power supply will be modified as follows:

a) Capacity (installed power) of a DC Charger will be at least doubled to increase pulse repetition rate and speed of scabbling.

b) PFN switch will be selected. The three prospective candidates are:

- Open spark gap as used in the most recent scabbling trials. It has certain objectionable, but still admissible, features:

- noisy operation, requiring bulky soundproofing;

- variable frequency, resulting in somewhat lower efficiency.

- Enclosed EG\&G spark gap. This spark gap operates rather quietly and forms regular pulses, but its lifetime is unacceptably short; some measures were undertaken by the vendor to increase the lifetime; tests planned for the near future should show if they succeeded. 


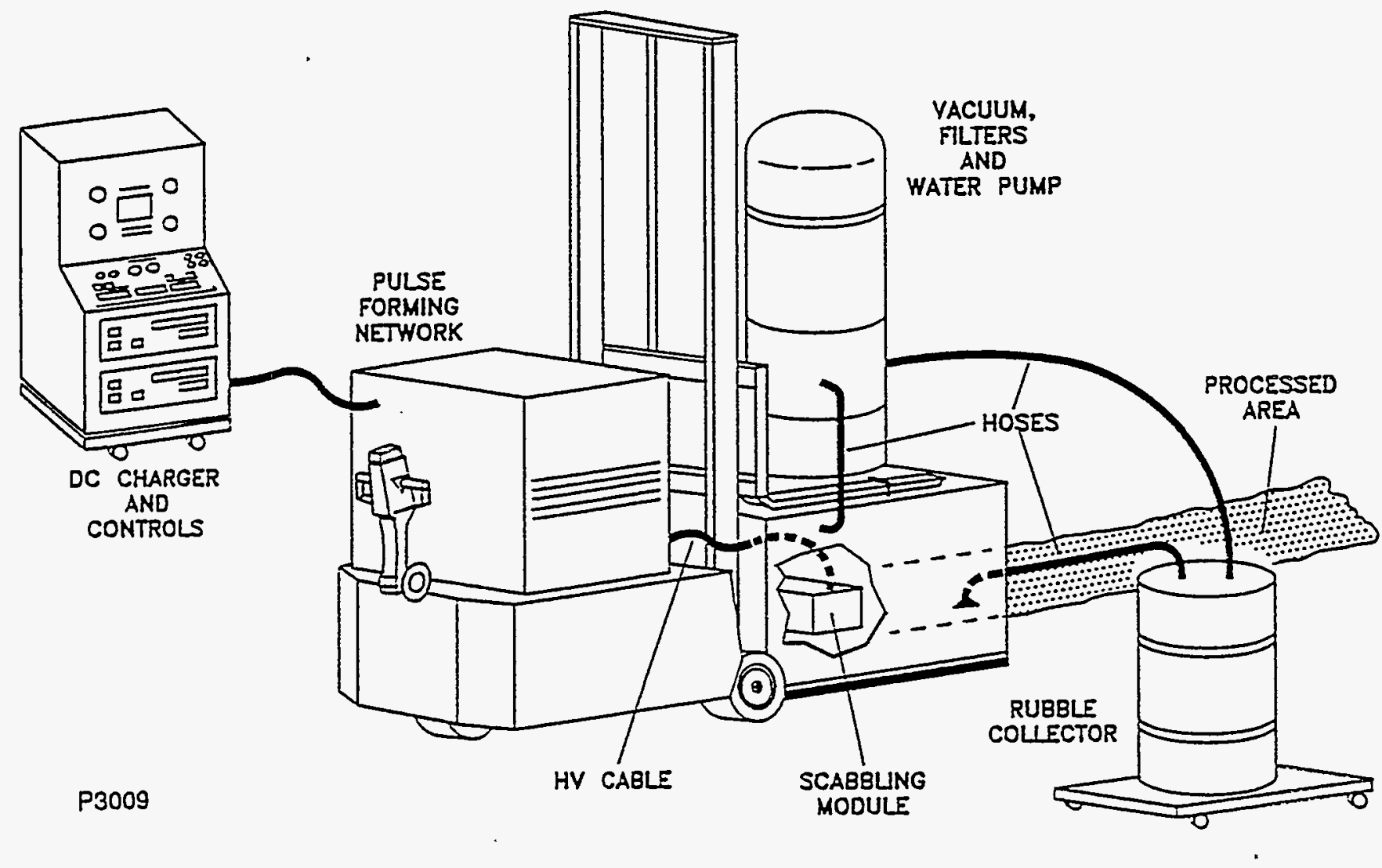

Figure 9-1 Conceptual Drawing of EHS-III Unit 


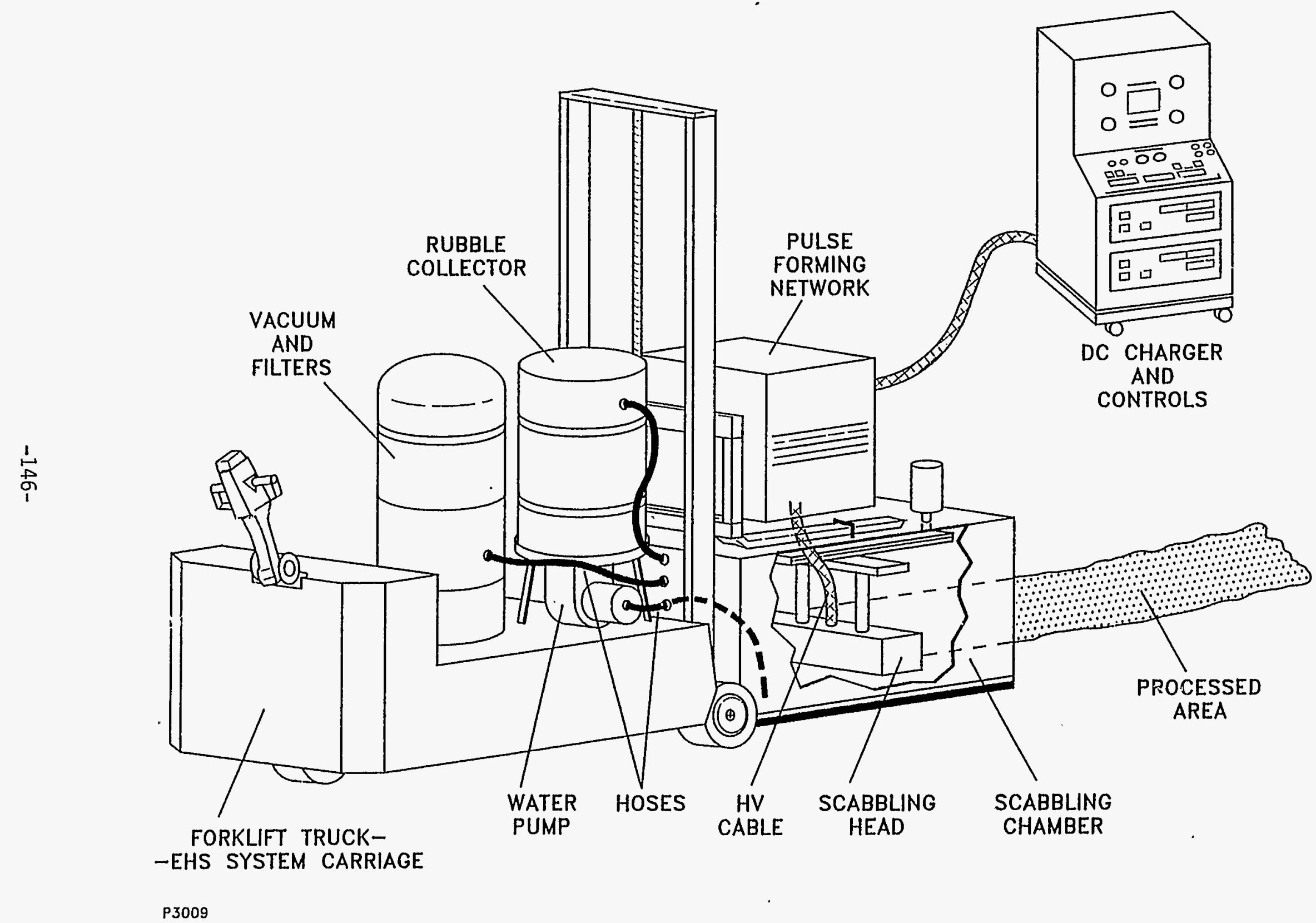

Figure 9-2 Artist's Rendering of Electro-Hydraulic Scabbling Commercial Prototype Unit 


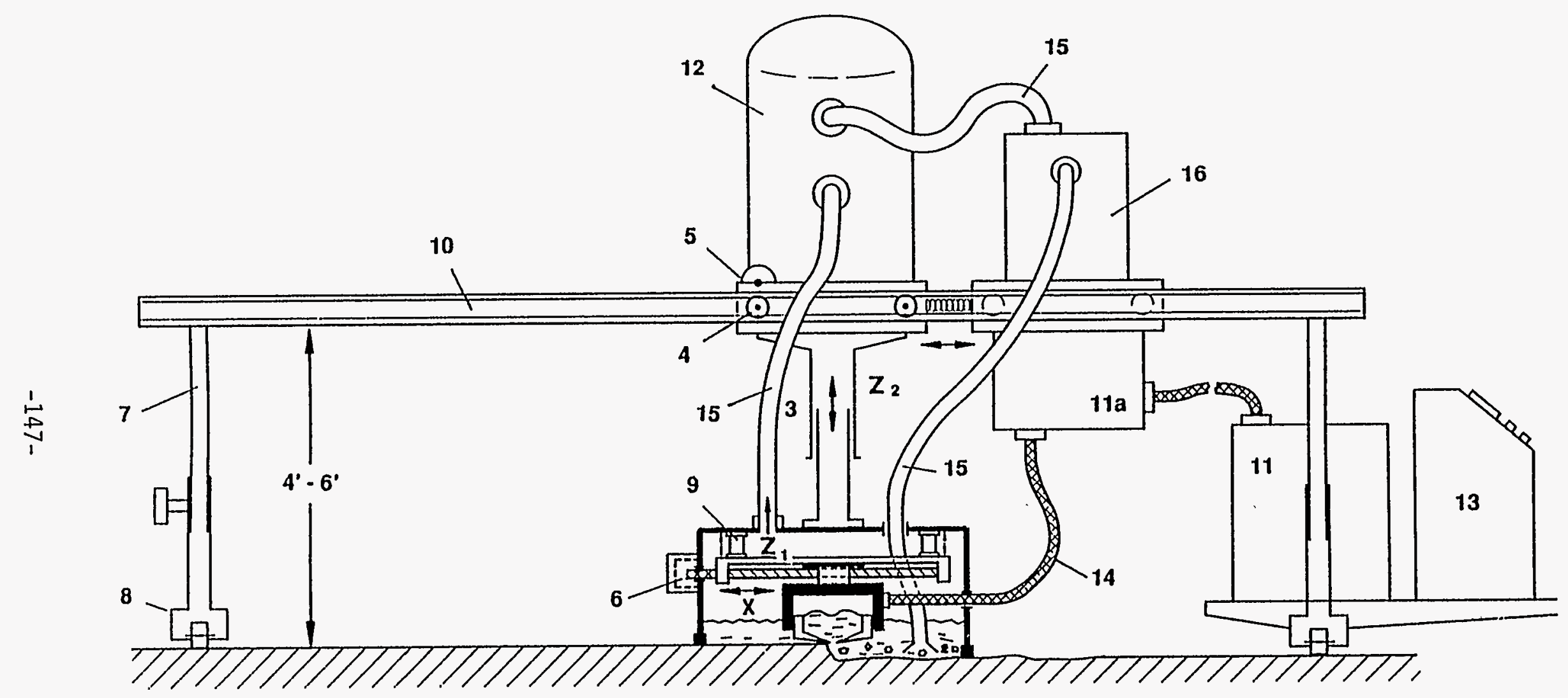

1 SCABBLING NODULE

2 ENCLOSURE (SCABBLING CHARGER)

3 SUPPORT HYDRAULIC COLUMN

4 CARAIAGE

5 MOTOR DRIVE - CARRIAGE

6 - X POSITIONER

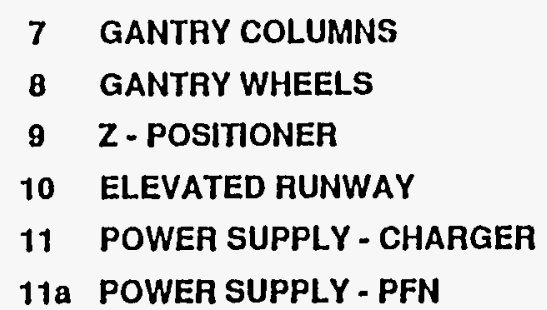

7 GANTRY COLUMNS

10 ELEVATED RUNWAY

11a POWER SUPPLY - PFN
12 WET VACUIJM SYSTEMS AND PUMPS

13 CONTROL STATION

14 HV CABLE

15 HOSES

16 DEBRIS SEPARATOR/COLLECTOR

0.302 .3

Figure 9-3 Alternative Elevated Runway EHS-IV Configuration for Decontamination of Larger Open Areas 
- Another spark gap, with graphite electrodes, is available from Physics International Co. This unit is expensive, but appears to have features that offset the added cost.

- Operation of the EHS system should be automated to include single push-button control for each scabbling cycle (i.e., scabbling and positioning), and an independent control for the enclosure travel-water recirculation-debris collection cycle.

- The following upgrade items are needed for the vacuum/water recirculation/debris removal subsystem:

a) Wet vacuum with a HEPA air filter and sufficient (about $150 \mathrm{cfm}$ ) flow capacity should be integrated with the scabbling chamber.

b) Water splash reflectors should be installed to reduce wear on the bottom water gaskets, and to reduce accumulation of debris at the perimeter of the enclosure.

c) A more compact, higher flow capacity pump is required for faster water removal from the enclosure between the scabbling cycles; because particulates produced by scabbling of strong concrete are of a small size, many types of pumps with moderate prefiltering can be used.

d) A complete removal of the heavy and sticky concrete debris from the floor area within the scabbling chamber appears to be difficult with either fixed or moving collecting nozzles. It seems more practical, at least at the current level of development, to supplement the scabbling chamber with an independent wet debris removing/collecting device located behind the chamber. This device (probably equipped with a rotating brush) can be unified with a wet vacuum used for pumping air from the chamber. Consultations with Power Products, -Inc. on modification and employing one of their commercially-available units are in progress.

The above listing demonstrates that many system components still require upgrade and improvements. On the other hand, all conceptual issues are already resolved and the remaining are of a clear technical nature to be addressed on the basis of Phase I and Phase II design and testing results.

\subsection{PROJECTED EHS-III SYSTEM PERFORMANCE}

The performance projections presented together with the system design/operating parameters in Table 9-1 are made on the basis of scabbling trials conducted at TSD Everett and the DOE Fernald sites.

It is assumed that, as a minimum, three ALE chargers of the total $16 \mathrm{~kW}$ nominal power are used, while higher power ( 24 to $30 \mathrm{~kW}$ ) and, accordingly, a higher scabbling rate can be provided with three paralleled chargers or a single larger charger of the same basic design. The final power level selection depends on the specified test/demonstration plan - size of area to be processed and schedule test/demo time available. per diem (or per shift), as well as total. The decision is not critical because, it does not seriously affect the whole system design.

A choice of a carriage affects the system configuration much more, and therefore should be made at the early stages. Again, carriage selection depends on the size, geometry, and other specific features of the test sites and working areas. Site experience suggests that 4 (net) hours of 
scabbling operation proper per 8-hour day shift is a realistic estimate. For these tests, at a 12 sq. $\mathrm{ft} . / \mathrm{hr}$. (min.) or 20 sq. ft. (max.) scabbling rate, 50 to $80 \mathrm{sq}$. ft. of contaminated concrete floor would be processed. Under these assumptions, a full-scale EHS technology demonstration will last about 4 weeks.

\subsection{ECONOMICS OF SMALL-SCALE INDUSTRIAL EHS SYSTEM}

The future EHS system of a somewhat larger processing capacity in its operating parameters, utility requirements and scabbling rate (per unit of installed electric power), should not differ substantially from the EHS-III unit.

The "small size industrial" system (EHS-IV) would incorporate only minor and straightforward engineering changes and is expected to show moderate performance improvements (compare data in Table 9-1 and Table 9-2). Not to risk technical and economic uncertainties probable for a substantial scale-up, we consider an EHS system about 1.5 times larger than the EHS-IIl unit, capable of decontaminating 24 to $31 \mathrm{sq}$. ft. of concrete floor per hour, for $1 / 2$ " or $1 / 4$ " deep scabbling, respectively. These specific scabbling depths are considered tentatively as typical for two situations:

a) 1/4". depth - as being close to a minimum "reliable" scabbling depth, which, in spite of concrete and scabbling nonuniformities, guarantees an absence of unscabbled floor "islands," and

b) $1 / 2$ " depth - as typical for areas where deeper, uniform, or local penetration of contaminants is likely.

Scabbling rates selected for the EHS-IV system will be adequate for a medium-scale D\&D operation for processing about 500 sq. ft. per week. As mentioned in Section 9.1, a concept of a "commercial prototype" EHS system was developed recently. This system is now suggested for Phase III trials. Due to higher installed power, it should provide higher scabbling rates than the EHS-III (see Table 9-3). A comparison of numbers in Tables 9-2 and 9-3 shows that the difference between them does not exceed uncertainty in the performance predictions as well as evolution of our knowledge of operating features and requirements. Therefore, estimates of capital and operating costs provided below can be attributed not only to EHS-IV but also to the commercial prototype system to be built and demonstrated in Phase III.

Table 9-4 provides estimated costs of the EHS-IV system components and total capital cost which includes cost of purchased/ manufactured items and assembly, integration, and shakedown testing labor for the main subsystems and the complete unit. Comparison with our earlier estimates (see Phase I Topical Report, Tables 7-1 and 7-5, Option A(HV) 1 or 3 module units) indicates that at the same installed electric power, the new design is expected to be less expensive (140 K\$ vs. about $200 \mathrm{~K} \$$ ). This results from the development of a concept based on a single electric circuit (switch, capacitor, etc.) power supply, and a much simpler scabbling module with a single pair of electrodes.

Table 9-5 shows estimates of the EHS concrete decontamination cost, which include capital (depreciation) and operating costs. The main assumptions involved in this evaluation follow this table. Some of them require further explanation.

At the moderate scabbling rate assumed for the EHS-IV unit, the labor cost dominates over all other cost items. Related assumption (3) is rather arbitrary, because the number of net scabbling hours available per time interval (shift, week, etc.) depends greatly on the site conditions, complexity of the decontamination program, H\&S requirements and regulations, and, above all, on the work organization/coordination level. These factors also define whether or not 
TABLE 9-1

\section{DESIGN/OPERATING PARAMETERS AND PERFORMANCE PROJECTIONS FOR EHS-III UNIT}

\begin{tabular}{|l|l|}
\hline Main Unit Dimensions LxWxH & $80-100 \times 36-44 \times 50-70 \mathrm{in}$. \\
\hline Unit Weight (total) & $800-1200 \mathrm{lbs}$. \\
\hline Nominal AC Power (scabbling) & $16-24 \mathrm{~kW}$ \\
\hline Nominal AC Power (ancillaries) & $4-6 \mathrm{~kW}$ \\
\hline Storage Capacitance & $10-18 \mu \mathrm{F}$ \\
\hline Operating (max) Voltage & $25-35 \mathrm{kV}$ \\
\hline Single Pulse Energy & $2-3 \mathrm{~kJ}$ \\
\hline Single Pulse Duration & $15-35 \mu \mathrm{s}$ \\
\hline Pulse Frequency & $3-5 \mathrm{~Hz}$ \\
\hline Electrode Width & $24-30 \mathrm{in}$. \\
\hline Electrode Gap & $1 / 4-1 / 2 \mathrm{in}$. \\
\hline Number of Pulses per Electrode Position & $100-250$ \\
\hline Distance.Between Sequential Electrode Positions & $1-2 \mathrm{in.}$ \\
\hline Length of Scabbled Area per Cycle (Chamber Position) & $24-40 \mathrm{in}$. \\
\hline Scabbled Area per Cycle & $5-8 \mathrm{sg} . \mathrm{ft}$. \\
\hline Scabbling Duration per Cycle & $12-30 \mathrm{~min}$. \\
\hline Module Positioning Time (per step) & $5-10 \mathrm{sec}$. \\
\hline Chamber Positioning Time & $3-8 \mathrm{~min}$. \\
\hline Water Recirculation plus Debris Removal Time & $5-10 \mathrm{~min}$. \\
\hline Total Duration per Cycle & $20-45 \mathrm{~min}$. \\
\hline Scabbling Depth (average) & $1 / 4-3 / 4 \mathrm{in}$. \\
\hline Scabbling Rate (net) & $18-30 \mathrm{sq} . \mathrm{ft} . / \mathrm{hr}$. \\
\hline Scabbling Rate (effective) & $12-20 \mathrm{sq} . \mathrm{ft} . / \mathrm{hr}$. \\
\hline Amount of Concrete Removed per Cycle & $15-40 \mathrm{lbs}$. \\
\hline Water Volume in the System & $20-30 \mathrm{gal}$. \\
\hline Water Consumption (makeup) & $0.5-1.5 \mathrm{gal./sq.} \mathrm{ft.}$ \\
\hline Compressed Air Requirements & $50-100 \mathrm{scfm}$ at $50 \mathrm{psi}$ \\
\hline Electric Energy Total Consumption & $0.7-1.3 \mathrm{kWh} / \mathrm{sq} . \mathrm{ft}$. \\
\hline & \\
\hline
\end{tabular}




\section{TABLE 9-2}

\section{DESIGN/OPERATING PARAMETERS AND PERFORMANCE PROJECTIONS FOR SMALL-SCALE INDUSTRIAL UNIT EHS-IV}

\begin{tabular}{|c|c|}
\hline Main Unit Dimensions LxWxH - in. & $80-100 \times 36-44 \times 50.70$ \\
\hline Unit Weight (total) - lbs. & $1000-1200$ \\
\hline Nominal AC Power (scabbling) & $32 \mathrm{~kW}(16 \times 2)$ \\
\hline Nominal AC Power (ancillaries) & $6 \mathrm{~kW}$ \\
\hline Storage Capacitance & $12 \mu \mathrm{F}$ \\
\hline Operating (max) Voltage & $30 \mathrm{kV}$ \\
\hline Single Pulse Energy & $4 \mathrm{~kJ}$ \\
\hline Single Pulse Duration & $20 \mu s$ \\
\hline Pulse Frequency & $6 \mathrm{~Hz}$ \\
\hline Electrode Width - in. & 30 \\
\hline Electrode Gap - in. & $1 / 4-1 / 2$ \\
\hline Number of Pulses per Electrode Position & 200 \\
\hline Distance between Sequential Electrode Positions - in. & $(1-2)$ \\
\hline Length of Scabbled Area per Cycle (each Chamber Position) - in. & 36 \\
\hline Scabbled Area per Cycle - sq. ft. & 7.5 \\
\hline Pulsing Duration per Cycle - min. & 13 \\
\hline Scabbling (pulsing+positioning) Duration per Cycle - min. & 15 \\
\hline Chamber Repositioning Time - min. & 3 \\
\hline Water Recirculation Time - min. & 3 \\
\hline Total Cycle Duration - min. & 21 \\
\hline Scabbling Depth (average) - in. & $1 / 2$ \\
\hline Scabbling Rate (net) - sq. ft./hr. & 33 \\
\hline Scabbling Rate (effective) - sq. ft./hr. & 24 \\
\hline Volume of Concrete Removed per Cycle - cu. ft. & 1.5 \\
\hline Mass of Concrete Removed per Cycle - lbs. & 21 \\
\hline Water Volume in System - gal. & 30 \\
\hline Water Consumption (makeup) - gal./sq. ft. & $0.5-1.0$ \\
\hline Compressed Air Requirements & $50-100 \mathrm{scfm}$ at $50 \mathrm{psi}$ \\
\hline Energy Consumption for Scabbling - kWh/sq. ft. & $0.45 \quad 0.75$ \\
\hline Energy Consumption for Flow System - kWh/sq. ft. & 0.40 \\
\hline Electric Energy Total Consumption - kWh/sq. ft. & 0.85 \\
\hline Energy Consumption per Unit Mass of Concrete Removed - J/g & 1200 \\
\hline
\end{tabular}

Data in left and right columns are for $1 / 4$ " and $1 / 2$ " scabbling depths, respectively. 
TABLE 9-3

\section{DESIGN AND OPERATING PARAMETERS FOR COMMERCIAL PROTOTYPE EHS UNIT}

\begin{tabular}{|c|c|}
\hline Main Unit Dimensions LxWxH & $80-100 \times 36-44 \times 50-70$ in. \\
\hline Unit Weight (total) & $800-1400$ lbs. \\
\hline Nominal AC Power (scabbling) & $24-32 \mathrm{~kW}$ \\
\hline Nominal AC Power (ancillaries) & $6-8 \mathrm{~kW}$ \\
\hline Storage Capacitance & $10-18 \mu \mathrm{F}$ \\
\hline Operating (max) Voltage & $25-35 \mathrm{kV}^{*}$ \\
\hline Single Pulse Energy & $2.0-3.5 \mathrm{~kJ}$ \\
\hline Single Pulse Duration & $15-35 \mu \mathrm{s}$ \\
\hline Pulse Frequency & $8-14 \mathrm{~Hz}$ \\
\hline Electrode Width & $26-32$ in. \\
\hline Electrode Gap & $3 / 16-7 / 16$ in. \\
\hline Number of Pulses per Electrode Position & $150-300$ \\
\hline Distance Between Sequential Electrode Positions & $1-2$ in. \\
\hline Length of Scabbled Area per Cycle (per Chamber Position) & $26-36$ in. \\
\hline Scabbled Area per Cycle & $5-7$ sq. ft. \\
\hline Scabbling Duration per Cycle, $T_{S}$ & $5-10 \mathrm{~min}$. \\
\hline Module Positioning Time, $\mathrm{T}_{\mathrm{p}}$ & $2-3 \mathrm{~min}$ \\
\hline Chamber Positioning Time, $\mathrm{T}_{\mathrm{c}}$ & 3-5 min. \\
\hline Water Recirculation plus Debris Removal Time, $\mathrm{T}_{\mathrm{w}}$ & 4-8 min. \\
\hline Total Duration per Cycle, $T_{s}+T_{p}+T_{c}+T_{w}$ & $20-40 \mathrm{~min}$ \\
\hline Scabbling Depth (average) & $1 / 4-3 / 4$ in. $^{* *}$ \\
\hline Scabbling Rate (net) $)^{\dagger}$ & $30-50$ sq. ft./hr. \\
\hline Scabbling Rate (effective) & $15-25$ sq. ft./hr. \\
\hline Amount of Concrete Removed per Cycle & $15-40 \mathrm{lbs}$. \\
\hline Water Volume in the System & 25-40 gal. \\
\hline Water Consumption (makeup) & $0.5-1.5 \mathrm{gal} . / \mathrm{sq} . \mathrm{ft}$. \\
\hline Compressed Air Requirements & $50-100 \mathrm{scfm}$ at $50 \mathrm{psi}$ \\
\hline Electric Energy Total Consumption & $0.7-1.3 \mathrm{kWh} / \mathrm{sq}$. ft. \\
\hline $\begin{array}{ll}* & 100 \mathrm{kV} \text { for optional design. } \\
* * & \text { Up to } 1 " . \\
\dagger & \text { Based on } \mathrm{T}_{\mathrm{s}}+\mathrm{T}_{\mathrm{p}}\end{array}$ & \\
\hline
\end{tabular}


TABLE 9-4

ESTIMATE OF CAPITAL (EQUIPMENT) COST FOR EHS-IV UNIT

\begin{tabular}{|l|r|}
\hline Item & Cost, K\$ \\
\hline 1. Electric Pulser & \\
DC Charger & 28 \\
Capacitors & 2 \\
Spark Gap Switches, Triggers & 8 \\
Cabinets, Cables, Resistors, etc. & $\underline{3}$ \\
Subtotal & 41 \\
Assembly, Testing (labor) & $\underline{20}$ \\
TOTAL & 61 \\
\hline EHS Module & \\
XZ Positioner & 4 \\
Scabbling Module & 3 \\
Scabbling Enclosure & $\underline{3}$ \\
Subtotal & 10 \\
Assembly Integration (labor) & $\underline{10}$ \\
TOTAL & 20 \\
\hline Slurry Management System & \\
Electric Rad Vac System & 5 \\
Rubble Collector/Separator & 3 \\
Water Pumps & 2 \\
Auxiliaries (flow/pressure controls, hoses, filters) & $\underline{3}$ \\
Subtotal & 13 \\
Assembly, Testing (labor) & $\underline{7}$ \\
TOTAL & 20 \\
\hline Carriage and Controls & 16 \\
Self-propelled Carriage & -8 \\
Process Controls & 24 \\
Subtotal & 15 \\
Assembly, Testing (labor) & 140 \\
TOTAL & \\
\hline EHS System Integration, Testing (labor) & \\
\hline TOTAL EHS SYSTEM COST* & \\
\hline
\end{tabular}

*This cost is not applicable to the first prototype unit to be assembled for Phase III trials. 
TABLE 9-5

\section{ESTIMATE OF TOTAL DECONTAMINATION COST} FOR OPERATING EHS-IV UNIT

\begin{tabular}{|c|c|c|}
\hline Item & \multicolumn{2}{|c|}{ Cost, $\$ / \mathrm{ft}^{2}$} \\
\hline Scabbling Depth & $1 / 4^{\prime \prime}$ & $1 / 2^{\prime \prime}$ \\
\hline $\begin{array}{l}\text { Scabbling Rate: } \\
\mathrm{ft}^{2} \text { per hour } \\
\mathrm{ft}^{2} \text { per day shift } \\
\mathrm{ft}^{2} \text { per year }\end{array}$ & $\begin{array}{l}31 \\
124 \\
41,000\end{array}$ & $\begin{array}{l}24 \\
96 \\
32,000 \\
\end{array}$ \\
\hline $\begin{array}{l}\text { Consumables: } \\
\text { Electricity(1) } \\
\text { Water } \\
\text { Electrodes, etc. }\end{array}$ & $\begin{array}{l}0.85 \\
0.04 \\
0.11\end{array}$ & $\begin{array}{l}1.20 \\
0.05 \\
0.15\end{array}$ \\
\hline Subtotal & 1.00 & 1.40 \\
\hline Capital Cost(2) & 0.89 & 1.14 \\
\hline Labor Cost $(3)$ & 6.47 & 8.30 \\
\hline Waste Disposal (4) & 0.24 & 0.50 \\
\hline Total, $\$ / \mathrm{ft}^{2}$ & 8.60 & 11.34 \\
\hline
\end{tabular}

Main Assumptions:

(1) At $0.1 \$ / \mathrm{kWh}$ rate.

(2)For 140,000 equipment cost, 1320 net scabbling hours per year, five years service life, yearly spare parts cost equal $22 \%$ of amortization cost ( $\$ 28,000$ and $\$ 6000$, respectively).

(3) At 6 hours per day, 1320 hours per year net operating time. Two operators (technicians) also performing setup and maintenance; $\$ 75 / \mathrm{hr}$ technician's labor cost, including overhead expenses, but not including H\&S services, sampling/analytical services, waste post-treatment, and removal from the work area.

(4) Waste (concrete rubble + process water + miscellaneous) disposal at $\$ 8 /$ cubic foot. 
a single technician is able to exercise two main functions - the scabbling proper and waste removal/collection within the main processing cycle.

Substantial uncertainty still remains with respect to the equipment lifetime, especially the wear on (slowly) consumed parts (i.e., spark gap electrodes and EH discharge electrodes), and maintenance schedule and requirements. A simplified estimation approach taken in assumption (2) seems realistic; better evaluation can be made only after results of a long-duration EHS operation become available.

Total cost of EHS decontamination shown in Table 9-5 is higher than the cost estimated on the basis of Phase I experiments (see Topical Report, Table 7-4). There are two main reasons for the estimated cost increase:

1) The concrete floor at the Fernald site is stronger than the floor at the TDS Everett site; accordingly, a larger number of pulses/longer scabbling time was required at Fernald. The higher concrete strength is assumed to be characteristic for the "nuclear" sites, and is used for the current estimates.

2) A number of net scabbling numbers was reduced to account for nuclear site operating conditions more realistically.

Taken together, these two factors reduced the processing rate, affecting the main cost component - labor. There are two other changes that are of less importance:

3) Cost of waste disposal was added as a factor important for the technology evaluation.

4) Reduction of capital cost due to improved design reduces the decontamination cost, but it is not explicitly present being "shadowed" by scabbling rate reduction due to other factors.

Modest capacity and operating rate of the EHS-IV (or similar) unit, which results in a relatively high operating cost, may not be a major factor for the moderate-scale decontamination tasks, where process organization and support services are probable to dominate the total cost. On the other hand, for the large-scale (i.e., large floor area) projects the processing rate may be a decisive factor; for these applications an EHS unit of higher scabbling capacity should be built.

The EHS cost is within the range claimed for other decontamination technologies. Quality of decontamination, reliability of equipment, and convenience of remote operation and environmental quality of the whole process will probably be more important factors for a choice of decontamination technology than the nominal operation cost differences. As usually is the case for specific sites and tasks, different technologies may have various advantages/ disadvantages, including cost.

\subsection{COMMERCIALIZATION OF EHS TECHNOLOGY}

Viable routes to the commercialization of EHS technology are being explored. Initially it was considered that the core modules that made up the EHS system could be beneficially integrated with the basic units (i.e., mobile cart, controls, positioner, etc.) of available mechanical scabbling systems. However, it became evident that the two systems did not complement each other, and that the features of the EHS system could best be utilized if not encumbered by the restrictions of existing processes. In addition, discussions with $\mathrm{D}$ and $\mathrm{D}$ management and service companies indicated that they would be most comfortable subcontracting EHS operations to a company familiar with the process and with experienced operators. 
It is now TSD's plan to design and construct the fully integrated EHS unit and to make it available along with a trained operator to $D$ and $D$ service companies. The unit will consist of three integrated modules: power and control systems, the scabbling head and positioner, and the recycle module. A video has been made describing the EHS system and showing it in operation at Fernald. The video is being distributed to D and D service companies for their comments and an invitation to participate as advisors in the Phase III program. 


\subsection{REFERENCES}

1. Goldfarb, V., Concrete Decontamination by Electro-Hydraulic Scabbling (EHS), DOE/METC Contract No. DE-AC21-93MC30164, Topical Report, November 1994.

2. Yutkin, L.A., Electrohydraulic Effect, Mashgiz, Moscow, 1955.

3. Arsent'ev, V.V., Theory of Development of Impulse Electric Discharge in Liquids, Proc. IV Conf. on Dielectric Breakdown, Leningrad, 1964, p. 199.

4. NaUgol'nykh, K.A., Roi, N.A., Spark Discharges in Water, 1971; English Translation UT, Austin, 1987.

5. Gavrilov, G.N., Gorobenko, C.G., Malushevsky, P.P., Ryabinin, A.G., Pulsed Discharge Technology for Processing Minerals, Kiev, 1979.

6. Zinovyev, N.T., et al., On Concrete Demolition by Electric Discharges, 2nd RILEM Int. Sympos. on Demolition and Reuse of Concrete, Chapman-Hall, London, 1988. 